\title{
Neuropsychological assessment at the memory clinic
}

\author{
Citation for published version (APA):
}

Gruters, A. A. A. (2020). Neuropsychological assessment at the memory clinic: Innovations in communicating neuropsychological test results. [Doctoral Thesis, Maastricht University]. Maastricht University. https://doi.org/10.26481/dis.20201218ag

Document status and date:

Published: 01/01/2020

DOI:

10.26481/dis.20201218ag

Document Version:

Publisher's PDF, also known as Version of record

\section{Please check the document version of this publication:}

- A submitted manuscript is the version of the article upon submission and before peer-review. There can be important differences between the submitted version and the official published version of record.

People interested in the research are advised to contact the author for the final version of the publication, or visit the DOI to the publisher's website.

- The final author version and the galley proof are versions of the publication after peer review.

- The final published version features the final layout of the paper including the volume, issue and page numbers.

Link to publication

\footnotetext{
General rights rights.

- You may freely distribute the URL identifying the publication in the public portal. please follow below link for the End User Agreement:

www.umlib.nl/taverne-license

Take down policy

If you believe that this document breaches copyright please contact us at:

repository@maastrichtuniversity.nl

providing details and we will investigate your claim.
}

Copyright and moral rights for the publications made accessible in the public portal are retained by the authors and/or other copyright owners and it is a condition of accessing publications that users recognise and abide by the legal requirements associated with these

- Users may download and print one copy of any publication from the public portal for the purpose of private study or research.

- You may not further distribute the material or use it for any profit-making activity or commercial gain

If the publication is distributed under the terms of Article $25 \mathrm{fa}$ of the Dutch Copyright Act, indicated by the "Taverne" license above, 

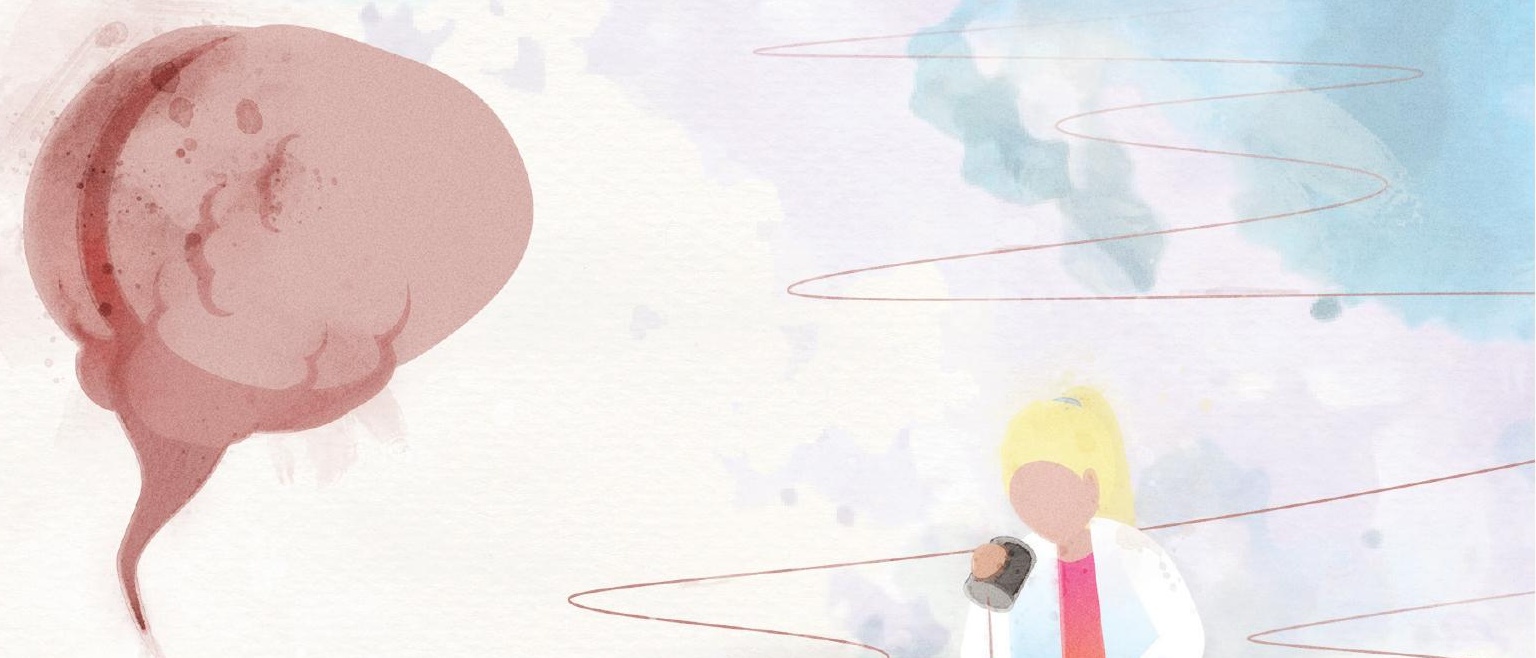

\section{NEUROPSYCHOLOGICAL ASSESSMENT AT THE MEMORY CLINIC}

INNOVATIONS IN COMMUNICATING

NEUROPSYCHOLOGICAL TEST RESULTS 


\section{NEUROPSYCHOLOGICAL ASSESSMENT AT THE MEMORY CLINIC}

Innovations in communicating neuropsychological test results 
(c) Angélique A. A. Gruters, Maastricht 2020

Cover design and lay-out:

Bas Frishert

Printing:

Ridderprint | www.ridderprint.nl

All rights reserved. No part of this book may be reproduced or transmitted in any form or by any means, without prior permission in writing by the author, or when appropriate, by the publishers of the publication. 


\section{NEUROPSYCHOLOGICAL ASSESSMENT AT THE MEMORY CLINIC}

Innovations in communicating neuropsychological test results

\section{PROEFSCHRIFT}

Ter verkrijging van de graad van doctor aan de Universiteit Maastricht,

op gezag van de Rector Magnificus, Prof. dr. Rianne M. Letschert, volgens het besluit van het College van Decanen,

in het openbaar te verdedigen op

vrijdag 18 december 2020

om 14.00 uur

door

\section{Angélique Anna Adriana Gruters}

Geboren op 25 mei 1992 te Nieuwegein 


\section{Promotoren}

Prof. dr. M.E. de Vugt

Prof dr. F.R.J. Verhey

Prof. dr. R.P.C. Kessels (Radboud Universiteit Nijmegen)

\section{Co-promotor}

Dr. I.H.G.B. Ramakers

\section{Beoordelingscommissie}

Prof. dr. R.W.H.M. Ponds, (voorzitter)

Prof. dr. A.F.G. Leentjens

Prof. dr. R.M.M. Crutzen

Prof. dr. S.B. Schagen (Universiteit van Amsterdam,

Antoni van Leeuwenhoek ziekenhuis)

Dr. E. van den Berg (Erasmus MC Rotterdam)

\section{Paranimfen}

Jeske van Diemen

Sara Bartels

The research described in this thesis was performed at the Alzheimer Center Limburg, Department of Psychiatry and Neuropsychology, School for Mental Health and Neuroscience, Maastricht University, Maastricht, The Netherlands. The work presented in this thesis was supported by Alzheimer Nederland (grant WE.21-2016-01) and by the Noaber foundation (grant WE21-INPAD).

Printing of this thesis was kindly supported by Alzheimer Nederland.
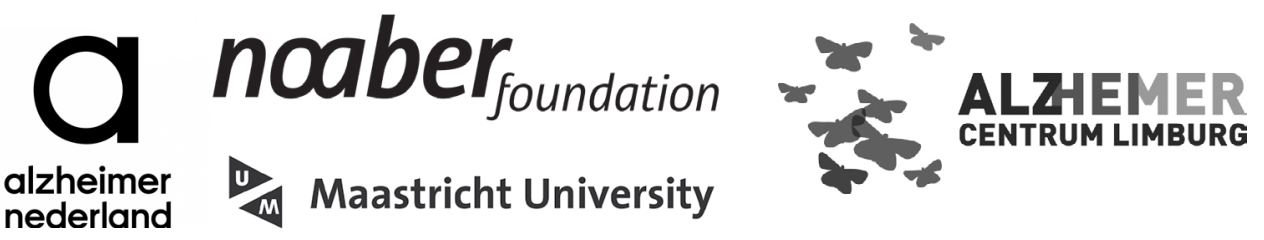


\section{CONTENTS}

Chapter 1 General introduction, thesis aims and outline 7

$\begin{array}{lll}\text { Part One Neuropsychological assessment at Dutch memory } & 15\end{array}$ clinics

Chapter 2 Development of memory clinics in the Netherlands over 16 twenty years: $1998-2016$ International Journal of Geriatric psychiatry, 2019

Chapter 3 Development of a Dutch monodisciplinary guideline neuropsychological assessment in patients with a mild cognitive impairment (MCl) and dementia Tijdschrift voor Neuropsychologie, 2020 (translated from Dutch)

Chapter 4 Neuropsychological assessment and diagnostic disclosure at a memory clinic: a qualitative study of the experiences of patients and their family member The Clinical Neuropsychologist, 2020

Chapter 5 Association between proxy- or self-reported cognitive 68 decline and cognitive performance in memory clinic visitors Journal of Alzheimer's Disease, 2019

\section{Part Two Insights into neuropsychological feedback and the} development of a visual aid

Chapter 6 A scoping review of communicating neuropsychological test results to patients and family members.

Under review

Chapter 7 An exploratory study of the development of an interactive visual tool of neuropsychological test results in memory

clinics.

Under review

Chapter 8 General discussion

Nederlandse samenvatting

Knowledge Valorization

Dankwoord (acknowledgments)

Thesis defenses from Alzheimer Center Limburg and MHeNS

List of publications 189

Curriculum Vitae 

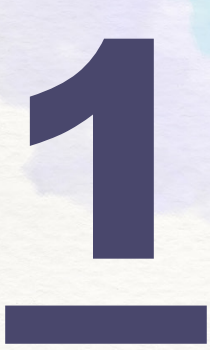

General introduction, aims and outline 


\section{Case study}

The following case illustrates the diagnostic procedures at an $\mathrm{MC}$ and the value of receiving neuropsychological feedback.

Mrs. J., a 71-year old woman, has been experiencing increased forgetfulness in the past two years. She has to look for her phone and keys, and when she is traveling by car she notices that it is becoming increasingly difficult to find her way in unknown areas. She used to be a successful professor at a university in Belgium and worked as a neurologist in the hospital. She is still a very active woman, doing volunteer work and taking part of many organizing committees. However, in the last year she has to record the meetings because she is unable to remember what is being discussed. Her husband, with whom she's married for 50 years, started noticing the memory problems as well. He has to remind her of her appointments and he notices that she often doesn't find the right words during their talks. He also had to take over cooking as she forgets to turn of the fire. Together with their children they decide to visit a memory clinic.

After being referred by the general practitioner they are sitting in the waiting room of the memory clinic in Maastricht. During that day Mrs. J sees many different faces and she undergoes all sorts of assessments (clinical interview, blood tests, MRl, neuropsychological testing), some of which she recognizes from her previous professional career. Results of these assessments are discussed in a multidisciplinary meeting. Neuropsychological testing showed that she had a very low performance on multiple memory and naming tests. On the MRI scan, hippocampal atrophy was found. It was concluded that Mrs. J. suffered from a mild stage of Alzheimer's disease dementia.

Three weeks later Mrs. J. and her husband return to the memory clinic to discuss the findings with the psychiatrist. After hearing the diagnosis, they are both overwhelmed. When they walk out of the door, the only thing they both remember, is that she has Alzheimer's disease. They are glad that they are referred to a case manager as they still have so many questions. Two weeks after receiving the diagnosis they have a separate appointment with the neuropsychologist. During this session they discuss the findings of the neuropsychological assessment in more detail. Both Mrs. J. and her husband are glad they can talk about the diagnosis again and feel there is more space to go into details they have forgotten during their last appointment. During the session the cognitive strengths and weaknesses are also discussed. They also discuss compensatory strategies on how to deal with this in daily life. A lot of information is being conveyed, so they are happy that they receive a written summary of the neuropsychological results on paper. They both agree this is information that they can use in daily life to better deal with a difficult situation. Mrs. $J$ and her husband express that they would like to see the neuropsychologist again. During these extra sessions they discuss how they can adapt 
to the diagnosis and the struggles they are undergoing. They are able to receive some extra tips and strategies to overcome these difficulties.

\section{Neuropsychological assessment}

A mainstream facility for the diagnosis and treatment of cognitive disorders, such as mild cognitive impairment (MCl) or dementia, are memory clinics (MCs). These centers adopt a multidisciplinary approach of which a neuropsychological assessment (NPA) is a routine assessment. An NPA includes a clinical interview, administration of cognitive tests, qualitative observations, as well as administration of self- and informant-report questionnaires with the aim to gain insight into cognitive and emotional functioning, and to evaluate the relationship between brain functioning and observable behavior. An NPA has a clear diagnostic value in clinical settings, as multiple studies found that an NPA led to increased diagnostic accuracy in patients with $\mathrm{MCl}$, dementia, stroke, and traumatic brain injury. ${ }^{1}$ Furthermore, an NPA is recommended in the early phases of cognitive decline due to neurodegenerative diseases by clinical guidelines ${ }^{2}$ while short cognitive screening tests, such as the Mini Mental Status Examination (MMSE) or the Montreal Cognitive Assessment (MoCA), are not. These screening tests are not always informative in individual cases due to their limited sensitivity and specificity. ${ }^{3-5}$ A timely diagnosis of cognitive decline due to a neurodegenerative disease is important because it can lead to feelings of relief in case of no cognitive impairment, or a confirmation of longer existing suspicions of decline. Furthermore, it offers a time frame during which a patient and his/her family can still make decisions regarding the future while cognitive capacities are relatively intact.6,7

\section{Concerns about cognitive complaints and dementia}

Subjective cognitive decline (SCD) can be defined as a self-perceived decline of cognitive functioning. ${ }^{8}$ The prevalence of SCD in the general population increases with age.9,10 In a large, community-based study, older age groups experienced more hindrance and worries as a result of these cognitive complaints. ${ }^{9}$ Patients who experience a cognitive decline often worry if their cognitive complaints could be caused by a neurodegenerative disease, such as Alzheimer's disease (AD), and may signal the onset of dementia. Dementia is a syndrome characterized by a decline in cognitive functioning (e.g., memory, attention), changes in behavior, and the inability to perform daily life activities independently ${ }^{11}$ as a result of a neurodegenerative disease. One of the most common causes of dementia is AD which is characterized by a decline mainly in the memory domain. ${ }^{11}$ Other causes of dementia include cerebrovascular pathology and frontotemporal lobar degeneration. Due to the double aging of the population (increase in life expectancy and increase proportion of older age groups compared to younger age groups) persons with dementia (PwD) are the fastest growing clinical population worldwide. Currently, around 46.8 million people live with dementia, and by 2050 this number is estimated to be 131.5 million. ${ }^{12}$ Dementia has a huge physical, mental, and social impact on PwD, their family and friends. Furthermore, dementia has 
a significant economic impact on our healthcare system. ${ }^{11,13}$ Informal caregivers of PwD have higher levels of subjective burden and lower levels of quality of life compared to caregivers of people without dementia. ${ }^{14}$ Due to all these factors, dementia was declared a public health priority by the World Health Organization. National and international organizations published global action plans, and most countries worldwide developed Dementia Strategy plans to achieve better physical, mental, and social wellbeing for PwD and their families. ${ }^{11,15-17}$

\section{Importance of a neuropsychological assessment}

The importance of an NPA, for clinicians, patients, and family members, has been extensively described in the literature, for example by increasing accuracy of diagnosis, offering psychoeducation and treatment planning, high referrer satisfaction, and positive patient outcomes (e.g., decrease in cognitive complaints). 1,18 A small body of literature shows positive findings regarding experiences of patients and family members with neuropsychological services, but more negative experiences (e.g., feelings of discomfort due to realization of cognitive decline) were found in patients with a severe cognitive impairment. ${ }^{1,19}$ One of the predictors of positive experiences and satisfaction with an NPA seems to be whether patients received neuropsychological feedback and whether they evaluated this feedback as useful. ${ }^{20}$

\section{Importance of giving neuropsychological feedback}

Providing feedback about the results of a (neuro)psychological assessment is part of psychological ethical standards. ${ }^{21,22}$ Neuropsychological feedback is the process of explaining NPA results to patients and family members with the goal of increasing understanding of their cognitive strengths and weaknesses, and their implications for daily life or care planning. ${ }^{23}$ Doing this in a collaborative manner and offering an explanation for their complaints might lead to less stress and relief. ${ }^{24}$ Neuropsychological feedback may also be related to improved quality of life and increased understanding of the diagnosis. ${ }^{25}$ However, in clinical practice, many colleagues experience that it is sometimes a challenge to adequately explain NPA results to patients. Furthermore, providing extensive neuropsychological feedback given by the neuropsychologist is not a universal service in Dutch MCs due to logistic or financial barriers. Another issue is that patients often have difficulties to store and retrieve medical information in general, and neuropsychological recommendations in specific. ${ }^{26-28}$ During a neuropsychological feedback session, a lot of information is given, which might be difficult to comprehend and to be remembered by some patients. For patients with cognitive impairments seen in an $\mathrm{MC}$, this is even a bigger challenge. Positive results have been found with regards to offering a written supplement after the neuropsychological feedback session. 27,28 However, other authors argue that neuropsychological reports are also difficult to understand for patients and family members. ${ }^{20}$ Therefore, visual aids might be helpful to support information provision in neuropsychological feedback sessions. In other fields, visual aids have been found to be helpful in understanding and remembering information. ${ }^{29,30}$ To our knowledge, no studies have been conducted 
on developing and evaluating a visual aid with different end-users (patients, family members, psychologists) to support giving neuropsychological feedback. Therefore, the Innovations in NeuroPsychological Assessment in the timely Diagnosis of Dementia (INPAD) project was launched in 2017.

\section{THESIS AIMS AND OUTLINE}

The general aim of this thesis was to investigate the role of NPA and neuropsychological feedback at Dutch MCs, and to investigate how a visual tool could help in communicating neuropsychological test results to patients and family members. This thesis consists of two general research questions. The first question was how memory clinics in the Netherlands developed over the last years, and in particular which are the important characteristics of the NPA (e.g., working methods, patient and family member experience with an NPA). In the second part a scoping review provided insight into the literature on giving neuropsychological feedback. The last study focused on the development of the visual tool as part of the INPAD project. The following research questions were addressed:

\section{Part One: $\quad$ Neuropsychological assessment at Dutch memory clinics}

What are current characteristics and working methods of MCs in the Netherlands and how have MCs developed in the past twenty years?

In Chapter 2 a survey was administered in 1998, 2004, 2009, and 2017 in all Dutch MCs to identify the characteristics and working methods in the past twenty years.

What are characteristics and working methods of the NPA in Dutch MCs in 2016 and how could a monodisciplinary guideline for NPA in MCs be developed?

Chapter 3 describes the findings of a survey administered in 2017 with additional in-depth interviews in psychologists involved in Dutch MCs. Furthermore, the development of the monodisciplinary guideline is described which led to consensus on a core cognitive battery to be used in the MC population.

What is the experience of patients and family members with an NPA and diagnostic disclosure in the $\mathrm{MC}$ ?

Four focus groups in three different MCs were carried out in Chapter $\mathbf{4}$ to gain insight into the experiences of patients and family members with an NPA and the diagnostic disclosure.

What is the relation between subjective and objective cognitive decline, depressive symptoms, and the predictive value of dementia in MC patients? 
The cross-sectional and longitudinal association between subjective and objective cognitive decline, depressive symptoms, and predictive value of dementia is investigated Chapter $\mathbf{5}$ in participants from the Biobank Alzheimer Center Limburg (BBACL) followup study. These were all participants who visited the MC in the Maastricht University Medical Center (MUMC+).

\section{Part Two: $\quad$ Insights into neuropsychological feedback and the development of a visual aid}

What is known in the literature about giving neuropsychological feedback to patients and family members and what clinical recommendations can be given to psychologists?

Chapter 6 provides a scoping literature review to identify what is known about giving neuropsychological feedback and communication methods. Based on the findings of the review, clinical recommendations were made.

Is a visual aid a helpful tool in the communication of neuropsychological test results in MC patients and their family members?

Chapter 7 presents the development phases of the INPAD project which consists of five co-creation phases. The overall aim of the INPAD project was to develop an interactive web-based visual tool of neuropsychological test results to increase understanding of these findings, improve information recall, and to harmonize and support communication between psychologist and the patient and family members.

The main findings and implications of all chapters within this doctoral thesis are discussed in Chapter $\mathbf{8}$. 


\section{REFERENCES}

1. Watt S, Crowe SF. Examining the beneficial effect of neuropsychological assessment on adult patient outcomes: a systematic review. Clin Neuropsychol. 2018;32(3):368-390.

2. Nederlandse Vereniging voor Klinische Geriatrie, Nederlandse Vereniging voor Neurologie, Nederlandse Vereniging voor Psychiatrie. Richtlijn diagnostiek en behandeling van dementie. https://www. nvvp.net/stream/richtlijn-diagnostiek-enbehandeling-van-dementie-2014. Published 2014. Accessed April 2020.

3. Mitchell AJ. A meta-analysis of the accuracy of the mini-mental state examination in the detection of dementia and mild cognitive impairment. J Psychiatr Res. 2009;43(4):411431.

4. Mitchell AJ, Malladi S. Screening and case finding tools for the detection of dementia. Part l: evidence-based meta-analysis of multidomain tests. Am J Geriatr Psychiatry. 2010;18(9):759-782.

5. Thissen AJAM, van Bergen F, de Jonghe JFM, Kessels RPC, Dautzenberg PLJ. Bruikbaarheid en validiteit van de Nederlandse versie van de Montreal Cognitive Assessment (MoCA-D) bij het diagnosticeren van Mild Cognitive Impairment. Tijdschr Gerontol Geriatr. 2010;41(6):231-240.

6. Woods B, Arosio F, Diaz A, et al. Timely diagnosis of dementia? Family carers' experiences in 5 European countries. Int $\mathrm{J}$ Geriatr Psychiatry. 2018;34(1):114-121.

7. de Vugt ME, Verhey FR. The impact of early dementia diagnosis and intervention on informal caregivers. Prog Neurobiol. 2013;110:54-62.
8. Jessen $\mathrm{F}$, Amariglio RE, van Boxtel $\mathrm{M}$, et al. A conceptual framework for research on subjective cognitive decline in preclinical Alzheimer's disease. Alzheimers Dement. 2014;10(6):844-852.

9. Ponds RW, Comissaris KJ, Jolles J. Prevalence and covariates of subjective forgetfulness in a normal population in the Netherlands. Int $J$ Aging Hum Dev. 1997;45:207-221.

10. Slavin MJ, Brodaty $H$, Kochan NA, et al. Prevalence and predictors of "subjective cognitive complaints" in the Sydney memory and ageing study. Am J Geriatr Psychiatry. 2010;18(8):701-710.

11. World Health Organization. Global action plan on the public health response to dementia 2017-2025. Geneva: World Health Organization; 2017.

12. Prince M, Wimo A, Wu Y, Prina M. World Alzheimer Report 2015: the global impact of dementia: analysis of prevalence, incidence, cost and trends. London: Alzheimer's Disease International; 2015.

13. Wimo A, Guerchet $\mathrm{M}$, Ali G-C, et al. The worldwide costs of dementia 2015 and comparisons with 2010. Alzheimers Dement. 2017;13(1):1-7.

14. Karg N, Graessel E, Randzio O, Pendergrass A. Dementia as a predictor of care-related quality of life in informal caregivers: a crosssectional study to investigate differences in health-related outcomes between dementia and non-dementia caregivers. BMC Geriatrics. 2018;18(1):189.

15. Deltaplan Dementie. Dementie? Samen keren we het tij. https://www.deltaplandementie.nl/ sites/default/files/flyer\%20DPD_def.pdf. Published 2012. Accessed April 2020.

16. Department of Health. The Irish National Dementia Strategy. Department of health; 2014. 
1. Department of Health. Living Well with Dementia: A National Dementia Strategy. London: Department of Health; 2009.

2. Lanca M, Giuliano AJ, Sarapas C, et al. Clinical outcomes and satisfaction following neuropsychological assessment for adults: AcCommunity hospital prospective quasiexperimental study. Arch Clin Neuropsychol. 2019.

3. Keady J, Gilliard J. The Experience of Neuropsychological Assessment for People with Suspected Alzheimer's Disease. In: Harris $\mathrm{BH}$, ed. The Person with Alzheimer's Disease. Pathways to understanding the experience. Baltimore: The John Hopkins University Press; 2002.

4. Bennett-Levy J, Klein-boonschate MA, Batchelor J, McCarter R, Walton N. Encounters with Anna Thompson: The consumer's experience of neuropsychological assessment. Clin Neuropsychol. 1994;8(2):219-238

5. American Psychological Association. Ethical principes of psychologists and code of conduct. https://www.apa.org/ethics/code/. Published January 2017.

6. Nederlands Instituut van Psychologen. Algemene Standaard Testgebruik NIP 2017. https://www.psynip.nl/uw-beroep/cotan/cotanbeoordelingssysteem-ast-en-beroepscode/ algemene-standaard-testgebruik-nip-2017/. Published January 2018. Accessed April 2020.

7. Postal KS, Armstrong K. Feedback that sticks: The art of effectively communicating neuropsychological assessment results. Oxford: Oxford University Press; 2013.

8. Gorske TT, Smith S. Collaborative Therapeutic Neuropsychological Assessment. New York: Springer Science and Business Media; 2009.

9. Rosado DL, Buehler S, Botbol-Berman E, et al. Neuropsychological feedback services improve quality of life and social adjustment. Clin Neuropsychol. 2018;32(3):422-435.
10. Kessels RPC. Patients' memory for medical information. J R Soc Med. 2003;96(5):219-222.

11. Fallows RR, Hilsabeck RC. Comparing two methods of delivering neuropsychological feedback. Arch Clin Neuropsychol. 2013;28(2):180-188.

12. Meth M, Calamia M, Tranel D. Does a simple intervention enhance memory and adherence for neuropsychological recommendations? Appl Neuropsychol Adult. 2016;23(1):21-28.

13. Cridland EK, Phillipson L, Brennan-Horley $C$, Swaffer K. Reflections and recommendations for conducting in-depth interviews with people with dementia. Qual Health Res. 2016;26(13):1774-1786.

14. Garcia-Retamero R, Galesic M. Who proficts from visual aids: Overcoming challenges in people's understanding of risks. Soc Sci. 2010;70(7):1019-1025. 

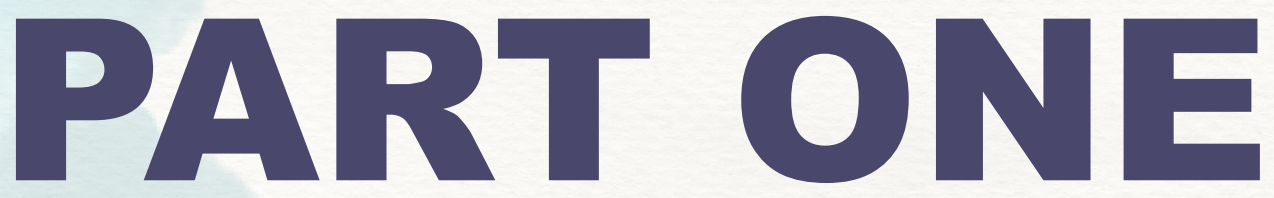

NEUROPSYCHOLOCICAL ASSESSMENT AT DUTCH MEMORY CLINICS 

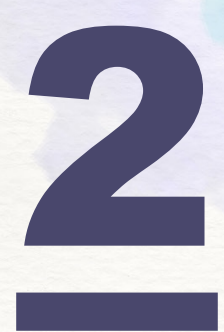

\section{Development of memory clinics in the Netherlands over twenty years: $1998-2016$}

Angélique AA Gruters, Inez HGB Ramakers, Roy PC Kessels, Femke H Bouwman, Marcel GM Olde Rikkert, Marco M Blom, Marjolein E de Vugt, Frans RJ Verhey.

International Journal of Geriatric Psychiatry, 2019 


\section{CHAPTER 2}

\section{ABSTRACT}

\section{Objectives}

Memory clinics (MCs) have been established to improve diagnosis and treatment of cognitive disorders, including dementia. The aim of this study was to determine the characteristics and working methods of MCs in the Netherlands in 2016. More insight into different working methods can be used to improve the quality of care in Dutch MCs. Additionally, the findings will be compared with earlier results to investigate the development of MCs since 1998.

\section{Methods}

A survey was sent in 1998, 2004, 2009, and 2017 to all operational Dutch MCs with questions about organization, collaboration, patients, and diagnostic procedures.

\section{Results}

From 1998 to 2016, the number of MCs increased substantially from 12 to 91 . The capacity increased from 1,560 patients to 24,388. In 1998, most patients received a dementia diagnosis (85\%), while in 2016, half of the patients were diagnosed with milder cognitive problems. MCs are more often part of regional care chains and are better embedded within regional care organizations. Diagnostic tools, such as blood tests (97\%), neuropsychological assessment (NPA) (95\%) and neuroimaging (92\%), were used in nearly all MCs. The number of patients in whom these tools were used differed greatly between MCs (NPA: 5-100\%, neuroimaging: 10-100\%, CSF: 0.5-80\%). There was an increase in the use of NPA, while the use of neuroimaging, CSF, and EEG/ ECG decreased by 8 to $15 \%$ since 2009 .

\section{Conclusions}

Since 1998, MCs have developed substantially and outgrown the primarily researchbased university settings. They are now accepted as regular care facilities for people with cognitive problems.

\section{Key points:}

- Memory clinics in the Netherlands developed considerably in the last twenty years and are now accepted as regular care facilities for people living with cognitive problems and dementia.

- $\quad$ People with cognitive problems attend the memory clinic in an earlier disease stage.

- Memory clinics in the Netherlands are increasingly collaborating with other regional care facilities and have psychosocial interventions more often as part of their treatment options. 


\section{CHAPTER 2}

\section{INTRODUCTION}

Early diagnosis of dementia enables improved understanding of the disease process, provides the opportunity to make decisions concerning the future while cognitive capacities are still relatively intact, ${ }^{1}$ and creates a time window to institute early interventions and support for patients and caregivers. ${ }^{2,3}$ With no cure available, early diagnosis may also have some drawbacks. An increasingly widespread view acknowledges 'timely diagnosis' as a more appropriate concept because it emphasizes a person-centered approach in which the diagnosis is related to the benefit of the patient and not to a disease stage. ${ }^{4,5}$ To improve early yet timely diagnosis, the development of specialized multidisciplinary memory clinics (MCs) has been promoted and recommended by national dementia strategies. ${ }^{6-12}$ The first clinics were established during the 1970s in the USA. During this time period, the perspective on the cause of dementia shifted from being an inevitable result of aging to being a disease..$^{13}$ The past three decades have shown significant growth in the development of MCs worldwide. The increasing number of MCs has been explained by the increasing prevalence of dementia, licensing of pharmacological treatments, and the improvement in care services. ${ }^{14-16}$ A comparable increase in MCs can be seen in the Netherlands. To gain more insight into the development and efficacy of these clinics, a first national survey in the Netherlands, the MC Monitor, was published in 1998. ${ }^{17}$ At that time, the authors described MCs as often being established in university-based hospitals with a focus on scientific research. The MC Monitor was repeated in 2004 and 2009 and showed an increase in the number and in the capacity of MCs. ${ }^{18,19}$ Since 2009, new MCs have been established, and the Dutch guideline "Diagnostics and Treatment of Dementia" was revised in $2014 .{ }^{20}$ The aim of this study was to determine the characteristics of MCs in the Netherlands in 2016. Two key topics of the survey were neuropsychological assessment and regional collaboration. More insight into different working methods can be used to improve the quality of care in MCs. In addition, the results were compared to the findings of the previous surveys to investigate the development of MCs in the last 20 years. 


\section{CHAPTER 2}

\section{METHODS}

To gain more insight into the characteristics of MCs, a semi structured questionnaire was sent out in 1998, 2004, 2009, and 2017 to all hospital-based MCs in the Netherlands asking for data from the previous year. An MC was defined as a multidisciplinary team with at least two disciplines (at least one medical profession) dedicated to the diagnosis of dementia. All relevant operational clinics were identified using the network of the Alzheimer Center Limburg and through internet searches. Every survey consisted of core items that were repeated in each survey. In addition, relevant items were added over time by an expert group. In addition, the survey was piloted in three academic hospitalbased Dutch Alzheimer Centers. In this survey, the following topics were included: organization, collaboration, number of patients, distribution of diagnosis and etiology, referrals, procedures, diagnostic criteria, additional assessments, neuropsychological assessment, treatment, policy, and professionalization. Participants were asked to answer questions by using information derived from official sources, but if this was unavailable, they were allowed to use estimations. In 1998 and 2004, the survey was sent by mail and then by e-mail and mail in 2009. In 2017, the survey was digitalized using Qualtrics software. MCs that did not respond received multiple reminders. A total of 91 MCs were identified, 78 of which returned the survey, resulting in a response rate of $86 \%$. This was comparable to the previous surveys in 1998 (88\%), 2004 (93\%), and 2009 (78\%). Most respondents were medical doctors. Statistical analyses were conducted using version 24 of the Statistical Package for Social Sciences (SPSS). To examine group differences between coordinating disciplines and university versus non-university-based MCs, analysis of variance (ANOVA) or independent t-tests were conducted. 


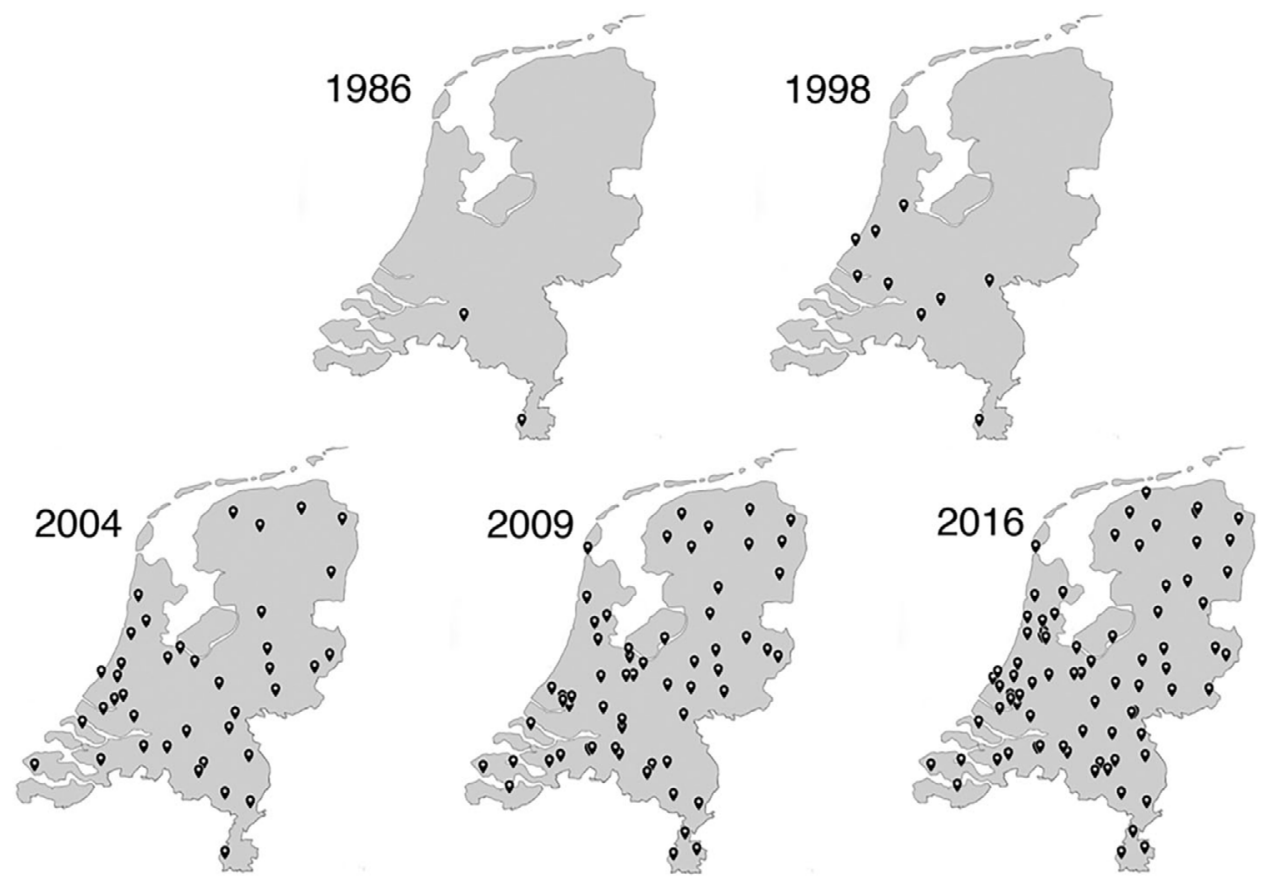

Figure 1. Distribution of MCs in the Netherlands from 1986 to 2016.

In addition to an increase in the number and distribution of MCs, the capacity also increased over time. The average number of newly referred patients per year increased from 130 in 1998 to 199 in 2004, 225 in 2009 to 268 in 2016 (see table 1). Since 1998, the total number of new patients increased from 1,560 to 24,388 . The variation between MCs was large, with the total number of new patients ranging between 30 and 1,000 patients per center. The mean percentage of patients younger than 65 years was $20.6 \%$ \pm 20.2 [range: 0-75\%]. University-based MCs and MCs coordinated by neurology have seen more younger patients on average than non-academic MCs (35\% versus $18 \%$, $\mathrm{p}=.019)$ and MCs coordinated by clinical geriatrics ( $35 \%$ versus $8 \%, p<001)$. 
Table 1. Development of MCs from 1998 to 2016.

\begin{tabular}{|c|c|c|c|c|}
\hline & 1998 & 2004 & 2009 & 2016 \\
\hline Number of MCs & 12 & 43 & 65 & 91 \\
\hline Average no. of newly referred patients & 130 & 199 & 225 & 268 \\
\hline Total no. of patients & 1,560 & 8,557 & 14,625 & 24,388 \\
\hline Regional collaboration (\%) & 15 & 63 & 87 & 89 \\
\hline \multicolumn{5}{|l|}{ Syndrome diagnosis (\%) 1} \\
\hline Dementia & 85 & 70 & 59 & 53 \\
\hline Cognitive disorders, no dementia & 10 & 24 & 24 & 25 \\
\hline No cognitive disorders & 5 & 6 & 15 & 22 \\
\hline Number of patients with dementia & 1,326 & 5,391 & 8,629 & 12,926 \\
\hline$\%$ of dementia incidence $(22,200)$ & 6 & 24 & 39 & 58 \\
\hline \multicolumn{5}{|l|}{ Diagnostics (\%) } \\
\hline Standardized protocol & 100 & 78 & 87 & 97 \\
\hline National dementia guideline & 100 & 50 & 71 & 82 \\
\hline \multicolumn{5}{|l|}{ Treatment (\%) } \\
\hline Pharmacological & 92 & 97 & 95 & 91 \\
\hline Psychosocial interventions & 38 & 65 & 53 & 72 \\
\hline Back to referral (\%) & 36 & 55 & 52 & 57 \\
\hline
\end{tabular}

${ }^{1}$ The syndrome diagnoses were estimated averages and therefore did not always result in a mean total of $100 \%$.

Organization

In 2016, MCs were coordinated by clinical geriatricians (39\%), neurologists (26\%), elderly care physicians (9\%), psychiatrists (1\%), or (neuro)psychologists (1\%). In addition, in $24 \%$ of the MCs, the coordination consisted of a collaboration between two or more disciplines. The professionals most frequently involved in MCs were neurologists (81\%), clinical geriatricians (73\%), psychiatrists $(46 \%)$, elderly care physicians $(30 \%)$, psychologists (94\%), and specialized dementia nurses (45\%). In comparison to 2009 , fewer psychiatrists and specialized dementia nurses were involved (figure 2). Both physician assistants and clinical nurse specialists were newly identified professionals within MCs.

In the Dutch healthcare system, doctor referral is mandatory. New patients were most often referred to MCs by a general practitioner (77\%, [range: 0-100\%]). Second opinions were obtained in $6 \%$ of the patients on average [range $0-70 \%$ ] and 
supra-regional referrals in $5 \%$ of the patients [range 0-40\%]. Both second opinions (22\% versus $4 \%, p<.001)$ and supra-regional referrals $(23 \%$ versus $3 \%, p<.001)$ were most often carried out by university-based MCs rather than by non-academic MCs.

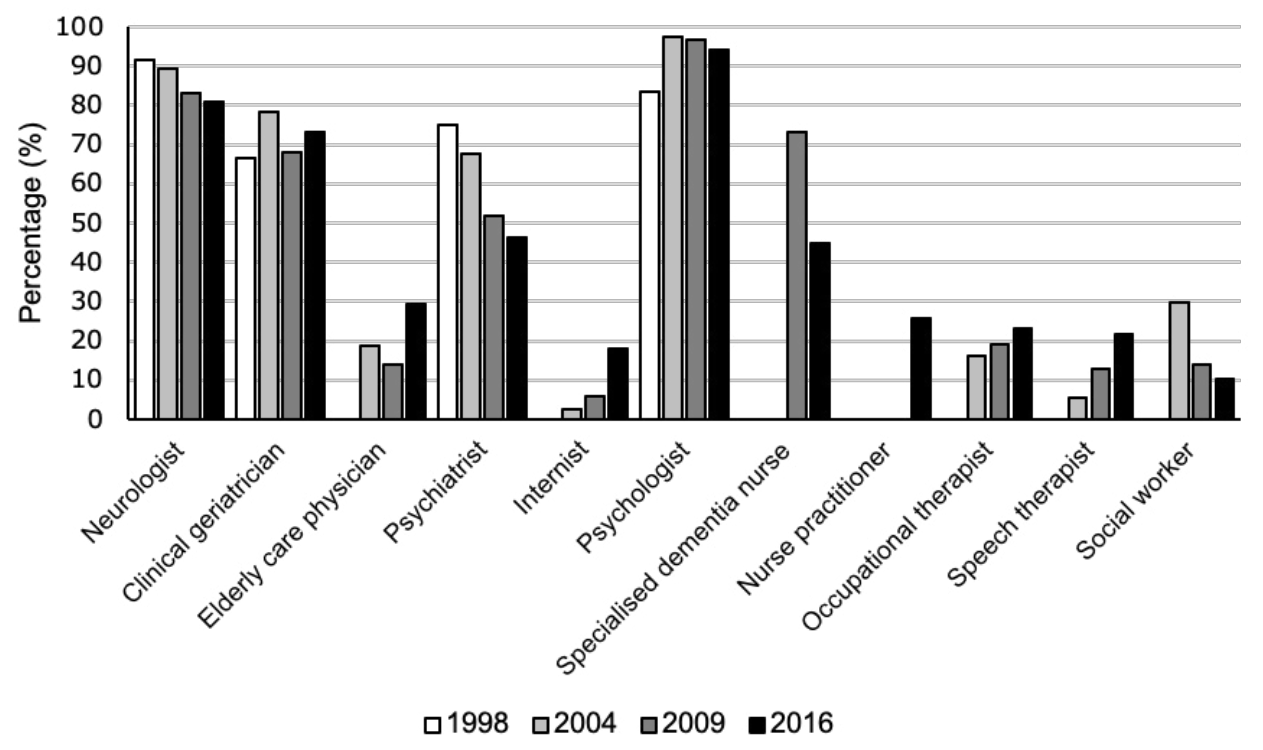

Figure 2. Changes in the professions involved in MCs over time.

\section{Diagnosis}

Although dementia was still the most common syndrome diagnosis made in MCs, the proportion decreased from 85\% in 1998 to 53\% [range: 10-85\%] in 2016. In contrast, the proportion of patients categorized as having 'cognitive impairments, without dementia' increased from 10\% in 1998 to $25 \%$ [range: 10-50\%] in 2016, and patients with 'no cognitive impairments' increased from $5 \%$ in 1998 to $22 \%$ [range: 0-50\%] in 2016 (table 1). The mean proportion of patients without cognitive impairments was most often seen in MCs coordinated by neurologists rather than in MCs coordinated by clinical geriatricians ( $16 \%$ versus $7 \%, p<.001)$. Given the current incidence of dementia in the Netherlands of $22,200,21,22$ and the estimation that in total approximately 12,926 patients were diagnosed in Dutch MCs per year, we calculated that MCs diagnosed $58 \%$ of all incident cases of dementia in 2016. This reflects an increase in the proportion of incident cases of dementia diagnosed by MCs compared to that reported in our previous surveys (table 1, 1998: 6\%, 2004: 24\%, 2009: 39\%).

The most common causes of dementia were Alzheimer's disease (AD) (46\%, [range: 5-80\%]), vascular dementia (VaD) (16\%, [range: 2-40\%]), and mixed causes (20\%. [range: 0-80\%]). In addition, rarer causes of dementia were also observed, such as frontotemporal dementia (FTD) (5\%, [range: 0-21\%]), Parkinson's dementia (3\%, [range: 0-10\%]), and Lewy body dementia (6\%, [range: 0-20\%]). 


\section{CHAPTER 2}

\section{Diagnostic assessment}

In 2016, the Dutch multidisciplinary guideline Diagnostics and Treatment of Dementia ${ }^{20}$ was used by $82 \%$ of the MCs. The multidisciplinary guideline includes multiple diagnostic criteria, such as McKahnn. ${ }^{23}$ In addition, the following criteria were used: DSM-IV-TR (19\%), ${ }^{24}$ DSM-5 (9\%), ${ }^{25}$ ICD-10 (12\%), ${ }^{26}$ McKahnn criteria (30\%), ${ }^{23}$ DuBois criteria (10\%), ${ }^{27}$ NINDS-AIREN (45\%), ${ }^{28}$ and Manchester Lund criteria (19\%). ${ }^{29}$ Five MCs (6\%) did not use any specific criteria.

\section{Cognitive screening}

In 2016, most MCs used a cognitive screening test during their intake (86\%). The MMSE $^{30}$ was most frequently used (91\%). The outcome of this test was most often used to determine additional diagnostic assessments (78\%) or to determine the treatment plan (52\%).

\section{Neuropsychological assessment}

The use of an NPA increased from 50\% in 1998 to $95 \%$ in 2016 . The proportion of patients in whom an NPA was performed differed largely between MCs [range: 5-100\%]. The reasons for carrying out an NPA were: to support the diagnosis (92\%), collect differential diagnostic information (91\%), to gain insight into strengths and weakness (44\%), and as a starting point for neuropsychological treatment (31\%). The most often reported reason for not carrying out an NPA was if a patient had a clinically evident diagnosis of dementia, in which case a neuropsychological assessment would not have any additional diagnostic value (78\%). Other reasons were lack of financial means (6\%) or no possibilities within the team (1\%). The cognitive tests varied per center. Nearly all MCs (96\%) held multidisciplinary meetings. In 92\% of the MCs, a psychologist participated in this meeting. The following topics were discussed by the psychologists: conclusion of the NPA (99\%), differential diagnosis (92\%), cognitive profile (85\%), and advice on how to cope with cognitive complaints in daily life (79\%). During the diagnostic disclosure performed by the medical doctor, the following aspects of an NPA were discussed: NPA conclusion (73\%), advice on how to cope with cognitive complaints (58\%), and results per cognitive domain (49\%).

\section{Additional assessment tools}

In addition to an NPA, laboratory tests (97\%) or neuroimaging studies (92\%) were frequently used in MCs. Compared to 2009, the number of MCs using neuroimaging decreased from $100 \%$ to $92 \%$, and the number of MCs using EEG, ECG, and CSF decreased from $59 \%$ to $45 \%, 74 \%$ to $60 \%$, and from $79 \%$ to $68 \%$, respectively (figure 3 ). There was a large variation between MCs with respect to the assessment tools used, the percentage of patients in whom these were applied and the average estimated time (NPA: 49\% [range: 5-100\%]; 281 [range: 63-300 minutes], lab tests: 96\% [range: 30-100\%]; 9 [range: 1-25 minutes, EEG: 17\% [range: 0.10-100\%]; 
47 [range: 30-120 minutes], ECG: 68\% [range: 1-100\%]; 9 [range: 5-15 minutes], CSF: 12\% [range: 0.10-75\%]; 29 [range: 5-60 minutes], neuroimaging: 82\% [range: 20100\%]); 29 [range: 10-60 minutes]).

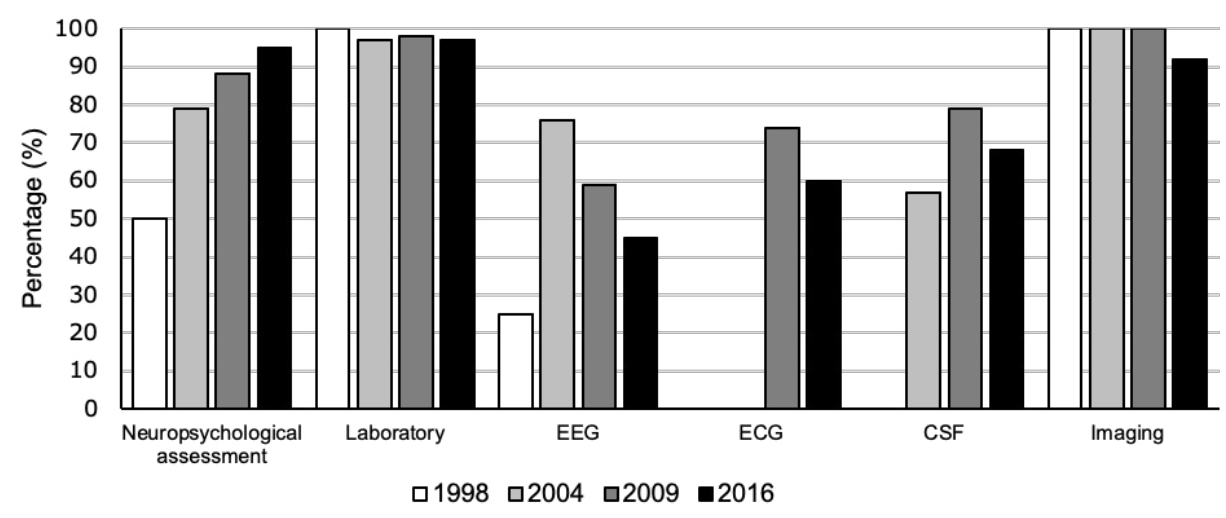

Figure 3. The use of the various assessment tools in MCs in the Netherlands over time. Abbreviations. EEG: electroencephalography, ECG: electrocardiogram, CSF: cerebrospinal fluid.

Scales for behavioral and daily functioning

With regard to assessment scales, both the Geriatric Depression Scale $(88 \%)^{31}$ and the Neuropsychiatric Inventory $(71 \%)^{32}$ were frequently used. To measure functioning in daily living, the Lawton \& Brody Instrumental Activities of Daily Living Scale $(66 \%)^{33}$ and the Interview for Deterioration in Daily Living Activities in Dementia $(39 \%)^{34}$ were most often used. There was a variation between MCs in the use of specific instruments for evaluating neuropsychiatric symptoms and daily living.

\section{Treatment}

From 1998 to 2016, pharmacological treatments were offered in approximately 90\% of the MCs (table 1). Psychosocial interventions were routinely offered in $38 \%$ of the MCs in 1998 , and this increased to $72 \%$ MCs in 2016 . On average $58 \%$ of the patients were referred back to the referring individual or center [10-100\%], while $42 \%$ remained in the care of the MC [5-90\%]. For people with an $\mathrm{MCl}$ diagnosis, this often consisted of a follow-up cognitive assessment after one year, and for people with a dementia diagnosis, it was a medication follow-up.

\section{Regional collaboration}

Collaboration with regional healthcare organizations increased from 15\% in 1998 to $89 \%$ in 2016. In 2016, $78 \%$ of all MCs were involved in regional care chains (table 1). MCs collaborated most often with primary care (65\%), mental health care (59\%), and local care organizations (58\%). A smaller number of MCs collaborated with other regional hospitals (28\%). Structural meetings with mental health care $(46 \%)$ or other local care organizations (41\%) occurred in approximately half of the MCs. 


\section{DISCUSSION}

This study provides new insights into the development of MCs between 1998 and 2016. The main findings showed that MCs have increased both in number and capacity and are geographically more widely distributed. In addition, our results show that MCs are better integrated within regional care facilities, and more frequent collaborations between medical disciplines have been established to coordinate MCs. The proportion of dementia diagnoses has decreased, while the proportion of milder cognitive problems has increased. Furthermore, a large variation in capacity, working methods, and in the use of additional assessments between MCs was identified.

The number of MCs has increased eightfold, the total number of newly referred patients sixteenfold, and the capacity per MC has doubled since 1998. The continuous growth in the number of MCs is in line with other countries. For example, the number of MCs increased on the British Isles from 20 in 1993 to 58 in 2000, and in Australia from 23 in 2009 to 30 in 2012. ${ }^{14-16}$ An English audit showed that memory services increased from 214 in 2013 to 222 in 2014. . $^{35,36}$ Initially, this increase may have been partly related to the launch of anti-dementia drugs such as rivastigmine in the Netherlands. The further increase found in our survey might be explained by the rising prevalence and increased awareness of dementia, and the relevance of a multidisciplinary approach in the timely diagnosis of dementia. ${ }^{37}$ A multidisciplinary approach has been shown to have added value in differentiating between dementia subtypes, detecting comorbidity, ${ }^{37}$ being cost-effective, and improving quality of life. ${ }^{38}$ The strong increase in patient numbers might also reflect the excellent availability of care facilities and demographic changes in the Netherlands. While the overall number of MCs has increased, five MCs have closed for the first time since our surveys began. The reasons for this are not clear. One MC reported that this was the result of a complex financial agreement between disciplines. One MC merged with another hospital. Another more speculative explanation could be that the substantial increase in MCs reached a sufficient capacity for the current demand.

MCs are by definition multidisciplinary and neurology, clinical geriatrics, and (neuro) psychology were the disciplines that were most frequently part of the MC team. Neurology and clinical geriatrics were most often involved as the leading disciplines. These numbers are comparable to what they have been over the last 20 years. Compared to previous surveys, currently, psychiatrists seem to be less involved. However, in other countries, psychiatrists are more frequently present in MCs (e.g., 70$80 \%$ in the UK), and neurologists and geriatricians are less frequently involved. ${ }^{14,15,39,40}$ The number of psychologists employed in MCs is similar to that of other countries, except for New Zealand, where only $14 \%$ of the MCs had a psychologist. ${ }^{40}$ These crossnational differences may be related to historical disciplinary developments.

NPA, lab tests and brain imaging are the most frequently used diagnostic assessment tools in MCs. This is comparable to MCs in other countries. ${ }^{14,16}$ Since 2009, the use of an NPA has further increased, while EEG, ECG, CSF and brain imaging tools are used by fewer MCs than in 2009 (a change of 8-15\%). This decrease might be related to the new Dutch multidisciplinary diagnostic guideline in which CSF, for example, is 
not recommended as a standard routine, and neuroimaging is recommended when the etiologic cause is uncertain. ${ }^{20}$ Other speculative reasons might be that new MCs are smaller. The proportion of patients in whom these tools were used, however, did not change (CSF; 2009: 12\%, 2016: 15\%). The increase in the use of an NPA could be related to the beneficial effect of an NPA on patient outcomes (e.g., accuracy of diagnosis). ${ }^{41,42}$ Although dementia is still the most common syndrome diagnosis in MCs, diagnoses have shifted towards milder cognitive problems. This is in line with the results from the national English Audit. ${ }^{35,36}$ This finding and the increased number of newly referred patients to MCs might be explained by the increased awareness of and attention directed towards dementia and early diagnosis in our society. The proportion of incident cases of dementia diagnosed at an MC has increased tenfold since 1998 from 6\% to 58\% (approximately 13,000 patients). Furthermore, the proportion of patients with cognitive impairment without dementia increased from 10\% to 25\% (approximately 6,000 patients). This is in line with the global dementia action plan, which stated that by $2025,50 \%$ of the countries should have diagnosed at least $50 \%$ of the incident cases of dementia. ${ }^{43}$ The timely diagnosis of dementia is not limited to MCs but is also practiced by general practitioners (GPS) or in community mental health institutions. In the previous survey in 2009, mental health institutions were included and appeared to differ greatly from hospital-based settings (e.g., fewer disciplines and diagnostic tools available). They also often did not identify themselves as an MC. Therefore, we have focused on the development of hospital-based MCs in this survey. A timely diagnosis of dementia is being promoted worldwide. ${ }^{44-46}$ The lack of a disease modifying treatment calls for a careful consideration of the benefits and disadvantages of an early diagnosis. Previous authors have shown that the majority of patients prefer a timely diagnosis.47,48 Furthermore, MCs can still offer much to patients in the predementia phase, including an evaluation of the prognosis, careful monitoring of cognitive decline, and psychosocial interventions. Psychosocial interventions are now more often a part of the regular care in Dutch MCs, which is in line with the MC quality indicators. ${ }^{49}$

MCs started as experimental university-based facilities. The increasing proportion of incident cases of dementia show that MCs are now accepted as mainstream healthcare facilities and as part of the standard care for the timely diagnosis of dementia. In addition, MCs offer a wider range of care and treatment options as a result of the integration with long-term care. MCs have been criticized in the past for being unclear about whether they were running projects or contributing to regional health services. ${ }^{50}$ Currently, MCs are no longer isolated facilities that focus solely on conducting research. In other countries, tensions have been reported with regard to the collaboration between care services and MCs. ${ }^{15}$ However, in this study, we found an increased integration of MCs in long-term care and an increased use of chain of care. Therefore, these tensions might not be present in MCs in the Netherlands. This was not explicitly asked in the current survey. The increase in regional collaborations is in line with the collaborative-care model between primary-and specialist healthcare in the Netherlands. Collaborative care, when compared to care as usual, has been shown to lead to improved outcomes (e.g., beneficial cost-benefit ratio, health-related quality of life). ${ }^{37,51,52}$ 
A large heterogeneity exists between MCs concerning the number of newly referred patients, staff members, distribution of syndrome diagnosis, use of additional assessments, cognitive instruments, and assessment scales. This heterogeneity might have different explanations. First, it might be related to differences in what an MC can offer (e.g., different types of professionals within the team, financial reimbursement). Second, diversity could also be caused by differences in education and/or knowledge within the team. Third, variation in patient groups could lead to different patient-specific needs. Harmonization of best practices could improve the collaboration between MCs, and more importantly, would make it easier to communicate and compare test results. An example of harmonization is the development of a Dutch monodisciplinary guideline for NPA in MCl and dementia, which will be available via the Dutch Institute for Psychologists (NIP). Transparency of offered MC services would enable patients to visit clinics where they would benefit from expertise related to the nature of their individual condition. To a certain extent, best practice between MCs should be shared to improve quality of care. Criticisms of MCs have also been described, such as their role in promoting stigma and issues surrounding over-assessment of patients.50 In contrast, a European study has shown that MCs facilitate early referrals and to some degree battle against stigma. ${ }^{53}$

A strength of this current study is the repeated measurement of a comparable survey over a twenty-year period. A high response rate was obtained, and we consequently argue that the study is an adequate representation of the current situation of Dutch MCs. Nonetheless, a few drawbacks should be mentioned. Although we made utmost efforts to include every MC in the Netherlands, we may have missed some newly established MCs. In addition, we did not obtain a response from all identified MCs. The estimated numbers should therefore be carefully interpreted. The nonresponding MCs were all non-academic hospitals, but differed in geographical location, size, and coordinating discipline. Another important point is that the results are mainly based on self-reported estimates rather than objective data from registries.

\section{CONCLUSION}

Since 1998, MCs in the Netherlands have shown substantial development in number, geographical distribution, and total capacity. MCs are no longer isolated, universitybased facilities with a strong focus on scientific research. They are now part of the regular care for the timely diagnosis of dementia and milder cognitive disorders and are integrated into regional care chains. Among MCs, a large diversity in specific working methods and diagnostic tools was identified. This diversity should be the focus of future research to increase transparency of the working methods of individual clinics and to harmonize best practices, which will both improve quality of care in Dutch MCs. 


\section{CHAPTER 2}

\section{ACKNOWLEDGEMENTS}

We are very grateful to all Dutch MCs that participated in our study. In addition, we would also like to thank the Dutch MC Network for spreading our survey among their network. This survey was supported by an independent grant from the Noaber Foundation and Alzheimer Nederland. 


\section{CHAPTER 2}

\section{REFERENCES}

1. Borson S, Frank L, Bayley PJ, et al. Improving dementia care: the role of screening and detection of cognitive impairment. Alzheimers Dement. 2013;9(2):151-159.

2. Prince M, Bryce R, Ferri CP. World Alzheimer Report 2011: The benefits of early diagnosis and intervention. Alzheimer's Disease International; 2011.

3. de Vugt ME, Verhey FR. The impact of early dementia diagnosis and intervention on informal caregivers. Prog Neurobiol. 2013;110:54-62.

4. Dhedhi SA, Swinglehurst D, Russell J. 'Timely' diagnosis of dementia: what does it mean? A narrative analysis of GPs' accounts. BMJ Open. 2014:4(3).

5. Woods B, Arosio F, Diaz A, et al. Timely diagnosis of dementia? Family carers' experiences in 5 European countries. Int $\mathrm{J}$ Geriatr Psychiatry. 2018:1-8.

6. Morgan DG, Crossley M, Kirk A, et al. Improving access to dementia care: Development and evaluation of a rural and remote memory clinic. Aging Ment Health. 2009;13(1):17-30.

7. Kelly C. Memory Clinics. Psychiatry. 2007;7:6163.

8. Jolley D, Benbow SM, Grizzell M. Memory clinics. Postgrad Med J. 2006;82:199-206.

9. Logiudice D, Wlatrowicz W, Brown K, Burrows C, Ames D, Flicker L. Do memory clinics improve quality life of carers? A randomized pilot trial. Int J Geriatr Psychiatry. 1999; 14(8):626-632.

10. Department of Health. Living Well with Dementia: A National Dementia Strategy. London: Department of Health; 2009.

11. Department of Health. The Irish National Dementia Strategy. 2014.

12. Alzheimer Nederland. Zorgstandaard dementie. https://www.alzheimer-nederland.nl/ sites/default/files/directupload/zorgstandaarddementie.pdf. Published 2013.

13. Katzman R. The prevalence and malignancy of Alzheimer's disease. Arch Neurol. 1976;33:217218.

14. Lindesay J, Marudkar M, van Diepen $\mathrm{E}$, Wilcock $\mathrm{G}$. The second Leicester survey of memory clinics in the British Isles. Int J Geriatr Psychiatry. 2002;17:41-47.

15. Cahill S, Pierce M, Moore V. A national survey of memory clinics in the Republic of Ireland. Int Psychogeriatr. 2014;26(4):605-613.

16. Woodward MC, Woodward E. A national survey of memory clinics in Australia. Int Psychogeriatr. 2009;21(4):696-702.

17. Verhey FRJ, Nods M, Ponds RWHM, Scheltens P. Geheugenpoliklinieken in Nederland. Neurologie. 1999;3:169 - 174.

18. Ramakers IH, Verhey FR. Development of memory clinics in the Netherlands: 1998 to 2009. Aging Ment Health. 2011;15(1):34-39.

19. Verhey FRJ, Ramakers IH, Jolles J, Scheltens P, Vernooij-Dassen M, Olde Rikkert MGM. Geheugenpoli's in Nederland: Ontwikkelingen sinds 1998. Tijdschr Gerontol Geriatr. 2007;38(5):237-245.

20. Nederlandse Vereniging voor Klinische Geriatrie, Nederlandse Vereniging voor Neurologie, Nederlandse Vereniging voor Psychiatrie. Richtlijn Diagnostiek en Behandeling van dementie. https://www. nvvp.net/stream/richtlijn-diagnostiek-enbehandeling-van-dementie-2014. Published 2014. Accessed September 2018.

21. Rijksinstituut voor Volksgezondheid en Milieu (RIVM). Hoeveel mensen met dementie zijn er? https://deltaplandementie.n//sites/ default/files/Dementie-Rene-Poos-15122016. pdf. Published December 2016. Accessed September 2018. 
1. van Bussel EF, Richard E, Arts DL, et al. Dementia incidence trend over 1992-2014 in the Netherlands: Analysis of primary care data. PLoS Med. 2017;14(3):e1002235.

2. McKhann GM, Knopman DS, Chertkow H, et al. The diagnosis of dementia due to Alzheimer's disease: recommendations from the National Institute on Aging-Alzheimer's Association workgroups on diagnostic guidelines for Alzheimer's disease. Alzheimers Dement. 2011;7(3):263-269.

3. American Psychiatric Association (APA). Diagnostic and statistical manual of mental disorders (4th ed., text rev.). Washington, DC: APA; 2000.

4. American Psychiatric Association. Diagnostic and statistical manual of mental disorders (5th ed.). Washington, DC: APA; 2013.

5. World Health Organization. The ICD-10 classification of mental and behavioural disorders: Clinical descriptions and diagnostic guidelines. Geneva: WHO; 1992.

6. Dubois B, Feldman $\mathrm{HH}$, Jacova $\mathrm{C}$, et al. Advancing research diagnostic criteria for Alzheimer's disease: the IWG-2 criteria. Lancet Neurol. 2014;13(6):614-629.

7. Roman GC, Tatemichi TK, Erkinjuntti T, et al. Vascular dementia: diagnostic criteria for research studies. Report of the NINDSAIREN International Workshop. Neurology. 1993;43(2):250-260.

8. The Lund and Manchester Groups. Clinical and neuropathological criteria for frontotemporal dementia. J Neurol Neurosurg Psychiatry. 1994;57(4):416-418.

9. Folstein MF, Folstein SE, McHugh PR. "Minimental state": A practical method for grading the cognitive status of patients for the clinician. J Psychiatr Res. 1975;12(3):189-198.
10. Sheikh JI, Yesavage JA. Geriatric Depression Scale (GDS): Recent evidence and development of a shorter version. Clin Gerontologist. 1986;5(1-2):165-173.

11. Cummings JL, Mega M, Gray K, RosenbergThompson S, Carusi DA, Gornbein J. The Neuropsychiatric Inventory: comprehensive assessment of psychopathology in dementia. Neurology. 1994;44:2308-2314.

12. Lawton MP, Brody EM. Assessment of Older People: Self-maintaining and instrumental activities of daily living. Gerontologist. 1969;9(3_Part_1):179-186.

13. Teunisse $S$, Derix MM. The interview for deterioration in daily living activities in dementia: agreement between primary and secondary caregivers. Int Psychogeriatr. 1997;9 Suppl 1:155-162.

14. Royal College of Psychiatrists. English National Memory Clinics Audit Report. London: Royal College of Psychiatrists; 2013.

15. Royal College of Psychiatrist. Second English National Memory Clinics Audit Report. London: Royal College of Psychiatrists; 2014.

16. Wolfs C, Kessels A, Dirksen C, Severens J, Verhey F. Integrated multidisciplinary diagnostic approach for dementia care: randomised controlled trial. Br J Psychiatry. 2008;192(4):300-305.

17. Wolfs CA, Dirksen CD, Kessels A, Severens $\mathrm{JL}$, Verhey FR. Economic evaluation of an integrated diagnostic approach for psychogeriatric patients: results of a randomized controlled trial. Arch Gen Psychiatry. 2009;66(3):313-323.

18. Werner P, Goldstein D, Heinik J. The process and organizational characteristics of memory clinics in Israel in 2007. Arch Gerontol Geriatr. 2009;49(2):e115-120.

19. Cheung $G$, Strachan J. A survey of memory clinics in New Zealand. Australas Psychiatry. 2008;16(4):244-247. 
1. Watt S, Crowe SF. Examining the beneficial effect of neuropsychological assessment on adult patient outcomes: a systematic review. Clin Neuropsychol. 2018;32(3):368-390.

2. Jansen WJ, Handels RL, Visser PJ, et al. The diagnostic and prognostic value of neuropsychological assessment in memory clinic patients. J Alzheimers Dis. 2017;55(2):679-689.

3. World Health Organization (WHO). Global action plan on the public health response to dementia 2017-2025. Geneva: WHO; 2017.

4. Alzheimer's Association. Factsheet: Healthy People 2020. https://www.alz.org/media/ Documents/healthy-people-fact-sheet-2015. pdf. Published April 2017. Accessed November 2018.

5. Alzheimer's Society. National dementia strategies. https://www.alzheimers.org.uk/ info/20090/national_policies. Accessed November 2018.

6. National Institute for Health and Care Excellence (NICE). Dementia: assesment, management and support for people living with dementia and their carers. London: NICE; 2018.

7. Pinner $G$, Bouman WP. Attitudes of patients with mild dementia and their carers towards disclosure of the diagnosis. Int Psychogeriatr. 2003; 15(3):279-288.

8. van den Dungen $P$, van Kuijk L, van Marwijk $\mathrm{H}$, et al. Preferences regarding disclosure of a diagnosis of dementia: a systematic review. Int Psychogeriatr. 2014;26(10):1603-1618.

9. Draskovic I, Vernooij-Dassen M, Verhey F, Scheltens P, Rikkert MO. Development of quality indicators for memory clinics. Int $J$ Geriatr Psychiatry. 2008;23(2):119-128.

10. Pelosi AJ, McNulty SV, Jackson GA. Role of cholinesterase inhibitors in dementia care needs rethinking. Br Med J. 2006;333(7566):491-493.
11. Dham $\mathrm{P}$, Colman $\mathrm{S}$, Saperson $\mathrm{K}$, et al Collaborative care for psychiatric disorders in older Adults: A systematic review. Can J Psychiatry. 2017;62(11):761-771.

12. Callahan $\mathrm{CM}$, Boustani MA, Unverzagt FW, et al. Effectiveness of collaborative care for older adults with Alzheimer disease in primary care: a randomized controlled trial. JAMA. 2006;295(18):2148-2157.

13. Vernooij-Dassen MJ, Moniz-Cook ED, Woods $\mathrm{RT}$, et al. Factors affecting timely recognition and diagnosis of dementia across Europe: from awareness to stigma. Int J Geriatr Psychiatry. 2005;20(4):377-386. 

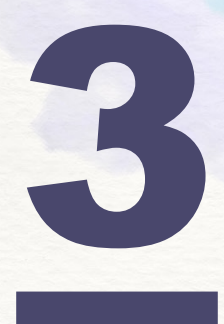

\section{Development of a Dutch monodisciplinary guideline neuropsychological assessment in patients with a mild cognitive impairment ( $\mathrm{MCl}$ ) and dementia}

Inez HGB Ramakers, Angélique AA Gruters, Annemarie PM Stiekema, Ben Schmand, Bregje Appels, Dymphie in de Braek, Annelien Duits, Alex Knipping, Roy PC Kessels, Marjolein E de Vugt.

Tijdschrift voor Neuropsychologie, 2020 (translated from Dutch) 


\section{CHAPTER 3}

\section{ABSTRACT}

One of themostimportantdiagnostictools in the multidisciplinary diagnostics of cognitive disorders and dementia is the neuropsychological assessment (NPA). Findings of a recent survey in psychologists about the working methods of an NPA in Dutch memory clinics showed that the procedure and content of the NPA varied. Furthermore, a need for a uniform approach of the NPA between memory clinics was expressed. This led to the development of the monodisciplinary guideline: 'Neuropsychological assessment in mild cognitive impairment (MCI) and dementia'. In this guideline a harmonized core battery of cognitive tests is recommended. This battery has to be supplemented with other relevant tests to answer individual diagnostic questions. By implementing this guideline, the quality of the NPA in this patient population can be warranted, variation between centers can be decreased, follow-up examinations can be interpreted more reliably, and communication between centers can be improved. 


\section{CHAPTER 3}

\section{INTRODUCTION}

In the upcoming decades, the number of the elderly will increase as a result of the double aging phenomenon. Age-related health problems will increase (e.g., dementia) and this will further impact healthcare demand. The question whether cognitive complaints are related to normal aging or indicate an underlying neurodegenerative process will be raised more often. A timely diagnosis of dementia is important to give insight into the changes in daily life functioning and behavior of a patient. Furthermore, a timely diagnosis offers a time frame during which important decisions can be made about the future, and there is room for treatment and guidance. ${ }^{1}$

Proper assessment of cognitive functioning through a neuropsychological assessment (NPA) remains an important aspect of the timely diagnosis of dementia. A recent systematic review showed that an NPA contributes to a more accurate diagnosis. ${ }^{2}$ By using an NPA, it is possible to give insight into the cognitive profile of strengths and weaknesses, which resembles the problems a patient experiences in daily life. In this regard, an NPA is a better reflection of patient functioning compared to biomarkers of neurodegeneration in cerebrospinal fluid or blood, and brain imaging. ${ }^{3,4}$ An NPA has a diagnostic value in the early phases of dementia ${ }^{5}$ but can also map disease progression. Insights into the cognitive profile can be used as a starting point for neuropsychological treatment. ${ }^{6}$

Therefore, the NPA has an important role in the diagnostics of mild cognitive impairment (MCl) and dementia. Furthermore, it is used in almost all Dutch memory clinics. ${ }^{7}$ Since 1992, the development of memory clinics has been examined through the 'Memory clinic monitor'. The results from the most recent survey in 2016 were reason to further evaluate NPA procedures in the early diagnostics of dementia. This was reason for the 'NPA monitor' in 2017. Results from this survey led to the development of the monodisciplinary guideline for NPA in mild cognitive impairment (MCI) and dementia. The first aim of this article is to describe the results of the NPA monitor. The secondary aim is to describe the development of the monodisciplinary guideline including the harmonized core battery. 


\section{CHAPTER 3}

\section{METHODS AND RESULTS}

\section{Phase 1: $\quad$ Survey NPA in Dutch memory clinics}

\section{Methods}

In the Memory clinic monitor 2016, all Dutch memory clinics were approached (n = 91) by using the contact details from the last survey in 2009, the network of the Dutch Alzheimer centers, and through internet searches. Respondents were asked to fill in the contact details of the (neuro)psychologist involved in the memory clinic for the NPA monitor. When these details were missing, or when a memory clinic did not participate in the memory clinic survey, they were contacted by phone to inquire after the contact details of the (neuro)psychologist. Afterwards, the NPA monitor, a digitalized questionnaire, was sent to all memory clinics that had at least one (neuro)psychologist in their team. They were informed that they were not obliged to participate. Three reminders were sent. The questionnaire contained 51 questions on the following topics: team of psychologists, procedures, NPA, and treatment. Eleven psychologists were approached for an additional in-depth interview to collect more detailed information. These psychologists were randomly selected, but geographical distribution and academic versus non-academic proportion was taken into account. During the interview, the following themes were addressed: cognitive screening tools, NPA, procedures, and treatment. The interviews were independently analyzed by two authors, using a systematic and deductive content analysis. ${ }^{8}$

Table 1. Composition of psychologist team within Dutch memory clinics

\begin{tabular}{|c|c|c|}
\hline Function & Number of clinics (\%) & Average of FTE \\
\hline Psychology degree (master level) & $29(38)$ & $0.62 \pm 0.36[0.13-1.5]$ \\
\hline $\begin{array}{l}\text { Psychologist in training for clinical } \\
\text { license }\end{array}$ & $25(33)$ & $0.93 \pm 1.80[0.04-8]$ \\
\hline $\begin{array}{l}\text { Licensed psychologist (basic } \\
\text { clinical license) }\end{array}$ & $49(65)$ & $0.79 \pm 0.54[0.11-2.22]$ \\
\hline $\begin{array}{l}\text { Licensed psychologist in training } \\
\text { for certification as clinical } \\
\text { psychologist }\end{array}$ & $6(8)$ & $0.50 \pm 0.33[0.2-1]$ \\
\hline Certified clinical psychologist & $17(22)$ & $0.58 \pm 0.31[0.2-1]$ \\
\hline $\begin{array}{l}\text { Licensed psychologist in training } \\
\text { for certification as clinical } \\
\text { neuropsychologist }\end{array}$ & $12(16)$ & $0.54 \pm 0.42[0.1-1.5]$ \\
\hline Certified clinical neuropsychologist & $30(40)$ & $0.72 \pm 0.63[0.05-3]$ \\
\hline Psychological assistant & $44(58)$ & $0.86 \pm 0.63[0.1-2.4]$ \\
\hline
\end{tabular}

Abbreviations. FTE: full time equivalent. 


\section{CHAPTER 3}

\section{Results}

A total of 87 memory clinics with a (neuro)psychologist were identified, 76 of which returned the survey (response rate: $87 \%$ ). Most respondents (85\%) had completed at least a training for the clinical license.

\section{Team composition}

The composition of the team of psychologists with the average of FTEs can be reviewed in table 1. Most memory clinics (95\%) had at least one psychologist with a clinical license. More than half of the memory clinics (68\%) had multiple psychologists in the team.

\section{Cognitive screening}

Based on both the survey and interviews it became clear that all memory clinics used a cognitive screening tool. Figure 1 shows the most used tools. The tools were usually administered by a psychological assistant $(n=45,60 \%)$, nurse ( $n=42,56 \%)$, doctor ( $n=41,55 \%)$, or psychologist ( $n=33,44 \%)$.

The interviews showed that a cognitive screening tool was often used to determine whether or not an extensive NPA would be conducted, or to map the disease course. Almost all psychologists expressed doubts about the sensitivity and specificity of these tools, and noticed that there was often a discrepancy between the outcome of the screening tools and the results of an NPA.

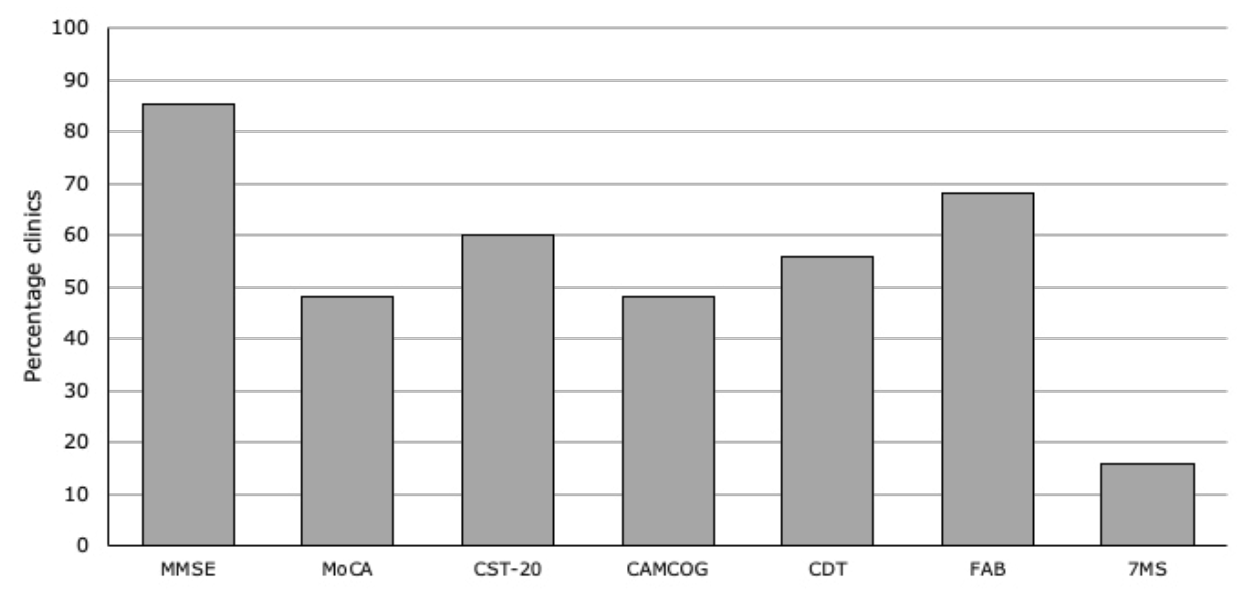

Figure 1. Most used cognitive screening tools. Abbreviations. MMSE: Mini Mental Status Examination, MoCA: Montreal Cognitive Assessment, CST: Cognitive Screening Test, CAMCOG: Cambridge Cognitive Examination, CDT: Clock Drawing Test, FAB: Frontal Assessment Battery, 7MS: Seven Minute Screen. 


\section{CHAPTER 3}

Neuropsychological assessment

The following reported numbers are the median with the minimum and maximum. The Memory clinic monitor 2016 showed that an NPA was used in nearly all memory clinics, but not in all patients. Per month and per center an NPA was administered in twelve patients [1-45]. When asked to estimate the proportion of syndrome diagnosis of patients in which an NPA was administered, the following distribution was reported: $90 \%$ [80-100\%] of patients with 'no cognitive disorders, no dementia', 100\% [30-100\%] of patients with 'cognitive disorders, no dementia', 100\% [50-100\%] of patients with 'mild dementia, and in 85\% [0-100\%] of patients with 'moderate to severe dementia'.

The length of an NPA can be reviewed in figure 2. A full NPA took on average 4,5 hours [80 - 480]. The separate components of an NPA were estimated to be: initial/ family interview 45 minutes [5 - 90], assessment 120 minutes [24 - 240], processing of results 60 minutes [15 - 240], the report 60 minutes [15 - 180], and feedback 30 minutes [0 - 90]. Of note is the large variation between clinics.

In the interviews, it appeared that there was an emphasis to conduct an NPA as short as possible in recent years. The opinions were divided about this trend. On one hand, some psychologists saw the benefit in faster diagnostics (efficiency, less costs, and less burden on the patient). On the other hand, other psychologists advocate for a longer NPA, because shortening causes loss of necessary information. As a result of the full program at the memory clinic, there was often not much room for additional tests in the NPA.

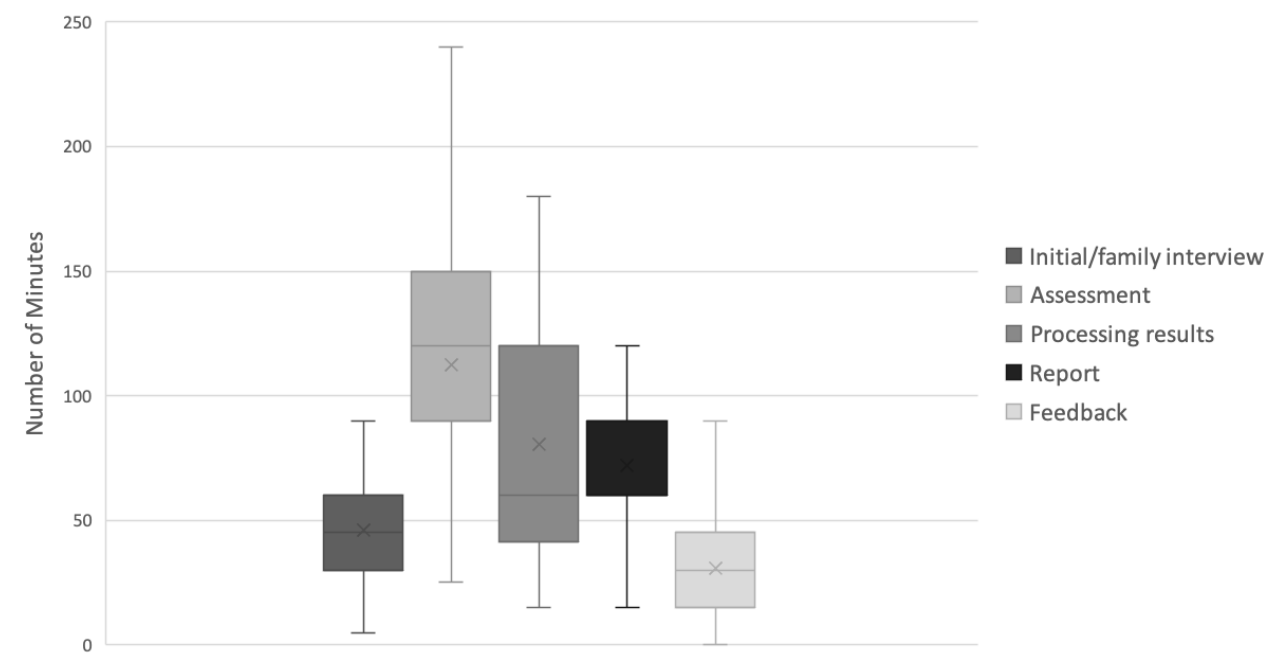

Figure 2. Variation in the length of components of NPA. Notes. The median is represented in the figure by the horizontal line and the average with the cross. The vertical line above and below the boxplot represent Q1 + $1.5 \times$ interquartile range and Q3 - $1.5 \times$ interquartile range. 
A large variation between clinics was present regarding the cognitive tests that were used. The majority of psychologists mentioned using a core battery ( $n=61,81 \%$ ), again with variation in content. All clinics administered tests on the domains of episodic memory, attention, and executive functioning. The most used memory tests in the core battery were the Verbal Learning Test $(n=53,87 \%)$ and the Visual Association Test $(n=$ $61,100 \%)$. In the cognitive domain of attention and executive functioning, the following tests were most often used: Trail Making Test $(n=57,93 \%)$, Digit Span $(n=51,84 \%)$, subtests of the Behavioral Assessment of the Dysexecutive Syndrome ( $n=49,80 \%$ ), and semantic fluency $(n=48,79 \%)$. Language $(90 \%)$ and praxis $(82 \%)$ tests were also often used. Tests for symptom validity (33\%) and social cognition (12\%) were less often part of the core battery. Next to cognitive tests most memory clinics used $(n=71,95 \%)$ questionnaires and rating scales (figure 3). Again, great variation was identified between clinics in these instruments.

It was estimated that 6\% [0-30\%] of the patients in 2016 did not speak to Dutch language, and/or were illiterate. In $71 \%$ of the clinics specific instruments were used for this patient population $(n=54,71 \%)$. Most often the Cross-Cultural Dementia screening (CCD) was used $(n=52,96 \%)$. In the interviews, the lack of testing material for this population was seen as a concern.

Only a small minority of the psychologists indicated that they used computerized neuropsychological tests $(n=11,15 \%)$. During the interviews, some psychologists were interested in digitalized testing, while others were more skeptical. They thought this way of testing was less appropriate for the patient population and were

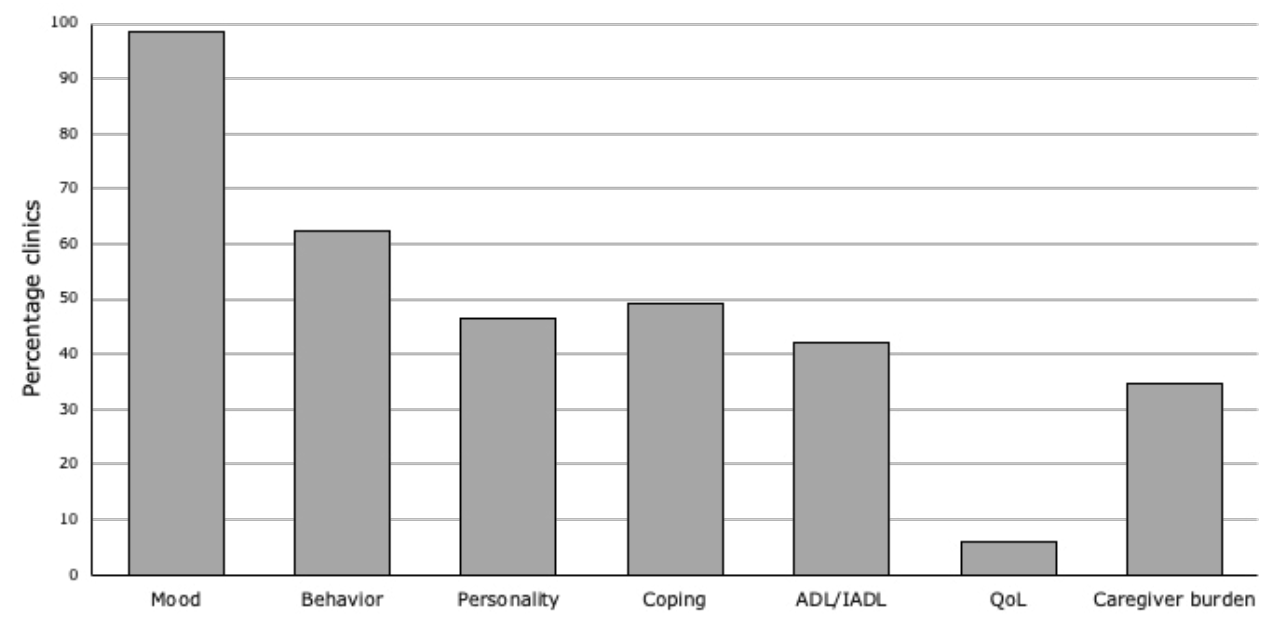

Figure 3. Domains of used questionnaires and rating scales. Abbreviations. ADL: activities of daily living, IADL: instrumental activities of daily living, QoL: quality of life. 


\section{CHAPTER 3}

especially worried about missing observations. An NPA was usually processed by using a combination of digital (e.g., Excel) and manual $(n=68,91 \%)$ data entry and normative calculation. The interpretation of the cut-off values varied, as represented in figure 4. Around $11 \%$ indicated that they used the cut-off values as described in the test manual.

\section{Impaired performance}

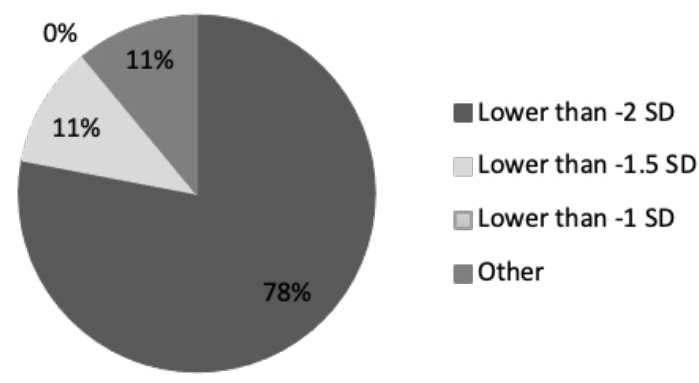

Figure 4. Used interpretation for test performance within memory clinics. Abbreviations. SD: standard deviation

In a few interviews it was emphasized by psychologists that it takes a lot of time to process NPA results. Most indicated that they would want to use full digital processing of NPA results $(n=69,93 \%$ ). During the interviews it also appeared that there were positive developments in terms of normative data. However the quality of the current available normative data was seen as a concern. Some normative data was outdated, and for some domains (e.g., social cognition and praxis) and specific patient populations (e.g., oldest old, not Dutch speaking or an intellectual disability) normative data was limited.

\section{Multidisciplinary contribution}

In most memory clinics a psychologist attended the multidisciplinary meeting ( $\mathrm{n}=$ $72,95 \%)$. The role of the psychologist during this meeting was mostly discussing the NPA conclusion ( $n=70,97 \%$ ) and differential diagnosis $(n=69,96 \%)$. Furthermore, in more than half of the clinics, a psychologist also discussed the results on the cognitive domains ( $n=49,68 \%$ ) and gave advice on how to deal with cognitive complaints ( $n=$ $48,67 \%$ ) during the multidisciplinary meeting.

Neuropsychological feedback

In the interviews it became clear that the extent of neuropsychological feedback varied between clinics. In some clinics the psychologist had the opportunity to give neuropsychological feedback, while in other clinics the diagnostic disclosure was given only by the medical specialist, and feedback was only also given by the psychologist on request of the patient or in case of complex diagnostic questions. 


\section{CHAPTER 3}

\section{Wish for uniformity}

The majority of psychologists were prepared to administer a nationally harmonized neuropsychological core battery ( $n=68,89 \%$ ) and expressed the need for a monodisciplinary guideline NPA in dementia ( $n=58,77 \%)$. The interviews showed that comparability and communication between clinics were the biggest motivation for a harmonized core battery. Through uniformity in cognitive tests, manner of administration, normative data, and interpretation, the variation between clinics could be decreased. Other reasons for a harmonized core battery were improving national quality, offering best practice, and to collect data for research. Furthermore, it was emphasized that it should be a non-binding advice with enough room for flexibility and adaptation of the core battery when necessary.

\section{Phase 2: $\quad$ Development monodisciplinary guideline}

Development guideline

In response to the results of the above mentioned NPA monitor, in collaboration with the Neuropsychology section of the Dutch Institute of Psychologists (NIP), a committee was established to develop a monodisciplinary guideline: 'Neuropsychological assessment in $\mathrm{MCl}$ and dementia'. The committee consisted of six certified clinical neuropsychologists, two licensed psychologists (basic clinical license), and one psychologist with a master degree that worked within different academic and nonacademic memory clinics spread over the Netherlands. Four face-to-face meetings were organized during which the results of the NPA monitor were presented and committee members discussed the aim, framework, and content of the guideline.

In the guideline the following themes, focused on our patient population, are discussed: initial/family interview, observations, NPA indication criteria, factors of interference, cross-cultural aspects, interpretation, and giving neuropsychological feedback. In the guideline, advice is given on which cognitive tests should be used per cognitive domain based on scientific literature, psychometric properties, and expertise within the guideline committee. Furthermore, a recommendation is made for a harmonized core battery in the early diagnostics of cognitive disorders and dementia, with normative data (table 2). In the appendix, cross-cultural aspects in the diagnostic of dementia are discussed. The monodisciplinary guideline is available via the NIP website (www.psynip.nl/secties/ neuropsychologie). 
Table 2. Recommendations for an NPA core battery taken from the monodisciplinary guideline 'Neuropsychological assessment in mild cognitive impairment (MCl) and dementia'.

\begin{tabular}{|c|c|c|c|c|}
\hline Test & Version & Norms & $\begin{array}{l}\text { Age } \\
\text { span }\end{array}$ & Parallel-version \\
\hline \multicolumn{5}{|l|}{ Memory } \\
\hline Verbal Learning Test & $\begin{array}{l}\text { Maastricht or } \\
\text { Groningen } \\
\text { version, auditive } \\
\text { modality }\end{array}$ & ANDI* & $14-97$ & Yes \\
\hline $\begin{array}{l}\text { Visual Association } \\
\text { Test }\end{array}$ & $65+$ : short version & Manual & $65-85$ & Yes \\
\hline \multicolumn{5}{|c|}{ Attention and executive functioning } \\
\hline Trail Making Test-AB & Reitan & ANDI & $8-97$ & No \\
\hline $\begin{array}{l}\text { Stroop Color-Word } \\
\text { Test }\end{array}$ & $\begin{array}{l}10 \times 10 \text { Hammes } \\
\text { et al. }\end{array}$ & ANDI & $16-91$ & No \\
\hline Digit Span & WAIS-IV & Manual & $16-84$ & No \\
\hline \multicolumn{5}{|l|}{ Language } \\
\hline Semantic fluency & $\begin{array}{l}\text { Animals and } \\
\text { occupations }\end{array}$ & ANDI & $17-97$ & No \\
\hline Phonemic fluency & $\begin{array}{l}\text { Letters (D-A-T, } \\
\text { K-O-M, P-G-R) }\end{array}$ & ANDI & $17-96$ & Yes \\
\hline Boston Naming Test & 60-item version & ANDI & $17-89$ & No \\
\hline \multicolumn{5}{|c|}{ Praxis and visuoconstruction } \\
\hline Clock Drawing Test & $\begin{array}{l}\text { Seven Minute } \\
\text { Screen }\end{array}$ & Manual & $41-89$ & No \\
\hline
\end{tabular}

* Norms are available via the Advanced Neuropsychological Diagnostics Infrastructure (ANDI) platform via: www.andi.nl

\section{Evaluation guideline}

After the guideline committee had developed a concept version of the guideline, this was sent to eight external reviewers (spread across the country) for evaluation purposes. All reviewers had at least a basic clinical license and worked at a memory clinic (five clinical neuropsychologists, one psychologist in training for certification as clinical neuropsychologists, one clinical psychologist, one psychologist with basic clinical license). The quality was evaluated using an adapted version of the Global Rating 
Scale, an instrument developed for the evaluation of practice-based guidelines. ${ }^{9}$ The evaluation could be given on items with a 7-point Likert scale ( $1=$ low quality, $7=$ high quality) in terms of presentation (e.g., structure of guideline, are recommendations easily found), quality (e.g., general quality of guideline, consistent and fitting with scientific literature), clinical applicability (e.g., are the recommendations clinically oriented), and recommendation (e.g., can this guideline be recommended for clinical practice). On all aspects, a high evaluation was seen of 6 points [range: 5 - 7]. Additional comments from the external reviewers were discussed among the guideline committee and the text was adapted if necessary.

\section{DISCUSSION}

In the early diagnostics of cognitive disorders and dementia, the NPA has an important function. The Memory clinic monitor 2016 showed that nearly all Dutch memory clinics used neuropsychological testing, which is in line with the recommendations given in the national multidisciplinary guideline 'Diagnostics and treatment of dementia ${ }^{10}$ and with the published quality indicators of memory clinics. ${ }^{11}$ The procedures, length, and content of the NPA varied greatly among memory clinics. ${ }^{7.12}$ The current NPA monitor showed that some memory clinics always used an NPA in their diagnostic routine, but other clinics first administered a cognitive screening tool to choose whether a full NPA would be used. The length of the NPA varied between 80 and 480 minutes. Concerning the content of the NPA, cognitive tests on the domains of memory, attention, and executive functioning were always administered. However, there was a lot of variation in which cognitive tests were used. The same was observed for questionnaires and rating scales. In the interpretation of the results, the majority used -2 standard deviation as indicator for an impaired performance.

The NPA monitor survey showed that an NPA was used less in the diagnostics of moderate to severe dementia, which is in line with a recent study that showed that the diagnostic benefit of an NPA was observed in the early phases of cognitive disorders and dementia. ${ }^{2,5}$ The manner in which neuropsychological feedback was given to patients varied between clinics. This was related to procedures and financial aspects. Multiple psychologists experienced the fact that they could not personally discuss neuropsychological findings with patients as a disadvantage. Neuropsychological feedback has a clear benefit on the quality of life of a patient, but also on understanding and coping with the disease..$^{13}$ Giving neuropsychological feedback is also described in both national and international guidelines. . $^{14,15}$

The diagnostics of dementia is multidisciplinary. The survey showed that there was a need for a monodisciplinary guideline and that psychologists were prepared to conform themselves to a national harmonized core battery, as long as there was room to deviate from this if necessary for the individual patient. The monodisciplinary guideline, which was developed because of these findings, can be seen as an addition on the already existing multidisciplinary guideline for dementia and the addendum for $\mathrm{MCl} .{ }^{10}$ The goals of the monodisciplinary guideline were to give an example of best practice to ensure quality of neuropsychological diagnostics, to decrease variation in 
outcome measures, and to increase the comparability of assessments between clinics. The recommended core battery (with an administration of 45-60 minutes) is meant as a harmonized starting point, but does not contain a complete NPA. This core battery is not sufficient to answer individual diagnostic questions. To conduct a full and valid NPA the core battery has to be supplemented with additional cognitive tests (which are also discussed in the guideline) using clinical judgement, expertise within the memory clinic, and differential diagnostic considerations. Both the NPA monitor and monodisciplinary guideline are applicable to hospital-based memory clinics. Ambulatory teams in mental health care institutions or nursing homes are not taken into account because they may have different needs. Another point of attention is that the reported findings from the survey are based on estimations (e.g., number of patients and length of NPA) as registered data was not available.

Lastly, another concern identified in the NPA monitor, interviews, and guideline committee was the limited availability of normative data in the oldest old and for specific cognitive domains. For the recommended core battery, normative data from the Advanced Neuropsychological Diagnostics Infrastructure (ANDI) project can be used. In this project, multiple Dutch datasets are combined, which results in more robust normative data. ${ }^{16}$ These norms are available via www.andi.nl. Within ANDI there is also the possibility to carry out multivariate tests to explore striking features within a cognitive profile. The normative data of ANDI has been extended with more cognitive tests (www.andinorms.nl), but these still do not contain all tests to compile a full NPA. Furthermore, in comparison to other age groups, the normative data for the highest age range (85+) remains an area of concern. This growing group of memory clinics visitors deserves the joining of forces in the Netherlands to collect good normative data to be able to make more valid statements about the oldest old. Another growing population are people with a non-western cultural background. The supplement in the guideline discusses obstacles and solutions pertaining to neuropsychological diagnostics in this group. The number of suitable tests with valid normative data is very limited and also deserves extra attention. ${ }^{17}$ 


\section{CHAPTER 3}

\section{ACKNOWLEDGEMENTS}

We would like to thank all psychologists for participating in the NPA monitor and for the willingness to participate in an additional in-depth interview. Special thanks to Merel Hermans for her help in conducting the interviews. The NPA monitor was supported by an independent grant from the Noaber Foundation and Alzheimer Nederland. We are also very grateful to all external reviewers and their valuable feedback on the concept version of the guideline, and the NIP section neuropsychology for the continuous support in the development of the guideline. 


\section{CHAPTER 3}

\section{REFERENCES}

1. de Vugt ME, Verhey FR. The impact of early dementia diagnosis and intervention on informal caregivers. Prog Neurobiol. 2013;110:54-62.

2. Watt $\mathrm{S}$, Crowe SF. Examining the beneficial effect of neuropsychological assessment on adult patient outcomes: a systematic review. Clin Neuropsychol. 2018;32(3):368-390.

3. Schmand B, Rienstra A, Tamminga $\mathrm{H}$, et al. Responsiveness of magnetic resonance imaging and neuropsychological assessment in memory clinic patients. J Alzheimers Dis. 2014;40(2):409-418.

4. Eckerstrom C, Olsson E, Bjerke M, et al. A combination of neuropsychological, neuroimaging, and cerebrospinal fluid markers predicts conversion from mild cognitive impairment to dementia. J Alzheimers Dis. 2013;36(3):421-431.

5. Jansen WJ, Handels RL, Visser PJ, et al. The diagnostic and prognostic value of neuropsychological assessment in memory clinic atients. J Alzheimers Dis. 2016;55(2):679689.

6. Harvey PD. Clinical applications of neuropsychological assessment. Dialogues Clin Neurosci. 2012;14(1):91-99.

7. Gruters AAA, Ramakers I, Kessels R, et al. Development of memory clinics in the Netherlands over the last twenty years. Int $J$ Geriatr Psychiatry. 2019;34(8):1267-1274.

8. Elo $S$, Kyngäs $H$. The qualitative content analysis process. J Adv Nurs. 2008;62(1):107115.

9. Brouwers MC, Kho ME, Browman GP, et al. The global rating scale complements the AGREE II in advancing the quality of practice guidelines. J Clin Epidemiol. 2012;65(5):526-534. 

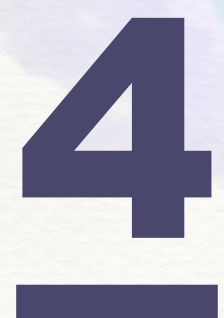

\section{Neuropsychological assessment and diagnostic disclosure at a memory clinic: a qualitative study of the experiences of patients and their family member}

Angélique AA Gruters, Hannah L Christie, Inez HGB Ramakers, Frans RJ Verhey, Roy PC Kessels, Marjolein E de Vugt.

The Clinical Neuropsychologist, 2020 


\section{CHAPTER 4}

\section{ABSTRACT}

\section{Objective}

The aim of this study was to gain insight into the experiences of patients and their family members regarding a neuropsychological assessment (NPA) and the diagnostic disclosure given by the medical specialist (psychiatrist, geriatrician or their residents) at the memory clinic (MC).

\section{Methods}

Patients with and without a cognitive impairment and their family members were recruited from three Dutch MCs. Four focus groups with 14 patients and 13 family members were analyzed using both inductive and deductive content analysis.

\section{Results}

Three themes were identified: uncertainty, early diagnostic paradox, and knowledge utilization. High levels of uncertainty were experienced throughout the NPA and diagnostic disclosure. The early diagnostic paradox refers to the coexistence of negative emotions, feeling distressed due to undergoing an NPA that made them aware of their cognitive complaints, and the experience of relief due to insight given by the outcome of the NPA and medical diagnosis. Knowledge utilization refers to a low recall of medical information.

\section{Conclusion}

Clinicians can reduce uncertainty by using clear communication, limiting interruptions during an NPA, and paying attention to contextual factors. Low information recall could possibly be improved by involving a family member and using visual aids or written information during the diagnostic disclosure. Finally, participants also appreciated being provided with neuropsychological feedback on the strengths and weaknesses of their cognitive profiles and with guidance on how to manage this diagnosis in their daily lives. 


\section{INTRODUCTION}

Memory clinics (MCs) focus on a timely diagnosis of dementia, and one of the most often used assessment tools in Dutch MCs is a neuropsychological assessment (NPA). ${ }^{1}$ The proportion of patients who undergo an NPA varies, but the most common reason to administer an NPA in these clinics is to support the diagnosis and to collect information for a differential diagnosis. NPAs are not carried out when there is evidence of severe dementia. ${ }^{1}$ An NPA provides insight into the nature and severity of cognitive impairment. ${ }^{2}$ The value of an NPA has been described in previous studies and has been shown to be related to increased diagnostic accuracy, referrer satisfaction, benefit prognostic decision-making, and treatment planning. ${ }^{3-5}$

Current trends in mental health care place more emphasis on the exploration of patient experiences to facilitate patient-centered care and to improve delivered health services. ${ }^{6}$ Previous studies exploring the experiences of patients and their family members in an $\mathrm{MC}$ report that they initially felt stressed and unnerved and that they often did not know what to expect of their visit to the clinic. ${ }^{7}$ However, in both qualitative and quantitative studies, the overall experience were found to be more positive than negative, and patients and family members were often satisfied with the diagnostic process. ${ }^{8-12}$

To our knowledge, little is known about the perspective of patients and their family members regarding NPAs. ${ }^{5}$ A few studies included patients without dementia from neuropsychology services and found that an NPA was evaluated as useful overall; only a minority of participants reported a negative experience, and most showed generally high levels of satisfaction with the NPA. ${ }^{13,14}$ The few studies including MC patients found that participants experienced mixed positive and negative feelings as result of undergoing an NPA ${ }^{8}$ and that feelings of insecurity and discomfort around an NPA were not uncommon in patients who had received a dementia diagnosis. ${ }^{15}$ The time between referral and the diagnostic assessment itself was considered stressful. ${ }^{16}$ A recent systematic review emphasized that more studies are needed to examine patient perceptions of an NPA, as research in this area is lacking. ${ }^{5}$

More studies have been performed on the experience with diagnostic disclosure by the medical specialist in the MC. Findings from two studies using retrospective surveys showed that the majority of patients wished to be informed of the diagnosis and found it helpful, and that relatively low levels of distress were reported., ${ }^{7,17}$ This finding is in line with a systematic review and a large prospective study in which the majority of patients favored a diagnostic disclosure. ${ }^{18,19}$ In contrast, others showed that patients were less positive about the clarity of the information regarding their diagnosis, found the diagnosis vague, and would have liked advice on how to cope with their family member with a dementia diagnosis. ${ }^{20,21}$ Furthermore, there were often unmet information needs and difficulties remembering the information. ${ }^{22,23}$ In summary, while some studies have specifically examined the diagnostic disclosure experience, there remains a lack of evidence regarding the perspective of patients on the NPA as a whole. It is also unclear how the NPA is evaluated by their family members. Insight into these experiences and identifying possible issues could improve the diagnostic assessment 
process related to current NPA and diagnostic disclosure procedures to better fit the needs of the MC population. To our knowledge, no focus group studies with both patients and family members has been conducted in this population regarding this topic. Therefore, the aim of this study is to gain more insight into the experiences of patients and family members with NPAs and diagnostic disclosure.

\section{METHODS}

\section{Memory clinic procedures}

Participants were recruited in three hospital-based MCs (Maastricht UMC+, Radboudumc Nijmegen, and Catharina Hospital Eindhoven) to ensure diversity in clinical procedures. The coordinating discipline in one center was psychiatry, while it was clinical geriatrics in the other two centers. All centers informed patients about their visit to the MC by sending a leaflet with additional information about the different assessments after the appointment was made. The following diagnostic assessments were conducted: clinical interview by the psychiatrist, clinical geriatrician or their residents (a detailed medical history, demographic characteristics, and a neurological, psychiatric and physical examination), NPA (testing took on average 2.5 hours in two centers and one hour in one center), blood tests, brain imaging (MRI or CT scan), and interview with a family member by nurses (to evaluate interference in daily living). In two centers, there was another clinical interview by the psychologist before testing. All diagnostic assessments were performed in one day in two centers. In the other center, it was determined after the initial clinical interview and blood tests whether an MRI or NPA was needed on a separate day. The diagnostic disclosure was done by the psychiatrist, clinical geriatrician or their residents. In one $\mathrm{MC}$, the diagnostic disclosure occurred on the same day, while in the other two clinics, the diagnosis was given within three weeks after the assessment day. Patients could access a copy of the final report via their online personal portal of the hospital. This report was also sent to the general practitioner and contained medical language. In one center, a separate consultation was planned with the neuropsychologist to give feedback on NPA results. During this session, the neuropsychologist evaluated what they still remembered from the consultation with the psychiatrist and answered questions. The neuropsychological test results were discussed, and tips and advice were given on how to cope with their cognitive problems in daily life. Another topic was discussing possibilities concerning practical support (e.g., Alzheimer cafés, daycare, and group treatment for $\mathrm{MCl}$ patients), depending on the diagnosis. The patients did not receive a written report about this consultation.

\section{Study participants}

Patients were included if they (1) were referred to an MC and underwent an NPA and (2) were diagnosed with no cognitive impairment ( $\mathrm{NCl}$ ), mild cognitive impairment ( $\mathrm{MCl}$ ) or mild dementia (Clinical Dementia Rating Scale (CDR) 1). The referral question was consistent in all patients: 'Does the patient have cognitive impairment, and if so, does this meet the criteria due to a neurodegenerative disease?' They were excluded if there 
was a severe cognitive impairment (CDR $\geq 2)$, aphasia or moderate to severe visual impairment. Family members were asked to provide their opinions. Patients and their family members were recruited using purposeful sampling to account for variability in age, gender, diagnosis and disease severity. This strategy was used to look for common patterns and capture this across the $\mathrm{MC}$ population ( $\mathrm{NCl}, \mathrm{MCl}$, dementia).

Between January and March 2018, 18 patients and 17 family members were recruited. Participants received written information about the study from the neuropsychologist during the assessment day. At least two weeks after receiving the diagnosis, the neuropsychologist contacted each patient to ask if he/she wanted to participate. Two dyads (patient and family member) declined to participate because of refusal of the patient or unavailability when the focus groups were planned. One dyad did not show up at the meeting as a result of illness, and another dyad forgot about the appointment. In total, 14 patients and 13 family members participated in this study (11 dyads). The patients in the dyads had the following diagnosis: NCl: $n=5, M C l: n=3$, Alzheimer's disease (AD) dementia: $n=1$, and other causes of dementia: $n=2$. Three patients participated alone because their family members were not available during the focus group meetings (NCl: $n=1, M C l: n=1$, Alzheimer's Disease (AD) dementia: $n=1$ ). Two family members participated alone; the first indicated that the patient already had mild AD dementia, and the other stated a preference to come alone (the patient had an $\mathrm{MCl}$ diagnosis). The Medical Ethics Committee of the Maastricht University Medical Center confirmed that the Medical Research Involving Human Subjects Act did not apply to this study (\#2017-0095), making the study exempt from formal ethical review. Prior to the group discussions, written informed consent was obtained.

\section{Procedures}

Four focus groups were planned with six to eight participants per group. Based on recommendations from previous studies, the modal size of six to eight participants per focus group was used. ${ }^{24}$ The number of participants in each group was based on the equal distribution of patients and family members during the four sessions. The group discussions lasted approximately 90 minutes and were conducted in Dutch. Previous studies indicate that information saturation was reached, and most topics were captured after four focus groups. ${ }^{24-26}$ After the fourth focus group, two authors independently confirmed data saturation, as no new themes had emerged. Each focus group session included an introduction and explanation of the procedure by the moderator and assistant (taking notes and distribution of materials). A semistructured guide was used (appendix 1). First, participants were asked about their experience of the NPA, and they had to choose between a green light for a positive experience, a red light for a negative experience, and an orange light for an experience that was both positive and negative. Using visual aids during in-depth interviews in patients with cognitive impairment is recommended. ${ }^{27}$ It gives participants time to reflect on their experience. During the second part, they were asked about their experience with the diagnostic disclosure given by the medical specialist (psychiatrist, geriatrician or their residents) and whether they had difficulty remembering the information. The moderator summarized key points 
throughout the session to obtain participant verification. ${ }^{26}$ All group discussions were video- and audio recorded. These recordings were stored on a protected server and were deleted after data analysis. To assure validity, triangulation of within-method data sources was used; the data consisting of video and audio recordings, as well as field notes taken by the assistant to identify potentially relevant cues and observations given by the participants.

\section{Data analysis}

The video recordings of the focus groups were transcribed verbatim. Both the transcripts and observations were analyzed independently by two authors using ATLAS.ti, version 8.1.3. One of these authors was not involved in conducting the focus groups but involved at a later stage to have an independent view when carrying out the dataanalysis. Both authors were experienced and trained in carrying out qualitative analysis. A combination of inductive and deductive content analysis was used. First, we used a deductive approach by determining the two themes based on our semistructured guide: experience with an NPA and experience with the diagnostic disclosure by the medical specialist. Then, an inductive approach was applied, using inductive reasoning and constant comparison to identify categories within these two themes. This approach was carried out by adding open codes in the transcript and reading it thoroughly. The open codes were first separated into two overall themes (experience with NPA and experience with diagnostic disclosure). After that, they were merged into categories and higher-order themes. To obtain consensus regarding the categories' discrepancies and interpretation, the categories were discussed with a third and fourth author. This approach is described by previous authors to improve credibility. ${ }^{28}$ The focus groups were analyzed separately to gain insight into differences in experiences between the three MCs. The quotes used in the results section were selected and translated from Dutch to English by two authors. 


\section{CHAPTER 4}

\section{RESULTS}

Background characteristics

Table 1 describes the characteristics of the 14 patients and 13 family members. The majority of family members were spouses ( $n=11,85 \%)$.

Table 1. Characteristics of patients $(n=14)$ and family members $(n=13)$.

$$
\text { Focus group participants }(n=27)
$$

\begin{tabular}{lll}
\cline { 2 - 3 } & Patients $(n=14)$ & Family members $(n=13)$ \\
\hline Age (mean \pm SD [min-max] $)$ & $66.1 \pm 7.9[49-76]$ & $62.9 \pm 15.1[30-82]$ \\
Women n (\%) & $5(36 \%)$ & $8(62 \%)$ \\
Diagnosis MC visitor & & \\
$\mathrm{NCl}$ & $6(43 \%)$ & $5(39 \%)$ \\
$\mathrm{MCl}$ & $3(21 \%)$ & $4(30 \%)$ \\
$\mathrm{AD}$ dementia & $3(21 \%)$ & $2(15 \%)$ \\
$\mathrm{CBS}$ & $1(7.5 \%)$ & $1(8 \%)$ \\
FTD & $1(7.5 \%)$ & $1(8 \%)$ \\
Relationship to MC visitor & & $11(85 \%)$ \\
Spouse & & $2(15 \%)$ \\
Child & &
\end{tabular}

Notes. Demographics are represented in $\mathrm{n}(\%)$ unless stated otherwise. Abbreviations. SD $=$ Standard Deviation, $\mathrm{NCl}$ = No Cognitive Impairment, $\mathrm{MCl}$ = Mild Cognitive Impairment, $\mathrm{AD}$ = Alzheimer's disease, CBS = Corticobasal syndrome, FTD = Frontotemporal Dementia.

Focus groups

Based on the evaluation of the participants' experiences with the NPA and the diagnostic disclosure by the medical specialist, three major themes were identified: (1) uncertainty, (2) early diagnostic paradox, and (3) knowledge utilization (table 2, figure 1). 


\section{CHAPTER 4}

Table 2. Overview of major themes and categories.

\section{Themes Categories}

\begin{tabular}{|c|c|}
\hline Uncertainty & $\begin{array}{l}\text { Uncertainties about complaints, NPA and } \\
\text { diagnosis } \\
\text { Influence of contextual factors }\end{array}$ \\
\hline Early diagnostic paradox & $\begin{array}{l}\text { Feelings of distress due to awareness of cognitive } \\
\text { complaints while undergoing an NPA } \\
\text { More insight due to outcome of NPA and medical } \\
\text { diagnosis } \\
\text { Adapting to diagnosis }\end{array}$ \\
\hline Knowledge utilization & $\begin{array}{l}\text { Recall and communication of medical } \\
\text { information } \\
\text { Unanswered questions } \\
\text { Lack of postdiagnostic support }\end{array}$ \\
\hline
\end{tabular}

\section{Uncertainty}

When looking back at their visit to the clinic, both patients and their family members expressed that they had experienced high levels of uncertainty. These uncertainties could be identified on different levels during the entire diagnostic phase. From the point of referral by their general practitioner to the diagnostic disclosure by the medical specialist, they had felt very uncertain. There were uncertainties about the general diagnostic procedure at the memory clinic. For example, the participants indicated that the procedure from assessment until diagnostic disclosure had taken too long. In the MC where the diagnostic disclosure was provided on the same day as the assessment, this issue was not reported. In some patients and family members, the question of whether a dementia diagnosis was valid based on the diagnostic assessment conducted in the MC was raised. These concerns and feelings of uncertainty remained even after the diagnostic disclosure.

"The intake and test day were very far away from each other. Almost two months. So, this was something that I thought took too long ...

I was in a sort of waiting period for over six months. I wondered what was going on in my head and which direction it was going. (FG04, patient)

"I am overwhelmed. I have all kinds of doubts about the assessment [NPA], because the diagnosis is something abstract ... How bulletproof is the diagnosis? What happens following these assessments?" (FG23, family member) 
There were also uncertainties about the NPA itself. For example, it was unclear what the tests meant and what they were used for. They often wondered if they were performing well or not.

"I don't know why I had to do those tests, and I am still curious about that. Like those colors [Stroop test], what do you do with my results? Does it say something about the conditioning of my brain? (FG10, patient)

"What I wrestled with? The things I had to draw... I don't know why I had to do that, and that is what I am curious about. What do you do with these results? ... And I could not judge it. If you have a page with symbols and numbers and you can make it only halfway, then I don't know whether it's bad or good." (FG10, patient)

Uncertainties during an NPA could also be caused or reinforced by contextual factors during the assessment (e.g., when clinicians would walk away during administration of the tests, when the clock was not set to the right time, or when the test assistant was searching for the right forms). Clear communication about the procedure could facilitate lower levels of uncertainty.

"After the assessment, he returned like; 'Pf, I don't understand this at all'. The intern kept walking away, and that made him very insecure. Like: 'I don't get it, maybe they don't get it themselves'" (FG25, family member)

Early diagnostic paradox

During the visit at the MC, a paradox could be identified. On the one hand, negative experiences and emotions were present during the NPA. Undergoing an NPA induced feelings of distress by making them aware of their cognitive complaints, and was seen as an exhausting experience that often increased their feelings of uncertainty. Furthermore, a stigma towards dementia was apparent.

"I thought it was very disconcerting that my short-term memory was so bad, I cried the first time I did the test." (FG14, patient)

"He had a very strong feeling of failing, you know. You cannot fail in one of these tests. But, he felt that strongly. 'I don't know this anymore, I can't do it anymore' ... To get insight was difficult." (FG26, family member)

"Then I heard "Alzheimer's" for the first time ... It's like you get a stamp. Alzheimer's. You imagine drooling men in a chair and you have to get used to that. But, I told my wider circle of friends what was going on because I do not want to be a pathetic man walking around ... If you break your leg or something physical ... This is something taboo." (FG22, patient) 
On the other hand, both patients and their family members appreciated the additional value of undergoing an NPA and realized that the outcome of an NPA contributed to receiving a clear diagnosis and therefore giving more certainty about their situation. It gave them insight and answered their question whether it was dementia or not. When the results indicated no cognitive impairment, they were often reassured. Relief was, however, also experienced when someone received a dementia diagnosis, as this explained complaints and changing behavior.

"The test was a confirmation that I was not crazy. All these things I experienced at home for years and talked about with the children. The other hospital gave me the impression that I did not quite understand everything. Because nothing was wrong with him." (FG04, family member)

"I also experienced it with my mother and then I noticed I did everything a whole lot better ... That was a very nice experience. I thought, 'Everything is alright.' I found that to be a very nice experience during the tests." (FG03, patient)

Being reassured or receiving a confirmation was observed as the start of acceptance, and it decreased the level of uncertainty in most of the patients and their family members. Some of the patients and family members stated that they could now do something with the feedback they received. Some started using memory strategies in their daily life, and some family members were now more able to adapt their behavior to their partner (e.g., not getting angry as quickly as before).

"But now I know that if something goes too fast and I do now write it down that I will forget it. So, I have to write it down immediately, and then, you learn to live with it. You also know the reason [for forgetting] now." (FG07, patient)

"I was not always as accommodating for him. If he did not respond quickly enough, I had to tell myself to stay calm. I can do that more now, but I still think it is difficult to deal with. (FG14, family member)

\section{Knowledge utilization}

The ability to understand and remember the information that was relayed during the medical diagnostic disclosure was seen as a prerequisite for decreasing the level of uncertainty they experienced. However, information recall was reported to be low, and patients and family members expressed several times that they did not remember the same information. Both patients and family members emphasized that the manner of communication was important. All participants preferred a face-to-face consultation. Using visual aids or receiving something on paper would have been considered helpful in remembering the information. The diagnosis should be conveyed in understandable language. 
"The specialist tells me everything, but in my mind, I am occupied with my disease. The words washed over me like water over stone, and I liked that if he [son] could not be there [during the visits to the MC], that my daughter could be there. Two know more than one." (FG11, patient)

"They really tried with effort to explain me what my results were. However, subsequently, I forgot all the details of the information ... Afterwards, I would have like to have received something on paper, because then I could have read it later again." (FG03, patient)

"The medical terms are understandable for you or for my general practitioner. But, if I reread the letter [from the medical specialist] after a few weeks, then I wouldn't understand it anymore." (FG16, family member)

Furthermore, after having received the diagnosis, both patients and family members expressed that they needed some time to fully appreciate the information that they remembered. Often, they had new questions one or two weeks after the consultation. One family member felt like that there was little to no information for the partner during the diagnostic disclosure.

"I needed some time afterwards [diagnostic disclosure] to process it, and then I had the need to know more about what it precisely meant." (FG03, patient)

"When you are standing outside, you find there are a thousand questions that you did not ask." (FG07, family member)

This need to process the information left some with unanswered questions after the consultation, and it remained unclear where they could go to receive the information or care they needed. Many remaining questions were related to how they could cope with their own diagnosis, or their partner's diagnosis, and to practical tips they could use in daily life. Where participants had a separate consultation with the neuropsychologist, participants were very satisfied and this was seen as an additional value. In the other two clinics the need for a follow-up consultation was reported. In case of a dementia diagnosis, in all centers, a care professional whom they could regularly contact (e.g., a case manager) to ask questions was preferred. This was considered a lack of postdiagnostic support, especially when less was known about a specific diagnosis. 


\section{CHAPTER 4}

"It would be nice if the consultations [at the MC] were maintained. It would help to have an appointment every two years to see what the decline or improvement is." (FG19, family member)

"What I missed after the diagnostic disclosure was how to proceed from this? ... We are wondering what we can do, what we have to do, what do I have to arrange? ... All this is also very vague with this disease [Corticobasal syndrome]." (FG26, family member)

\section{THE EARLY DIAGNOSTIC PARADOX}

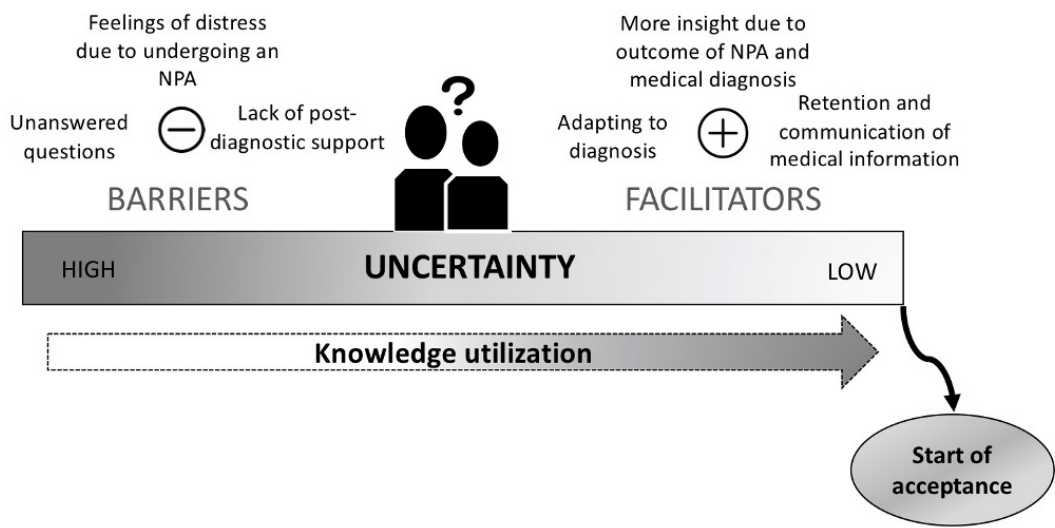

Figure 1. Visual representation of the major themes: uncertainty, early diagnostic paradox, and knowledge utilization in patients and their family members 


\section{DISCUSSION}

Following the discussion with both patients and family members, the evaluation of the experiences regarding an NPA and medical diagnostic disclosure at a memory clinic resulted in the identification of three themes: 'uncertainty', 'early diagnostic paradox', and 'knowledge utilization'. It is important to note that an NPA was one of several diagnostic assessments used at the MC. Participants were not prompted to reflect on their perspective on other diagnostic procedures (e.g., neuroimaging, cerebrospinal fluid) because that was not within the aim of the current study. The diagnostic disclosure by the medical specialist focused on the results of all the different assessments conducted at the MC. However, the analysis showed that the experiences with an NPA and the diagnostic disclosures were overlapping and they are therefore described together. During the analysis, we also evaluated possible differences between patients and family members or between men and women, but these differences could not be identified. An important insight from this study was that both positive and negative experiences coexisted during the diagnostic procedures at an MC. In addition, feelings of uncertainty were present before, during, and after the MC visit. In this study, the feelings of distress and negative experiences, resulting from undergoing a cognitive assessment, eventually led to relief and decreasing levels of uncertainty, as well as an improved ability to start the acceptance process.

The first theme, uncertainty, reflects how patients and family members expressed their feelings of uncertainty and nervousness before and during the cognitive assessment, and these feelings even persisted for some people after the diagnostic disclosure. The responses of patients showed that the theme of uncertainty was present throughout the whole diagnostic trajectory (as illustrated by the long bar labeled 'uncertainty' in figure 1). For instance, they questioned how reliable the diagnosis was based on the tools used or what the cognitive tests were measuring and whether they performed well. These findings support and build on a small body of studies focusing on the experience with an NPA and diagnostic disclosure in MC patients. ${ }^{8,15,16}$ To our knowledge, no other studies have investigated the experience of both NPA and medical diagnostic disclosure in an MC population. It is important to gain more insight into these experiences, as a recent study found that family members who were unsatisfied with MC services reported more caregiver burden after two years. ${ }^{12}$ These findings contrast with the results of two previous studies that investigated the experience of NPAs in patients without dementia, who were referred to a neuropsychologist in a hospital, rehabilitation center, or academic neuropsychology service. More positive experiences were found in these studies, and they also found that perceptions could be moderated by different factors, such as expectations regarding the assessment, perceived relevance, and provision of feedback. ${ }^{13,14}$ While this may appear to be in contrast to the previously described studies on the MC population specifically, this difference may be explained by the characteristics of patients visiting an $\mathrm{MC}$, such as reporting more cognitive complaints, experiencing lower quality of life, having more worries due to a positive family history of dementia, and more deterioration in daily life. ${ }^{29}$ The current study further extends evidence of the NPA experience to a clinical population actively 
seeking help for their cognitive complaints.

Regarding the second theme, early diagnostic paradox, our findings on the experience of patients and their family members showed that both negative (e.g., feelings of distress due to awareness of their cognitive complaints while undergoing an NPA) and positive experiences (e.g., less uncertainty due to the outcome of the NPA) were present during the visit at the MC (illustrated in figure 1). Reducing uncertainty could facilitate the start of the acceptance process in cases of cognitive impairment. This is in line with a recent study that showed that an early diagnosis with high quality diagnostic disclosure was associated with better adjustment and less negative emotional impact both in the short and the long term. ${ }^{30}$ In our study, patients without a cognitive impairment were relieved when they learned that the NPA was going well. They were even further relieved after obtaining the confirmation that they did not have a cognitive impairment or dementia during the diagnostic disclosure. Receiving a dementia diagnosis was often experienced as a confirmation and was also accompanied by relief, which was previously described by other authors. ${ }^{31}$ A study showed that the diagnostic disclosure was a crucial moment, after which patients and their family members had to start making important decisions regarding the future. ${ }^{32}$

A too early diagnosis of $\mathrm{MCl}$ and dementia has been criticized when no disease modifying therapies are available. ${ }^{33,34}$ Receiving an $\mathrm{MCl}$ diagnosis might even be related to more uncertainty compared to a dementia diagnosis. Patients with $\mathrm{MCl}$ have been shown to have an increased risk of conversion to dementia, while some remain cognitively stable. ${ }^{35}$ Many patients with $\mathrm{MCl}$ are unsure about their future and may live with the fear of eventually developing dementia. De Vugt and Verhey ${ }^{36}$ described the impact of an early dementia diagnosis and found that it offered family members the opportunity to adapt to their role as caregivers. The authors emphasized that, especially in this early phase, the level of stress and burden are still low and therefore create a window of opportunity to empower caregivers. Effective psychosocial interventions have been developed that help caregivers improve adaptation to changes that are characterized by the progressive nature of dementia, improve caregiver well-being, maintain psychological health, and delay institutionalization. ${ }^{37,38}$ A systematic review examining positive aspects of caregiving in dementia demonstrated that one of the key factors for a positive experience was acceptance of the situation and its ongoing consequences. ${ }^{39}$ A qualitative study also showed that acknowledgement (e.g., acceptance of the disease and symptoms and strategies to cope with the symptoms) and resistance (e.g., denial and normalization) are simultaneously present in caregivers of patients with early stage AD dementia. ${ }^{40}$ With respect to the early diagnostic paradox identified in this study, it is therefore important to stress that a low level of uncertainty facilitates the acceptance process, which in turn enables caregivers to be more compassionate and empathetic and to approach the situation with a more positive attitude. $^{39}$

The final theme, knowledge utilization, sheds light on the fact that the reported information recall following the medical diagnostic disclosure was generally low. Patients and family members experienced differences in who remembered what, and many details were reported to be forgotten. This is in line with previous findings 
describing that up to 40 to $80 \%$ of medical information provided by professionals was forgotten immediately ${ }^{22}$ and may especially be the case with people visiting a memory clinic. Low information recall and difficulties with understanding the diagnosis might lead to less adequate coping. ${ }^{41}$ As illustrated in figure 1, low knowledge utilization would lead to more uncertainty. This information recall problem might be related to health literacy, which refers to the understanding that is needed to make well-informed decisions. ${ }^{42}$ Previous authors have suggested that providing more detailed and clear information might be helpful, or else providing written information to improve the recall of information. 811,13 Visual aids have also been shown to improve professional-patient discussions, information recall, and health literacy. ${ }^{22,42}$

In Dutch MCs, it is often the medical specialist who discloses the diagnosis, also explaining and discussing the conducted assessments (e.g., MRl, blood tests, and NPA). Previous research showed that providing the patient and family with extensive feedback on the neuropsychological findings was not a universal service in Dutch MCs. ${ }^{1}$ However, providing patients with feedback on their cognitive performance was shown to lead to improved quality of life and social adjustment. ${ }^{43}$ Other studies have also shown that patients evaluated the feedback they received from the neuropsychologist as useful. ${ }^{13,14,44}$ Offering a follow-up consultation made it possible for the patient and their family member to evaluate whether the information is understood, to answer remaining questions, and to further explore the need for help. In our findings, we observed that participants who received a separate consultation with the neuropsychologist appreciated this consultation, while the participants who did not receive them reported experiencing a need for this consultation. Therefore, the authors see it as an example of good practice. In the Dutch healthcare system, it is mandatory to be referred by a doctor for it to be covered by the insurance companies. The proportion of patients who remained in care of Dutch MCs varied between $10 \%$ and $100 \% .{ }^{1}$ However, most clinics do not offer a second consultation shortly after the diagnostic disclosure, which might be related to financial barriers or procedures within the clinics themselves. In addition, Dutch MCs focus on the diagnostic assessment, and for additional treatment, the patient is often referred back to the general practitioner or to other organizations (e.g., mental health institutions or local care organizations). ${ }^{1}$ In the case of a dementia diagnosis, an appointed case manager might be helpful. This is in line with findings from a European study focusing on the evaluation of access to timely formal dementia care. ${ }^{45}$

One of the strengths of this study was the inclusion of patients of three different MCs in the Netherlands, in different regions and with different procedures. By doing this, we used the maximum variation strategy and gained more insight into different experiences in patients visiting MCs that showed service variability. Another strength was the qualitative method of focus groups that allowed for open discussions and offered the opportunity to gain in-depth insight into a range of perspectives. ${ }^{26,46}$ The moderators of the focus groups were experienced psychologists with years of clinical experience who made sure that all participants were given the opportunity to express their opinion. Within-method triangulation of the data (e.g., combining observations, field notes and written transcripts) enriched the analyzed data. Inclusion of both patients and their family members provided information on the experience of both and 
the dynamics of the couples. Purposive sampling is often used in qualitative research, as it ensures the selection of participants who are knowledgeable about a topic. In doing so, a wide range of participants with different diagnoses were included. This heterogeneous sample reflects the reality of MCs.

Limitations should be also considered when interpreting the findings of the current study. First of all, the small sample size makes it difficult to gain insight into differences between subgroups (e.g., between men and women, or between patients and family members). Future research should preferably use a mixed-methods design to gain more insight into these differences. Although we took the variability between MCs into account it might be difficult to generalize our findings to the overall MC population in the Netherlands. A self-selection bias might also influence the generalizability of the results as those willing to participate might be a different group of patients and family members than those who refused. However, in our study only one patient refused to participate. Furthermore, patients with moderate to severe dementia were not included. A severe cognitive impairment might have led to difficulties recalling the experiences they had during the NPA and diagnostic disclosure. However, this makes it a challenge to generalize the results to every type of cognitive impairment. Including both patients and their family members may have affected the responses given during the group interview. For instance, a patient or family member might have not felt comfortable enough to express everything about their significant other. ${ }^{47}$ Another limitation related to focus group methodology, is the risk of conformity where participants might not feel comfortable in sharing their opinion when this differs from the rest of the group or when they are afraid to raise their voice. 


\section{Clinical implications and recommendations}

1) Clinicians should be aware of the high level of uncertainty and take steps to reduce this by:

- Using clear communication that is adapted to the needs of the patient and family member.

- Clearly explaining the procedure of an NPA.

- $\quad$ Paying attention to contextual details (e.g., making sure the wall clock is set to the correct time or not having to look for papers during the assessment).

2) Clinicians should be aware of the low information recall after an MC visit. This could be improved by:

- Involving a family member during the consultations.

- Using visual aids.

- $\quad$ Providing written information (that can be taken home).

3) After patients have received a diagnosis at the $\mathrm{MC}$, the following procedures are recommended:

- $\quad$ Provide clear future steps to patients.

- Offer a second consultation with the patient after receiving the diagnosis.

- $\quad$ Evaluate the needs and wishes of the patient and their family member.

- $\quad$ Provide patients with a key contact person in case of dementia diagnosis.

4) A consultation with the neuropsychologist regarding neuropsychological

feedback focused on cognitive strengths and weaknesses with recommendations for daily life is helpful.

\section{CONCLUSION}

This study identified an early diagnostic paradox during the NPA and medical diagnostic disclosure at the MC. This paradox consisted of the coexistence of conflicting positive and negative emotions: feelings of distress caused by awareness of their cognitive complaints during an NPA, versus increased insight in the situation by the outcome of the NPA and diagnosis. This was influenced by the amount of uncertainty experienced during the entire process. Decreasing these levels of uncertainty facilitated the acceptance process associated with the diagnosis, resulting in more positive feelings of validation and reassurance. Another important factor that increased uncertainty was low information recall and inaccurate communication of information, as this information was not always adjusted to the health-literacy level and individual needs of the patient. For early dementia diagnostics, it is recommended that clinicians be made aware of the necessity of guiding the patient and their caregivers through the acceptance process. 


\section{CHAPTER 4}

\section{ACKNOWLEDGEMENTS}

We would like to thank all the participants for their time and effort. Furthermore, we would also like to thank Angela Wenting and Susanne Valentijn, who enabled us to organize a focus group in the Catharina Hospital in Eindhoven. This study was supported by an independent grant from the Noaber Foundation and Alzheimer Nederland. 


\section{CHAPTER 4}

\section{REFERENCES}

1. Gruters AAA, Ramakers I, Kessels R, et al. Development of memory clinics in the Netherlands over the last twenty years. Int $\mathrm{J}$ Geriatr Psychiatry. 2019;34(8):1267-1274.

2. Lezak MD, Howieson DB, Bigler ED, Tranel D. Neuropsychological Assessment. Fifth edition ed. New York: Oxford University Press; 2012.

3. Harvey PD. Clinical applications of neuropsychological assessment. Dialogues Clin Neurosci. 2012;14(1):91-99.

4. Jansen WJ, Handels RL, Visser PJ, et al. The diagnostic and prognostic value of neuropsychological assessment in memory clinic patients. J Alzheimers Dis. 2017;55(2):679-689.

5. Watt S, Crowe SF. Examining the beneficial effect of neuropsychological assessment on adult patient outcomes: a systematic review. Clin Neuropsychol. 2018;32(3):368-390.

6. Mohammed K, Nolan MB, Rajjo T, et al. Creating a patient-centered health care delivery system: A systematic review of health care quality from the patient perspective. Am J Med Qual. 2016;31(1):12-21.

7. Mastwyk M, Dow B, Ellis KA, Ames D. Why attend a memory clinic? What do patients and their families want and/or expect? Australas J Ageing. 2016;35(3):220-224.

8. Cahill SM, Gibb M, Bruce I, Headon M, Drury M. 'I was worried coming in because I don't really know why it was arranged': The subjective experience of new patients and their primary caregivers attending a memory clinic. Dementia (London). 2008;7(2):175-189.

9. Hailey E, Hodge S, Burns A, Orrell M. Patients' and carers' experiences of UK memory services. Int J Geriatr Psychiatry. 2016;31(6):676-680.

10. Foreman P, Gardner IL, Davis S. Multidisciplinary memory clinics: what is important to caregivers and clients? Int J Geriatr Psychiatry. 2004;19(6):588-589.

11. Hodge S, Doncaster E, Moniz-Cook E, Purandare N, Orrell M. Two sides of the same coin? Patients' and carers' views of UK memory services. Aging Health. 2013;9(3):275-280.

12. Park MH, Smith SC, Hendriks AAJ, Black N. Caregiver burden and quality of life two years after attendance at a memory clinic. Int $J$ Geriatr Psychiatry. 2018.

13. Westervelt HJ, Brown LB, Tremont G, Javorsky DJ, Stern RA. Patient and family perceptions of the neuropsychological evaluation: How are we doing? Clin Neuropsychol. 2007;21(2):263273.

14. Bennett-Levy J, Klein-boonschate MA, Batchelor J, McCarter R, Walton N. Encounters with Anna Thompson: The consumer's experience of neuropsychological assessment. Clin Neuropsychol. 1994;8(2):219-238.

15. Keady J, Gilliard J. The experience of neuropsychological assessment for people with suspected Alzheimer's Disease. In: Harris $\mathrm{BH}$, ed. The person with Alzheimer's Disease. Pathways to understanding the experience. Baltimore: The John Hopkins University Press; 2002.

16. Hill K, O'Brien JT, Morant N, Levy R. User expectations of a memory clinic. Clin Psychol Forum. 1995;83:9-11.

17. Mormont E, de Fays K, Jamart J. Experiences of the patients and their caregivers regarding the disclosure of the diagnosis of Alzheimer's disease: a Belgian retrospective survey. Acta Neurol Belg. 2012;112(3):249-254. 
1. van den Dungen $P$, van Kuijk L, van Marwijk $\mathrm{H}$, et al. Preferences regarding disclosure of a diagnosis of dementia: a systematic review. Int Psychogeriatr. 2014;26(10):1603-1618.

2. Mahieux F, Herr M, Ankri J. What are the preferences of patients attending a memory clinic for disclosure of Alzheimer's disease? Rev Neurol (Paris). 2018;174(7):564-570.

3. van Hout HP, Vernooij-Dassen MJ, Hoefnagels WH, Grol RP. Measuring the opinions of memory clinic users: patients, relatives and general practitioners. Int J Geriatr Psychiatry. 2001;16(9):846-851.

4. Kunneman M, Pel-Littel R, Bouwman FH, et al. Patients' and caregivers' views on conversations and shared decision making in diagnostic testing for Alzheimer's disease: The ABIDE project. Alzheimers Dement (N Y). 2017;3(3):314-322.

5. Kessels RPC. Patients' memory for medical information. J R Soc Med. 2003;96(5):219-222.

6. Abley C, Manthorpe J, Bond J, et al. Patients' and carers' views on communication and information provision when undergoing assessments in memory services. J Health Serv Res Policy. 2013;18(3):167-173.

7. Guest G, Namey E, McKenna K. How many focus groups are enough? Building an evidence base for nonprobability sample sizes. Field Methods. 2017;29(1):3-22.

8. Francis JJ, Johnston M, Robertson C, et al. What is an adequate sample size? Operationalising data saturation for theorybased interview studies. Psychol Health. 2010;25(10):1229-1245.

9. Hennink M. International focus croup research. A handbook for the health and social sciences. Cambridge: University Press; 2007.
10. Cridland EK, Phillipson L, Brennan-Horley C, Swaffer K. Reflections and recommendations for conducting in-depth interviews with people with dementia. Qual Health Res. 2016;26(13):1774-1786.

11. Graneheim UH, Lundman B. Qualitative content analysis in nursing research: concepts, procedures and measures to achieve trustworthiness. Nurse Educ Today. 2004;24(2):105-112.

12. Ramakers $I H$, Visser PJ, Bittermann AJ, Ponds RW, van Boxtel MP, Verhey FR. Characteristics of help-seeking behaviour in subjects with subjective memory complaints at a memory clinic: a case-control study. Int J Geriatr Psychiatry. 2009;24(2):190-196.

13. Woods B, Arosio F, Diaz A, et al. Timely diagnosis of dementia? Family carers' experiences in 5 European countries. Int $\mathrm{J}$ Geriatr Psychiatry. 2018;34(1):114-121.

14. van Vliet D, de Vugt ME, Bakker C, et al. Time to diagnosis in young-onset dementia as compared with late-onset dementia. Psychol Med. 2013;43(2):423-432.

15. Karnieli-Miller $\mathrm{O}$, Werner $\mathrm{P}$, Aharon-Peretz J, Sinoff G, Eidelman S. Expectations, experiences, and tensions in the memory clinic: the process of diagnosis disclosure of dementia within a triad. Int Psychogeriatr. 2012;24(11):1756-1770.

16. Pelosi AJ, McNulty SV, Jackson GA. Role of cholinesterase inhibitors in dementia care needs rethinking. BrMed J. 2006;333(7566):491-493.

17. Alzheimer-Europe. Discussion paper on ethical issues linked to the changing definitions/ use of terms related to Alzheimer's disease. http://alzheimer-europe.org/content/ download/148609/915430/file/03487\%20 Alzheimer\%20Europe\%20ethics\%20report\%20 2016.pdf. Published 2016. 
1. Vega JN, Newhouse PA. Mild cognitive impairment: diagnosis, longitudinal course, and emerging treatments. Curr Psychiatry Rep. 2014;16(10):490.

2. de Vugt ME, Verhey FR. The impact of early dementia diagnosis and intervention on informal caregivers. Prog Neurobiol. 2013;110:54-62.

3. Boots LM, de Vugt ME, van Knippenberg RJ, Kempen Gl, Verhey FR. A systematic review of internet-based supportive interventions for caregivers of patients with dementia. Int $J$ Geriatr Psychiatry. 2014;29(4):331-344.

4. Dickinson C, Dow J, Gibson G, Hayes L, Robalino S, Robinson L. Psychosocial intervention for carers of people with dementia: What components are most effective and when? A systematic review of systematic reviews. Int Psychogeriatr. 2017;29(1):31-43.

5. Lloyd J, Patterson T, Muers J. The positive aspects of caregiving in dementia: A critical review of the qualitative literature. Dementia (London). 2016;15(6):1534-1561.

6. MacQuarrie CR. Experiences in early stage Alzheimer's disease: understanding the paradox of acceptance and denial. Aging Ment Health. 2005;9(5):430-441.

7. Lee SM, Roen K, Thornton A. The psychological impact of a diagnosis of Alzheimer's disease. Dementia (London). 2014;13(3):289-305.

8. Pratt M, Searles GE. Using Visual Aids to Enhance Physician-Patient Discussions and Increase Health Literacy. J Cutan Med Surg. 2017;21(6):497-501.

9. Rosado DL, Buehler S, Botbol-Berman E, et al. Neuropsychological feedback services improve quality of life and social adjustment Clin Neuropsychol. 2018;32(3):422-435.
10. Postal KS, Armstrong K. Feedback that sticks: The art of effectively communicating neuropsychological assessment results Oxford: Oxford University Press; 2013.

11. Kerpershoek L, Wolfs C, Verhey F, et al. Optimizing access to and use of formal dementia care: Qualitative findings from the European Actifcare study. Health Soc Care Community. 2019;27(5):e814-e823.

12. Kitzinger J. Qualitative Research: Introducing focus groups. BMJ. 1995;311(7000):299-302

13. Karnieli-Miller $O$, Werner $P$, Neufeld-Kroszynski G, Eidelman S. Are you talking to me?! An exploration of the triadic physician-patientcompanion communication within memory clinics encounters. Patient Educ Couns. 2012;88(3):381-390. 


\section{CHAPTER 4}

\section{APPENDIX 1}

\section{Semistructured focus group guide}

A. General introduction and informed consent (20 minutes)

B. Short introduction round (10 minutes)

C. Core question 1: Experience with the neuropsychological (15 minutes) assessment

You can see three pictures on the table. A green, orange and red traffic light. You may choose the picture that best reflects your experience with the neuropsychological assessment. Green means you had a positive experience, orange means both positive and negative experiences, and red means a negative experience.

1. Could you explain your choice?

$1.1 \quad$ What was nice? What was not?

1.1.1 Which test did you like most/least?

1.2 What did the family member hear back about it?

1.3 What induced distress?

1.4 What did you think about the length of the assessment?

1.5 What did the neuropsychological assessment give you?

D. Core question 2: Experience with diagnostic disclosure (15 minutes)

2. How did you receive the diagnosis at the memory clinic?

What was your experience?

2.1 What this conversation enough for you?

Was there anything that was missing?

2.2 What did you remember from this conversation?

2.3 Did you think about this conversation at a later moment? 

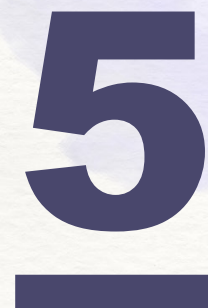

\section{Association between proxy- or self- reported cognitive decline and cognitive performance in memory clinic visitors}

Angélique AA Gruters, Inez HGB Ramakers, Frans RJ Verhey, Sebastian Köhler, Roy PC Kessels, Marjolein E de Vugt.

Journal of Alzheimer's Disease, 2019 


\section{CHAPTER 5}

\section{ABSTRACT}

\section{Background}

It is uncertain whether self- and proxy-reported cognitive decline in older adults reflect an actual objective cognitive dysfunction in the clinical sense, and if these are predictive for developing dementia. The aim of the present study is to investigate the crosssectional and longitudinal relation between subjective cognitive decline and objective cognitive performance, depressive symptoms, and to determine the predictive value for development of dementia.

\section{Methods}

We included 405 patients without dementia at first visit from the Maastricht memory clinic participating in a longitudinal cohort study. Subjective cognitive decline was measured using a self- and proxy-report questionnaire. All patients underwent a standardized neuropsychological assessment. Follow-up assessments were performed yearly for three consecutive years, and once after five years.

\section{Results}

Subjective cognitive decline was associated with lower cognitive performance and more depressive symptoms. When comparing self- $(n=342,84 \%)$ and proxy-reported decline $(n=110,27 \%)$, it was shown that proxy reports were associated with a more widespread pattern of lower cognitive performance. In participants without cognitive impairment proxy-reported decline was not associated with depressive symptoms. In contrast, self-reported decline was associated with a stable course of depressive symptoms at follow-up. Proxy-reported cognitive decline ( $\mathrm{HR}=1.76,95 \% \mathrm{Cl}=1.12-2.78)$, and mutual complaints ( $\mathrm{HR}=1.73, \mathrm{Cl}$ :1.09-2.76) predicted incident dementia while selfreported decline did not reach statistical significance $(\mathrm{HR}=1.26,95 \% \mathrm{Cl}=0.65-2.43)$.

\section{Conclusion}

Proxy-reported cognitive decline was consistently associated with lower cognitive performance and conversion to dementia over 5 years. Self-reported cognitive decline in patients without cognitive impairment might indicate underlying depressive symptoms and thus deserve clinical attention, too. 


\section{INTRODUCTION}

Subjective cognitive decline is defined as self-perceived worsening of cognition over time, which is common in older adults. ${ }^{1}$ It is often a reason for concern, resulting in visits to healthcare facilities, such as memory clinics. There is increasing evidence that the experience of cognitive decline is related to a greater risk of conversion to mild cognitive impairment (MCI) and Alzheimer's Disease (AD) dementia. ${ }^{2-4}$ A meta-analysis shows that elderly people experiencing cognitive decline are twice as likely to develop dementia. ${ }^{3}$ However, previous studies have generated inconsistent findings with regard to the relation with objective cognitive performance and risk of conversion to dementia. ${ }^{2,5,6}$ Some studies have shown that subjective cognitive decline reflects worse objective cognitive performance both at baseline and over time, ${ }^{7-10}$ whereas other studies found no associations with cognition. ${ }^{11-14}$ On the other hand, cognitive complaints have also been shown to be closely associated with personality traits, depressive symptoms and other psychiatric conditions.,11-14 Differences in study design might explain this heterogeneity, as studies that found an association between subjective cognitive decline and objective cognitive performance have generally adopted a longitudinal and community-based design in a cognitively healthy sample while studies focusing on a memory clinic population have not always demonstrated differences in cognitive performance. ${ }^{15,16}$

The differential prognostic value of self- as compared with proxy-reported cognitive decline is another unresolved issue. Indeed, some studies indicate that proxyreported decline has a higher accuracy of indicating subsequent objective cognitive performance and predict future cognitive decline in comparison to self-reported decline. ${ }^{17,18}$ Proxy-reported decline has also been shown to differentiate normal aging from future conversion to dementia, while self-reported decline did not. ${ }^{19,20}$ In contrast, other studies found weak associations between proxy-reported decline and cognitive test performances. ${ }^{14,21}$ These discrepancies could be explained by methodological differences, variability in terminology, and a focus on subjective memory complaints and noton other cognitive domains, suchas attention. Consequently, the clinical significance and prognostic value of self- and proxy-reported cognitive decline remain unclear. More insight into subjective cognitive decline might allow for identification of an at-risk population for developing AD dementia that is easily implemented in clinical practice. It would also facilitate the implementation of early interventions. ${ }^{2}$ This study will extend evidence from predominantly cognitively healthy subjects to a clinical population of memory clinic visitors who actively sought help using a large memory clinic cohort and a long follow-up period. In addition, we will explicitly focus on contrasting proxy- and self-reported cognitive decline, which includes reports of both memory and attention complaints and is based on a standardized instrument asking for the decline compared to one year prior to the assessment. To our knowledge only a few studies have studied this in memory clinic visitors, usually focusing on current subjective complaints. Our primary aim is to investigate the cross-sectional and longitudinal associations between self- and proxy-reported cognitive decline and objective cognitive performances in nondemented memory clinic visitors. The secondary aim is to determine association with conversion to dementia in patients with and without self- and proxy-reported cognitive 
decline at baseline. The third aim is to investigate the cross-sectional and longitudinal associations between self- and proxy-reported cognitive decline and depressive symptoms, and to repeat this analysis separately in patients with and without cognitive impairment.

\section{MATERIALS AND METHODS}

Study design and participant selection

Participants were selected from the Bio-Bank Alzheimer Center Limburg (BBACL) study, which is an ongoing prospective cohort study of patients referred to the memory clinic of the Maastricht University Medical Center in the Netherlands for an evaluation of their cognitive complaints. Patients were included if they were 55 years or older, had no cognitive impairment ( $\mathrm{NCl}$ ), or mild cognitive impairment ( $\mathrm{MCl}$ ) in the absence of dementia. Participants were classified as having $\mathrm{MCl}$ when they had an objectified impairment on one or more cognitive tests, ${ }^{22}$ had a Clinical Dementia Rating (CDR) score of $\leq 0.5$, and no significant interference in daily life. Performance on a cognitive test was considered impaired if the score was more than 1.5 Standard Deviation (SD) below the age-, sex, and education-adjusted normative mean. ${ }^{23-25}$ Participants were excluded if they had dementia at baseline, and medical disorders, which could result in cognitive impairment. This includes Normal Pressure Hydrocephalus, Huntington's disease, recent cerebrovascular disorders (Transient Ischemic Attack [TIA] or /stroke $<2$ years prior to the assessment or cognitive decline within 3 months after a TIA or stroke), brain tumor, epilepsy or encephalitis. Participants were also excluded if they had a history $(<$ 12 months) of or current treatment for major depressive disorder, bipolar disorder, or psychotic disorder (NOS) based on DSM-IV-TR criteria. Cognitive problems as a result of excessive use of alcohol (clinician judgement) and the expectation that the participant would not reach the first-year follow-up also led to exclusion. For the present study, we selected participants who completed the self- and proxy questionnaires on cognitive decline. This resulted in a sample size of $n=405$ at baseline. Figure 1 shows the flow chart of this study. Ethical approval was given by the Medical Ethics Review Committee of Maastricht University Medical Center. Participants gave written informed consent.

\section{Baseline assessment}

Standard clinical assessment as part of the diagnostic procedure at baseline included a detailed medical history of the patient, demographic information, neurological, psychiatric and physical examinations. Furthermore, a standardized interview based on the Disability Assessment for Dementia Scale ${ }^{26}$ was conducted with a proxy to evaluate significant interference in daily life which was also based on clinical judgement. Also, self- and proxy-reported information of cognitive decline, and a neuropsychological assessment were part of the baseline assessment. 


\section{CHAPTER 5}

Self- and proxy reported cognitive decline

Self-reported cognitive decline was measured by the Subjective Cognitive Functioning (SCF) questionnaire. ${ }^{27}$ Participants had to rate their cognitive change in the past year on a scale from -3 (very strong decline) to +3 (very strong improvement) in the domains of memory and concentration. Two groups were identified: those who reported a cognitive decline (in memory or in concentration, or in both) (SCF $<0$ ), and those who reported no change or an improvement in these domains (SCF $\geq 0$ ). The Dutch translation of the Détérioriation Cognitive Observée (DECO) ${ }^{28}$ was used to measure proxy-reported cognitive decline. It consists of 19 items concerning the degree of change in cognitive functioning in the past year on a scale from 2 (no change) to 0 (great decline). It has been shown to be highly sensitive for changes in cognitive functioning. ${ }^{28}$ Furthermore, it shows high discriminability, with a sensitivity of $79 \%$ and specificity of $90 \%$ for detecting dementia using a cutoff score of $\leq 24$, which is not influenced by level of education. ${ }^{29}$ This cutoff was used to identify two groups: those who reported a greater decline in cognitive functioning (DECO $\leq 24)$, and those who did not (DECO > 24). 


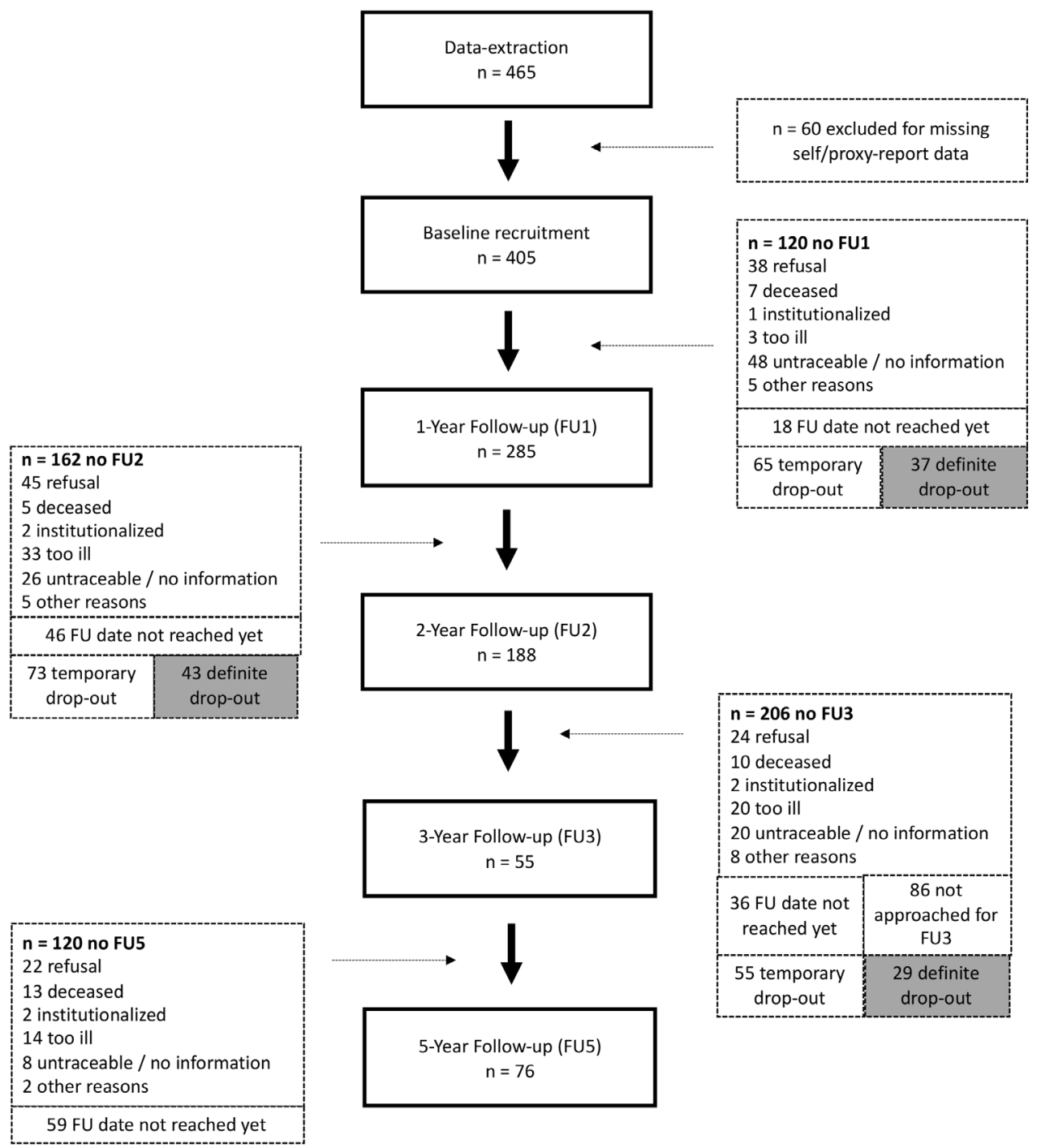

Figure 1. Flowchart of ongoing longitudinal BBACL cohort 
Neuropsychological assessment

All participants underwent neuropsychological assessment by use of a standardized test battery. The following cognitive domains were measured: general cognitive functioning (MMSE) ${ }^{30}$, episodic memory, both for verbal (Dutch version of the verbal learning test; $\mathrm{VLT})^{31}$ and visual information (Visual Association Test; VAT) ${ }^{32}$, information processing speed (Stroop Color-Word Test part I; SCWT-133, and Trail Making Test part A; TMT- $A^{34}$ or Concept Shifting Task part A; CST- $A^{35}$ ), executive functioning (interference index of the SCWT, ${ }^{33}$ concept shifting ${ }^{35}$ ), and semantic word fluency (1-minute animal naming ${ }^{36}$ ). All cognitive performances were translated to z-scores adjusted for age, education and, if appropriate, sex. ${ }^{23-25,37}$ Extreme z-scores were found for SCWT-I (4.7\% of all scores), SCWT interference (5.3\% of all scores), CSTA/TMTA (1.1\% of all scores), and concept shifting ( $1.9 \%$ of all score). These scores were winsorized at a lower (-5) and upper $(+5)$ boundary. Presence and severity of depressive symptoms were measured using the 15-item Geriatric Depression Scale. ${ }^{38}$

\section{Follow-up assessments}

Follow-up (FU) assessments took place one, two, three, and five years (FU1, FU2, FU3, FU5) after baseline. Comparable to baseline, every follow-up assessment included a medical history and neuropsychological assessment using parallel versions to reduce material-specific test-retest effects. The consultation with a family member, based on the $D A D$, was also taken again to evaluate interference in daily living and decline from a previous level of functioning (social or occupational). The DECO, SCF, and GDS questionnaires were also included at the follow-up assessments. Dementia diagnosis was reviewed at every assessment according to DSM-IV-TR criteria using all available information (outcome of the neuropsychological assessment, medical history, family history, and evaluation of interference in daily live). ${ }^{39}$ In the case significant interference in daily life was suspected, the medical specialist (psychiatrist) from the memory clinic was consulted. After reviewing all data (e.g., earlier brain scans, current new information) the medical specialist made the dementia diagnosis.

\section{Statistical analysis}

Statistical analyses were performed using SPSS version 20.0 for Mac OSX. Differences in baseline characteristics between the self- and proxy-reported cognitive decline groups and dementia converters and non-converters were compared using independentsample t-tests (or Mann-Whitney $U$ tests in case of no normal distribution), and $\chi^{2}$-tests (categorical variables). To estimate associations between self- or proxyreported cognitive decline with objective cognitive performance over time, linear mixed models were used with a random intercept and random slope to account for correlated repeated measurements within individuals. The unstructured covariance structure type was chosen as this gave the best model fit using likelihood ratio testing. The cognitive test z-scores were used as dependent variables in the model with a separate model for each subtest. The independent terms included the self-reported cognitive decline group, time (categorical: baseline, FU1, FU2, FU3, FU5) and group by time interaction. 
The interaction term was added to investigate future cognitive decline or improvement between the groups. The null hypothesis of no difference in course of cognitive performance was tested with an $\mathrm{F}$ test to examine whether there was a significant group effect and group-by-time interaction across all time points. Furthermore, estimated means were calculated in this analysis for group by time. All models were adjusted for age, sex, education (low, middle, high), and depressive symptoms. The same model was run with the proxy-reported group as independent term. Because time was added as a categorical variable the differences between the groups could be identified at each measurement. To study the association between subjective cognitive decline and depressive symptoms the linear mixed model analysis was also run with the GDS-15 score as dependent term and the same independent terms as described above. This model was adjusted for age, sex, and education. Cox regression analyses adjusted for age, sex, education, and depressive symptoms were performed to evaluate if proxy-and self-reported cognitive decline were associated with conversion to dementia. Causespecific hazard ratios were calculated with competing risk of death $(n=35,9.6 \%$ ). The outcome was dementia converters versus non-converters. The survival time was time to diagnosis of dementia (converters) or last available follow-up diagnosis (nonconverters). The alpha-level was set at .05 in two-sided tests throughout.

\section{RESULTS}

Baseline characteristics

At baseline, $84.4 \%$ of the patients were identified as having self-reported cognitive decline (SCF < 0 ) and $27.2 \%$ as having proxy-reported cognitive decline (DECO $\leq$ 24). The combination of both self- and proxy reported cognitive decline was present in $23.5 \%$ of the patients, while in $11.5 \%$ no subjective cognitive decline was reported by either the patient or family member. The baseline demographic characteristics are shown in Table 1. Most proxies were partners (71.4\%). Other proxies included children $(20 \%)$, acquaintances (3\%), siblings (2.2\%), other family members (2.2\%), and ex-partners (1.2\%). Overall, most proxies had daily $(75.6 \%)$ or at least once a week $(21.4 \%)$ contact with the patient. Patients with self- or proxy-reported cognitive decline showed no significant differences with respect to demographic features (Table 1). The prevalence of $\mathrm{MCl}$ was comparable between participants with and without self- $\left(\chi^{2}(1)=0.64, p=\right.$ $.425)$ or proxy-reported $\left(\chi^{2}(1)=1.63, p=.202\right)$ cognitive decline. In addition, patients with self- or proxy-reported cognitive decline had significantly higher mean scores of depressive symptoms than those without (self-report: $U=7853, p=.002$, proxy-report: $U=11691, p<.001)$. 
Table 1. Comparison of demographic characteristics in patients with and without selfor proxy-reported cognitive decline $(n=405)$

\begin{tabular}{|c|c|c|c|c|}
\hline & \multicolumn{2}{|c|}{$\begin{array}{l}\text { Self-reported } \\
\text { cognitive decline }\end{array}$} & \multicolumn{2}{|c|}{$\begin{array}{l}\text { Proxy-reported } \\
\text { cognitive decline }\end{array}$} \\
\hline & Present & Absent & Present & Absent \\
\hline n (\%) & $342(84.4)$ & 63 (15.6) & $110(27.2)$ & 295 (72.8) \\
\hline Age, years & $70.0 \pm 8.3$ & $70.1 \pm 8.9$ & $71.1 \pm 9.0$ & $69.6 \pm 8.2$ \\
\hline Sex, n female (\%) & $128(37.4)$ & $29(46.0)$ & $42(38.2)$ & 115 (39.0) \\
\hline \multicolumn{5}{|l|}{ Education n (\%) } \\
\hline Low & $128(37.4)$ & $30(47.7)$ & $47(42.7)$ & $111(37.6)$ \\
\hline Middle & $128(37.4)$ & 21 (33.3) & 37 (33.6) & 112 (38.0) \\
\hline High & $86(25.2)$ & 12 (19.0) & $26(23.7)$ & $72(24.4)$ \\
\hline \multicolumn{5}{|l|}{ Diagnosis n (\%) } \\
\hline $\mathrm{NCl}$ & 139 (40.6) & $29(46.0)$ & $40(36.4)$ & $128(43.4)$ \\
\hline $\mathrm{MCl}$ & $203(59.4)$ & $34(54.0)$ & 70 (63.6) & $167(56.6)$ \\
\hline GDS-15 score & $3.6 \pm 3.0^{a}$ & $2.6 \pm 2.8$ & $4.6 \pm 3.6^{b}$ & $3.1 \pm 2.6$ \\
\hline MMSE score & $27.6 \pm 2.4$ & $27.2 \pm 2.5$ & $26.7 \pm 2.6^{a}$ & $27.8 \pm 2.2$ \\
\hline
\end{tabular}

Notes. Demographics are represented in mean \pm SD unless stated otherwise. Education was stratified following the Dutch education system in low (primary), average (lower secondary or vocational), and high (higher secondary education, higher vocational, university) education. Groups were compared using Student's t-tests, Mann-Whitney U-tests and Pearson's chi-squared tests where appropriate. a $p=<.05$. b p $=<.001$. Abbreviations. $\mathrm{NCl}=$ No Cognitive Impairment, $\mathrm{MCl}=$ Mild Cognitive Impairment, GDS = Geriatric Depression Scale; MMSE = Mini Mental Status Examination 
Association between self- and proxy-reported cognitive decline and cognitive performance.

The differences in course of cognitive performance for patients with and without self- or proxy-reported cognitive decline are shown in Table 2 and Figure 2. In these analyses, we did not differentiate between patients with and without cognitive impairment. At baseline, linear mixed models, corrected for age, sex, education, and depressive symptoms, showed no significant differences regarding cognitive performance between patients with and without self-reported decline. In addition, no significant overall interaction effect was found with time. However, averaged over all time points together, patients with self-reported cognitive decline at baseline had a lower performance on the VLT immediate recall $(F(1,475)=11.68, p=.001)$, VLT delayed recall $(F(1,463)=15.50, p<.001)$, semantic fluency $(F(1,473)=7.59, p=$ $.006)$ and SCWT-I $(F(1,456)=10.10, p=.002)$ (Figure 2 and Table 2$)$ in comparison to patients who did not report a subjective cognitive decline.

Patients with proxy-reported cognitive decline had a lower performance on the CSTA/TMTA and SCWT-I at baseline compared to those without (table 2). However, no differences were found on the other cognitive tests. Averaged over all time points, while accounting for correlated measures within individuals, patients with proxy-reported cognitive decline had a lower performance on the VLT delayed recall $(F(1,448)=4.63$, $p=.032)$, VAT $(F(1,435)=23.75, p<.001)$, semantic fluency $(F(1,464)=11.14, p=$ $.001)$, CSTA/TMTA $(F(1,460)=12.72, p=<001)$, concept shifting $(F(1,376)=5.53, p=$ .019), SCWT-1 $(F(1,463)=25.62, p<.001)$, and SCWT-interference $(F(1,420)=11.13$, $p=.001)$, and higher scores on GDS-15 $(F(1,478)=9.60, p=.002)$. Also, a significant overall interaction with time shows that the cognitive performance of patients with proxy-reported cognitive decline significantly decreased over time on the VAT (F (4, $389)=3.75, p=.005)$, CSTA/TMTA $(F(4,411)=4.18, p=.003)$, SCWT-I $(F(4,406)=$ $5.42, p<.001)$, and SCWT interference $(F(4,357)=5.37, p<.001)$. No significant overall interaction was found on the other cognitive tests. 


\section{CHAPTER 5}

A

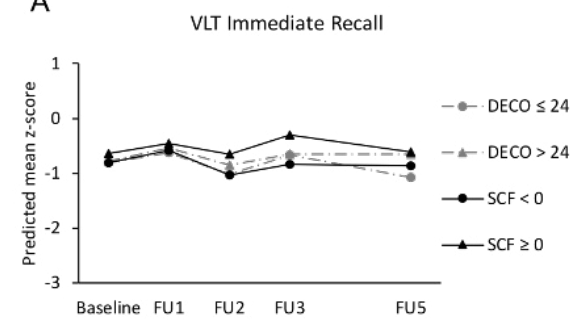

C

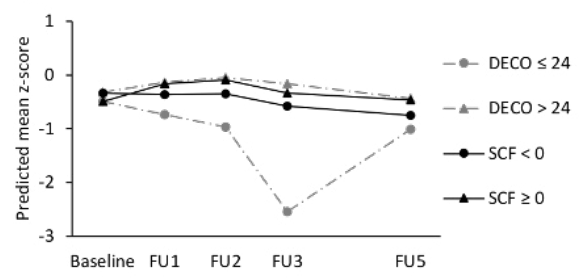

$E$

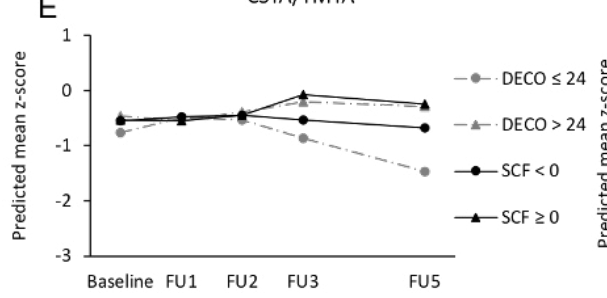

SCWT-I

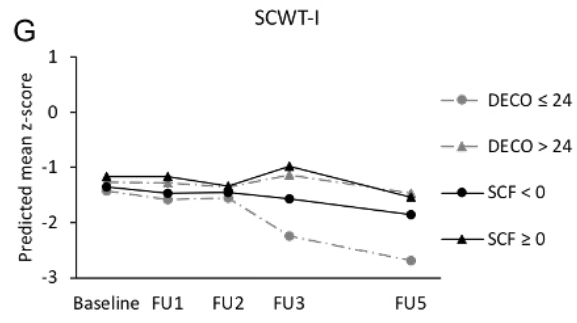

B

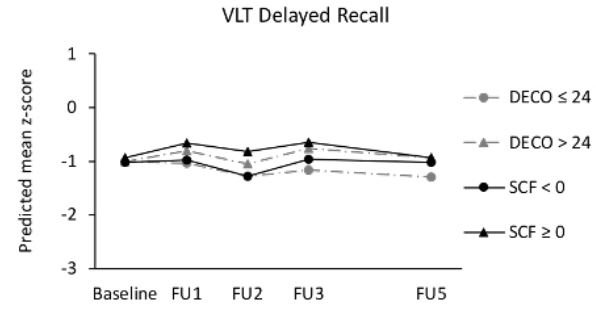

$\mathrm{D}$
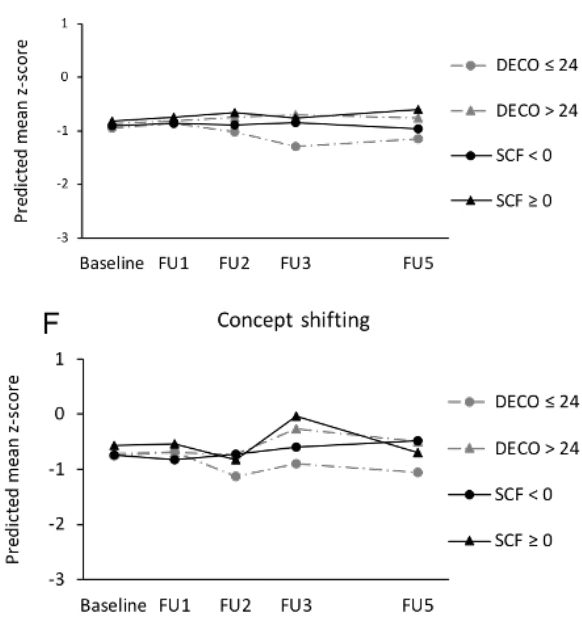

$\mathrm{H} \quad$ SCWT interference

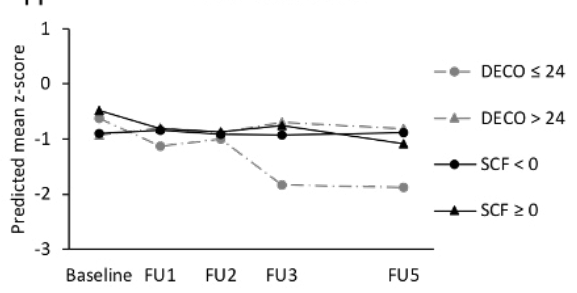

Figure 2. Course of cognitive performances by subjective cognitive decline groups. Notes. DECO $\leq 24$ : proxy-reported cognitive decline, DECO $>24$ : no proxy-reported cognitive decline, SCF $<0$ : self-reported cognitive decline, SCF $\geq 0$ : no self-reported cognitive decline. A: Course of VLT IR scores. B: Course of VLT DR. C: Course of VAT scores. D: Course of fluency scores. E: Course of CSTA/TMTA scores. F: Course of concept shifting scores. G: Course of SCWT-I scores. H: Course of SCWT interference scores. The groups were compared using random-effects analysis with random intercept, random slope and unstructured covariance structure, adjusted for age, gender, education, and depressive symptoms. Predicted mean scores are estimated marginal means of subjective cognitive decline group by time. Higher mean scores represent a better cognitive performance ( $z$-Score). Abbreviations. SCF = Subjective Cognitive Functioning, DECO = Détérioration Cognitive Observée, VLT = 15-Word Learning Test, DR = Delayed Recall, IR = Immediate Recall, VAT $=$ Visual Association Test, CST $=$ Concept Shifting Test, $T M T=$ Trail Making Test. SCWT $=$ Stroop Color and Word Test. 


\section{CHAPTER 5}

Table 2. Differences in cognitive performances between participants with or without self- or proxy-reported cognitive decline per follow-up

\begin{tabular}{|c|c|c|c|c|c|c|c|c|c|c|c|c|}
\hline \multirow[t]{2}{*}{ Parameter } & \multicolumn{2}{|c|}{ Baseline } & \multicolumn{2}{|r|}{ FU1 } & \multicolumn{2}{|c|}{ FU2 } & \multicolumn{2}{|c|}{ FU3 } & \multicolumn{2}{|r|}{ FU5 } & \multicolumn{2}{|c|}{ Group by time ${ }^{c}$} \\
\hline & $\beta$ & $95 \% \mathrm{Cl}$ & $\beta$ & $95 \% \mathrm{Cl}$ & $\beta$ & $95 \% \mathrm{Cl}$ & $\beta$ & $95 \% \mathrm{Cl}$ & $\beta$ & $95 \% \mathrm{Cl}$ & $F$ & $p$ \\
\hline \multicolumn{13}{|l|}{ Self-reported decline } \\
\hline VLT IR & -0.17 & $-0.47,0.12$ & -0.13 & $-0.36,0.10$ & $-0.39^{b}$ & $-0.64,-0.13$ & $-0.54^{a}$ & $-1.03,-0.05$ & -0.25 & $-0.66,0.17$ & 0.99 & .411 \\
\hline VLT DR & -0.09 & $-0.36,0.19$ & $-0.32^{b}$ & $-0.56,-0.08$ & $-0.45^{b}$ & $-0.73,-0.18$ & -0.32 & $-0.84,0.21$ & $-0.60^{b}$ & $-1.05,-1.6$ & 1.33 & .259 \\
\hline VAT & 0.15 & $-0.26,0.56$ & -0.21 & $-0.57,0.15$ & -0.25 & $-0.71,0.20$ & -0.23 & $-1.30,0.83$ & -0.29 & $-0.95,0.38$ & 0.64 & .636 \\
\hline Semantic fluency & -0.10 & $-0.30,0.11$ & -0.12 & $-0.30,0.06$ & $-0.24^{a}$ & $-0.43,-0.04$ & -0.09 & $-0.46,0.29$ & $-0.36^{a}$ & $-0.68,-0.05$ & 0.73 & .572 \\
\hline CST-A / TMT-A & -0.02 & $-0.35,0.31$ & 0.05 & $-0.24,0.34$ & -0.00 & $-0.33,0.32$ & -0.43 & $-1.04,0.17$ & -0.49 & $-1.01,0.04$ & 1.22 & .302 \\
\hline Concept shifting & -0.15 & $-61,0.32$ & -0.28 & $-0.59,0.04$ & 0.06 & $-0.27,0.40$ & -0.55 & $-1.20,0.09$ & 0.21 & $-0.31,0.74$ & 1.52 & .195 \\
\hline SCWT - I & -0.21 & $-0.70,0.29$ & -0.37 & $-0.73,0.01$ & -0.16 & $-0.57,0.25$ & -0.33 & $-1.10,0.44$ & -0.56 & $-1.23,0.10$ & 0.37 & .832 \\
\hline SCWT interference & -0.25 & $-0.88,0.37$ & -0.24 & $-0.76,0.27$ & 0.10 & $-0.44,0.63$ & -0.26 & $-1.26,0.74$ & 0.25 & $-0.59,1.08$ & 0.49 & .743 \\
\hline Proxy-reported decline & & & & & & & & & & & & . \\
\hline VLT IR & -0.02 & $-0.27,0.22$ & -0.10 & $-0.40,0.21$ & -0.17 & $-0.54,0.21$ & -0.01 & $-0.57,0.56$ & -0.47 & $-1.00,0.07$ & 0.64 & .635 \\
\hline VLT DR & -0.01 & $-0.25,0.22$ & -0.23 & $-0.55,0.08$ & -0.23 & $-0.62,0.17$ & -0.40 & $-1.00,0.20$ & -0.35 & $-0.92,0.22$ & 0.75 & .557 \\
\hline VAT & -0.17 & $-0.52,0.18$ & $-0.60^{b}$ & $-1.05,-0.15$ & $-0.93^{b}$ & $-1.57,-0.29$ & $-2.39^{b}$ & $-3.62,-1.15$ & -0.57 & $-1.44,0.30$ & 3.75 & $.005^{b}$ \\
\hline Semantic fluency & 0.09 & $-0.26,0.08$ & -0.05 & $-0.28,0.18$ & -0.27 & $-0.57,0.03$ & $-0.60^{b}$ & $-1.04,-0.15$ & -0.38 & $-0.79,0.03$ & 1.87 & .115 \\
\hline CST-A/TMT-A & $-0.30^{a}$ & $-0.57 .-0.03$ & 0.01 & $-0.36,0.37$ & -0.16 & $-0.62,0.29$ & -0.61 & $-1.28,0.05$ & $-1.46^{b}$ & $-2.12,-0.81$ & 4.18 & $.003^{b}$ \\
\hline Concept shifting & -0.07 & $-0.44,0.30$ & -0.12 & $-0.53,0.29$ & -0.48 & $-0.98,0.03$ & -0.63 & $-1.38,0.11$ & -0.53 & $-1.26,0.20$ & 1.05 & .383 \\
\hline SCWT - I & $-0.48^{a}$ & $-0.89,-0.07$ & -0.37 & $-0.84,0.10$ & -0.26 & $-0.83,0.31$ & $-1.13^{b}$ & $-1.98,-0.29$ & $-2.30^{b}$ & $-3.11,-1.49$ & 5.42 & $<.001^{b}$ \\
\hline SCWT interference & 0.38 & $-0.12,0.88$ & -0.25 & $-0.91,0.42$ & 0.36 & $-0.41,1.13$ & $-1.70^{b}$ & $-2.77,-0.63$ & $-1.58^{b}$ & $-2.66,-0.50$ & 5.37 & $<.001^{b}$ \\
\hline
\end{tabular}

Notes. Groups were compared using linear mixed models. Model: cognitive z score (dependent), time, group, group by time, sex, age, education, and depressive symptoms. Groups were compared using linear mixed models and differences are represented in $\beta$. Abbreviations. FU = Follow Up, Cl = confidence interval, VLT= verbal learning test, IR = Immediate Recall, DR = Delayed Recall, VAT = Visual Association Test, CST = Concept Shifting Test, TMT = Trail Making Test. SCWT = Stroop Color and Word Test. ${ }^{a} \mathrm{p}<.05 .{ }^{\mathrm{b}} \mathrm{p}<.01$. c Overall interaction between group and time 


\section{CHAPTER 5}

Self- and proxy-reported cognitive decline and conversion to dementia As shown in table 3,23.3\% of the participants at baseline converted to dementia within five years. Converters had a higher age $(U=8110, p<.001)$, had more often $\mathrm{MCl}\left(\chi^{2}(1)\right.$ $=44.7, p<.001)$ and proxy-reported decline $\left(\chi^{2}(1)=6.28, p=.012\right)$ than nonconverters. Converters were also characterized by lower GDS-15 $(U=10680, p=.001)$ and MMSE scores $(U=8928, p<.001)$. Cox regression, adjusted for age, sex, education, and depressive symptoms, were conducted separately for self- and proxy-reported cognitive decline at baseline to investigate the association with conversion to dementia. Table 4 shows that patients with proxy-reported cognitive decline and mutual self- and proxyreported cognitive decline at baseline were significantly associated with developing dementia compared to patients who did not report proxy-reported cognitive decline or mutual complaints. Patients with self-reported decline also were related with developing dementia compared to patients without self-reported decline, however statistical significance could not be reached. If neither the patient nor a family member reported cognitive decline, patients developed dementia less often, but statistical significance could not be reached (table 4). 
Table 3. Summary characteristics of patients with and without conversion to dementia.

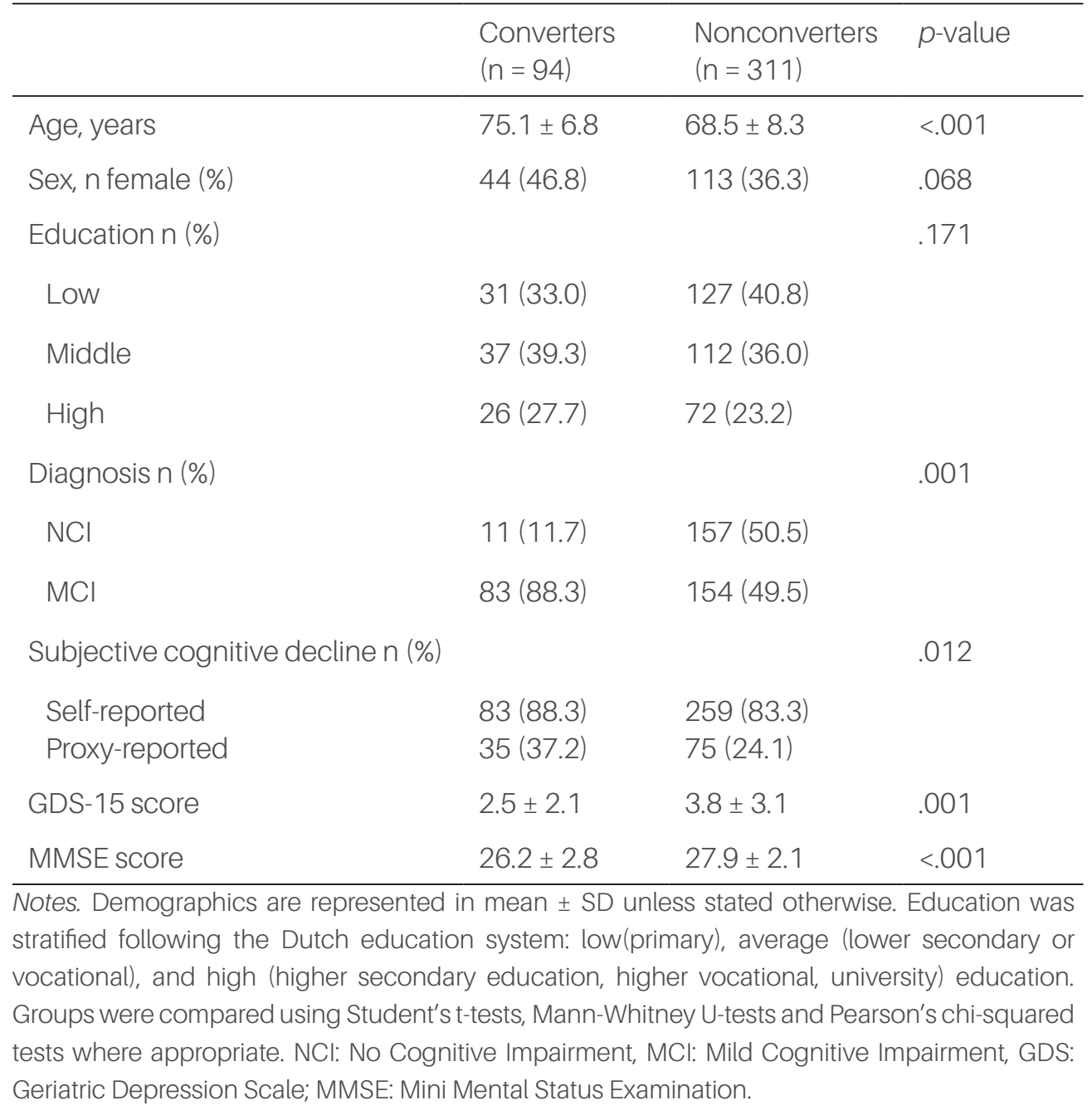


Table 4. Cox regression models for time to dementia diagnosis.

\begin{tabular}{|c|c|c|c|}
\hline & No of cases & $\begin{array}{l}\text { Hazard ratio } \\
(95 \% \mathrm{Cl})\end{array}$ & p-value \\
\hline \multirow{2}{*}{$\begin{array}{l}\text { Self-reported cognitive decline } \\
\text { versus no self-reported decline }\end{array}$} & $83 / 342(24 \%)$ & \multirow[t]{2}{*}{1.26 (0.65 to 2.43 ) } & \multirow[t]{2}{*}{.489} \\
\hline & $11 / 63(18 \%)$ & & \\
\hline \multirow{2}{*}{$\begin{array}{l}\text { Proxy-reported cognitive decline } \\
\text { versus no proxy-reported decline }\end{array}$} & $35 / 110(32 \%)$ & \multirow[t]{2}{*}{1.76 (1.12 to 2.78 ) } & \multirow[t]{2}{*}{$.015^{\mathrm{a}}$} \\
\hline & 59/295 (20\%) & & \\
\hline \multirow{2}{*}{$\begin{array}{l}\text { No self or proxy reported cognitive decline } \\
\text { versus self- or proxy-reported decline }\end{array}$} & $8 / 48(17 \%)$ & \multirow[t]{2}{*}{0.68 (0.32 to 1.43$)$} & \multirow[t]{2}{*}{.307} \\
\hline & $86 / 357(24 \%)$ & & \\
\hline \multirow{2}{*}{$\begin{array}{l}\text { Both self and proxy reported cognitive decline } \\
\text { versus no self and proxy reported decline }\end{array}$} & $32 / 95(34 \%)$ & \multirow[t]{2}{*}{1.73 (1.09 to 2.76} & \multirow[t]{2}{*}{$.021^{\mathrm{a}}$} \\
\hline & $62 / 310(20 \%)$ & & \\
\hline
\end{tabular}

Notes. Each row represents a separate cox regression analysis adjusted for sex, age, education, and depressive symptoms. Number of cases indicates how many participants of the group were diagnosed with dementia. Cl: confidence interval. ${ }^{a} \mathrm{p}<.05$

Association between self- and proxy reported cognitive decline and depressive symptoms

Taking together the group as a whole ( $\mathrm{NCI}$ and $\mathrm{MCl}$ ) linear mixed models, corrected for age, sex, and education showed that participants with self- reported cognitive decline had more depressive symptoms averaged over all time points together $(F(1,462)=$ 31.50, $\mathrm{p}<.001$ ) and level of symptoms were significantly higher at FU1, FU2, and FU5 (table 5). Participants with proxy-reported cognitive decline also had reported more depressive symptoms averaged across all time points $(F(1,478)=9.60, p=.002)$ and these were significantly higher at baseline and follow-up one (table 5) compared to no proxy-reported decline. No interaction with time was found for both self- and proxyreported cognitive decline.

Table 5 and figure 3 show the results of the separate linear mixed model analyses in patients with $\mathrm{NCl}$ or $\mathrm{MCl}$. In $\mathrm{NCl}$ patients, self-reported decline was significantly associated with more depressive symptoms at each follow-up, but not at baseline. A significant overall interaction with time showed that the depressive symptoms in participants who experienced self-reported cognitive decline remained stable over time, while the depressive symptoms decreased over time in the group without selfreported decline. In contrast, no significant differences at each measurement or overall interaction with time were found for the proxy-reported decline group as compared to no proxy-reported decline. In MCl patients, self-reported decline was associated with more depressive symptoms at baseline, FU1 and FU5. Proxy-reported decline was associated with more depressive symptoms at baseline and FU1. No significant interaction with time was found for either self- or proxy reported cognitive decline. 


\section{CHAPTER 5}

Table 5. Differences between participants with and without self or proxy-reported decline in depressive symptoms per follow-up moment.

\begin{tabular}{|c|c|c|c|c|c|c|c|c|c|c|c|c|}
\hline \multirow[t]{2}{*}{ Parameter } & \multicolumn{2}{|c|}{ Baseline } & \multicolumn{2}{|r|}{ FU1 } & \multicolumn{2}{|c|}{ FU2 } & \multicolumn{2}{|c|}{ FU3 } & \multicolumn{2}{|r|}{ FU5 } & \multicolumn{2}{|c|}{ Group by time ${ }^{c}$} \\
\hline & $\beta$ & $95 \% \mathrm{Cl}$ & $\beta$ & $95 \% \mathrm{Cl}$ & $\beta$ & $95 \% \mathrm{Cl}$ & $\beta$ & $95 \% \mathrm{Cl}$ & $\beta$ & $95 \% \mathrm{Cl}$ & $F$ & $p$ \\
\hline \multicolumn{13}{|c|}{ Both $\mathrm{NCl}$ and $\mathrm{MCl}$} \\
\hline \multicolumn{13}{|c|}{ Self-reported decline } \\
\hline GDS-15 & 0.55 & $-0.12,1.22$ & $1.30^{b}$ & $0.75,1.85$ & $1.00^{b}$ & $0.38,1.63$ & 1.08 & $-0.12,2.28$ & $1.78^{b}$ & $0.77,2.80$ & 1.27 & .282 \\
\hline \multicolumn{13}{|c|}{ Proxy-reported decline } \\
\hline GDS-15 & $0.90^{b}$ & $0.34,1.46$ & $1.06^{b}$ & $0.34,1.78$ & 0.68 & $-0.24,1.60$ & 0.37 & $-1.02,1.76$ & 1.01 & $-0.32,2.35$ & 0.27 & .895 \\
\hline \multicolumn{13}{|c|}{$\mathrm{NCl}$ patients only } \\
\hline \multicolumn{13}{|c|}{ Self-reported decline } \\
\hline GDS-15 & -0.47 & $-1.43,0.49$ & $1.41^{b}$ & $0.59,2.23$ & $1.52^{b}$ & $0.63,2.41$ & $1.85^{a}$ & $0.09,3.62$ & $2.20^{b}$ & $0.75,3.65$ & 3.45 & $.009^{b}$ \\
\hline \multicolumn{13}{|c|}{ Proxy-reported decline } \\
\hline GDS-15 & 0.80 & $-0.05,1.66$ & 0.30 & $-1.12,1.72$ & 0.86 & $-0.62,2.34$ & 0.41 & $-1.88,2.69$ & 1.85 & $-0.60,4.31$ & 0.38 & .822 \\
\hline \multicolumn{13}{|c|}{$\mathrm{MCl}$ patients only } \\
\hline \multicolumn{13}{|c|}{ Self-reported decline } \\
\hline GDS-15 & $1.50^{b}$ & $0.58,2.41$ & $1.14^{b}$ & $0.39,1.90$ & 0.64 & $-0.23,1.50$ & 0.58 & $-1.04,2.20$ & $1.46^{b}$ & $0.07,2.85$ & 0.71 & .587 \\
\hline \multicolumn{13}{|c|}{ Proxy-reported decline } \\
\hline GDS-15 & $0.99^{b}$ & $0.34,1.46$ & $1.23^{b}$ & $0.38,2.08$ & 0.49 & $-0.69,1.67$ & 0.38 & $-1.40,2.16$ & 0.66 & $-0.98,2.30$ & 0.39 & .815 \\
\hline
\end{tabular}

Notes. Groups were compared using linear mixed models. Model: depressive symptoms (dependent), time, group, group by time, sex, age, and education. Groups were compared using linear mixed models and differences are represented in $\beta$. Abbreviations. FU = Follow Up, Cl= confidence interval, GDS: Geriatric Depression Scale.

${ }^{\mathrm{a}} \mathrm{p}<.05 .{ }^{\mathrm{b}} \mathrm{p}<.01$.

${ }^{\circ}$ Overall interaction between group and time 

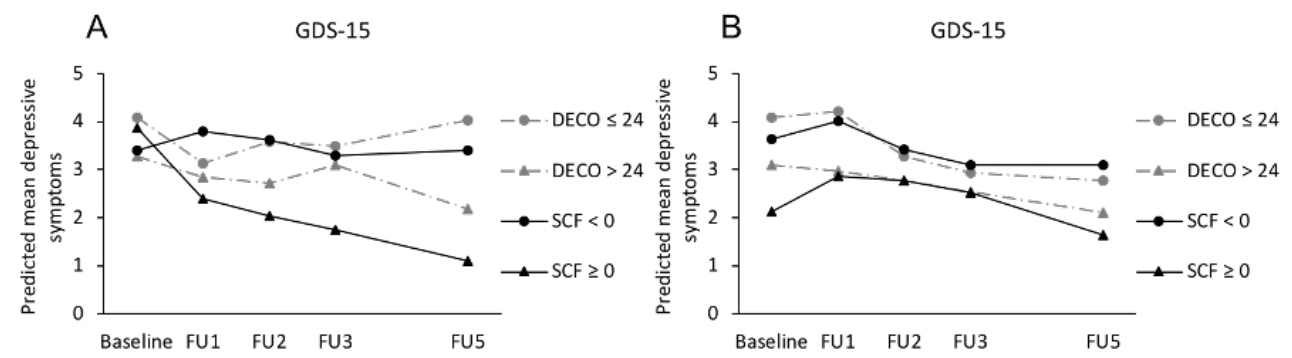

Figure 3. Course of depressive symptoms by subjective cognitive decline groups. Notes. $\mathrm{DECO} \leq 24$ : proxy-reported cognitive decline, DECO > 24: no proxy-reported cognitive decline, SCF $<0$ : self-reported cognitive decline, SCF $\geq 0$ : no self-reported cognitive decline. A: Course of depressive symptoms in patients with $\mathrm{NCl}$. B: Course of depressive symptoms in patients with $\mathrm{MCl}$. These figures are based on random-effects analyses adjusted for age, gender, and education. The predicted mean scores are estimated marginal means of time by group. Higher mean scores represent a higher level of depressive symptoms. Abbreviations. SCF: Subjective Cognitive Functioning, DECO: Détérioration Cognitive Observée, GDS: Geriatric Depression Scale.

\section{DISCUSSION}

This study aimed to gain further insight into the association between self- and proxyreported cognitive decline and objective cognitive performance, depressive symptoms, and dementia conversion in memory clinic visitors. At baseline, self-reported cognitive decline was not associated with lower cognitive performance, while proxy-reported decline was associated with a lower performance on two subtests. However, averaged over the course of five years, both self- and proxy-reported decline were associated with generalized lower objective cognitive performance. Proxy-reported decline also related to a significant decline over time on cognitive tests and to developing dementia, while self-reported decline did not reach statistical significance. Participants more often developed dementia when self-reported decline was confirmed by a proxy. Furthermore, both self- and proxy reported decline were associated with higher rates of depressive symptoms. In patients without cognitive impairment self-reported decline was significantly associated with more depressive symptoms while proxy-reported decline was not.

Our findings are in line with previous studies that found an association with subjectively perceived cognitive decline and objective cognitive performance, but contrasts with other studies.-11,17 An explanation for these conflicting findings could be the differences in methodology, such as use of different populations, questionnaires and conceptual discrepancies. ${ }^{2,40}$ We found that proxy reported decline was more often associated with a lower performance on cognitive tests, cognitive decline, and conversion to dementia than self-reported decline. This is consistent with earlier studies that showed that proxy-reported cognitive decline is a better predictor of cognitive performance and development of dementia than self-reported decline in patients with no cognitive impairment and mild AD dementia. ${ }^{19,21}$ Only a handful 
studies, however, have contrasted self- and informant reported cognitive decline in a memory clinic population. Studies conducted in a memory clinic population reported that experiencing more mutual complaints were associated with a worse cognitive trajectory, while other cross-sectional studies demonstrated that self- or proxy-reported decline did not result in any cognitive differences. ${ }^{16,41,42}$ This study extends evidence to a clinical population from a memory clinic ranging from no cognitive disorders to $\mathrm{MCl}$ with a longer follow-up period. The lack of association between cognition and self- and proxy-reported decline at baseline might be explained by the difference between subjective and objective measurements. The questionnaires (SCF and DECO) require a subjective judgment of cognitive complaints in the past year, while cognitive performance is an objective measure at a single time point in which the premorbid level cannot be taken into account. The cross-sectional objective measurements might not be sensitive enough to determine subtle intra-individual changes as reflected in the subjective report of the complaints, as proposed by a recent review. ${ }^{2}$ Although proxyreported cognitive decline was related to almost all cognitive test performances, it was shown that self-reported decline was related to a lower performance on selective cognitive tests only. Patients with self-reported cognitive decline performed worse on tasks concerning episodic memory and verbal fluency. These cognitive domains have been extensively described in the literature as one of the first characteristics of cognitive decline in prodromal AD. ${ }^{43,44}$ Decreased episodic memory scores could be a first sign of underlying AD pathology, such as medial temporal lobe damage or elevated betaamyloid burden, which in turn is also associated with self-reported decline. ${ }^{45}$ These findings contrast with recent studies in memory clinic visitors in which self-reported decline was not associated with cognitive differences. ${ }^{15,42}$ This could, however, be explained by smaller sample sizes, the use of a non-standardized way to measure selfreported cognitive decline or cross-sectional analyses. Recently, more evidence has become available showing that the combination of self-reported cognitive decline with AD positive biomarkers improves the ability of predicting objective cognitive decline and dementia. 15,46

In both proxy- and self-reported cognitive decline an association with depressive symptoms was found. The finding that participants without cognitive impairment reported more depressive symptoms remained significant for the selfreported cognitive decline group, while this was not found for proxy-reported decline. Depressive symptoms have been considered one of the most influential factors associated with subjective cognitive decline in the absence of cognitive impairment. 11,47 The question remains what underlies the co-existence of subjective complaints and depressive symptoms. On one hand, the "cognitive model of depression" emphasizes that depressed patients often view themselves, others, and their future in a negatively distorted way. ${ }^{48}$ This negative cognitive bias has been thought to mediate the impaired ability to accurately self-assess cognitive functioning. ${ }^{49}$ A recent study shows an underestimation of cognitive functioning in depressed patients and an overestimation in healthy participants. ${ }^{50}$ On the other hand, previous studies have found that depressive symptoms and major depression are related to lower hippocampal volumes and increased vascular brain lesions, which could cause cognitive impairment. ${ }^{51,52}$ 
The DSM-IV criteria of a Major Depressive Disorder also include having difficulties concentrating and an impaired ability to make decisions. ${ }^{53}$ Conversely, it is also debated that depressive symptoms could be the result of realizing cognitive decline. ${ }^{54}$ It is highly likely that these theories play a role in the association between subjective cognitive decline and depressive symptoms. Another explanation of the association between self-reported decline and depressive symptoms could be the high prevalence of depressive symptoms among patients referred to a memory clinic. ${ }^{55}$ Since the memory clinic in this study is embedded within the psychiatric department, the prevalence could be even higher. Therefore, depressive symptoms might indicate underlying depressive symptomatology in memory clinic visitors which asks for a multidisciplinary approach in the evaluation of cognitive complaints.

Our study shows that proxy-reported cognitive decline is predictive for cognitive decline and developing dementia, while statistical significance was not reached for self-reported cognitive decline. This is in line with previous studies suggesting that informant report may enable identification of very early decline and that only a small proportion of participants with self-reported decline in a memory clinic develop dementia. ${ }^{2,15}$ In turn, other findings pointing towards a higher risk of conversion to $\mathrm{MCl}$ or dementia for memory clinic patients with self-reported decline.3,56 However, our findings should be carefully interpreted because participants with self-reported cognitive decline seems to be a heterogeneous group and therefore less sensitive and discriminative for decline in cognitive performance. The high prevalence might have led to lack of contrast when comparing those with and without subjective cognitive decline to the cognitive outcomes. For the dementia outcome, large standard errors and wide 95\% confidence intervals indeed suggest large variability, which might have led to a relatively high and non-significant p-value despite an HR around 1.5 (and similar to the one found for proxy-reported decline). Obviously, subjective cognitive decline denotes a still very heterogeneous group of patients that was of limited predictive value. In contrast, proxy-reported decline seems to have a higher sensitivity for cognitive outcome and for conversion to dementia. This could be explained by less influence of reporting bias. ${ }^{57}$ Proxy-reports have also been described as a more objective measure because they can give insight into more implicit processes which are often not noticed by the patient due to subtle changes. ${ }^{58}$ When both self- and proxy-reported cognitive decline was present, this identified a group that more often converted to dementia than those with proxy-reported decline alone. This is in line with diagnostic criteria, which often includes cognitive complaints corroborated by family members. ${ }^{22}$ In addition, mutual proxy- and self-reported cognitive decline have been shown to be associated with AD neuropathology. ${ }^{41}$ These findings underline the importance of taken informantbased information into account in diagnostics at memory clinic settings.

For the current study both strengths and limitations have to be kept in mind when interpreting the findings. The strengths of this study are the large sample size and the long follow-up period of up to five years. In addition, not many studies have focused on subjective cognitive decline in memory clinic visitors with and without cognitive impairment. In addition, a broad range of inclusion criteria were chosen to maximize generalizability in a clinical population. However, some limitations should be 
mentioned. Self-reported cognitive decline was measured using a new questionnaire that needs further psychometric evaluation. This questionnaire consists of two questions in which patients could indicate the range of the experienced change (from strong decline to strong improvement) on both memory and attention. This is likely to have a better validity and reliability than the use of one single question in which the patients only answers with yes or no, which has been used in several other studies. ${ }^{59}$ Other studies have used more extensive questionnaires, such as the CFQ, but this does not include the opportunity to report improvements and focuses only on memory complaints. Nonetheless, standardization of measurements for self-reported cognitive decline is important, which is also highlighted in the recently proposed framework for subjective cognitive decline.,40 In addition, we should consider that only 67 participants could be included in the five year follow-up measurement, which is partly due to the ongoing nature of this cohort study. For example, 159 participants (39.6\%) were included in the study after 2013 and therefore did not reach their fifthyear assessment yet. In addition, the number of participants at the three-year follow-up was relatively small due to the study design, which did not include a regular threeyear follow-up assessment initially. This resulted in less data for cognitive tests and therefore could have led to less robust findings (e.g. VAT follow-up 3, figure 2). The drop-outs may have resulted in non-differential attrition bias. When comparing groups at baseline, the drop-outs were frailer, that is, older and performing worse on most cognitive tests, leaving a less impaired sample in the analyses. This might have led to an underestimation of group differences due to the attrition of patients with cognitive impairment. However, the maximum likelihood estimation in the repeated-measures design takes this into account and is relatively robust against missing data points when covariates related to missing data are included. ${ }^{60} \mathrm{It}$ is also important to note that this study has been conducted in memory clinic visitors, and its outcome can therefore not be generalized to the general population.

\section{CONCLUSION}

In summary, the present study shows that both self- and proxy- reported cognitive decline was related to lower cognitive performance and more depressive symptoms. Proxy-reported decline indicated future cognitive decline and conversion to dementia. When subjective cognitive decline is confirmed by both the patient and informant it showed the strongest relation with subsequent dementia onset. The current findings may be useful for earlier identification of patients at-risk for dementia. This could lead to a larger time frame to implement interventions, guidance, and an increased understanding of the disease process. It has been shown that early interventions can be beneficial for caregivers in the pre-dementia phase when levels of stress and burden are still relatively low. ${ }^{61-63}$ Our findings suggest that when a patient is referred to a memory clinic, the role of both depressive symptomatology and proxy-reported cognitive decline is very important to take into account. 


\section{REFERENCES}

1. Ponds RW, Comissaris KJ, Jolles J. Prevalence and covariates of subjective forgetfulness in a normal population in the Netherlands. Int $J$ Aging Hum Dev. 1997;45:207-221.

2. Jessen $F$, Amariglio RE, van Boxtel M, et al. A conceptual framework for research on subjective cognitive decline in preclinical Alzheimer's disease. Alzheimers Dement. 2014; 10(6):844-852.

3. Mitchell AJ, Beaumont H, Ferguson D, Yadegarfar M, Stubbs B. Risk of dementia and mild cognitive impairment in older people with subjective memory complaints: meta-analysis. Acta Psychiatr Scand. 2014;130:439-451.

4. Buckley RF, Maruff P, Ames D, et al. Subjective memory decline predicts greater rates of clinical progression in preclinical Alzheimer's disease. Alzheimers Dement. 2016;12(7):796804.

5. Benito-Leon J, Mitchell AJ, Vega S, BermejoPareja F. A population-based study of cognitive function in older people with subjective memory complaints. J Alzheimers Dis. 2010;22(1):159-170.

6. Mitchell AJ. The clinical significance of subjective memory complaints in the diagnosis of mild cognitive impairment and dementia: a meta-analysis. Int J Geriatr Psychiatry. 2008;23:1191-1202.

7. Miranda B, Madureira S, Verdelho A, et al. Selfperceived memory impairment and cognitive performance in an elderly independent population with age-related white matter changes. J Neurol Neurosurg Psychiatry. 2008;79(8):869-873.

8. Koppara A, Wagner M, Lange C, Ernst A, Wiese $B$, König H. Cognitive performance before and after the onset of subjective cognitive decline in old age. Alzheimers Dement (Amst). 2015;1(2):194-205.
9. Dufouil C, Fuhrer R, Alpérovitch A. Subjective cognitive complaints and cognitive decline: Consequence or predictor? The epidemiology of vascular aging study. J Am Geriatr Soc. 2005;53:616-621.

10. Glodzik-Sobanska L, Reisberg B, De Santi S, et al. Subjective memory complaints: presence, severity and future outcome in normal older subjects. Dement Geriatr Cogn Disord. 2007;24(3):177-184.

11. Zlatar ZZ, Muniz M, Galasko D, Salmon DP. Subjective cognitive decline correlates with depression symptoms and not with concurrent objective cognition in a clinic-based sample of older adults. J Gerontol B Psychol Sci Soc Sci. 2018;73(7):1198-1202.

12. Hohman TJ, Beason-Held LL, Resnick SM. Cognitive complaints, depressive symptoms, and cognitive impairment: are they related? J Am Geriatr Soc. 2011;59(10):1908-1912.

13. Zlatar ZZ, Moore RC, Palmer BW, Thompson WK, Jeste DV. Cognitive complaints correlate with depression rather than concurrent objective cognitive impairment in the SAGE baseline sample. J Geriatr Psychiatry Neurol. 2014;27(3):181-187.

14. Slavin MJ, Brodaty $H$, Kochan NA, et al. Prevalence and predictors of "subjective cognitive complaints" in the Sydney memory and ageing study. Am J Geriatr Psychiatry. 2010;18(8):701-710.

15. Hessen E, Eckerstrom M, Nordlund A, et al. Subjective cognitive impairment is a predominantly benign condition in memory clinic patients followed for 6 years: The Gothenburg-Oslo MCI study. Dement Geriatr Cogn Dis Extra. 2017;7(1):1-14. 
1. Perrotin A, La Joie R, de La Sayette $V$, et al. Subjective cognitive decline in cognitively normal elders from the community or from a memory clinic: Differential affective and imaging correlates. Alzheimers Dement. 2017; 13(5):550-560.

2. Nicholas CR, Dowling NM, Racine AM, et al. Longitudinal assessment of self- and informant-subjective cognitive complaints in a sample of healthy late-middle aged adults enriched with a family history of Alzheimer's disease. J Int Neuropsychol Soc. 2017;23(8):617-626.

3. Slavin MJ, Sachdev PS, Kochan NA, et al. Predicting cognitive, functional, and diagnostic change over 4 Years using baseline subjective cognitive complaints in the Sydney memory and ageing Study. Am J Geriatr Psychiatry. 2015;23(9):906-914.

4. Rabin LA, Wang C, Katz MJ, Derby CA, Buschke H, Lipton RB. Predicting Alzheimer's disease: neuropsychological tests, self-reports and informant reports of cognitive difficulties. $J$ Am Geriatr Soc. 2012;60(1128-1134).

5. Valech N, Mollica MA, Olives J, et al. Informants' perception of subjective cognitive decline helps to discriminate preclinical Alzheimer's disease from normal aging. $J$ Alzheimers Dis. 2015;48 Suppl 1:S87-98.

6. Caselli RJ, Chen K, Locke DE, et al. Subjective cognitive decline: self and informant comparisons. Alzheimers Dement. 2014;10(1):93-98.

7. Albert MS, DeKosky ST, Dickson D, Dubois $\mathrm{B}$, Feldman $\mathrm{HH}$, Fox NC. The diagnosis of mild cognitive impairment due to Alzheimer's disease: recommendations from the National Institute on Aging-Alzheimer's Association workgroup on diagnostic guidelines for Alzheimer's disease. Alzheimers Dement. 2011;7(270-279).
8. Van der Elst W, Van Boxtel MP, Van Breukelen GJ, Jolles J. Normative data for the animal, profession and letter $\mathrm{M}$ naming verbal fluency tests for Dutch speaking participants and the effects of age, education and sex. J Int Neuropsychol Soc. 2006;12:80-89.

9. Van der Elst W, Van Boxtel MP, Van Breukelen GJ, Jolles J. The Stroop color-word test: influence of age, sex and education; and normative data for a large sample across the adult age range. Assessment. 2006;13:62-79.

10. Van der Elst W, van Boxtel MPJ, van Breukelen GJ, Jolles J. Rey's Verbal Learning Test: normative data from 1855 healthy participants aged 24-81 years and the influence of age, sex, education, and mode of presentation. J Int Neuropsychol Soc. 2005;11:290-302.

11. Gelinas I, Gauthier L, McIntyre M, Gauthier S. Development of a functional measure for persons with Alzheimer's disease: the disability assessment for dementia. Am J Occup Ther. 1999;53(5):471-481.

12. Aalten $P$, Ramakers IHGB, Biessels GJ, et al. The Dutch Parelsnoer Institute Neurodegenerative diseases; methods, design and baseline results. BMC Neurol. 2014;14(1):254.

13. Ritchie K, Fuhrer R. A comparative study of the performance of screening tests for senile dementia using receiver operating characteristics analysis. J Clin Epidemiol. 1992;45(6):627-637.

14. Ritchie K, Fuhrer R. The validation of an informant screening test for irreversible cognitive decline in the elderly: performance characteristics within a general population sample. Int J Geriatr Psychiatry. 1996;11(2):149-156.

15. Kok R, Verhey F. Dutch translation of the mini mental state examination (Folstein et al., 1975) 2002. 
1. Lezak MD, Howieson DB, Bigler ED, Tranel D. Neuropsychological Assessment. fifth edition ed. New York: Oxford University Press; 2012.

2. Lindeboom J, Schmand B. Visual Association Test to detect early dementia of the Alzheimer type. J Neurol Neurosurg Psychiatry. 2002;73(126-133).

3. Houx PJ, Jolles J, Vreeling FW. Stroop interference: Aging effects assessed with the Stroop color-word test. Exp Aging Res. 1993;19(204-224).

4. Reitan RM. Validity of the Trail Making Test as an indication of organic brain damage. Percept Mot Skills. 1985:8:271-276.

5. Vink $M$, Jolles J. A new version of the TrailMaking Test as an informant processing task. $J$ Clin Neuropsychol. 1985;7:162.

6. Tombaugh T, Kozak J, Rees L. Normative data stratified by age and education for two measures of verbal fluency: FAS and animal naming. Arch Clin Neuropsychol. 1999;14(2):167-177.

7. Schmand B, Houx P, de Koning I. Normen voor Stroop kleur-woord tests, Trail Making Test en story recall van Rivermead Behavioural Memory Test. Amsterdam: Nederlands Instituut voor Psychologen, Sectie Neuropsychologie; 2003.

8. De Craen AJM, Heeren TJ, Gussekloo J. Accuracy of the 15-item Geriatric Depression Scale (GDS-15) in a community sample of the oldest old. Int J Geriatr Psychiatry. 2003;18:6366.

9. American Pschiatric Association (APA). Diagnostics and Statistical Manual of Mental Disorders, fourth edition. Washington DC: APA; 1994.

10. Rabin LA, Smart CM, Crane PK, et al. Subjective cognitive decline in older adults: An overview of self-report measures used across 19 international research studies. J Alzheimers Dis. 2015;48 Suppl 1:S63-86.
11. Gifford KA, Liu D, Hohman TJ, et al. A Mutual self- and informant-report of cognitive complaint correlates with neuropathological outcomes in mild cognitive impairment. PloS One. 2015;10(11):e0141831.

12. Silva MR, Moser D, Pfluger M, et al. Selfreported and informant-reported memory functioning and awareness in patients with mild cognitive impairment and Alzheimer s disease. Neuropsychiatr. 2016;30(2):103-112.

13. Hamel R, Kohler S, Sistermans N, et al. The trajectory of cognitive decline in the predementia phase in memory clinic visitors: findings from the 4C-MCl study. Psychol Med. 2015;45(7):1509-1519.

14. Ritchie K, Ropacki M, Albala B, et al. Recommended cognitive outcomes in preclinical Alzheimer's disease: Consensus statement from the European Prevention of Alzheimer's Dementia project. Alzheimers Dement. 2017;13(2):186-195.

15. Amariglio RE, Becker JA, Carmasin J, et al. Subjective cognitive complaints and amyloid burden in cognitively normal older individuals. Neuropsychologia. 2012;50(12):2880-2886.

16. Eckerström M, Göthlin M, Rolstad S, et al. Longitudinal evaluation of criteria for subjective cognitive decline and preclinical Alzheimer's disease in a memory clinic sample. Alzheimers Dement (Amst). 2017;8:96-107.

17. Harvey PD, Twamley EW, Pinkham AE, Depp CA, Patterson TL. Depression in schizophrenia: Associations with cognition, functional capacity, everyday functioning, and selfassessment. Schizophr Bull. 2017;43(3):575582.

18. Beck A, Rush J, Shaw B, Emery G. Cognitive therapy of depression. New York: Guilford; 1979. 
1. Crane MK, Bogner HR, Brown GK, Gallo JJ. The link between depressive symptoms, negative cognitive bias and memory complaints in older adults. Aging Ment Health. 2007;11(6):708715.

2. Schwert C, Stohrer M, Aschenbrenner S, Weisbrod M, Schroder A. Biased neurocognitive self-perception in depressive and in healthy persons. J Affect Disord. 2018;232:96-102.

3. Mulders PC, van Eijndhoven PF, Schene AH, Beckmann CF, Tendolkar I. Resting-state functional connectivity in major depressive disorder: A review. Neurosci Biobehav Rev. 2015;56:330-344.

4. Kohler S, van Boxtel M, Jolles J, Verhey F. Depressive symptoms and risk for dementia: a 9-year follow-up of the Maastricht Aging Study. Am J Geriatr Psychiatry. 2011;19(10):902-905.

5. American Psychiatric Association (APA). Diagnostic and Statistical Manual of Mental Disorders, fifth edition. Washington, DC: APA; 2013.

6. Amieva H, Le Goff M, Millet X, et al. Prodromal Alzheimer's disease: successive emergence of the clinical symptoms. Ann Neurol. 2008;64(5):492-498.

7. Knapskog A-B, Barca ML, Engedal K. Prevalence of depression among memory clinic patients as measured by the Cornell Scale of Depression in Dementia. Aging Ment Health. 2014;18(5):579-587.

8. Yim SJ, Yi D, Byun MS, et al. Screening ability of subjective memory complaints, informant-reports for cognitive decline, and their combination in memory clinic setting. Psychiatry Investig. 2017;14(5):640-646.

9. Li M, Harris I, Lu ZK. Differences in proxyreported and patient-reported outcomes: assessing health and functional status among medicare beneficiaries. BMC Med Res Methodol. 2015;15:62.
10. Schwartz CE, Ayandeh A, Rodgers JD, Duberstein P, Weinstock-Guttman B, Benedict $\mathrm{RH}$. A new perspective on proxy report: Investigating implicit processes of understanding through patient-proxy congruence. Qual Life Res. 2015;24(11):26372649.

11. Reid LM, Maclullich AM. Subjective memory complaints and cognitive impairment in older people. Dement Geriatr Cogn Disord. 2006:22(5-6):471-485.

12. Moerbeek M, van Breukelen GJ, Berger MP. A comparison between traditional methods and multilevel regression for the analysis of multicenter intervention studies. J Clin Epidemiol. 2003;56(4):341-350.

13. de Vugt ME, Verhey FR. The impact of early dementia diagnosis and intervention on informal caregivers. Prog Neurobiol. 2013;110:54-62.

14. Joosten-Weyn Banningh LW, Kessels RP, Olde Rikkert MG, Geleijns-Lanting CE, Kraaimaat FW. A cognitive behavioural group therapy for patients diagnosed with mild cognitive impairment and their significant others: feasibility and preliminary results. Clin Rehabil. 2008;22(8):731-740.

15. Banningh LW, Vernooij-Dassen MJ, Vullings M, Prins JB, Rikkert MG, Kessels RP. Learning to live with a loved one with mild cognitive impairment: effectiveness of a waiting list controlled trial of a group intervention on significant others' sense of competence and well-being. Am J Alzheimers Dis Other Demen. 2013;28(3):228-238. 

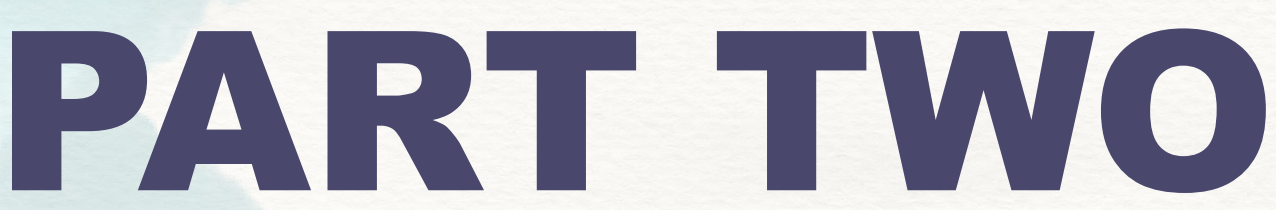

INSICHTS INTO NEUROPSYCHOLOCICAL FEEDBACK AND THE DEVELOPMENT OF A VISUAL AID 

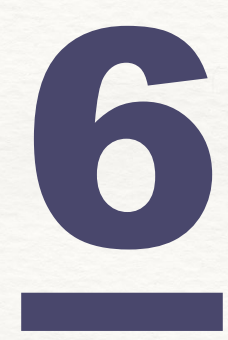

\section{A scoping review of communicating neuropsychological test results to patients and family members}

Angélique AA Gruters, Inez HGB Ramakers, Frans RJ Verhey, Roy PC Kessels, Marjolein E de Vugt.

\section{Under review}




\section{CHAPTER 6}

\section{ABSTRACT}

Feedback of neuropsychological test results to patients and family members can encompass several aspects, such as psychoeducation and implications for daily life. This scoping review aimed to provide an overview of the literature on neuropsychological feedback and to offer clinical recommendations. In accordance with formal scoping review methodology, PubMed, Psyclnfo, Web of Science, CINAHL, and Embase databases were searched. Studies were included if they reported neuropsychological feedback, if full papers were available, and if they included human participants. All languages were included, and no limit was placed on the year of publication. Of the 2,173 records screened, 34 publications met the inclusion criteria. Five additional publications were included after cross-referencing. An update of the search led to the inclusion of two additional papers. Of these 41 publications, 26 were research papers. Neuropsychological feedback is provided for a wide spectrum of diagnoses and usually given in person and has been related to a positive effect on patient outcomes (e.g. increased quality of life). Most papers reported on satisfaction and found that satisfaction with an NPA increased when useful feedback was provided. However, information retention was found to be low, but communication aids, such as written information, were found to be helpful in improving retention. The current review demonstrated the benefits of neuropsychological feedback and that this should be part of standard clinical procedures when conducting a neuropsychological assessment. Further research on the benefits of neuropsychological feedback and how to improve information provision would enrich the neuropsychological literature. 


\section{CHAPTER 6}

\section{INTRODUCTION}

An important role of healthcare providers is to deliver feedback from diagnostic findings and medical information to patients. A neuropsychological assessment (NPA) evaluates the cognitive performance of a patient and can provide insight into cognitive strengths and weaknesses. ${ }^{1}$ Explaining these assessment results to patients and family members is referred to as neuropsychological feedback. The ethical standard of the American Psychological Association states that a psychologist must make a reasonable attempt to explain the results of their assessment. ${ }^{2}$ The goal of neuropsychological feedback is to help patients and family members understand NPA results and their implications for daily life functioning. ${ }^{3}$ Neuropsychological feedback has also been recommended in clinical guidelines. ${ }^{4,5}$ Furthermore, neuropsychological feedback might provide patients insight into more effective ways of responding and dealing with their cognitive complaints. ${ }^{3}$ An explanation for their cognitive complaints can lead to feelings of relief, reduced distress, and reduced caregiver burden.,7 Furthermore, neuropsychological feedback gives the opportunity to evaluate rehabilitation or treatment planning, provide support to patients and family members who might experience difficulties with adapting to a diagnosis, offer guidelines for decision-making, and answer questions or concerns patients may have about their NPA results. ${ }^{6,8}$ Neuropsychological feedback is not only often given to the patient but also to family members or to the school or work environment and can lead to improved communication within these systems. ${ }^{3,6}$ To our knowledge, research evaluating the benefits of neuropsychological feedback and how to communicate feedback is limited. It is important to gain more insight into what is known about neuropsychological feedback to improve quality of care. This scoping review aims to provide an overview (e.g., study types, methods used, results, quality of papers) about communicating neuropsychological feedback to patients and family members. Furthermore, another aim is to offer recommendations for clinical practice. 


\section{METHODS}

Design

A preliminary literature search resulted in diversity of methods and multiple sources concerning neuropsychological feedback. Consequently, a scoping review was chosen over a systematic review due to the broader approach, as scoping reviews include multiple sources, such as studies with different designs, opinion or position papers, and gray literature. ${ }^{9,10}$ A scoping review is used to provide an overview of the literature in the area of interest, to identify gaps of knowledge in the evidence base and to summarize relevant findings. ${ }^{9}$ The current review was guided by the methodological framework described by Arksey and $\mathrm{O}^{\prime}$ Malley ${ }^{9}$ and additional recommendations of Levac et al. ${ }^{11}$ This framework consisted of five stages guiding the scoping process of identifying the research question, identifying relevant studies, study selection, charting the data, and summarizing and reporting the results. ${ }^{11}$ Furthermore, the PRISMA checklist for scoping reviews was used as reporting guideline. ${ }^{12}$ Although a quality appraisal is not often applied in scoping reviews, we opted to use the Mixed Method Appraisal Tool 2018 version. ${ }^{13}$ This is a reliable and efficient critical appraisal tool to review quality of methodology in systematic reviews, and has been used in prior scoping reviews. ${ }^{14,15}$

\section{Inclusion and exclusion criteria}

We included books, book chapters, and research articles reporting on providing neuropsychological feedback to patients and/or family members. All types of research designs, patient groups, and languages were included. No restrictions were made on year of publication. Research papers were excluded when no results were reported on neuropsychological feedback. Books, book chapters and opinion or position papers were excluded if neuropsychological feedback was not included as the main topic. Papers were also excluded if no full paper was available (e.g., conference abstracts) or in the case of nonhuman studies.

\section{Data sources and search strategy}

We searched the following databases: PubMed, Psyclnfo, Web of Science, CINAHL, and Embase. A combination of free text terms in Title/Abstract and descriptor terms (e.g., MeSH terms) were used in the search string. The full search strategy for each database is provided in the supplementary material. The literature search was carried out on December 9, 2019. The search was updated on June 11, 2020.

\section{Study selection}

Two authors (AG, IR) independently screened the titles and abstracts. They met in person after having screened the first 50 abstracts to discuss challenges and uncertainties related to study selection. After completion of abstract screening, the interrater reliability was excellent (Cohen's k = 0.89). ${ }^{16}$ Afterwards, one author (AG) evaluated all full texts to determine eligibility for inclusion. The second author (IR) screened $10 \%(n=8)$ of all full texts, randomly selected, which also resulted in excellent interrater reliability (Cohen's k $=1.00$ ). When it was uncertain whether to include a full text, this was discussed with the 


\section{CHAPTER 6}

second author. Cross-referencing was used to determine if other relevant publications should be included.

\section{Charting of data}

One of the reviewing authors (AG) extracted and summarized the data from the included publications. A data extraction plan was piloted for applicability and completeness and discussed among the other authors. The following was included in the chart: study design, setting, study population, sample size, methodology, intervention type and comparator, outcomes, outcome measurements, analysis, characteristics of NPA, characteristics of neuropsychological feedback, framework for feedback, key findings related to neuropsychological feedback, and key findings related to aids in neuropsychological feedback. The main topics were analyzed (qualitative content approach) and thematically classified and narratively described. The first draft of topics was discussed among the authors until consensus was reached. Quantitative analyses were not conducted due to the diversity of studies and the descriptive nature of most studies.

\section{RESULTS}

The search yielded a total of 3,214 records; 2,173 remained after duplicates were removed. After screening the abstracts, 78 papers were evaluated for full text screening. A total of 34 papers were included, and five additional papers were identified through cross-referencing. The search was updated on June 11, 2020, which led to 84 extra records that were screened and three that underwent full text screening. Two papers were included from the updated search. Figure 1 shows the flowchart of the selection process. In this study, the findings from 41 papers are summarized using a narrative report. An overview of the characteristics and outcomes of these publications is described in Table 1. 


\section{CHAPTER 6}

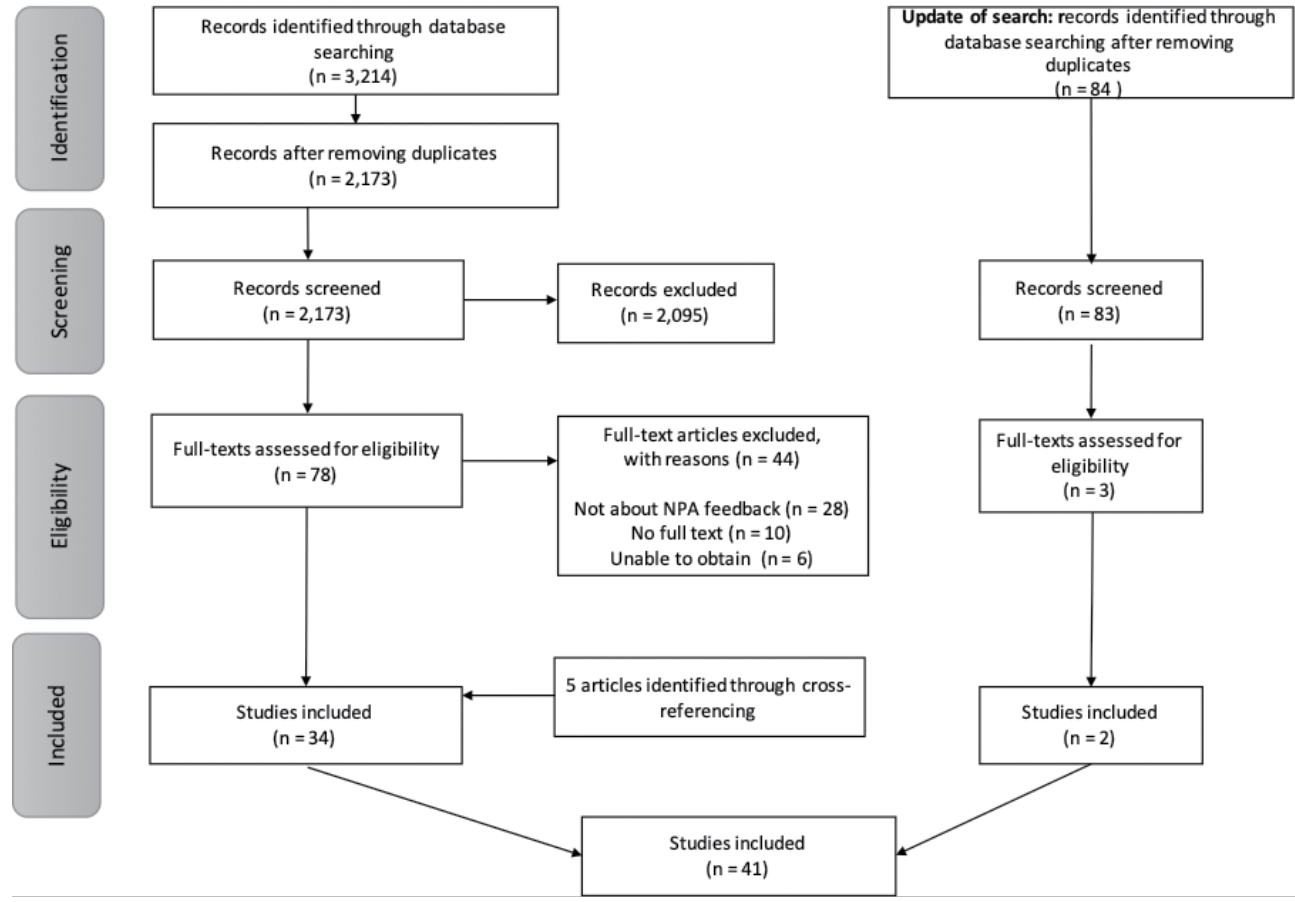

Figure 1. Flow diagram of current scoping review. 


\section{CHAPTER 6}

Table 1. Summary of included publications

\begin{tabular}{|c|c|c|c|c|}
\hline $\begin{array}{l}\text { Reference } \\
\text { Type of document }\end{array}$ & Purpose/aim & $\begin{array}{l}\text { Design (D) } \\
\text { Population (P) } \\
\text { Setting (S) }\end{array}$ & $\begin{array}{l}\text { Methods (M) } \\
\text { Intervention type (I) } \\
\text { Relevant outcomes }(\mathrm{O})\end{array}$ & $\begin{array}{l}\text { Relevant results/ } \\
\text { recommendations }\end{array}$ \\
\hline $\begin{array}{l}\text { Allen et al, } 1986 \\
\text { Position paper }\end{array}$ & $\begin{array}{l}\text { Advocate a collaborative } \\
\text { process approach to NPA } \\
\text { and provide guidelines for } \\
\text { discussing the results with } \\
\text { psychiatric patients and family } \\
\text { members }\end{array}$ & $\begin{array}{l}\text { P: Psychiatric patients and } \\
\text { family members }\end{array}$ & $N / A$ & $\begin{array}{l}\text { Advice to begin with in- } \\
\text { person feedback to evaluate } \\
\text { misunderstandings and emotional } \\
\text { reactions. }\end{array}$ \\
\hline $\begin{array}{l}\text { Arffa and Knapp, } \\
2008\end{array}$ & $\begin{array}{l}\text { Examine utility and value } \\
\text { ratings of NPA by measuring }\end{array}$ & $\begin{array}{l}\text { D: quantitative, descriptive } \\
\text { P: } 64 \text { parents of children with }\end{array}$ & $\begin{array}{l}\text { M: survey (70\% response rate), } \\
\text { medical records }\end{array}$ & $\begin{array}{l}\text { Feedback was given in-person, } 2 \\
\text { weeks to } 2 \text { months later. All received }\end{array}$ \\
\hline Research paper & $\begin{array}{l}\text { parent perceptions, as well as } \\
\text { determining whether testing } \\
\text { led to diagnostic changes or } \\
\text { recommendations }\end{array}$ & $\begin{array}{l}\text { complex neuro-developmental } \\
\text { and acquired neurological } \\
\text { disorders } \\
\text { S: neurodevelopmental } \\
\text { outpatient clinic }\end{array}$ & $\begin{array}{l}\text { O: satisfaction with NPA, } \\
\text { number of recommendations }\end{array}$ & $\begin{array}{l}\text { a written report. Greatest utility rating } \\
\text { of NPA was understanding strengths } \\
\text { and weaknesses. An average of } \\
6.5 \text { primary and } 11.1 \text { secondary } \\
\text { recommendations were given. }\end{array}$ \\
\hline Belciug, 2006 & Evaluate caregiver concerns & D: quantitative, descriptive & M: survey & Concerns related to safety, the future, \\
\hline Research paper & $\begin{array}{l}\text { after neuropsychological } \\
\text { feedback }\end{array}$ & $\begin{array}{l}\text { P: } 45 \text { caregivers of patients } \\
\text { with stroke }\end{array}$ & $\begin{array}{l}\text { O: concern regarding patient's } \\
\text { level of functioning after NPA } \\
\text { with feedback }\end{array}$ & $\begin{array}{l}\text { dealing with emotional aspects, } \\
\text { and what to do when the patient } \\
\text { cannot perform a task independently } \\
\text { were the most prominent after the } \\
\text { feedback session. }\end{array}$ \\
\hline
\end{tabular}




\section{CHAPTER 6}

\begin{tabular}{|c|c|c|c|c|}
\hline $\begin{array}{l}\text { Reference } \\
\text { Type of document }\end{array}$ & Purpose/aim & $\begin{array}{l}\text { Design (D) } \\
\text { Population (P) } \\
\text { Setting (S) }\end{array}$ & $\begin{array}{l}\text { Methods (M) } \\
\text { Intervention type (I) } \\
\text { Relevant outcomes }(\mathrm{O})\end{array}$ & $\begin{array}{l}\text { Relevant results/ } \\
\text { recommendations }\end{array}$ \\
\hline $\begin{array}{l}\text { Bennett-Levy et al, } \\
1994 \\
\text { Research paper }\end{array}$ & $\begin{array}{l}\text { To explore the consumer } \\
\text { experience with an NPA and } \\
\text { how neuropsychologists can } \\
\text { improve their quality of service }\end{array}$ & $\begin{array}{l}\text { D: quantitative, descriptive } \\
\text { P: } 129 \text { patients with various } \\
\text { diagnoses (most common } \\
\text { head injury and stroke) } \\
\text { S: } 5 \text { outpatient clinics ( } 2 \\
\text { hospitals, } 3 \text { rehabilitation } \\
\text { centers) }\end{array}$ & $\begin{array}{l}\text { M: survey ( } 51 \% \text { response rate) } \\
\text { O: experience with NPA }\end{array}$ & $\begin{array}{l}\text { One influence on NPA consumer } \\
\text { experience was whether they } \\
\text { received feedback and if this was } \\
\text { seen as useful. A total of } 32 \% \text { patients } \\
\text { did not receive feedback, and when } \\
\text { it was given, this was not always } \\
\text { remembered (30\%) or understood } \\
\text { ( } 24 \% \text { ). The majority found the } \\
\text { feedback session useful ( } 67 \% \text { ). Only } \\
26 \% \text { received feedback on paper. }\end{array}$ \\
\hline $\begin{array}{l}\text { Bodin et al, } 2007 \\
\text { Research paper }\end{array}$ & $\begin{array}{l}\text { Enhance understanding of } \\
\text { parent satisfaction with pediatric } \\
\text { neuropsychological evaluation }\end{array}$ & $\begin{array}{l}\text { D: quantitative, descriptive } \\
\text { P: } 117 \text { parents of children } \\
\text { with various diagnoses (most } \\
\text { common ADHD and epilepsy) } \\
\text { S: outpatient clinic (children's } \\
\text { hospital) }\end{array}$ & $\begin{array}{l}\text { M: survey ( } 35 \% \text { response rate) } \\
\text { O: satisfaction with NPA }\end{array}$ & $\begin{array}{l}\text { All received a written report. Overall, } \\
\text { parents were satisfied and } 54 \% \\
\text { found the session helpful. A total of } \\
68 \% \text { felt that it helped them address } \\
\text { their child's problems. The majority } \\
\text { agreed that feedback helped in } \\
\text { understanding the child's strengths } \\
\text { and suggested ways of addressing } \\
\text { problems. }\end{array}$ \\
\hline $\begin{array}{l}\text { Carone et al, } 2010 \\
\text { Opinion paper }\end{array}$ & $\begin{array}{l}\text { Present conceptual framework } \\
\text { for providing feedback } \\
\text { regarding invalid responding or } \\
\text { effort with recommendations for } \\
\text { how to handle complaints }\end{array}$ & P: any diagnostic group & $\mathrm{N} / \mathrm{A}$ & $\begin{array}{l}\text { In-person feedback model with three } \\
\text { phases (Table 3) }\end{array}$ \\
\hline
\end{tabular}




\section{CHAPTER 6}

\begin{tabular}{|c|c|c|c|c|}
\hline $\begin{array}{l}\text { Reference } \\
\text { Type of document }\end{array}$ & Purpose/aim & $\begin{array}{l}\text { Design (D) } \\
\text { Population (P) } \\
\text { Setting (S) }\end{array}$ & $\begin{array}{l}\text { Methods (M) } \\
\text { Intervention type (I) } \\
\text { Relevant outcomes }(\mathrm{O})\end{array}$ & $\begin{array}{l}\text { Relevant results/ } \\
\text { recommendations }\end{array}$ \\
\hline $\begin{array}{l}\text { Carone et al, } 2013 \\
\text { Opinion paper }\end{array}$ & $\begin{array}{l}\text { Review and update symptom } \\
\text { validity feedback model and } \\
\text { describe feedback approach } \\
\text { with patients reporting with } \\
\text { persisting symptoms after MTBI }\end{array}$ & P: MTBI patients & $\mathrm{N} / \mathrm{A}$ & $\begin{array}{l}\text { In-person feedback model with } \\
\text { three phases with additional tips for } \\
\text { patients with MTBI (Table 3) }\end{array}$ \\
\hline $\begin{array}{l}\text { Carone et al, } 2017 \\
\text { Opinion paper }\end{array}$ & $\begin{array}{l}\text { Present a feedback model for } \\
\text { patients who are not reassured } \\
\text { by feedback because they } \\
\text { blame external factors }\end{array}$ & $\begin{array}{l}\text { P: patients with high level of } \\
\text { cognitive complaints, but } \\
\text { normal test performance }\end{array}$ & $N / A$ & $\begin{array}{l}\text { In-person feedback model with three } \\
\text { phases (Table 3) }\end{array}$ \\
\hline $\begin{array}{l}\text { Cheung et al, } 2014 \\
\text { Research paper }\end{array}$ & $\begin{array}{l}\text { Explored parent and } \\
\text { teacher understanding of } \\
\text { neuropsychology reports, } \\
\text { implementation rates for } \\
\text { recommendations and their } \\
\text { perceived effectiveness. Barriers } \\
\text { were also evaluated }\end{array}$ & $\begin{array}{l}\text { D: qualitative } \\
\text { P: } 17 \text { parents of childhood } \\
\text { who had a brain tumor and } 8 \\
\text { teachers } \\
\text { S: children's hospital }\end{array}$ & $\begin{array}{l}\text { M: semi-structured interviews } \\
\text { O: perceived effectiveness } \\
\text { of report, difficulty } \\
\text { of implementing } \\
\text { recommendations }\end{array}$ & $\begin{array}{l}\text { Feedback was given in-person, all } \\
\text { received written report. Majority of } \\
\text { parents found the reports clear and } \\
\text { comprehensive. Recommendations } \\
\text { were evaluated as effective and easy } \\
\text { to implement. A need for a more } \\
\text { practical translation to daily life, a } \\
\text { glossary for terminology, and a follow- } \\
\text { up consultation was expressed. }\end{array}$ \\
\hline $\begin{array}{l}\text { Clement et al, } 2001 \\
\text { Opinion paper }\end{array}$ & $\begin{array}{l}\text { Describe use of a } \\
\text { neuropsychology telemedicine } \\
\text { clinic in an army medical center. }\end{array}$ & $\begin{array}{l}\text { P: patients with neurological } \\
\text { disorders or brain injury } \\
\text { S: army medical center }\end{array}$ & $N / A$ & $\begin{array}{l}\text { Experiences with feedback via } \\
\text { telemedicine were positive in areas } \\
\text { where these services otherwise } \\
\text { would not be available. }\end{array}$ \\
\hline
\end{tabular}




\section{CHAPTER 6}

\begin{tabular}{|c|c|c|c|c|}
\hline $\begin{array}{l}\text { Reference } \\
\text { Type of document }\end{array}$ & Purpose/aim & $\begin{array}{l}\text { Design }(\mathrm{D}) \\
\text { Population }(\mathrm{P}) \\
\text { Setting }(\mathrm{S})\end{array}$ & $\begin{array}{l}\text { Methods (M) } \\
\text { Intervention type (I) } \\
\text { Relevant outcomes }(\mathrm{O})\end{array}$ & $\begin{array}{l}\text { Relevant results/ } \\
\text { recommendations }\end{array}$ \\
\hline $\begin{array}{l}\text { Connery et al, } 2016 \\
\text { Research paper }\end{array}$ & $\begin{array}{l}\text { Examine impact of } \\
\text { neuropsychological } \\
\text { consultation when invalid } \\
\text { performance has been } \\
\text { identified in a pediatric } \\
\text { population. Additionally, provide } \\
\text { a conceptual feedback model }\end{array}$ & $\begin{array}{l}\text { D: quantitative, non- } \\
\text { randomized } \\
\text { P: } 70 \text { parents of children with } \\
\text { history of MTBI } \\
\text { S: outpatient pediatric } \\
\text { concussion program }\end{array}$ & $\begin{array}{l}\text { M: survey } \\
\text { l: comparing group with } \\
\text { noncredible effort and } \\
\text { feedback model }(n=9) \text { to } \\
\text { those with no validity concerns } \\
\text { present and feedback care as } \\
\text { usual ( } n=61 \text { ) } \\
\text { O: post-concussive symptom } \\
\text { reduction, parent satisfaction } \\
\text { with NPA }\end{array}$ & $\begin{array}{l}\text { In both the group with the feedback } \\
\text { model (noncredible effort) and the } \\
\text { care as usual group (credible effort) } \\
\text { similarly high levels of satisfaction } \\
\text { were found. In the noncredible group, } \\
\text { a greater reduction of self-reported } \\
\text { symptoms was found after feedback } \\
\text { compared to children with a credible } \\
\text { performance. }\end{array}$ \\
\hline $\begin{array}{l}\text { Crosson, } 2000 \\
\text { Book chapter }\end{array}$ & $\begin{array}{l}\text { Describe applications of } \\
\text { NPA results and summarizes } \\
\text { problems arising when giving } \\
\text { neuropsychological feedback } \\
\text { and principles to use against } \\
\text { these problems }\end{array}$ & Not specified & $\mathrm{N} / \mathrm{A}$ & $\begin{array}{l}\text { Describes potential pitfalls and } \\
\text { solutions for delivering in-person } \\
\text { feedback (Table 3). }\end{array}$ \\
\hline $\begin{array}{l}\text { Evans et al, } 2019 \\
\text { Position paper }\end{array}$ & $\begin{array}{l}\text { Highlight current challenges } \\
\text { and barriers in composing } \\
\text { neuropsychological reports and } \\
\text { communicating key findings to } \\
\text { Spanish speaking caregivers of } \\
\text { school-aged Latino children }\end{array}$ & $\begin{array}{l}\text { P: Spanish speaking caregivers } \\
\text { of school-aged Latino children }\end{array}$ & $\mathrm{N} / \mathrm{A}$ & $\begin{array}{l}\text { Recommendations for report writing, } \\
\text { such as language translation and } \\
\text { considering both cultural and } \\
\text { linguistic differences. }\end{array}$ \\
\hline
\end{tabular}




\section{CHAPTER 6}

\begin{tabular}{|c|c|c|c|c|}
\hline $\begin{array}{l}\text { Reference } \\
\text { Type of document }\end{array}$ & Purpose/aim & $\begin{array}{l}\text { Design (D) } \\
\text { Population (P) } \\
\text { Setting (S) }\end{array}$ & $\begin{array}{l}\text { Methods (M) } \\
\text { Intervention type (I) } \\
\text { Relevant outcomes }(\mathrm{O})\end{array}$ & $\begin{array}{l}\text { Relevant results/ } \\
\text { recommendations }\end{array}$ \\
\hline $\begin{array}{l}\text { Fallows and } \\
\text { Hilsabeck, } 2013 \\
\text { Research paper }\end{array}$ & $\begin{array}{l}\text { To see whether supplementing } \\
\text { oral feedback with written } \\
\text { information leads to greater } \\
\text { retention of information and } \\
\text { improved adherence to } \\
\text { recommendations }\end{array}$ & $\begin{array}{l}\text { D: quantitative, randomized } \\
\text { P: } 66 \text { veterans with cognitive or } \\
\text { no cognitive disorders } \\
\text { S: veterans administration in a } \\
\text { neuropsychology clinic }\end{array}$ & $\begin{array}{l}\text { M: structured interview after } \\
\text { feedback and } 1 \text { month later by } \\
\text { phone } \\
\text { l: group with oral feedback } \\
\text { ( } \mathrm{n}=36 \text { ) and group with oral } \\
\text { feedback + written information } \\
\text { ( } \mathrm{n}=30 \text { ) } \\
\text { O: retention of diagnostic } \\
\text { information, adherence to } \\
\text { treatment recommendations }\end{array}$ & $\begin{array}{l}\text { Group with both in-person feedback } \\
\text { and supplemental written letter freely } \\
\text { recalled more recommendations one } \\
\text { month after feedback compared to } \\
\text { the no letter group. Overall recall of } \\
\text { recommendations and diagnostic } \\
\text { information (with exception of } \\
\text { knowing they had cognitive } \\
\text { problems) was low. }\end{array}$ \\
\hline $\begin{array}{l}\text { Farmer and Brazeal, } \\
1998 \\
\text { Research paper }\end{array}$ & $\begin{array}{l}\text { Evaluate reaction of parents to } \\
\text { their child's NPA, specifically } \\
\text { related to their parent } \\
\text { perceptions of their child and } \\
\text { their ability to cope with their } \\
\text { child's disease. }\end{array}$ & $\begin{array}{l}\text { D: quantitative, } \\
\text { descriptive } \\
\text { P: } 55 \text { parents of children } \\
\text { with neurodevelopmental } \\
\text { problems } \\
\text { S: outpatient clinic (hospital) }\end{array}$ & $\begin{array}{l}\text { M: survey ( } 47 \% \text { response rate) } \\
\text { O: effect of NPA on parent } \\
\text { perceptions of their child, } \\
\text { coping with child's disability, } \\
\text { adequacy of NPA }\end{array}$ & $\begin{array}{l}25 \% \text { of parents found the in-person } \\
\text { feedback session most helpful of } \\
\text { NPA. Majority evaluated the report } \\
\text { as most useful. Feedback increased } \\
\text { understanding of child's strengths } \\
\text { and weaknesses and helped make } \\
\text { a difference for their child. Strongest } \\
\text { predictor of NPA satisfaction were } \\
\text { perceptions of professional's concern, } \\
\text { technical competence, and rating of } \\
\text { recommendations. }\end{array}$ \\
\hline
\end{tabular}




\section{CHAPTER 6}

\begin{tabular}{|c|c|c|c|c|}
\hline $\begin{array}{l}\text { Reference } \\
\text { Type of document }\end{array}$ & Purpose/aim & $\begin{array}{l}\text { Design (D) } \\
\text { Population (P) } \\
\text { Setting (S) } \\
\end{array}$ & $\begin{array}{l}\text { Methods (M) } \\
\text { Intervention type (I) } \\
\text { Relevant outcomes }(\mathrm{O})\end{array}$ & $\begin{array}{l}\text { Relevant results/ } \\
\text { recommendations }\end{array}$ \\
\hline $\begin{array}{l}\text { Foran et al, } 2016 \\
\text { Research paper }\end{array}$ & $\begin{array}{l}\text { Develop and pilot a measure } \\
\text { of patient satisfaction that } \\
\text { encompasses themes, activities, } \\
\text { settings and interactions } \\
\text { specific to NPA process }\end{array}$ & $\begin{array}{l}\text { D: mixed-methods } \\
\text { P: } 81 \text { patients with various } \\
\text { diagnosis (most common } \\
\text { chronic illness, psychiatric } \\
\text { diagnosis or traumatic injury) } \\
\text { S: neuropsychology outpatient } \\
\text { clinic (hospital) }\end{array}$ & $\begin{array}{l}\text { M: systematic search, focus } \\
\text { groups, pilot study } \\
\text { O: satisfaction with NPA }\end{array}$ & $\begin{array}{l}\text { Overall, high satisfaction with NPA } \\
\text { (79\%). Satisfaction with testing (85\%) } \\
\text { higher than pre-assessment (77\%) } \\
\text { and feedback (68\%). A total of } 44 \% \\
\text { patients received feedback from a } \\
\text { neuropsychologist, 38\% from a third } \\
\text { party and } 18 \% \text { no feedback. Critique } \\
\text { on feedback was related to difficulty } \\
\text { of understanding the information and } \\
\text { emotional impact of diagnosis. }\end{array}$ \\
\hline $\begin{array}{l}\text { Gass and Brown, } \\
1992 \\
\text { Opinion paper }\end{array}$ & $\begin{array}{l}\text { General framework for } \\
\text { presenting feedback is } \\
\text { described with an emphasis } \\
\text { on techniques designed to } \\
\text { maximize patient benefit. } \\
\text { Special issues are discussed }\end{array}$ & P: patients with brain injury & $\mathrm{N} / \mathrm{A}$ & $\begin{array}{l}\text { In-person feedback model with six } \\
\text { phases (Table 3) }\end{array}$ \\
\hline $\begin{array}{l}\text { Gorske, } 2007 \\
\text { Position paper }\end{array}$ & $\begin{array}{l}\text { Present a humanistic model for } \\
\text { providing neuropsychological } \\
\text { feedback }\end{array}$ & Not specified & $N / A$ & $\begin{array}{l}\text { In-person feedback model with five } \\
\text { phases (Table 3) }\end{array}$ \\
\hline $\begin{array}{l}\text { Gorske and Smith, } \\
2009 \\
\text { Book }\end{array}$ & $\begin{array}{l}\text { Describe a client-centered } \\
\text { approach in using NPA } \\
\text { feedback therapeutically. }\end{array}$ & Not specified & $N / A$ & $\begin{array}{l}\text { In-person feedback model with five } \\
\text { phases (Table 3) }\end{array}$ \\
\hline
\end{tabular}




\section{CHAPTER 6}

\begin{tabular}{|c|c|c|c|c|}
\hline $\begin{array}{l}\text { Reference } \\
\text { Type of document }\end{array}$ & Purpose/aim & $\begin{array}{l}\text { Design (D) } \\
\text { Population (P) } \\
\text { Setting (S) }\end{array}$ & $\begin{array}{l}\text { Methods (M) } \\
\text { Intervention type (I) } \\
\text { Relevant outcomes (O) }\end{array}$ & $\begin{array}{l}\text { Relevant results/ } \\
\text { recommendations }\end{array}$ \\
\hline $\begin{array}{l}\text { Green, } 2000 \\
\text { Book chapter }\end{array}$ & $\begin{array}{l}\text { Discusses the final stage of NPA, } \\
\text { provision of feedback to the } \\
\text { patient and others, and planning } \\
\text { of treatment interventions and } \\
\text { follow-up services. }\end{array}$ & Not specified & $N / A$ & $\begin{array}{l}\text { Recommendations given for in- } \\
\text { person feedback, such as that it } \\
\text { is sometimes more appropriate } \\
\text { to receive feedback from another } \\
\text { professional or to ensure that the } \\
\text { information is understood and } \\
\text { accepted. }\end{array}$ \\
\hline $\begin{array}{l}\text { Griffin and Christie, } \\
2008 \\
\text { Opinion paper }\end{array}$ & $\begin{array}{l}\text { Discusses current approaches } \\
\text { in NPA of children }\end{array}$ & $\begin{array}{l}\text { P: children } \\
\text { S: hospital- or community- } \\
\text { based }\end{array}$ & $\mathrm{N} / \mathrm{A}$ & $\begin{array}{l}\text { An audit showed that most } \\
\text { families found the report difficult } \\
\text { to understand or unhelpful. } \\
\text { Recommendations given for } \\
\text { in-person feedback, such as } \\
\text { communicating in an understandable } \\
\text { manner and sending a written report } \\
\text { with creative/child-friendly language. }\end{array}$ \\
\hline $\begin{array}{l}\text { Gruters et al, } 2020 \\
\text { Research paper }\end{array}$ & $\begin{array}{l}\text { Gain insight into experiences } \\
\text { of patients and family members } \\
\text { with an NPA and diagnostic } \\
\text { disclosure at the memory clinic }\end{array}$ & $\begin{array}{l}\text { D: qualitative } \\
\text { P: } 14 \text { memory clinic patients } \\
\text { and } 13 \text { family members } \\
\text { S: three hospital-based clinics }\end{array}$ & $\begin{array}{l}\text { M: focus groups } \\
\text { O: experiences with NPA and } \\
\text { diagnostic disclosure }\end{array}$ & $\begin{array}{l}\text { The following themes were identified: } \\
\text { uncertainty, early diagnostic } \\
\text { paradox (both positive and negative } \\
\text { experiences with NPA and diagnostic } \\
\text { disclosure) and knowledge utilization } \\
\text { (low information retention). }\end{array}$ \\
\hline
\end{tabular}




\section{CHAPTER 6}

\begin{tabular}{|c|c|c|c|c|}
\hline $\begin{array}{l}\text { Reference } \\
\text { Type of document }\end{array}$ & Purpose/aim & $\begin{array}{l}\text { Design (D) } \\
\text { Population (P) } \\
\text { Setting (S) }\end{array}$ & $\begin{array}{l}\text { Methods (M) } \\
\text { Intervention type (I) } \\
\text { Relevant outcomes }(\mathrm{O})\end{array}$ & $\begin{array}{l}\text { Relevant results/ } \\
\text { recommendations }\end{array}$ \\
\hline $\begin{array}{l}\text { Holst et al, } 2009 \\
\text { Research paper }\end{array}$ & $\begin{array}{l}\text { Investigate patient's } \\
\text { recollections of satisfaction with } \\
\text { feedback after an NPA. }\end{array}$ & $\begin{array}{l}\text { D: quantitative, } \\
\text { descriptive } \\
\text { P: } 32 \text { patients with ADHD or } \\
\text { autism spectrum disorder } \\
\text { S: } 2 \text { psychiatric outpatient } \\
\text { clinics }\end{array}$ & $\begin{array}{l}\text { M: survey } \\
\text { O: satisfaction with feedback, } \\
\text { self-perceived health, basic and } \\
\text { earning self-esteem }\end{array}$ & $\begin{array}{l}\text { Low levels of in-person feedback was } \\
\text { related to low self-esteem. The more } \\
\text { satisfied group had better physical } \\
\text { and mental health, felt confirmed by } \\
\text { the examiner, and had higher basic } \\
\text { self-esteem. }\end{array}$ \\
\hline $\begin{array}{l}\text { Kirkwood et al, } 2016 \\
\text { Research paper }\end{array}$ & $\begin{array}{l}\text { Examine efficacy of a } \\
\text { neuropsychological } \\
\text { consultation as intervention } \\
\text { for youth with persistent post- } \\
\text { concussive symptoms following } \\
\text { mild TBI }\end{array}$ & $\begin{array}{l}\text { D: quantitative, non- } \\
\text { randomized } \\
\text { P: } 80 \text { children with MTBI and } \\
\text { their parents } \\
\text { S: outpatient pediatric } \\
\text { concussion program }\end{array}$ & $\begin{array}{l}\text { M: survey } 1 \text { week before and } 1 \\
\text { and } 3 \text { months after NPA } \\
\text { I: neuropsychological } \\
\text { consultation with direct } \\
\text { feedback } \\
\text { O: post-concussive symptom } \\
\text { rating }\end{array}$ & $\begin{array}{l}\text { Significant decrease in post } \\
\text { concussive symptoms } 1 \text { week and } \\
3 \text { months after in-person feedback } \\
\text { in both parents and children. All } \\
\text { received a summary of the report. }\end{array}$ \\
\hline $\begin{array}{l}\text { Kirkwood et al, } 2017 \\
\text { Research paper }\end{array}$ & $\begin{array}{l}\text { Examine parent satisfaction } \\
\text { with neuropsychological } \\
\text { consultation following MTBI in } \\
\text { school-age children }\end{array}$ & $\begin{array}{l}\text { D: quantitative, descriptive } \\
\text { P: } 71 \text { parents of children with } \\
\text { MTBI } \\
\text { S: outpatient pediatric } \\
\text { concussion program }\end{array}$ & $\begin{array}{l}\text { M: survey } \\
\text { O: satisfaction with NPA }\end{array}$ & $\begin{array}{l}\text { Majority satisfied with NPA. A total of } \\
93 \% \text { found in-person feedback helpful } \\
\text { and the majority thought feedback } \\
\text { helped them understand problems } \\
\text { (88\%), strengths (86\%), and ways to } \\
\text { address problems (72\%). }\end{array}$ \\
\hline $\begin{array}{l}\text { Lanca et al, } 2019 \\
\text { Research paper }\end{array}$ & $\begin{array}{l}\text { Examine self-reported cognitive } \\
\text { and psychiatric symptoms, } \\
\text { self-efficacy, motivation, and } \\
\text { satisfaction following NPA with } \\
\text { interventional feedback session }\end{array}$ & $\begin{array}{l}\text { D: quantitative, descriptive } \\
\text { P: } 31 \text { patients with ADHD or } \\
\text { mood disorders } \\
\text { S: neuropsychology outpatient } \\
\text { clinic (community hospital) }\end{array}$ & $\begin{array}{l}\text { M: survey } \\
\text { O: satisfaction with NPA, } \\
\text { psychiatric and cognitive } \\
\text { symptoms, perceived memory } \\
\text { ability, self-efficacy }\end{array}$ & $\begin{array}{l}\text { One month after in-person feedback, } \\
\text { reduction in psychiatric and cognitive } \\
\text { symptoms was reported, as well } \\
\text { as improved cognition and self- } \\
\text { efficacy. Furthermore, high levels of } \\
\text { satisfaction with NPA were reported. }\end{array}$ \\
\hline
\end{tabular}


CHAPTER 6

\begin{tabular}{|c|c|c|c|c|}
\hline $\begin{array}{l}\text { Reference } \\
\text { Type of document }\end{array}$ & Purpose/aim & $\begin{array}{l}\text { Design (D) } \\
\text { Population (P) } \\
\text { Setting (S) }\end{array}$ & $\begin{array}{l}\text { Methods (M) } \\
\text { Intervention type (I) } \\
\text { Relevant outcomes }(\mathrm{O})\end{array}$ & $\begin{array}{l}\text { Relevant results/ } \\
\text { recommendations }\end{array}$ \\
\hline $\begin{array}{l}\text { Longley et al, } 2012 \\
\text { Protocol }\end{array}$ & $\begin{array}{l}\text { (1) investigate psychological } \\
\text { benefit of NPA with feedback } \\
\text { for patients with MS and their } \\
\text { main caregivers following the } \\
\text { feedback session and } 2 \text { months } \\
\text { later } \\
\text { (2) identify characteristics of } \\
\text { patients and caregivers who will } \\
\text { most benefit from assessment } \\
\text { with feedback }\end{array}$ & $\begin{array}{l}\text { P: patients with MS } \\
\text { S: MS center }\end{array}$ & $\begin{array}{l}\text { M: survey } \\
\text { I: NPA + feedback, control } \\
\text { group sham waiting list } \\
\text { O: knowledge of cognitive } \\
\text { profile, coping }\end{array}$ & $\begin{array}{l}\text { Protocol for randomized controlled } \\
\text { trial (study results to date yet } \\
\text { unpublished; recruitment status: } \\
\text { stopped early). }\end{array}$ \\
\hline $\begin{array}{l}\text { Lopez et al, } 2008 \\
\text { Research paper }\end{array}$ & $\begin{array}{l}\text { Outline a short intervention } \\
\text { (three-session assessment and } \\
\text { feedback module that translate } \\
\text { NPA findings to daily life and } \\
\text { eating symptoms) designed to } \\
\text { identify and address information } \\
\text { processing bias (poor set- } \\
\text { shifting or strong detail focus) in } \\
\text { patients with anorexia nervosa }\end{array}$ & $\begin{array}{l}\text { D: qualitative (case study) } \\
\text { P: } 2 \text { patients with anorexia } \\
\text { nervosa } \\
\text { S: outpatient clinic }\end{array}$ & $N / A$ & $\begin{array}{l}\text { In-person feedback led to adapted } \\
\text { behavior in one patient and stopped } \\
\text { rapid weight loss in the other patient. }\end{array}$ \\
\hline
\end{tabular}




\section{CHAPTER 6}

\begin{tabular}{|c|c|c|c|c|}
\hline $\begin{array}{l}\text { Reference } \\
\text { Type of document }\end{array}$ & Purpose/aim & $\begin{array}{l}\text { Design (D) } \\
\text { Population (P) } \\
\text { Setting (S) }\end{array}$ & $\begin{array}{l}\text { Methods (M) } \\
\text { Intervention type (I) } \\
\text { Relevant outcomes (O) }\end{array}$ & $\begin{array}{l}\text { Relevant results/ } \\
\text { recommendations }\end{array}$ \\
\hline $\begin{array}{l}\text { Malla et al, } 1997 \\
\text { Research paper }\end{array}$ & $\begin{array}{l}\text { Determine whether detailed } \\
\text { assessment of cognitive } \\
\text { functions in people suffering } \\
\text { from psychotic disorder can } \\
\text { assist in their psychosocial } \\
\text { rehabilitation while they are } \\
\text { living in the community }\end{array}$ & $\begin{array}{l}\text { D: qualitative (case study) } \\
\text { P: } 3 \text { patients with } \\
\text { schizophrenia } \\
\text { S: community treatment } \\
\text { program }\end{array}$ & $\mathrm{N} / \mathrm{A}$ & $\begin{array}{l}\text { In-person feedback in three patients } \\
\text { led to improved outcomes by } \\
\text { emphasizing strengths. In one patient } \\
\text { it also led to improved feelings of self- } \\
\text { esteem. }\end{array}$ \\
\hline $\begin{array}{l}\text { Martin and } \\
\text { Schroeder, } 2020 \\
\text { Research paper }\end{array}$ & $\begin{array}{l}\text { Present survey results on how } \\
\text { neuropsychologists approach } \\
\text { feedback about invalid testing } \\
\text { across various clinical settings. }\end{array}$ & $\begin{array}{l}\text { D: quantitative, descriptive } \\
\text { P: } 209 \text { clinical } \\
\text { neuropsychologists } \\
\text { S: various settings }\end{array}$ & $\begin{array}{l}\text { M: survey } \\
\text { O: base rate of invalidity, } \\
\text { present three clinical case } \\
\text { vignettes and inquire how they } \\
\text { would give feedback }\end{array}$ & $\begin{array}{l}\text { The majority (98\%) of psychologists } \\
\text { would include description of invalid } \\
\text { findings and provide explanations } \\
\text { (67\%). There was little agreement on } \\
\text { the approach in delivering feedback } \\
\text { and what the goal was of the } \\
\text { feedback session. }\end{array}$ \\
\hline $\begin{array}{l}\text { Meth et al, } 2016 \\
\text { Research paper }\end{array}$ & $\begin{array}{l}\text { Test a simple intervention } \\
\text { (providing supplemental } \\
\text { letter) in communicating } \\
\text { neuropsychological feedback. } \\
\text { Additionally, investigates the } \\
\text { impact of including caregivers in } \\
\text { the feedback session to explore } \\
\text { whether differences exist in } \\
\text { recall for recommendation } \\
\text { between patients and family } \\
\text { members }\end{array}$ & $\begin{array}{l}\text { D: quantitative, randomized } \\
\text { P: } 79 \text { patients with various } \\
\text { diagnosis (most common } \\
\text { psychiatric diagnosis, mild } \\
\text { cognitive impairment, } \\
\text { dementia) and } 36 \text { caregivers } \\
\text { S: outpatients from } \\
\text { neuropsychology lab } \\
\text { (hospital) }\end{array}$ & $\begin{array}{l}\text { M: telephone interview } 7 \text { weeks } \\
\text { after NPA } \\
\text { l: group with letter }(n=35) \text { and } \\
\text { group with no-letter }(n=44) \\
\text { O: retention and adherence to } \\
\text { recommendations }\end{array}$ & $\begin{array}{l}\text { Recall of recommendations was } \\
\text { better in caregivers (not in patients) } \\
\text { in the group with in-person and } \\
\text { a supplemental letter compared } \\
\text { to no letter. Overall level of } \\
\text { recommendations remained low. No } \\
\text { differences in adherences were found } \\
\text { between the two groups. }\end{array}$ \\
\hline
\end{tabular}




\section{CHAPTER 6}

\begin{tabular}{|c|c|c|c|c|}
\hline $\begin{array}{l}\text { Reference } \\
\text { Type of document }\end{array}$ & Purpose/aim & $\begin{array}{l}\text { Design (D) } \\
\text { Population (P) } \\
\text { Setting (S) }\end{array}$ & $\begin{array}{l}\text { Methods (M) } \\
\text { Intervention type (I) } \\
\text { Relevant outcomes }(\mathrm{O})\end{array}$ & $\begin{array}{l}\text { Relevant results/ } \\
\text { recommendations }\end{array}$ \\
\hline $\begin{array}{l}\text { Meth et al, } 2019 \\
\text { Research paper }\end{array}$ & $\begin{array}{l}\text { Identify types of } \\
\text { recommendations that } \\
\text { neuropsychologists provide to } \\
\text { patients, and determine which } \\
\text { specific recommendations are } \\
\text { most and least consistently } \\
\text { given to patients across and } \\
\text { within different diagnostic } \\
\text { populations }\end{array}$ & $\begin{array}{l}\text { D: quantitative, descriptive } \\
\text { P: } 309 \text { licensed clinical } \\
\text { psychologists }\end{array}$ & $\begin{array}{l}\text { M: survey } \\
\text { O: type/frequency of } \\
\text { recommendations }\end{array}$ & $\begin{array}{l}\text { Most given recommendations across } \\
\text { diagnoses were compensatory } \\
\text { strategies, address cognitive } \\
\text { deficits and to improve health. } \\
\text { Psychologists were more likely to } \\
\text { give recommendations that could be } \\
\text { carried out without help from external } \\
\text { sources. }\end{array}$ \\
\hline $\begin{array}{l}\text { Postal and } \\
\text { Armstrong, } 2013 \\
\text { Book }\end{array}$ & $\begin{array}{l}\text { Reflect on how to communicate } \\
\text { neuropsychological assessment } \\
\text { results. }\end{array}$ & $\begin{array}{l}\text { D: qualitative } \\
\text { P: } 82 \text { psychologists }\end{array}$ & M: semi-structured interviews & $\begin{array}{l}\text { Framework given on how to make } \\
\text { in-person feedback stick (Table 3). } \\
\text { Furthermore, concrete examples } \\
\text { are given on how to give feedback } \\
\text { on specific aspects based on the } \\
\text { interviews with the psychologists. }\end{array}$ \\
\hline $\begin{array}{l}\text { Pritchard et al, } \\
2014 \\
\text { Research paper }\end{array}$ & $\begin{array}{l}\text { Preliminary evaluation of added } \\
\text { value associated with NPA in the } \\
\text { identification and treatment of } \\
\text { ADHD in youth }\end{array}$ & $\begin{array}{l}\text { D: quantitative, non- } \\
\text { randomized } \\
\text { P: } 188 \text { parents of children with } \\
\text { ADHD } \\
\text { S: neuropsychology outpatient } \\
\text { clinic (hospital) }\end{array}$ & $\begin{array}{l}\text { M: survey after NPA and after } 5 \\
\text { months } \\
\text { I: children who recently } \\
\text { received NPA (NP+) and those } \\
\text { who have not (NP-) } \\
\text { O: parent rating of child } \\
\text { symptoms, parent rating of } \\
\text { child quality of life, satisfaction } \\
\text { with NPA }\end{array}$ & $\begin{array}{l}\text { Both patients with and without NPA } \\
\text { reported significant improvements in } \\
\text { the child's behavioral and emotional } \\
\text { symptoms. Feedback was seen as } \\
\text { helpful and satisfaction with NPA was } \\
\text { high. }\end{array}$ \\
\hline
\end{tabular}


CHAPTER 6

\begin{tabular}{|c|c|c|c|c|}
\hline $\begin{array}{l}\text { Reference } \\
\text { Type of document }\end{array}$ & Purpose/aim & $\begin{array}{l}\text { Design (D) } \\
\text { Population (P) } \\
\text { Setting (S) }\end{array}$ & $\begin{array}{l}\text { Methods (M) } \\
\text { Intervention type (I) } \\
\text { Relevant outcomes (O) }\end{array}$ & $\begin{array}{l}\text { Relevant results/ } \\
\text { recommendations }\end{array}$ \\
\hline $\begin{array}{l}\text { Quillen et al, } 2011 \\
\text { Research paper }\end{array}$ & $\begin{array}{l}\text { To determine whether } \\
\text { neuropsychological } \\
\text { recommendations were } \\
\text { implemented by families and } \\
\text { whether the suggestions } \\
\text { improved the survivor's quality } \\
\text { of life (as perceived by parents) } \\
\text { and school experience }\end{array}$ & $\begin{array}{l}\text { D: quantitative, descriptive } \\
\text { P: } 20 \text { parents of childhood } \\
\text { history of cancer } \\
\text { S: oncology center (hospital) }\end{array}$ & $\begin{array}{l}\text { M: survey } \\
\text { O: implementation of } \\
\text { recommendations, } \\
\text { improvement of parent } \\
\text { perceived child quality of life }\end{array}$ & $\begin{array}{l}\text { Most recommendations were } \\
\text { academic or educational in nature } \\
\text { and } 48 \% \text { were followed-up. All } \\
\text { parents at least followed one } \\
\text { recommendation, but adherence } \\
\text { ranged between 16-100\%. A total of } \\
97 \% \text { of the recommendations were } \\
\text { seen as helpful in improving parent- } \\
\text { perceived child quality of life. }\end{array}$ \\
\hline $\begin{array}{l}\text { Rosado et al, } 2018 \\
\text { Research paper }\end{array}$ & $\begin{array}{l}\text { Examine the impact of } \\
\text { patient feedback regarding } \\
\text { neuropsychological testing on } \\
\text { patient outcomes }\end{array}$ & $\begin{array}{l}\text { D: quantitative, non- } \\
\text { randomized } \\
\text { P: } 84 \text { patients with various } \\
\text { diagnosis }\end{array}$ & $\begin{array}{l}\text { M: survey at baseline and 6-8 } \\
\text { weeks later semi-structured } \\
\text { interview } \\
\text { l: patients who attended } \\
\text { feedback sessions ( } \mathrm{n}=49 \text { ) } \\
\text { versus those who did not } \\
\text { receive feedback ( } \mathrm{n}=35 \text { ) } \\
\text { O: perceived stress, } \\
\text { understanding of condition, } \\
\text { coping }\end{array}$ & $\begin{array}{l}\text { Patient with in-person feedback } \\
\text { had increased quality of life, } \\
\text { understanding of condition, ability to } \\
\text { cope with condition compared to the } \\
\text { group without feedback. }\end{array}$ \\
\hline
\end{tabular}


CHAPTER 6

\begin{tabular}{|c|c|c|c|c|}
\hline $\begin{array}{l}\text { Reference } \\
\text { Type of document }\end{array}$ & Purpose/aim & $\begin{array}{l}\text { Design (D) } \\
\text { Population (P) } \\
\text { Setting (S) }\end{array}$ & $\begin{array}{l}\text { Methods (M) } \\
\text { Intervention type (I) } \\
\text { Relevant outcomes }(\mathrm{O})\end{array}$ & $\begin{array}{l}\text { Relevant results/ } \\
\text { recommendations }\end{array}$ \\
\hline $\begin{array}{l}\text { Ruppert and Attix, } \\
2014 \\
\text { Book chapter }\end{array}$ & $\begin{array}{l}\text { Brief summary of purposes and } \\
\text { recommended practices for } \\
\text { providing } \\
\text { feedback on cognitive } \\
\text { test results to patients and } \\
\text { caregivers }\end{array}$ & $\begin{array}{l}\text { P: patients with a cognitive } \\
\text { impairment }\end{array}$ & $\mathrm{N} / \mathrm{A}$ & $\begin{array}{l}\text { Recommendations given for } \\
\text { in-person feedback, such as } \\
\text { clear communication, querying } \\
\text { understanding throughout session, } \\
\text { allowing patients/family to take notes, } \\
\text { and provide written materials. }\end{array}$ \\
\hline $\begin{array}{l}\text { Stimmel et al, } 2019 \\
\text { Research paper }\end{array}$ & $\begin{array}{l}\text { Explore rates of adherence } \\
\text { to neuropsychological } \\
\text { recommendations, reasons for } \\
\text { nonadherence, and the effect } \\
\text { of oral (phone call) and written } \\
\text { feedback over written feedback } \\
\text { alone }\end{array}$ & $\begin{array}{l}\text { D: quantitative, descriptive } \\
\text { P: } 55 \text { patients with MS } \\
\text { S: MS center (medical center) }\end{array}$ & $\begin{array}{l}\text { M: semi-structured interview, } \\
\text { retrospective record review } \\
\text { O: adherence to treatment } \\
\text { recommendations }\end{array}$ & $\begin{array}{l}\text { Self-reported adherence to } \\
\text { recommendations was 38\%, but this } \\
\text { varied per recommendation type } \\
\text { (high adherence for pharmacological } \\
\text { management and lower for } \\
\text { psychotherapy or psychiatry referral/ } \\
\text { cognitive rehabilitation). Reasons for } \\
\text { nonadherence were needing more } \\
\text { information and wanting to speak } \\
\text { with physician. }\end{array}$ \\
\hline
\end{tabular}




\section{CHAPTER 6}

\begin{tabular}{|c|c|c|c|c|}
\hline $\begin{array}{l}\text { Reference } \\
\text { Type of document }\end{array}$ & Purpose/aim & $\begin{array}{l}\text { Design (D) } \\
\text { Population (P) } \\
\text { Setting (S) }\end{array}$ & $\begin{array}{l}\text { Methods (M) } \\
\text { Intervention type (I) } \\
\text { Relevant outcomes (O) }\end{array}$ & $\begin{array}{l}\text { Relevant results/ } \\
\text { recommendations }\end{array}$ \\
\hline $\begin{array}{l}\text { Tharinger and } \\
\text { Pilgrim, } 2012 \\
\text { Research paper }\end{array}$ & $\begin{array}{l}\text { Evaluate whether receiving } \\
\text { developmentally appropriate } \\
\text { feedback in the form of } \\
\text { individualized fables would } \\
\text { affect how children and parents } \\
\text { reported experiencing an NPA }\end{array}$ & $\begin{array}{l}\text { D: quantitative, randomized } \\
\text { P: } 32 \text { parents of children with } \\
\text { primarily ADHD, CAPD or } \\
\text { dysgraphia } \\
\text { S: private practice }\end{array}$ & $\begin{array}{l}\text { M: survey } \\
\text { l: group with feedback } \\
\text { following standard procedure } \\
\text { ( } \mathrm{n}=17 \text { ) and in experimental } \\
\text { group with addition of child } \\
\text { feedback through a fable ( } \mathrm{n} \\
=15 \text { ) } \\
\text { O: parent and child experience } \\
\text { with NPA, satisfaction with NPA }\end{array}$ & $\begin{array}{l}\text { Children that received in-person } \\
\text { with illustrative fables in a booklet } \\
\text { experienced a greater sense of } \\
\text { learning about themselves, more } \\
\text { positive relationship with assessor, } \\
\text { and a sense that their parents learned } \\
\text { more about them. Parents in the } \\
\text { experimental group reported a more } \\
\text { positive relationship with their child } \\
\text { and assessor, a greater sense of } \\
\text { collaboration, and a higher level of } \\
\text { satisfaction. }\end{array}$ \\
\hline $\begin{array}{l}\text { Turner et al, } 2012 \\
\text { Research paper }\end{array}$ & $\begin{array}{l}\text { Evaluate the feasibility of } \\
\text { providing comprehensive } \\
\text { neuropsychological evaluations } \\
\text { and feedback via telemedicine } \\
\text { to veterans receiving services } \\
\text { from an urban veteran medical }\end{array}$ & $\begin{array}{l}\text { D: quantitative, non- } \\
\text { randomized } \\
\text { P: } 15 \text { veterans with cognitive } \\
\text { and/or psychiatric disorders } \\
\text { S: urban veteran medical } \\
\text { center }\end{array}$ & $\begin{array}{l}\text { M: informal questions during } \\
\text { NPA } \\
\text { I: group with in-person } \\
\text { evaluation ( } n=7) \text {, and group } \\
\text { via telemedicine ( } n=8) \\
\text { O: satisfaction with NPA }\end{array}$ & $\begin{array}{l}\text { Both groups were satisfied with } \\
\text { receiving in-person feedback of } \\
\text { feedback via telemedicine. NPA via } \\
\text { telemedicine was deemed to be } \\
\text { feasible and comparable to an in- } \\
\text { person evaluation. }\end{array}$ \\
\hline
\end{tabular}




\section{CHAPTER 6}

\begin{tabular}{|c|c|c|c|c|}
\hline $\begin{array}{l}\text { Reference } \\
\text { Type of document }\end{array}$ & Purpose/aim & $\begin{array}{l}\text { Design (D) } \\
\text { Population (P) } \\
\text { Setting (S) }\end{array}$ & $\begin{array}{l}\text { Methods (M) } \\
\text { Intervention type (I) } \\
\text { Relevant outcomes (O) }\end{array}$ & $\begin{array}{l}\text { Relevant results/ } \\
\text { recommendations }\end{array}$ \\
\hline $\begin{array}{l}\text { Westervelt et al, } \\
2007 \\
\text { Research paper }\end{array}$ & $\begin{array}{l}\text { Assess patient perceptions } \\
\text { of neuropsychological } \\
\text { evaluations. Furthermore, } \\
\text { evaluated responses } \\
\text { to neuropsychological } \\
\text { recommendations. }\end{array}$ & $\begin{array}{l}\text { D: quantitative, descriptive } \\
\text { P: } 129 \text { patients with various } \\
\text { diagnosis and } 80 \text { family } \\
\text { members } \\
\text { S: academic medical center } \\
\text { neuropsychology program }\end{array}$ & $\begin{array}{l}\text { M: survey ( } 37 \% \text { response rate) } \\
\text { O: satisfaction with NPA }\end{array}$ & $\begin{array}{l}\text { Patients were satisfied with NPA and } \\
\text { receiving in-person feedback. Most } \\
\text { were satisfied with the length of the } \\
\text { feedback session and reported that } \\
\text { it helped them understand problems, } \\
\text { deal with problems, and reduce } \\
\text { stress. }\end{array}$ \\
\hline
\end{tabular}

Abbreviations. NPA = neuropsychological assessment, N/A = not applicable, $\mathrm{ADHD}=$ attention deficit hyperactivity disorder, $\mathrm{MTBI}=$ mild traumatic brain injury, $\mathrm{MS}=$ multiple sclerosis. 


\section{Type and quality of evidence}

The following 41 publications were identified: 26 research papers, seven opinion papers, two position papers, three book chapters, two books, and one research protocol. In terms of study designs, the research papers included four qualitative studies, three randomized trials, five non-randomized trials, thirteen descriptive studies, and one mixed-methods study. Only the overall quality of the research papers could be assessed (see supplementary material). Overall, the quality criteria were met; in some studies, subitems were not met (e.g., due to insufficient detailed information about the completeness of the data). In two studies, there was also a high risk for a nonresponse bias due to low response rates.

\section{Characteristics of neuropsychological feedback}

Most research papers used in-person feedback $18,24,26,29-31,36-40,42-45,49,52,54$ and most of the other publications recommended in-person feedback.,3,6,17,21-23,27,32-35,50 A minority gave feedback via phone, ${ }^{51}$ via telemedicine, ${ }^{25,53}$ or via a written report. ${ }^{28}$ Usually, feedback was given by the neuropsychologist a few weeks after the assessment. In four studies, this was given directly after testing 26,38,39,45

The length and content of the feedback session was often not specified; when specified, it usually took approximately one hour and focused on cognitive strengths and weaknesses, the impacts of emotional functioning, the translation of results to daily life, and diagnostic issues and recommendations with compensatory strategies. A review of the included papers showed that neuropsychological feedback was provided for a wide spectrum of diagnoses (e.g., psychiatric, neurodevelopmental, brain injury, dementia, epilepsy, brain tumor). Most settings were neuropsychological outpatient clinics in a hospital. Whether neuropsychological feedback was always part of standard routine was not often specified. Two survey studies found that $26-44 \%$ of the patients received neuropsychological feedback and that the majority of all participants wanted more information. ${ }^{19,31}$

\section{Satisfaction with neuropsychological services}

Approximately half of the research papers $(k=13)$, mostly survey studies, focused on experiences and satisfaction with the NPA. Overall, high levels of satisfaction with the NPA and feedback sessions were described for both patients and family members. ${ }^{26,31,38,39,47,52-54}$ Patients were more satisfied with the NPA when they received feedback, and if they experienced this as useful. ${ }^{19}$ In one qualitative study, it was found that both positive (relief or confirmation due to NPA outcome and diagnosis) and negative experiences (feeling distressed due to awareness of cognitive complaints) coexisted during an NPA and diagnostic disclosure at a memory clinic. ${ }^{36}$ The highest utility ratings of NPA were related to understanding cognitive strengths, weaknesses, and the relation between results and everyday behavior. ${ }^{18}$ Sometimes feedback was a mere confirmation of suspicions, but this was also seen as helpful. ${ }^{54}$ Other predictors of NPA satisfaction included perceptions of professional competence and rating of neuropsychological recommendations..$^{30}$ Only in a minority of the studies 
were participants less satisfied with the feedback session and felt that they did not provide as much help as they had expected. ${ }^{20}$ In another study, participants criticized neuropsychological feedback because the results were difficult to understand and the need for additional feedback sessions. ${ }^{31}$ Holst et al. ${ }^{37}$ found that low levels of satisfaction was related to low levels of self-esteem. Participants who were more satisfied were able to develop a positive relationship with the examiner. ${ }^{37}$

\section{Recommendations given in neuropsychological feedback}

Both the research papers, opinion/position papers, books, and book chapters showed that the recommendations given most often by psychologists across diagnoses were focused on compensatory strategies, cognitive deficits, and health improvements. A survey study showed that most psychologists gave feedback and explanations about invalid test results. ${ }^{44}$ Quantitative studies showed that differences in recommendations were identified between diagnoses (e.g., more focused on support/independence or driving in dementia and on rehabilitation referrals in patients with traumatic brain injury) ${ }^{46,48}$ On average, six primary and eleven secondary recommendations were given. ${ }^{18}$ The majority of participants were positive and experienced recommendations as helpful.24,48 However, the overall adherence to recommendations was found to be around $40 \%$ in four different quantitative studies. ${ }^{24,48,51,54}$ Identified barriers were unwillingness to adapt to the recommendations of the family member, patient misunderstandings, a need for more information, disagreement with recommendations, a desire to speak with a physician regarding the recommendations, and level of difficulty obtaining recommended services. ${ }^{24,51,54}$ Higher adherence rates were found for pharmacological management and recommendations related to patient safety. ${ }^{51,54}$

\section{Information provision during neuropsychological feedback}

One quantitative study and one mixed-methods study showed that neuropsychological feedback was not always remembered or understood. 19,31 Two randomized controlled trials showed that offering supplemental written information improved the free recall of recommendations, ${ }^{29,45}$ especially in family members. ${ }^{45}$ However, the recall of diagnostic information did not differ between the groups with and without supplemental written information. ${ }^{29,45}$ One survey study found that only one-third of the participants received a written report, ${ }^{19}$ while in three studies (two survey studies, one non-randomized trial), it was found that the patients experienced the written report as helpful. ${ }^{19,30,47}$ A qualitative study and one opinion paper identified the following barriers in report writing: difficult to understand or unhelpful information, language proficiency, level and quality of education, ethnicity, country and culture of origin. ${ }^{28,35}$ Some recommendations offered for report writing by these authors were to use as little information as possible, use intext formatting, and organize headings by audience, diagnosis, and recommendations. Further advice was to be aware of cultural and linguistic differences, transparency, and translation of scores to daily life. ${ }^{28}$

In one randomized controlled trial, a group of children and parents who received feedback with illustrative individualized fables reported that children experienced a 
greater sense of learning and collaboration, and a more positive relationship with the examiner compared to children and parents that received feedback without these fables. Parents experienced a greater sense of collaboration and a more positive relationship with their child and the examiner; they also reported higher satisfaction with the NPA. ${ }^{52}$ No other studies focused on using visual aids in neuropsychological feedback; however, in one case study, one book, and two opinion papers, visual aids were recommended.,31,32,42 The use of props (e.g., brain model) or several shorter feedback sessions was recommended in two publications., 32,32

Postal and Armstrong $^{3}$ described six principles of improving retention of neuropsychological feedback in their book: (1) simplicity (core message), (2) unexpectedness (novel information is better remembered), (3) concreteness (translation to daily life), (4) credibility (trusted source), (5) emotions (enhancing effects of emotions on memory), and (6) stories (transform passive listeners to active imaginers). They also advocate using motivational interviewing. Understanding something might lead to improved recall, but being convinced of the information delivered might change behavior permanently.

\section{Neuropsychological feedback and patient outcomes}

Eight research papers explored the impact of neuropsychological feedback on patient outcomes. Patients with a mood disorder and/or ADHD reported reductions in psychiatric and cognitive symptoms and improvements in self-efficacy for general-and evaluation-specific goals one month after an NPA with feedback. ${ }^{40}$ Two case studies of patients with anorexia nervosa or schizophrenia reported that feedback gave patients insight into their cognitive functioning so that they could deal with their disease in a different way in their daily life. ${ }^{42,43}$ Patients who attended neuropsychological feedback sessions had a greater improvement in quality of life and an increased understanding of and ability to cope with their condition compared to those who did not attend these sessions. ${ }^{49}$ Two studies found a decrease in self-reported post-concussive symptoms in both parents and children. ${ }^{26,38}$ Greater initiation of parent behavior management and special education services and medication management were reported when parents of children with ADHD received neuropsychological feedback. ${ }^{47}$ After receiving feedback, the concerns of family members of patients with a stroke were related to safety, what the future will bring, knowing what to do when the patient is unable to perform a task, and dealing with the emotional changes of the patient. ${ }^{7}$

\section{Feedback frameworks and clinical recommendations}

Table 2 shows an overview of the different feedback frameworks offered by six authors from one non-randomized study, three opinion papers, and two books. In all frameworks, some overlap can be identified: an explanation of the nature of NPA and rationale of feedback sessions, an explanation of strengths and weaknesses, and the provision of recommendations and compensatory strategies. Furthermore, in these feedback models, a collaborative approach using plain and understandable language without jargon is advocated. Some clinical recommendations, based on the earlier described 


\section{CHAPTER 6}

frameworks, one position paper, one opinion paper, and three book chapters that gave clinical recommendations. ${ }^{27,28,34,35,50}$

Table 2. Frameworks for giving neuropsychological feedback in different settings.

\begin{tabular}{|c|c|c|}
\hline Author & Patient group & Framework \\
\hline $\begin{array}{l}\text { Carone et al, } \\
\text { 2013; Carone et } \\
\text { al, } 2010\end{array}$ & $\begin{array}{l}\text { MTBI patients with } \\
\text { invalid effort. }\end{array}$ & $\begin{array}{l}\text { Before: Establish good working relationship. } \\
\text { Phase 1: Build rapport and obtain informed consent. } \\
\text { Phase 2: Complete evaluation and preliminary discussions } \\
\text { (avoid accusatory, emotionally laden terms). } \\
\text { Phase 3: Feedback session (ask their input first, explain } \\
\text { strengths/weaknesses, explain incredible effort as good/ } \\
\text { bad news based on objective data and inquire whether } \\
\text { they agree that they should perform as a clinically impaired } \\
\text { group, ask how they feel after hearing this). }\end{array}$ \\
\hline Carone, 2017 & $\begin{array}{l}\text { Patients with high } \\
\text { level of cognitive } \\
\text { complaints, } \\
\text { but normal test } \\
\text { performance. }\end{array}$ & $\begin{array}{l}\text { Before: Establish good working relationship. } \\
\text { Phase 1: Build rapport and obtain informed consent. } \\
\text { Phase 2: Complete evaluation and let patient self-rate } \\
\text { performance on cognitive tests. } \\
\text { Phase 3: Feedback session (show patient table with } \\
\text { objective and self-report ratings of performance). }\end{array}$ \\
\hline $\begin{array}{l}\text { Connery et al, } \\
2016\end{array}$ & $\begin{array}{l}\text { Children with invalid } \\
\text { effort. }\end{array}$ & $\begin{array}{l}\text { Phase 1: Start with opening statement about invalid effort. } \\
\text { Phase 2: Emphasize that performance validity test is an } \\
\text { important finding. } \\
\text { Phase 3: Give recommendations } \\
\rightarrow \text { Give feedback to parents first. Brief explanation to } \\
\text { children is usually sufficient. }\end{array}$ \\
\hline $\begin{array}{l}\text { Gass and Brown, } \\
1992\end{array}$ & $\begin{array}{l}\text { Patients with brain } \\
\text { injuries and their } \\
\text { family members }\end{array}$ & $\begin{array}{l}\text { Phase 1: Review purpose of testing in plain and } \\
\text { understandable language (avoid jargon). } \\
\text { Phase 2: Define the tests (use behavioral samples). } \\
\text { Phase 3: Explain results and behavior per cognitive domain } \\
\text { (explain normative comparison, ask for feedback after each } \\
\text { domain to maintain attention). } \\
\text { Phase 4: Describe strengths and weaknesses. } \\
\text { Phase 5: Address diagnostic/prognostic issues. } \\
\text { Phase 6: Give recommendations. }\end{array}$ \\
\hline
\end{tabular}




\begin{tabular}{|c|c|c|}
\hline Author & Patient group & Framework \\
\hline $\begin{array}{l}\text { Gorske and } \\
\text { Smith, } 2009\end{array}$ & Clinical setting & $\begin{array}{l}\text { Collaborative Therapeutic Neuropsychological } \\
\text { Assessment: } \\
\text { Phase 1: Set agenda and introduce feedback report } \\
\text { (ask about the central cognitive emotional complaint, } \\
\text { how they experienced the NPA, provide copy of } \\
\text { feedback report). } \\
\text { Phase 2: Develop life implications questions (two to } \\
\text { three, acknowledge strengths and limitations of NPA). } \\
\text { Phase 3: Determine personal skill profile (explain } \\
\text { normative scores, use graphic illustration). } \\
\text { Phase 4: Discuss individual test results focusing on } \\
\text { strengths and weaknesses. } \\
\text { Phase 5: Summarize relationship between results, life } \\
\text { areas, and patient questions. } \\
\rightarrow \text { Give feedback in person-centered manner using } \\
\text { principles from motivation interviewing (elicit - } \\
\text { provide - elicit, respond with open-ended questions, } \\
\text { affirmations, reflective statements, and summaries). }\end{array}$ \\
\hline $\begin{array}{l}\text { Postal and } \\
\text { Armstrong, } \\
2013\end{array}$ & Clinical setting & $\begin{array}{l}\text { Phase 1: Reorient patient and family (explain nature } \\
\text { of session, remind of collaborative process, review } \\
\text { goal of patient and family). } \\
\text { Phase 2: Gather more information and start with a } \\
\text { compliment. } \\
\text { Phase 3: be flexible. } \\
\text { Phase 4: Lead with the core message (else difficult } \\
\text { to listen to details) and give feedback on testing } \\
\text { process and goals, explain normative scores, focus } \\
\text { on strengths and weaknesses, and use concrete } \\
\text { metaphors for cognitive domains. Conclude with } \\
\text { offering recommendations and compensatory } \\
\text { strategies. } \\
\rightarrow \text { Create a therapeutic atmosphere during feedback, } \\
\text { connect with patient and family, don't use jargon or } \\
\text { take too long giving feedback. }\end{array}$ \\
\hline
\end{tabular}


Table 3. Clinical recommendations for giving neuropsychological feedback.

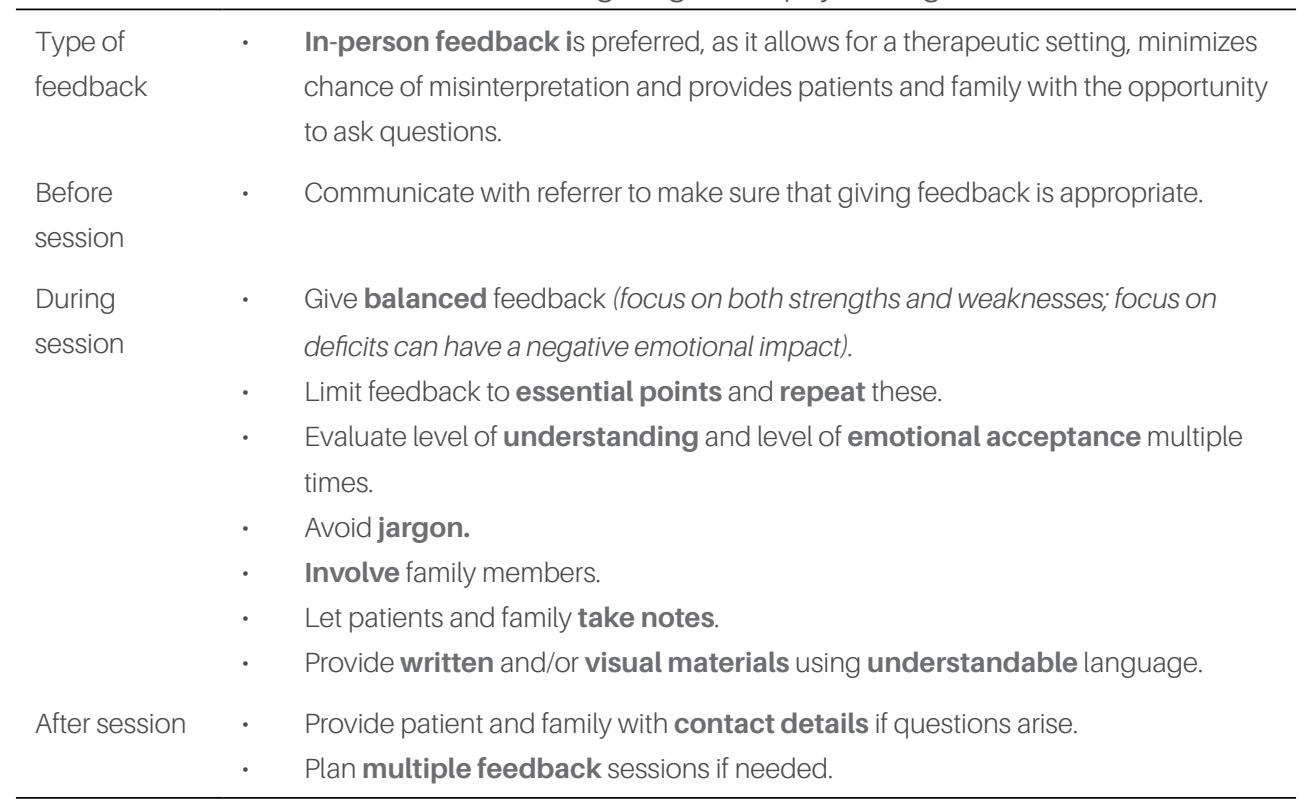

\section{DISCUSSION}

This scoping review identified 41 publications on neuropsychological feedback to patients and family members in diverse settings. Several themes related to neuropsychological feedback could be identified: characteristics of neuropsychological feedback, satisfaction with neuropsychological services, patient outcomes, recommendations given in neuropsychological feedback, information provision during neuropsychological feedback, feedback frameworks and clinical recommendations. A critical evaluation of the methodological quality of the included research papers showed that most met the criteria, but not all intervention studies included a control group, not all were randomized, and not all described the sample or outcome data in detail. Most prominent was the risk of response bias in the cross-sectional survey studies as a result of low response rates.

The majority of publications recommended or used in-person feedback. Approximately thirty years ago, Pope ${ }^{56}$ stated that feedback was the most neglected part of psychology assessments. In our review, one survey study and one mixedmethods study evaluating clinical practice showed that neuropsychological feedback was not given to all patients. ${ }^{19,31}$ However, one of these studies was carried out over 25 years ago. When reviewing broader psychological assessment practices (e.g., also considering personality assessment), two survey studies showed that the majority of psychologists gave in-person feedback, although this was not always a routine part of their assessment. ${ }^{57,58}$ Based on these results, it seems that psychologists currently give feedbackin psychological diagnostic procedure more often than 25 years ago. However, it is still not a clinical routine, and the content of neuropsychological feedback depends on the clinical context. Nonetheless, the potential clinical benefits of feedback have 
been demonstrated, such as improved patient well-being, self-esteem, hopefulness, and reduced symptomss. ${ }^{59-63}$ Giving feedback also led to a better therapeutic alliance in psychotherapy. ${ }^{59,64}$ Furthermore, a meta-analysis showed that only when psychological assessment procedures were combined with personalized and collaborative feedback did clinically meaningful effects on treatment emerge. ${ }^{65}$ Although research is lacking on the therapeutic value of collaborative neuropsychological feedback, it is highly likely that it has similar effects as in other psychological assessment fields. However, when looking at multidisciplinary practices, the diagnostic disclosure (based on all diagnostic assessments) is often given only by the medical specialist. Offering an additional consultation with a neuropsychologist to discuss NPA findings in multidisciplinary practices could be helpful in patients and offers the opportunity to improve information retention and answer remaining questions. Furthermore, it offers the opportunity to provide support and guidance due to the emotional impact of the diagnosis.

Consumer experience and satisfaction with NPA were the most reported outcomes in the current scoping review. Generally, positive experiences and high satisfaction with neuropsychological procedures were reported. Gaining more insight into consumer experiences and satisfaction is relevant, as it may lead to improvement of the quality of service and patient outcomes, such as reduced patient anxiety due to good communication. ${ }^{66}$ However, the validity of satisfaction in treatment outcomes has been criticized as a result of not taking psychological factors, communication, and patient expectations into account. ${ }^{67,68}$ In terms of an NPA, patient satisfaction was related to receiving feedback that was evaluated as valuable. ${ }^{19}$ This is in line with the findings of Smith et al., ${ }^{57}$ who showed that patients appreciated that psychological feedback helped understand their problems, which could result in positive changes. However, not understanding or remembering neuropsychological feedback might negatively influence satisfaction. Therefore, Brenner ${ }^{8}$ has developed a framework that psychologists can use to increase the beneficial value of and satisfaction with psychological assessments: elimination of jargon, focus on referral questions, individualized assessment reports, emphasis on patient strengths, and including concrete recommendations.

The current review also showed that information retention of neuropsychological feedback was low. A few quantitative studies reported low percentages of information retention, especially recommendations were difficult to remember. ${ }^{45}$ This is in line with earlier studies that showed that the retention of medical information was generally low. ${ }^{69}$ This is alarming, as adherence to treatment recommendations is related to understanding, recall, and satisfaction with the consultation. ${ }^{70}$ Remembering neuropsychological feedback may be even more difficult in patients who have a cognitive impairment. Retention might also be hampered by emotional arousal or valence related to receiving (bad news) or not receiving (good news) a diagnosis. ${ }^{71}$ On the one hand, receiving a 'bad news' diagnosis has profound emotional effect on both the patient and family members, such as feelings of stress and anxiety. It is very likely that this leads to lower recall of information. On the other hand, feeling relieved if the feared diagnosis is not confirmed might also negatively influence information retention. A few studies have explored the mode of information as a suitable 
target for communication aids. The current scoping review showed that offering supplemental written information might be helpful, but no studies have been conducted on whether visual aids could improve information retention in neuropsychological feedback. Some promising findings were seen in other fields, and a systematic review showed better recall in multiple studies when visual aids were used. ${ }^{72}$ It is essential that neuropsychological feedback can be remembered so that it can lead to improved treatment outcomes.

A strength of the current study is its use of the scoping review methodology to gain insight into a broad spectrum of literature on providing neuropsychological feedback. It synthesizes evidence on an emerging topic while using a systematic process that is both replicable, transparent and rigorous. Furthermore, the review has been carried out by experts in the field of clinical neuropsychology with the involvement of an expert librarian. Most scoping reviews do not include a critical appraisal of the quality of the included studies. However, we have included this to not only describe the scope of the research questions but also to give an impression of the validity.

Some limitations must be mentioned as well. One limitation is that reviews are time consuming, and new publications might have emerged since the search. However, we have recently updated the search, which resulted in the inclusion of two full papers. A second limitation is that although we have tried to discuss the most important findings, due to the limited space, some details might have not been described. Furthermore, the variation between the document types and range of data collection, methodology and analysis techniques made it sometimes difficult to present the results in a compact and integrated way.

Finally, future research should include more studies adopting a randomized controlled trial to gain more insight into the benefits of neuropsychological feedback. It would also be of interest to evaluate neuropsychological feedback in specific settings with a multidisciplinary nature, such as memory clinics. Furthermore, more attention is needed to train psychologists in providing neuropsychological feedback. It would be helpful if more attention could be given about this topic during graduate and postgraduate education courses of psychologists. The clinical recommendations offered in this paper could be used. Finally, more research is also needed focusing on how neuropsychological feedback could be best communicated in terms of information retention, for example by, using visual aids. 


\section{CHAPTER 6}

\section{CONCLUSION}

Overall, the current scoping review shows that neuropsychological feedback is a vital and therapeutic component of clinical practice that can lead to improved patient outcomes and satisfaction with neuropsychological services. However, there seems to be a discrepancy in the content and frequency of feedback. Furthermore, low levels of information retention seem to be present. Although using communication aids seems promising, more research is warranted.

\section{ACKNOWLEDGEMENTS}

We are grateful to Stefan Jongen (Maastricht University Library) for his advice and help in developing the search strategy. 


\section{REFERENCES}

1. Lezak MD, Howieson DB, Bigler ED, Tranel D. Neuropsychological Assessment. Fifth edition ed. New York: Oxford University Press; 2012.

2. American Psychological Association. Ethical principes of psychologists and code of conduct. https://www.apa.org/ethics/code/. Published January 2017. Accessed March 2020.

3. Postal KS, Armstrong K. Feedback that sticks: The art of effectively communicating neuropsychological assessment results. Oxford: Oxford University Press; 2013.

4. Baxendale S, Wilson SJ, Baker GA, et al. Indications and expectations for neuropsychological assessment in epilepsy surgery in children and adults. Epileptic Disord. 2019;21(3):221-234.

5. Wilson SJ, Baxendale S, Barr W, et al. Indications and expectations for neuropsychological assessment in routine epilepsy care: Report of the ILAE Neuropsychology Task Force, Diagnostic Methods Commission, 2013-2017. Epilepsia. 2015;56(5):674-681.

6. Gorske TT, Smith S. Collaborative Therapeutic Neuropsychological Assessment. New York: Springer Science and Business Media; 2009.

7. Belciug MP. Concerns and anticipated challenges of family caregivers following participation in the neuropsychological feedback of stroke patients. Int J Rehabil Res. 2006;29(1):77-80.

8. Brenner E. Consumer-focused psychological assessment. Prof Psychol Res Pr. 2003;34(3):240-247.

9. Arksey H, O'Malley L. Scoping studies: towards a methodological framework. Int J Soc. 2005;8(1):19-32.
10. Peters MD, Godfrey $C M$, Khalil $H, M c$ Inerney $P$, Parker D, Soares CB. Guidance for conducting systematic scoping reviews. Int J Evid Based Healthc. 2015;13(3):141-146.

11. Levac $D$, Colquhoun $H, O^{\prime}$ Brien KK. Scoping studies: advancing the methodology. Implement Sci. 2010;5(1):69.

12. Tricco AC, Lillie E, Zarin W, et al. PRISMA Extension for scoping reviews (PRISMA-ScR): Checklist and explanation. Ann Intern Med. 2018;169(7):467-473.

13. Pace $R$, Pluye $P$, Bartlett $G$, et al. Testing the reliability and efficiency of the pilot Mixed Methods Appraisal Tool (MMAT) for systematic mixed studies review. Int J Nurs. 2012;49(1):4753.

14. Breneol S, Belliveau J, Cassidy C, Curran JA. Strategies to support transitions from hospital to home for children with medical complexity: A scoping review. Int J Nurs. 2017;72:91-104.

15. Bieber A, Nguyen N, Meyer G, Stephan A. Influences on the access to and use of formal community care by people with dementia and their informal caregivers: a scoping review. BMC Health Serv Res. 2019;19(1):88.

16. Altman DG. Practical statistics for medical research. CRC press; 1990.

17. Allen JG, Lewis L, Blum S, Voorhees S, Jernigan S, Peebles MJ. Informing psychiatric patients and their families about neuropsychological assessment findings. Bull Menninger Clin. 1986;50(1):64-74.

18. Arffa S, Knapp JA. Parental perceptions of the benefits of neuropsychological assessment in a neurodevelopmental outpatient clinic. Appl Neuropsychol. 2008;15(4):280-286. 
1. Bennett-Levy J, Klein-boonschate MA, Batchelor J, McCarter R, Walton N. Encounters with Anna Thompson: The consumer's experience of neuropsychological assessment. Clin Neuropsychol. 1994;8(2):219-238..

2. Bodin D, Beetar JT, Yeates KO, Boyer K, Colvin AN, Mangeot S. A survey of parent satisfaction with pediatric neuropsychological evaluations. Clin Neuropsychol. 2007;21(6):884-898.

3. Carone DA, Iverson GL, Bush SS. A model to approaching and providing feedback to patients regarding invalid test performance in clinical neuropsychological evaluations. Clin Neuropsychol. 2010;24(5):759-778.

4. Carone DA, Bush SS, Iverson GL. Providing feedback on symptom validity, mental health, and treatment in mild traumatic brain injury. In: Mild traumatic brain injury: Symptom validity assessment and malingering. New York, NY, US: Springer Publishing Company; 2013:101118.

5. Carone DA. But the scores don't show how i really function: A feedback method to reveal cognitive distortions regarding normal neuropsychological test performance. Appl Neuropsychol Adult. 2017;24(2):160-168.

6. Cheung LL, Wakefield CE, Ellis SJ, Mandalis A, Frow E, Cohn RJ. Neuropsychology reports for childhood brain tumor survivors: implementation of recommendations at home and school. Pediatr Blood Cancer. 2014;61(6):1080-1087.

7. Clement PF, Brooks FR, Dean B, Galaz A. A neuropsychology telemedicine clinic. Mil Med. 2001;166(5):382-384.

8. Connery AK, Peterson RL, Baker DA, Kirkwood MW. The impact of pediatric neuropsychological consultation in mild traumatic brain injury: a model for providing feedback after invalid performance. Clin Neuropsychol. 2016;30(4):579-598.
9. Crosson B. Application of neuropsychological assessment results. In: Vanderploeg RD, ed. Clinician's guide to neuropsychological assessment. New Jersey London: Lawrence Erlbaum Associates Publishers; 2000:181-225.

10. Evans CL, Pulsifer MB, Grieco JA. Communication of neuropsychological results to caregivers of Latino immigrant children. Transl Issues Psychol Sci. 2019;5(1):42-50.

11. Fallows RR, Hilsabeck RC. Comparing two methods of delivering neuropsychological feedback. Arch Clin Neuropsychol. 2013;28(2):180-188.

12. Farmer JE, Brazeal TJ. Parent perceptions about the process and outcomes of child neuropsychological assessment. Appl Neuropsychol. 1998;5(4):194-201.

13. Foran A, Millar E, Dorstyn D. Patient satisfaction with a hospital-based neuropsychology service. Aust Health Rev. 2016;40(4):447-452.

14. Gass CS, Brown MC. Neuropsychological test feedback to patients with brain dysfunction. Psychol Assess. 1992;4(3):272-277.

15. Gorske TT. Therapeutic Neuropsychological Assessment: A humanistic model and case example. Journal of Humanistic Psychology. 2007;48(3):320-339.

16. Green J. Providing feedback and planning follow-up services. In: Green J, ed. Neuropsychological Evaluation of the Older Adult: A clinician's guidebook. San Diego: Academic Press; 2000:205-215.

17. Griffin A, Christie D. Taking a systemic perspective on cognitive assessments and reports: reflections of a paediatric and adolescent psychology service. Clin Child Psychol P.. 2008;13(2):209-219. 
1. Gruters AAA, Christie HL, Ramakers IHGB, Verhey FRJ, Kessels RPC, de Vugt ME. Neuropsychological assessment and diagnostic disclosure at a memory clinic: A qualitative study of the experiences of patients and their family members. Clin Neuropsychol. 2020:1-17.

2. Holst $\mathrm{Y}, \mathrm{Nyman} \mathrm{H}$, Larsson J-O. Predictors of patient satisfaction with the feedback after a neuropsychological assessment. Am J Psychiatry. 2009;3:50-55.

3. Kirkwood MW, Peterson RL, Connery AK, Baker DA, Forster J. A pilot study investigating neuropsychological consultation as an intervention for persistent postconcussive symptoms in a pediatric sample. Pediatrics. 2016;169:244-249.e241.

4. Kirkwood MW, Peterson RL, Baker DA, Connery AK. Parent satisfaction with neuropsychological consultation after pediatric mild traumatic brain injury. Child Neuropsychol. 2017;23(3):273-283.

5. Lanca M, Giuliano AJ, Sarapas C, et al. Clinical outcomes and satisfaction following neuropsychological assessment for adults: A community hospital prospective quasiexperimental study. Arch Clin Neuropsychol. 2019.

6. Longley WA, Tate RL, Brown RF. A protocol for measuring the direct psychological benefit of neuropsychological assessment with feedback in multiple sclerosis. Brain Impair. 2012;13(2):238-255.

7. Lopez C, Roberts ME, Tchanturia K, Treasure J. Using neuropsychological feedback therapeutically in treatment for anorexia nervosa: two illustrative case reports. Eur Eat Disord Rev. 2008;16(6):411-420.

8. Malla AK, Lazosky A, McLean T, Rickwood A, Cheng S, Norman RMG. Neuropsychological assessment as an aid to psychosocial rehabilitation in severe mental disorders. Psychiatr Rehabil J.. 1997;21(2):169-173.
9. Martin PK, Schroeder RW. Feedback with patients who produce invalid testing: Professional values and reported practices. Clin Neuropsychol. 2020:1-20.

10. Meth M, Calamia M, Tranel D. Does a simple intervention enhance memory and adherence for neuropsychological recommendations? Appl Neuropsychol Adult. 2016;23(1):21-28

11. Meth M, Bernstein JPK, Calamia M, Tranel

D. What types of recommendations are we giving patients? A survey of clinical neuropsychologists. Clin Neuropsychol. 2019;33(1):57-74.

12. Pritchard AE, Koriakin T, Jacobson LA, Mahone EM. Incremental validity of neuropsychological assessment in the identification and treatment of youth with ADHD. Clin Neuropsychol. 2014;28(1):26-48

13. Quillen J, Crawford E, Plummer B, Bradley $\mathrm{H}$, Glidden R. Parental follow-through of neuropsychological recommendations for childhood-cancer survivors. J Pediatr Oncol Nurs. 2011;28(5):306-310.

14. Rosado DL, Buehler S, Botbol-Berman E, et al. Neuropsychological feedback services improve quality of life and social adjustment. Clin Neuropsychol. 2018;32(3):422-435.

15. Ruppert PD, Attix DK. Evaluation and treatment of geriatric neurocognitive disorders. In: Pachana NA, Laidlaw K, eds. The Oxford handbook of clinical geropsychology. Oxford: Oxford University Press; 2014.

16. Stimmel M, Shagalow S, Seng EK, et al. Short Report: Adherence to neuropsychological recommendations in patients with multiple sclerosis. Int J MS Care. 2019;21(2):70-75.

17. Tharinger DJ, Pilgrim S. Parent and child experiences of neuropsychological assessment as a function of child feedback by individualized fable. Child Neuropsychol. 2012;18(3):228-241. 
1. Turner TH, Horner MD, Vankirk KK, Myrick H, Tuerk PW. A pilot trial of neuropsychological evaluations conducted via telemedicine in the Veterans Health Administration. Telemed JE Health. 2012;18(9):662-667.

2. Westervelt HJ, Brown LB, Tremont G, Javorsky DJ, Stern RA. Patient and family perceptions of the neuropsychological evaluation: How are we doing? Clin Neuropsychol. 2007;21(2):263273.

3. Gorske TT, Smith SR. Collaborative Therapetuic Neuropsychological Assessment. New York: Springer; 2009.

4. Pope KS. Responsibilities in providing psychological test feedback to clients. In. Vol 4. US: American Psychological Association; 1992:268-271.

5. Smith SR, Wiggins CM, Gorske TT. A survey of psychological assessment feedback practices. Assessment. 2007;14(3):310-319.

6. Curry KT, Hanson WE. National survey of psychologists' test feedback training, supervision, and practice: A mixed methods study. J Pers Assess. 2010;92(4):327-336.

7. Ackerman SJ, Hilsenroth MJ, Baity MR, Blagys MD. Interaction of therapeutic process and alliance during psychological assessment. J Pers Assess. 2000;75(1):82-109.

8. Allen A, Montgomery M, Tubman J, Frazier $L$, Escovar L. The effects of assessment feedback on rapport-building and selfenhancement processes. J Ment Health Couns. 2003;25(3):165-182.

9. Finn SE, Tonsager ME. Therapeutic effects of providing MMPI-2 test feedback to college students awaiting therapy. In. Vol 4. US: American Psychological Association; 1992:278-287.

10. Finn SE, Tonsager ME. Information-gathering and therapeutic models of assessment: Complementary paradigms. Psychol Assess. $1997 ; 9(4): 374-385$
11. Newman ML, Greenway P. Therapeutic effects of providing MMPI-2 test feedback to clients at a university counseling service: A collaborative approach. In. Vol 9. US: American Psychological Association; 1997:122-131.

12. Hilsenroth MJ, Peters EJ, Ackerman SJ. The development of therapeutic alliance during psychological assessment: patient and therapist perspectives across treatment. J Pers Assess. 2004;83(3):332-344.

13. Poston JM, Hanson WE. Meta-analysis of psychological assessment as a therapeutic intervention. Psychol Assess. 2010;22(2):203212.

14. van Osch $M$, van Dulmen $S$, van Vliet $L$, Bensing J. Specifying the effects of physician's communication on patients' outcomes: A randomised controlled trial. Patient Educ Couns. 2017;100(8):1482-1489.

15. Verbeek J. Patient satisfaction: is it a measure for the outcome of care or the process of care? J Clin Epidemiol. 2004;57(2):217.

16. Hudak PL, McKeever P, Wright JG. The metaphor of patients as customers: implications for measuring satisfaction. J Clin Epidemiol. 2003;56(2):103-108.

17. Kessels RPC. Patients' memory for medical information. J R Soc Med. 2003;96(5):219-222.

18. Ley $\mathrm{P}$. Memory for medical information. $\mathrm{Br} \mathrm{J}$ Soc Psychol. 1979;18(2):245-255.

19. Kensinger EA. Remembering the details: Effects of emotion. Emot Rev. 2009;1(2):99113.

20. Watson PW, McKinstry B. A systematic review of interventions to improve recall of medical advice in healthcare consultations. J R SOC Med. 2009;102(6):235-243. 


\section{CHAPTER 6}

\section{APPENDIX 1}

\section{Search strategy}

\section{Pubmed:}

('neuropsychological assessment'[Title/Abstract] OR 'neuropsychological evaluation'[Title/Abstract] OR 'neuropsychology'[Title/Abstract] OR 'neuropsychologist'[Title/Abstract] OR 'neuropsychological'[Title/Abstract] OR neuropsychological test * [Title/Abstract] OR neuropsychological result* [Title/Abstract] OR"Neuropsychology/instrumentation"[Mesh] OR"Neuropsychology/methods"[Mesh] OR "Neuropsychology/organization and administration"[Mesh] OR "Neuropsychology/ standards"[Mesh] OR "Neuropsychology/trends"[Mesh] OR "Neuropsychological Tests/instrumentation"[Mesh] OR "Neuropsychological Tests/methods"[Mesh] OR "Neuropsychological Tests/standards"[Mesh]) AND (feedback[Title/Abstract] OR recommendations[Title/Abstract] OR communicat*[Title/Abstract] OR "Feedback/ instrumentation"[Mesh] OR "Feedback/methods" [Mesh] OR "Feedback, Psychological/ instrumentation"[Mesh] OR "Feedback, Psychological/methods" [Mesh] OR "Feedback, Psychological/organization and administration"[Mesh] OR "Feedback, Psychological/ standards"[Mesh] OR "Feedback, Psychological/trends"[Mesh] OR "Communication/ diagnosis"[Mesh] OR "Communication/instrumentation"[Mesh] OR "Communication/ methods"[Mesh] OR "Communication/organization and administration"[Mesh] OR "Communication/psychology"[Mesh] OR "Communication/standards"[Mesh] OR "Communication/trends"[Mesh]) AND (patient OR family members OR carers)

\section{Psycinfo/CINAHL:}

( $A B$ 'neuropsychological assessment' OR AB 'neuropsychological evaluation' OR AB 'neuropsychology' OR AB 'neuropsychologist' OR 'AB 'neuropsychological' OR AB 'neuropsychological test*' ORAB'neuropsychological result*' ORDE'neuropsychology' OR DE 'neuropsychological assessment') AND

(AB 'feedback' OR AB 'recommendations' OR AB 'communicat *' OR DE 'feedback' OR DE 'communication') AND ('patient' OR 'family members' or 'carers')

\section{Embase:}

(*neuropsychology/ or *neuropsychological test/ or (neuropsychological test or neuropsychological evaluation or neuropsychology or neuropsychologist or neuropsychological or neuropsychological test $*$ or neuropsychological result $\star$ ).ti,ab.) and (*psychological feedback/ or (feedback or recommendations or communicat*). ti,ab.) and (patient or family members or carers).mp.

\section{Web of Science:}

$\mathrm{TI}=$ (neuropsychological assessment OR neuropsychological evaluation OR neuropsychology OR neuropsychologist OR neuropsychological OR neuropsychological test* OR neuropsychological result*) AND TS=(feedback OR recommendations OR communicat $*$ ) AND ALL=(patient OR family members OR carers) 


\section{CHAPTER 6}

\section{APPENDIX 2}

\section{Quality assessment research papers $(k=26)$}

Table 1. Quality assessment based on Mixed Model Appraisal Tool.

\begin{tabular}{|c|c|c|c|c|c|}
\hline \multirow[t]{3}{*}{ Author(s) (Year) } & \multirow[t]{3}{*}{ Study type } & \multirow[t]{3}{*}{ Criteria } & \multicolumn{3}{|c|}{ Criteria met by studies } \\
\hline & & & Yes & No & Not enough \\
\hline & & & & & information \\
\hline \multirow[t]{8}{*}{ Cheung et al (2014) } & Qualitative & 1.1 Relevant qualitative approach & $x$ & & \\
\hline & & 1.2 Adequate qualitative data & $x$ & & \\
\hline & & collection & & & \\
\hline & & 1.3 Findings adequately derived & $x$ & & \\
\hline & & from data & & & \\
\hline & & 1.4 Adequate interpretation of & $x$ & & \\
\hline & & results & & & \\
\hline & & 1.5 Coherence between data & $x$ & & \\
\hline \multirow[t]{8}{*}{ Gruters et al (2020) } & Qualitative & 1.1 Relevant qualitative approach & $x$ & & \\
\hline & & 1.2 Adequate qualitative data & $x$ & & \\
\hline & & collection & & & \\
\hline & & 1.3 Findings adequately derived & $x$ & & \\
\hline & & from data & & & \\
\hline & & 1.4 Adequate interpretation of & $x$ & & \\
\hline & & results & & & \\
\hline & & 1.5 Coherence between data & $x$ & & \\
\hline \multirow[t]{8}{*}{ Lopez et al (2008) } & Qualitative & 1.1 Relevant qualitative approach & $x$ & & \\
\hline & & 1.2 Adequate qualitative data & $x$ & & \\
\hline & & collection & & & \\
\hline & & 1.3 Findings adequately derived & $x$ & & \\
\hline & & from data & & & \\
\hline & & 1.4 Adequate interpretation of & $x$ & & \\
\hline & & results & & & \\
\hline & & 1.5 Coherence between data & $x$ & & \\
\hline \multirow[t]{8}{*}{ Malla et al (1997) } & Qualitative & 1.1 Relevant qualitative approach & $x$ & & \\
\hline & & 1.2 Adequate qualitative data & $x$ & & \\
\hline & & collection & & & \\
\hline & & 1.3 Findings adequately derived & $x$ & & \\
\hline & & from data & & & \\
\hline & & 1.4 Adequate interpretation of & $x$ & & \\
\hline & & results & & & \\
\hline & & 1.5 Coherence between data & $x$ & & \\
\hline
\end{tabular}




\section{CHAPTER 6}

\begin{tabular}{|c|c|c|c|c|c|}
\hline \multirow[t]{3}{*}{ Author(s) (Year) } & \multirow[t]{3}{*}{ Study type } & \multirow[t]{3}{*}{ Criteria } & \multicolumn{3}{|c|}{ Criteria met by studies } \\
\hline & & & Yes & No & Not enough \\
\hline & & & & & information \\
\hline \multirow[t]{5}{*}{$\begin{array}{l}\text { Fallows \& Hilsabeck } \\
\text { (2013) }\end{array}$} & $\begin{array}{l}\text { Quantitative } \\
\text { randomized }\end{array}$ & 2.1 Appropriate randomization & & & $x$ \\
\hline & & $\begin{array}{l}2.2 \text { Comparable groups at } \\
\text { baseline }\end{array}$ & $x$ & & \\
\hline & & 2.3 Complete outcome data & $x$ & & \\
\hline & & 2.4 Outcome assessors blind & & $x$ & \\
\hline & & 2.5 Adherence to intervention & $x$ & & \\
\hline \multirow[t]{5}{*}{ Meth et al (2016) } & Quantitative & 2.1 Appropriate randomization & $x$ & & \\
\hline & randomized & $\begin{array}{l}2.2 \text { Comparable groups at } \\
\text { baseline }\end{array}$ & $x$ & & \\
\hline & & 2.3 Complete outcome data & $x$ & & \\
\hline & & 2.4 Outcome assessors blind & $x$ & & \\
\hline & & 2.5 Adherence to intervention & $x$ & & \\
\hline Tharinger and & Quantitative & 2.1 Appropriate randomization & $x$ & & \\
\hline \multirow[t]{4}{*}{ Pilgrim (2012) } & randomized & $\begin{array}{l}2.2 \text { Comparable groups at } \\
\text { baseline }\end{array}$ & $x$ & & \\
\hline & & 2.3 Complete outcome data & $x$ & & \\
\hline & & 2.4 Outcome assessors blind & & $x$ & \\
\hline & & 2.5 Adherence to intervention & $x$ & & \\
\hline \multirow[t]{6}{*}{$\begin{array}{l}\text { Connery et al } \\
(2016)\end{array}$} & $\begin{array}{l}\text { Quantitative } \\
\text { non- }\end{array}$ & 3.1 Representative sample & $x$ & & \\
\hline & randomized & 3.2 Appropriate measures & $x$ & & \\
\hline & & 3.3 Complete outcome data & $x$ & & \\
\hline & & 3.4 Confounders accounted for & $x$ & & \\
\hline & & 3.5 Intervention administered as & $x$ & & \\
\hline & & intended & & & \\
\hline \multirow[t]{5}{*}{ Rosado et al (2018) } & Quantitative & 3.1 Representative sample & $x$ & & \\
\hline & non- & 3.2 Appropriate measures & $x$ & & \\
\hline & randomized & 3.3 Complete outcome data & $x$ & & \\
\hline & & 3.4 Confounders accounted for & & & $x$ \\
\hline & & 3.5 Intervention administered as & $x$ & & \\
\hline
\end{tabular}




\section{CHAPTER 6}

\begin{tabular}{|c|c|c|c|c|c|}
\hline \multirow[t]{3}{*}{ Author(s) (Year) } & \multirow[t]{3}{*}{ Study type } & \multirow[t]{3}{*}{ Criteria } & \multicolumn{3}{|c|}{ Criteria met by studies } \\
\hline & & & Yes & No & Not enough \\
\hline & & & & & information \\
\hline \multirow[t]{7}{*}{ Turner et al (2012) } & Quantitative & 3.1 Representative sample & $x$ & & \\
\hline & non- & & & & \\
\hline & randomized & 3.2 Appropriate measures & & $x$ & \\
\hline & & 3.3 Complete outcome data & & & $x$ \\
\hline & & 3.4 Confounders accounted for & & $x$ & \\
\hline & & 3.5 Intervention administered as & $x$ & & \\
\hline & & intended & & & \\
\hline \multirow{7}{*}{$\begin{array}{l}\text { Kirkwood et al } \\
\text { (2017) }\end{array}$} & Quantitative & 3.1 Representative sample & $x$ & & \\
\hline & non- & & & & \\
\hline & randomized & 3.2 Appropriate measures & $x$ & & \\
\hline & & 3.3 Complete outcome data & $x$ & & \\
\hline & & 3.4 Confounders accounted for & $x$ & & \\
\hline & & 3.5 Intervention administered as & $x$ & & \\
\hline & & intended & & & \\
\hline \multirow{7}{*}{$\begin{array}{l}\text { Pritchard et al } \\
\text { (2014) }\end{array}$} & Quantitative & 3.1 Representative sample & $x$ & & \\
\hline & non- & & & & \\
\hline & randomized & 3.2 Appropriate measures & $x$ & & \\
\hline & & 3.3 Complete outcome data & $x$ & & \\
\hline & & 3.4 Confounders accounted for & $x$ & & \\
\hline & & 3.5 Intervention administered as & $x$ & & \\
\hline & & intended & & & \\
\hline \multirow{6}{*}{$\begin{array}{l}\text { Arffa and Knapp } \\
\text { (2008) }\end{array}$} & Quantitative & 4.1 Sampling strategy relevant & $x$ & & \\
\hline & descriptive & & & & \\
\hline & & 4.2 Representative sample & $x$ & & \\
\hline & & 4.3 Appropriate measurements & $x$ & & \\
\hline & & 4.4 Low risk of nonresponse bias & $x$ & & \\
\hline & & 4.5 Appropriate statistical analysis & $x$ & & \\
\hline \multirow[t]{6}{*}{ Belciug (2006) } & Quantitative & 4.1 Sampling strategy relevant & $x$ & & \\
\hline & descriptive & & & & \\
\hline & & 4.2 Representative sample & & & $x$ \\
\hline & & 4.3 Appropriate measurements & $x$ & & \\
\hline & & 4.4 Low risk of nonresponse bias & $x$ & & \\
\hline & & 4.5 Appropriate statistical analysis & $x$ & & \\
\hline
\end{tabular}




\section{CHAPTER 6}

\begin{tabular}{|c|c|c|c|c|c|}
\hline \multirow[t]{3}{*}{ Author(s) (Year) } & \multirow[t]{3}{*}{ Study type } & \multirow[t]{3}{*}{ Criteria } & \multicolumn{3}{|c|}{ Criteria met by studies } \\
\hline & & & Yes & No & Not enough \\
\hline & & & & & information \\
\hline \multirow{6}{*}{$\begin{array}{l}\text { Bennet-Levy et al } \\
\text { (1994) }\end{array}$} & Quantitative & 4.1 Sampling strategy relevant & $x$ & & \\
\hline & descriptive & & & & \\
\hline & & 4.2 Representative sample & $x$ & & \\
\hline & & 4.3 Appropriate measurements & $x$ & & \\
\hline & & 4.4 Low risk of nonresponse bias & $x$ & & \\
\hline & & 4.5 Appropriate statistical analysis & $x$ & & \\
\hline \multirow{6}{*}{$\begin{array}{l}\text { Farmer and Brazeal } \\
\text { (1998) }\end{array}$} & Quantitative & 4.1 Sampling strategy relevant & $x$ & & \\
\hline & descriptive & & & & \\
\hline & & 4.2 Representative sample & $x$ & & \\
\hline & & 4.3 Appropriate measurements & $x$ & & \\
\hline & & 4.4 Low risk of nonresponse bias & & $x$ & \\
\hline & & 4.5 Appropriate statistical analysis & $x$ & & \\
\hline \multirow[t]{5}{*}{ Holst et al (2009) } & Quantitative & 4.1 Sampling strategy relevant & $x$ & & \\
\hline & descriptive & 4.2 Representative sample & $x$ & & \\
\hline & & 4.3 Appropriate measurements & $x$ & & \\
\hline & & 4.4 Low risk of nonresponse bias & $x$ & & \\
\hline & & 4.5 Appropriate statistical analysis & $x$ & & \\
\hline \multirow[t]{5}{*}{ Lanca et al (2019) } & Quantitative & 4.1 Sampling strategy relevant & $x$ & & \\
\hline & descriptive & 4.2 Representative sample & $x$ & & \\
\hline & & 4.3 Appropriate measurements & $x$ & & \\
\hline & & 4.4 Low risk of nonresponse bias & $x$ & & \\
\hline & & 4.5 Appropriate statistical analysis & $x$ & & \\
\hline Martin and & Quantitative & 4.1 Sampling strategy relevant & $x$ & & \\
\hline \multirow[t]{4}{*}{ Schroeder (2020) } & descriptive & 4.2 Representative sample & $x$ & & \\
\hline & & 4.3 Appropriate measurements & $x$ & & \\
\hline & & 4.4 Low risk of nonresponse bias & $x$ & & \\
\hline & & 4.5 Appropriate statistical analysis & $x$ & & \\
\hline \multirow[t]{4}{*}{ Meth et al (2019) } & Quantitative & 4.1 Sampling strategy relevant & $x$ & & \\
\hline & descriptive & 4.2 Representative sample & $x$ & & \\
\hline & & 4.3 Appropriate measurements & $x$ & & \\
\hline & & 4.4 Low risk of nonresponse bias & $x$ & & $x$ \\
\hline
\end{tabular}




\section{CHAPTER 6}

\begin{tabular}{|c|c|c|c|c|c|}
\hline \multirow[t]{3}{*}{ Author(s) (Year) } & \multirow[t]{3}{*}{ Study type } & \multirow[t]{3}{*}{ Criteria } & \multicolumn{3}{|c|}{ Criteria met by studies } \\
\hline & & & Yes & No & Not enough \\
\hline & & & & & information \\
\hline \multirow[t]{5}{*}{ Quillen et al (2011) } & Quantitative & 4.1 Sampling strategy relevant & $x$ & & \\
\hline & descriptive & 4.2 Representative sample & $x$ & & \\
\hline & & 4.3 Appropriate measurements & & & $x$ \\
\hline & & 4.4 Low risk of nonresponse bias & $x$ & & \\
\hline & & 4.5 Appropriate statistical analysis & & & $x$ \\
\hline \multirow[t]{5}{*}{ Stimmel et al (2019) } & Quantitative & 4.1 Sampling strategy relevant & $x$ & & \\
\hline & descriptive & 4.2 Representative sample & $x$ & & \\
\hline & & 4.3 Appropriate measurements & $x$ & & \\
\hline & & 4.4 Low risk of nonresponse bias & $x$ & & \\
\hline & & 4.5 Appropriate statistical analysis & $x$ & & \\
\hline \multirow{6}{*}{$\begin{array}{l}\text { Westervelt et al } \\
\text { (2007) }\end{array}$} & Quantitative & 4.1 Sampling strategy relevant & $x$ & & \\
\hline & descriptive & & & & \\
\hline & & 4.2 Representative sample & $x$ & & \\
\hline & & 4.3 Appropriate measurements & $x$ & & \\
\hline & & 4.4 Low risk of nonresponse bias & $x$ & & \\
\hline & & 4.5 Appropriate statistical analysis & $x$ & & \\
\hline \multirow[t]{6}{*}{ Bodin et al (2006) } & Quantitative & 4.1 Sampling strategy relevant & $x$ & & \\
\hline & descriptive & & & & \\
\hline & & 4.2 Representative sample & $x$ & & \\
\hline & & 4.3 Appropriate measurements & $x$ & & \\
\hline & & 4.4 Low risk of nonresponse bias & & $x$ & \\
\hline & & 4.5 Appropriate statistical analysis & $x$ & & \\
\hline \multirow{6}{*}{$\begin{array}{l}\text { Kirkwood et al } \\
\text { (2017) }\end{array}$} & Quantitative & 4.1 Sampling strategy relevant & $x$ & & \\
\hline & descriptive & & & & \\
\hline & & 4.2 Representative sample & $x$ & & \\
\hline & & 4.3 Appropriate measurements & $x$ & & \\
\hline & & 4.4 Low risk of nonresponse bias & $x$ & & \\
\hline & & 4.5 Appropriate statistical analysis & $x$ & & \\
\hline \multirow[t]{9}{*}{ Foran et al (2015) } & Mixed- & 5.1 Adequate rationale for mixed & $x$ & & \\
\hline & methods & methods & & & \\
\hline & & 5.2 Components adequately & $x$ & & \\
\hline & & integrated & & & \\
\hline & & 5.3 Components adequately & $x$ & & \\
\hline & & interpreted & & & \\
\hline & & 5.4 Differences addressed & $x$ & & \\
\hline & & 5.5 Components adhere quality & $x$ & & \\
\hline & & criteria & & & \\
\hline
\end{tabular}



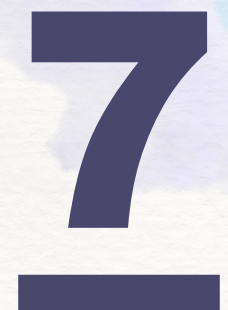

An exploratory study of the development of an interactive visual tool of neuropsychological test results in memory clinics

Angélique AA Gruters, Inez HGB Ramakers, Annemarie PM Stiekema, Frans RJ Verhey, Roy PC Kessels, Marjolein E de Vugt. 


\section{CHAPTER 7}

\section{ABSTRACT}

\section{Objectives}

The aim of this study was to develop a web-based visual tool to improve the explanation and understanding of neuropsychological results, information retention and psychologist-patient communication.

\section{Methods}

The visual tool was developed and optimized using an iterative five-phase stepwise approach to determine its usability, technology acceptance, and feasibility in a memory clinic population. Feedback from different user perspectives (patients, family members, and psychologists) was obtained in each phase using a multimethod approach (e.g., a multidisciplinary brainstorm session, think-aloud sessions, focus groups). The prototype was subsequently tested in a pilot study.

\section{Results}

The first phases offered insights that led to optimization of the prototype. On a scale ranging from 0 to 100, psychologists evaluated the usability as high [88.1 $\pm 7.6,70-87]$. Patients and significant others gave positive feedback, but information retention in patients remained low. All participants thought the benefits of the visual tool included seeing cognitive strengths and weaknesses with a translation to daily life all at one glance and receiving feedback on paper to take home. Important barriers were mentioned by psychologists, such as a limited set of tests included and no integration with hospital systems.

\section{Conclusion}

Overall, patients, family members, and psychologists reported that a visual display of the cognitive profile with insights into daily life had added value to clinical practice. Feedback from the pilot study was adopted in the tool for future implementation purposes. 


\section{INTRODUCTION}

A dementia diagnosis has a huge impact on patients and their significant others. Understanding the consequences of this diagnosis may, however, enable them to make positive adjustments and cope with the experienced loss. ${ }^{1-3}$ Therefore, accurate and clear communication during the diagnostic process and disclosure are required. A common assessment tool in supporting the diagnostics of dementia is a neuropsychological assessment (NPA). A recent systematic review showed the added value of an NPA in improving the accuracy of diagnosis, predicting patient outcomes, and increasing referrer satisfaction. ${ }^{4}$ The majority of patients also perceived an NPA as helpful. ${ }^{4}$

Neuropsychological feedback is an important component of the NPA process that offers the opportunity to discuss cognitive strengths and weaknesses and provides recommendations for daily life functioning.5,6 Furthermore, neuropsychological feedback increases a patient's quality of life, understanding of a disease, and coping abilities. ${ }^{7}$ Previous studies showed that patients were more satisfied with NPAs when they received such feedback and that they perceived this feedback as useful. . $^{-11}$ However, a standardized approach in communication techniques for providing feedback is lacking. ${ }^{12}$ Giving feedback may be challenging due to the complex nature of neuropsychological test results. ${ }^{5,6}$ In addition, information retention of medical information is low in general. ${ }^{13-15}$ Written information is more easily remembered compared to verbal information, and the former was found to improve treatment adherence and enhance free recall of neuropsychological recommendations. ${ }^{13,16,17}$ However, neuropsychological reports sometimes face challenges related to readability and complexity for laypersons. Understanding written reports and remembering neuropsychological feedback might be even more challenging for people with cognitive impairments or low literacy. ${ }^{18}$ Adapting these reports is often necessary to make findings more understandable for patients and family. ${ }^{19}$

In other medical fields it has been shown that visual aids enhance the recall of spoken medical instructions. ${ }^{20,21}$ Visual aids also improved the understanding of medical instructions, especially when a combination of visual, written, and verbal instructions was used. ${ }^{22}$ To our knowledge, no studies have explored the use of visual aids in providing neuropsychological feedback. A patient-friendly tool to visualize neuropsychological test performances could enable professionals to deliver patient-tailored information and may improve understanding of cognitive strengths and weaknesses and patient satisfaction.

The aim of this study was to develop a web-based visual tool for neuropsychological test results to increase the understanding of neuropsychological performances, to improve information retention and to support communication during feedback sessions. The second aim of this study was to determine the usability, technology acceptance, and feasibility of the tool. 


\section{CHAPTER 7}

\section{ITERATIVE DEVELOPMENT PROCESS}

An iterative process was used to develop the web-based interactive visual tool during the "Innovations in NeuroPsychological assessment in the timely Diagnosis of Dementia" (INPAD) project. The visual tool was cocreated with patients, family members and neuropsychology experts using a stepwise approach including five consecutive phases spread over a 3-year time period (2017 - 2020) (Figure 1). All sessions in each phase were audiotaped and analyzed by summarizing and grouping the feedback.
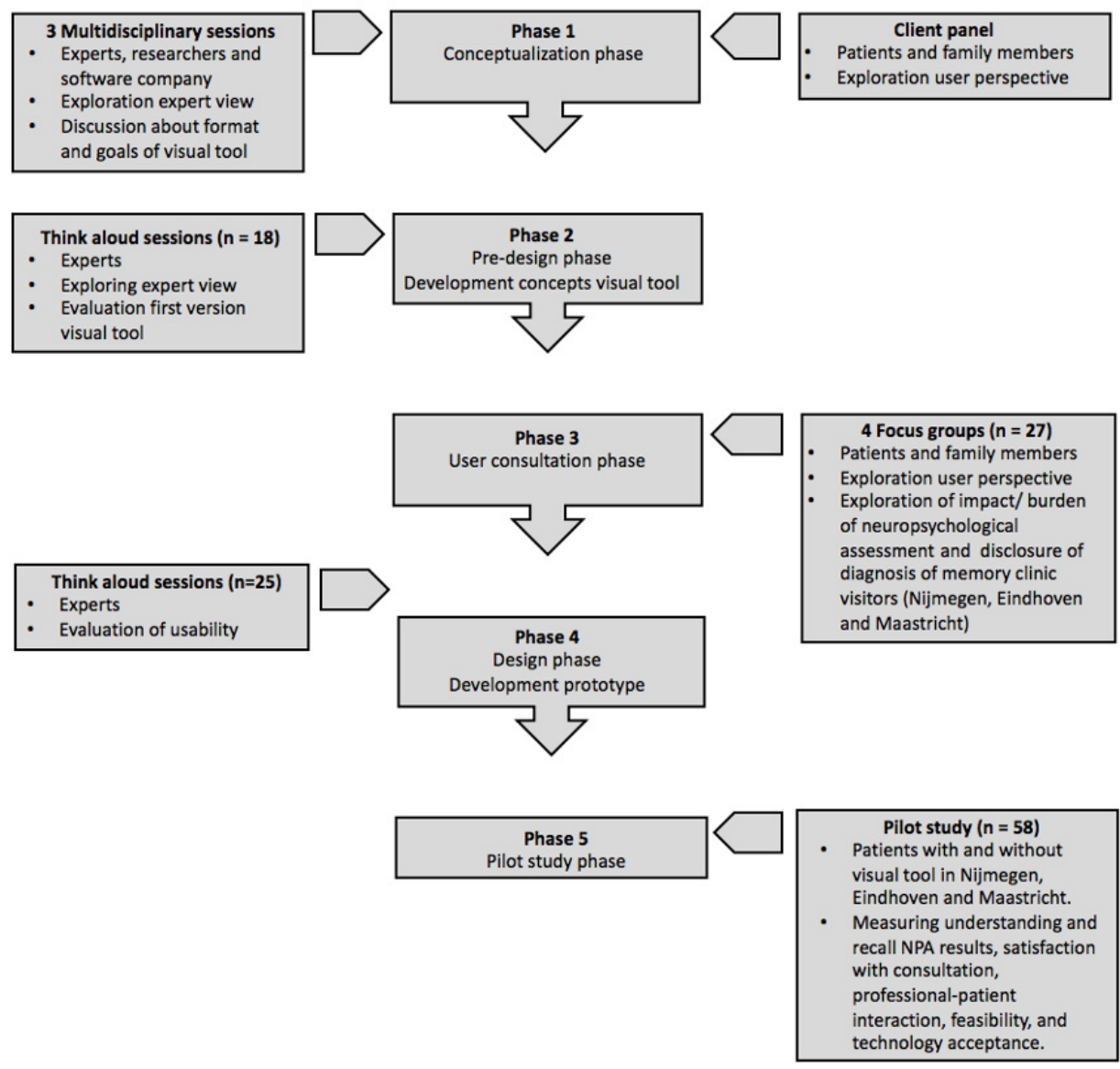

Figure 1. Overview of the iterative development process of the visual tool.

\section{Phase 1: $\quad$ Conceptualization phase}

\section{Methods}

During the conceptualization phase, the content and design of the visual tool was developed using input from three multidisciplinary sessions with different disciplines (INPAD project group, neuropsychologists, software developers, interaction designer) and client panel members from the Alzheimer Center Limburg. 


\section{CHAPTER 7}

\section{Results}

Following the conceptualization phase, a consensus was reached on a visual tool with two modules (separate modules for psychologists and patients/family members) and on the cognitive tests to be included (supplementary material). The module for the psychologist should improve the diagnostic workflow and should contain detailed information regarding neuropsychological results. The module for the patient should be easy to read and include recommendations for daily life functioning.

Table 1. Overview of cognitive domains and tests for the visual tool based on consensus in the multidisciplinary sessions.

\begin{tabular}{l|l}
\hline Mental speed/Attention & $\begin{array}{l}\text { Concept Shifting Test A + B or Trail Making Test A } \\
\text { Stroop Color-Word Test 1 + } 2^{25} \\
\text { Letter Digit Substitution Test (LDST) } 26 \\
\text { Digit Span forwards (WAIS-IV) 27 }\end{array}$ \\
\hline Executive functioning & $\begin{array}{l}\text { Concept Shifting Test C or Trail Making Test B }{ }^{23,24} \\
\text { Stroop Color-Word Test 325 } \\
\text { Category fluency (animals/occupations) }\end{array}$ \\
& Digit Span backwards and sorting (WAIS-IV) ${ }^{27}$ \\
\hline Memory & $\begin{array}{l}\text { Auditory Verbal Learning Test }{ }^{29} \\
\text { Visual Association Test (short and long version) } 30\end{array}$ \\
\hline
\end{tabular}

\section{Phase 2: $\quad$ Pre-design phase}

\section{Methods}

Based on the input from phase 1, concept versions of the visual tool were developed and evaluated using the think-aloud method ${ }^{31}$ by neuropsychology experts $(n=18)$ working at memory clinics across twelve Dutch hospitals. These potential users were asked to think out loud while inspecting the different versions of both the patient and clinician modules. They were asked to rank the versions according to their preference.

\section{Results}

In general, experts had positive feedback about the visualization concept versions and the table with raw and standardized z-scores. All experts provided comments regarding the design (e.g., font size, colors, and contrasts) and content (e.g., missing cognitive tests, questionnaires and observations, missing "language" as relevant cognitive domain, descriptions of daily life consequences too brief). They preferred the incorporation of a reliable change index ${ }^{32,33}$ in the tool.

\section{Phase 3: $\quad$ User consultation phase}

All feedback from phase 2 led to new conceptual versions. These new versions were presented to fourteen patients and thirteen family members during four focus group sessions across three Dutch MCs. Participants were asked to participate if they were referred to the memory clinic for the evaluation of cognitive complaints and if they 


\section{CHAPTER 7}

had had an NPA in the past year. More information about this procedure is described elsewhere ${ }^{34}$ The participants were asked for their opinions regarding these new concept versions and to rank the versions according to their preference.

Table 2. Characteristics of patients $(n=14)$ and family members $(n=13)$.

\begin{tabular}{lll}
\hline & \multicolumn{2}{c}{ Focus group participants $(\mathrm{n}=27)$} \\
\cline { 2 - 3 } & Patients $(\mathrm{n}=14)$ & Family members $(\mathrm{n}=13)$ \\
\hline Age (mean \pm SD [min-max]) & $66.1 \pm 7.9[49-76]$ & $62.9 \pm 15.1[30-82]$ \\
Women $n$ (\%) & $5(36 \%)$ & $8(62 \%)$ \\
Diagnosis MC visitor & & $5(39 \%)$ \\
$\mathrm{NCl}$ & $6(43 \%)$ & $4(30 \%)$ \\
$\mathrm{MCl}$ & $3(21 \%)$ & $2(15 \%)$ \\
AD dementia & $3(21 \%)$ & $1(8 \%)$ \\
CBS & $1(7.5 \%)$ & $1(8 \%)$ \\
FTD & $1(7.5 \%)$ & \\
Relationship to MC visitor & & $11(85 \%)$ \\
Spouse & & $2(15 \%)$ \\
Child & & \\
\hline
\end{tabular}

Notes. Demographics are represented in $\mathrm{n}(\%)$ unless stated otherwise. Abbreviations. SD $=$ Standard Deviation, $\mathrm{NCl}=$ No Cognitive Impairment, $\mathrm{MCl}=$ Mild Cognitive Impairment, $\mathrm{AD}=$ Alzheimer's disease, CBS $=$ Corticobasal syndrome, FTD = Frontotemporal Dementia .

\section{Results}

Characteristics of patients and family members are presented in table 1. Overall, the visualized concepts were positively rated, and some feedback was given on the design (e.g., preference for larger fonts, red color for reflecting impaired scores was too confronting for patients). A line graph was most commonly preferred, due to its simplicity. All patients and family members indicated that explanations by a psychologist were required to fully understand the tool. In addition, they expressed the need for more information about the daily life consequences of the presented cognitive profile and how to deal with deficits.

\section{Phase 4: $\quad$ Design phase}

The web-based prototype was developed using all feedback from the first three phases. Dutch normative data ${ }^{35}$ were used for transforming the raw scores into age and education-adjusted standard score, as well as for computing reliable change indices according to Jacobson and Truax ${ }^{32}$ or Chelune et al. ${ }^{33}$, and implemented in the tool. The cognitive tests battery was adapted to the recently published 
monodisciplinary guideline for NPAs in the diagnostic work up for mild cognitive impairment and dementia. ${ }^{36}$ The usability of the prototype was evaluated by the same neuropsychological experts $(n=18)$ who participated in phase 2. Additional experts working at seven different institutions were recruited to maximize variation (total $n=$ 25). The think-aloud procedure was repeated, but this time, experts had to fill in raw test results from a dummy patient into the web-based prototype. They also completed a survey about the design of the tool with eleven items scored on a 7-point Likert scale ( 1 = totally disagree, 7 = totally agree). Experts were also asked to list three positive and negative aspects of the tool. Usability was evaluated using the System Usability Scale (SUS), which consists of ten items scored on a 5-point Likert scale (1 = strongly disagree, 5 = strongly agree) with a maximum of 100; this scale has been shown to have good psychometric properties.37,38

\section{Results}

Overall, the experts were satisfied with the adaptations in the tool (e.g., more detailed description of daily life implications, easy data entry). Some additional remarks to optimize usability were given (e.g., the need for more specific fields for observations during the NPA, clearer warnings for data entry, choice in type of standard scores). On the survey, experts reported being very satisfied with the design $(6.1 \pm 0.8$, range: 5 7), and the usability was rated as excellent (88.1 \pm 7.6 , range: $70-87)$ [31]. The most commonly listed positive aspects were user-friendliness, clear information to give to patients, and opportunity to improve harmonization between MCs. The most frequently mentioned negative aspects were the lack of other commonly used tests, and fonts being too small.

\section{Phase 5: $\quad$ Pilot study phase}

\section{Methods}

All feedback from phase 4 was implemented, resulting in an optimized prototype of the visual tool (figures 2 and 3 ). An essential adaptation consisted of extending the section on everyday life implications. Here, psychologists could select implications of the NPA results for the patient's daily life and provide corresponding tips per cognitive domain (e.g., 'you can switch your attention very well when doing multiple things, 'learning new information costs a lot of effort', 'writing things down could help you to remember to do the things you have planned', 'try and use pictures as a memory aid'). Next to standard sentences psychologists could add their own interpretations to individualize these recommendations. This prototype was subsequently used in the pilot evaluation in which two groups were compared (one receiving neuropsychological feedback without the tool and one with the visual tool) in three hospital-based centers in the Netherlands (Maastricht UMC+, Catharina Hospital Eindhoven, Radboudumc Nijmegen) to ascertain diversity in diagnostic disclosure procedures. 


\section{CHAPTER 7}

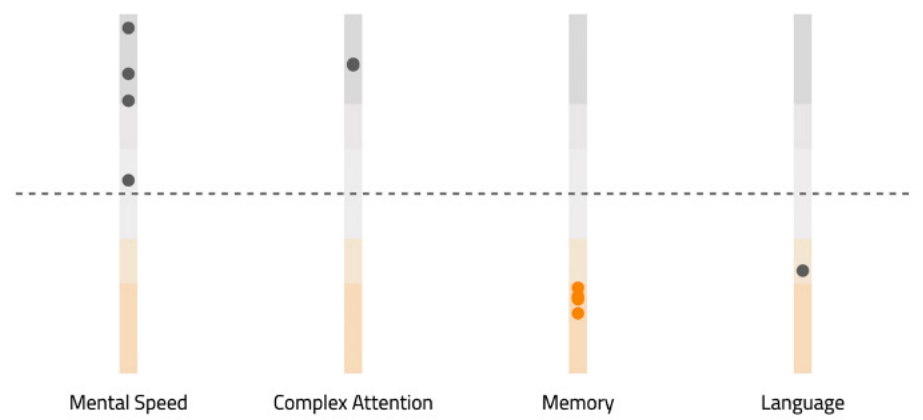

This assessment - $\bullet$ January 2020

Averages

What does this mean in your daily life?

Mental speed and complex attention

- Your mental speed is good

- You can switch your attention very well when doing multiple things

Memory

- Learning new information costs a lot of effort

- Repeating information is less helpful

Tips

- Use figures as a memory aid

- Write things down

Figure 2. Patient view (of a fictional patient) in visual tool. Notes. This figure shows the results of the most recent assessment on the domains of mental speed, complex attention, memory, and language. Each point in the bar above the cognitive domains represents the score on a subtest. An orange point indicates a performance lower than minus 2 standard deviations. Below the figure the translation to daily-life functioning can be found. 


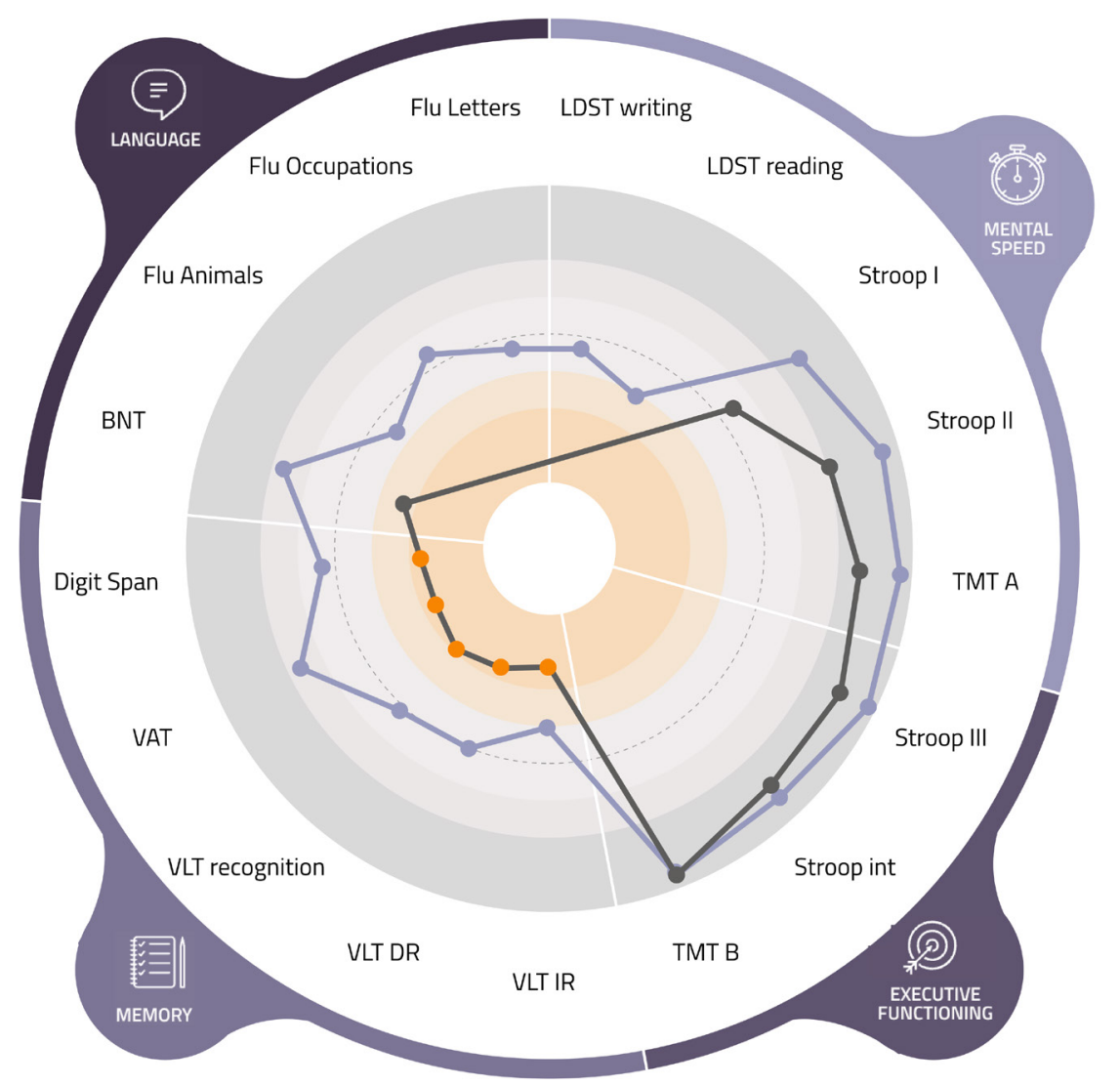

Figure 3. Example of radar plot within psychologist view (of a fictional patient) of the visual tool. Abbreviations. LDST: Letter Digit Substitution Test, CST = Concept Shifting Test, TMT = Trail Making Test, int = interference, VLT $=$ Verbal Learning Test, VAT $=$ Visual Association Test, BNT = Boston Naming Test, Flu = Fluency.

\section{Study participants}

In each center, ten patients from the memory clinic (with a family member, if available) were recruited (30 dyads). Patients were recruited when they were referred for an NPA. Patients were excluded if they had an MMSE $<20$, impaired vision (i.e., would not be able to perceive the visual tool), an intellectual disability, or a history of $(<12$ months) or current treatment for psychiatric disorders (e.g., major depressive disorder, bipolar disorder, psychotic disorder). Between February and December 2019, 37 patients and 35 family members were recruited for this pilot study. During the intake with the psychologist, patients and family members received written information about the study. Two weeks before the consultation with the psychologist, they were contacted by phone to inquire if they wanted to participate. Four patients and two family members 
did not want to participate, and three patients were excluded. In total, 30 patients and 28 family members participated in the study. One dyad participated in the study but did not return the surveys, despite several reminders by phone. Furthermore, the eight psychologists who used the visual tool participated in the pilot study.

\section{Procedures}

During the pilot study, patients $(n=15)$ and family members $(n=15)$ received individual neuropsychological feedback without the visual tool. Next, the visual tool was implemented in the participating centers and used by the psychologists during individual feedback sessions with patients $(n=15)$ and family members $(n=13)$. After the feedback session, patients and family members of both groups completed several questionnaires. Furthermore, in both groups, six dyads (patient - family members) were randomly selected for in-depth interviews. A semi-structured guide was used with questions about their experience with the consultation and, if applicable, the visual tool. The psychologists also completed a questionnaire after each consultation, and participated in an in-depth interview using a semi-structured guide with questions about the experience with the visual tool during neuropsychological feedback.

\section{Questionnaire for the patients and family members}

To assess whether patients and their family members understood the explained findings of the NPA, three items ("I understand my NPA results", "The explanation gave insight into cognitive weaknesses", "The explanation gave insight into cognitive strengths") were constructed by the authors. Items could be scored on a 5-point Likert scale (1 = fully disagree, 5 = fully agree). To evaluate the interaction between participants and psychologists, questions from the Patient Provider Interaction questionnaire40 were adapted and translated into Dutch. Items were scored on a 4-point Likert scale ( 1 = no, 2 = possibly no, 3 = possibly yes, 4 = yes). Several other questionnaires were also administered after they were translated into Dutch. First, the Patient Satisfaction Questionnaire (PSQ) was used to measure the satisfaction following the consultation using a visual analogue scale ranging from 0 (not satisfied at all) to 100 (extremely satisfied). ${ }^{41}$ The Patient-Doctor Relationship Questionnaire (PDRQ-9) evaluated the perceived relationship (e.g., helpfulness, trustworthiness, understanding) with the psychologist, ${ }^{42}$ and items could be scored on a 5 -point Likert scale ( $1=$ not at all appropriate, 5 = totally appropriate). The participants who received feedback with the visual tool were asked additional questions regarding the added value ("The graph made me understand the information better", "The graph made it easier to follow the consultation", "The graph gave me more insight into the cognitive complaints", "Receiving the graph to take home had added value"), layout, and application of the visual tool (e.g., whether or not they inspected it at home or discussed it with others). These items were constructed by the authors and could be scored on a 5-point Likert scale ( 1 = totally disagree, 5 = totally agree). 


\section{CHAPTER 7}

Questionnaire for the psychologists

To investigate the level of acceptance, the psychologists completed the Technology Acceptance Model questionnaire. ${ }^{43}$ The questions addressed the following domains: perceived usefulness, perceived ease of use, intention to use, and attitude toward using the technology. The higher the scores on these domains, the more likely someone is to use the technology in question (figure 4). ${ }^{43}$ Additional questions on feasibility and satisfaction with the visual tool were constructed by the authors. All items (technology acceptance, feasibility, and satisfaction) were scored on a 7-point Likert scale ( 1 = totally disagree, 7 = totally agree)

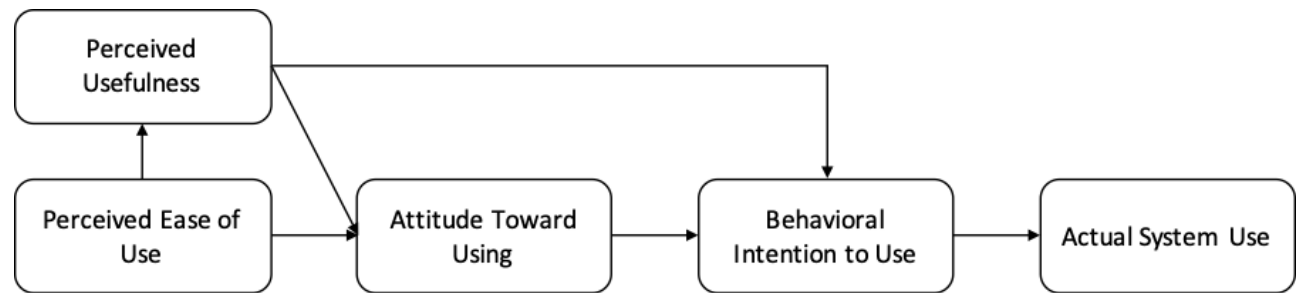

Figure 4. Relation between domains of Technology Acceptance Model and actual system use.

Data analysis

Statistical analyses were conducted using version 24 of the Statistical Package for Social Sciences (SPSS). To examine group differences between the groups (with versus without visual tool), $\chi^{2}$-tests or independent samples t-tests were conducted. Furthermore, descriptive statistics were reported. All interviews were transcribed verbatim and analyzed independently by two raters using ATLAS.ti version 8.4.4. One of the authors was not involved in previous phases of the INPAD study and became involved at a later stage to ascertain an independent view when conducting the analysis. First, an inductive approach was applied by adding open codes in the transcript. Then, themes were based on both the open codes and the semi-structured guide: expectations, experiences during the consultation, facilitators and barriers in remembering the information, and adjustment after the consultation. The categories and codes were discussed with two other authors to improve credibility. ${ }^{44}$ To gain insight into differences between the centers, the interviews were analyzed separately. The quotes used in the results section were selected and translated from Dutch into English.

\section{Results patients and family members}

Background characteristics

Table 2 describes the characteristics of 30 patients and 28 family members. The majority of family members were spouses and had daily contact with the patient. No significant differences regarding age, sex, and education were found between participants in the group with and without the tool. 


\section{CHAPTER 7}

Expectations before the consultation

Both patients and family members with and without the visual tool expressed that they did not know what to expect from the consultation. This was present in two centers where patients received the diagnostic disclosure together with neuropsychological feedback. These patients were worried and experienced feelings of uncertainty. Furthermore, they were all focused on the question of whether they, or their family member, had dementia or not. In one center where neuropsychological feedback was given after two weeks, these feelings were not present.

"Those are all things you bring with you ... There is a signal in your head that is dormant, but present. Then I think, my God, what will be waiting for me if that [a dementia diagnosis] is the case?" (center 2, patient with visual tool) 
Table 3. Characteristics of patients $(n=30)$ and family members $(n=28)$.

\begin{tabular}{|c|c|c|c|c|}
\hline & \multicolumn{2}{|c|}{ Without visual tool $(n=30)$} & \multicolumn{2}{|c|}{ With visual tool $(n=28)$} \\
\hline & Patients $(n=15)$ & Family members ( $n=15)$ & Patients ( $n=15)$ & Family members $(n=13)$ \\
\hline $\begin{array}{l}\text { Age, y (mean } \pm S D \text { [min- } \\
\text { max }])\end{array}$ & $72.5 \pm 8.7[49-85]$ & $67.2 \pm 12.2[44-77]$ & $71.1 \pm 7.9[59-88]$ & $65.3 \pm 13.3[37-89]$ \\
\hline Women & $6(40 \%)$ & $11(73 \%)$ & $6(43 \%)$ & $9(75 \%)$ \\
\hline \multicolumn{5}{|l|}{ Education } \\
\hline Low & $0(0 \%)$ & $0(0 \%)$ & $0(0 \%)$ & $0(0 \%)$ \\
\hline Middle & $10(67 \%)$ & $9(60 \%)$ & $10(71 \%)$ & $5(42 \%)$ \\
\hline High & $5(33 \%)$ & $6(40 \%$ & $4(29 \%)$ & $7(58 \%)$ \\
\hline \multicolumn{5}{|l|}{ Diagnosis } \\
\hline $\mathrm{NCl}$ & $6(40 \%)$ & & $7(47 \%)$ & \\
\hline $\mathrm{MCl}$ & $6(40 \%)$ & & $6(40 \%)$ & \\
\hline Dementia & $3(20 \%)$ & & $2(13 \%)$ & \\
\hline \multicolumn{5}{|l|}{ Relationship to patient } \\
\hline Spouse & & $13(87 \%)$ & & $10(83 \%)$ \\
\hline Child & & $2(13 \%)$ & & $2(17 \%)$ \\
\hline \multicolumn{5}{|l|}{ Contact with patient } \\
\hline Daily & & $13(87 \%)$ & & $10(83 \%)$ \\
\hline 4-6 times a week & & $0(0 \%)$ & & $0(0 \%)$ \\
\hline 1-3 times a week & & $2(13 \%)$ & & $2(17 \%)$ \\
\hline 1-3 times a month & & $0(0 \%)$ & & $0(0 \%)$ \\
\hline
\end{tabular}

Notes. Demographics are represented in $\mathrm{n}(\%)$ unless stated otherwise. Abbreviations. SD = Standard Deviation, $\mathrm{NCl}$ = No Cognitive Impairment, $\mathrm{MCl}$ = Mild Cognitive Impairment .

Experiences during the consultation

Overall, patients and family members in both groups were very positive regarding the consultation with the psychologist. They liked the psychologists' tranquility, clear explanation, and attitude. They also appreciated the opportunity to ask all the questions they wanted, and they felt no time constraints. On the questionnaire, no significant differences were found between the groups concerning interaction, patientpsychologist relationship, and satisfaction with the consultation (table 4). 
"I went home feeling relieved. Perhaps due to receiving attention for the first time. Those people know what they are doing. So many people do not understand it at all. You get the feeling that you are stupid." (center 3, patient without visual tool)

Table 4. Comparison between groups without $(n=30)$ and with visual tool $(n=28)$ concerning communication, satisfaction and psychologist relationship.

\begin{tabular}{lllll}
\hline & \multicolumn{2}{l}{ Without visual tool $(n=30)$} & With visual tool $(n=28)$ & \\
\cline { 2 - 4 } & Patients $(n=15)$ & Family members $(n=15)$ & Patients $(n=15)$ & Family members $(n=13)$ \\
\hline Communication & $46.7 \pm 4.7[23-43]$ & $49.9 \pm 3.9[39-52]$ & $47.6 \pm 3.6[41-52]$ & $49.8 \pm 2.3[44-52]$ \\
Satisfaction with & & & & \\
Needs addressed & $80.7 \pm 14.9[60-100]$ & $83.3 \pm 9.8[70-100]$ & $74.3 \pm 22.1[20-100]$ & $80.0 \pm 12.1[50-100]$ \\
Patient's involvement & $83.3 \pm 12.9[60-100]$ & $86.0 \pm 9.9[70-100]$ & $79.3 \pm 23.0[20-100]$ & $84.2 \pm 10.0[70-100]$ \\
Information given & $84.0 \pm 12.4[60-100]$ & $86.0 \pm 11.8[60-100]$ & $76.4 \pm 22.4[20-100]$ & $84.2 \pm 9.9[70-100]$ \\
Emotional support & $78.7 \pm 24.8[0-100]$ & $84.0 \pm 11.8[70-100]$ & $77.9 \pm 19.7[40-100]$ & $80.8 \pm 14.4[50-100]$ \\
Interaction in general & $85.33 \pm 11.9[70-100]$ & $86.7 \pm 10.5[70-100]$ & $81.4 \pm 16.1[50-100]$ & $84.2 \pm 10.0[70-100]$ \\
Overall satisfaction & $82.4 \pm 11.1[66-100]$ & $85.2 \pm 9.3[70-100]$ & $77.9 \pm 19.6[32-100]$ & $82.7 \pm 9.9[64-100]$ \\
Relationship & $39.7 \pm 4.9[32-45]$ & $38.7 \pm 4.9[32-45]$ & $37.9 \pm 6.2[27-45]$ & $39.3 \pm 4.2[33-45]$ \\
\hline
\end{tabular}

Notes. All scores are represented in mean \pm SD [range]. The higher the score represents the more the patients or family members agreed.

Regardless of the visual tool, information retention was reported to be low, which was experienced more by patients than by family members. They often remembered the diagnosis (or only that it was not dementia) but forgot other details. In case of no dementia this was accompanied by feelings of relief; in case of a dementia diagnosis, this was a confirmation of their suspicions. Participants needed some time during the consultation to process the information about the diagnosis.

"It lets you know where this is coming from. This gives some piece of mind even though it is a disease that is not really nice. Then you know what caused it and that you are not going crazy." (center 1, patient with visual tool)

Patients and family members especially perceived benefits due to receiving information and concrete recommendations about the implications of the NPA results for daily life. The group in which the visual tool was used, appreciated that they could take home the concrete tips on paper. In both groups, the consultation mainly focused on cognitive weaknesses, and participants would have liked to hear more about cognitive strengths as well.

Facilitators and barriers in remembering information

Over $60 \%$ of the patients and $80 \%$ of the family members in the group without the visual 
tool indicated that they would have liked to receive something on paper to take home and thought that a visual aid would have been helpful. During the interviews, they explained that receiving information on paper meant that they could read it at home at their own pace. When the visual tool was used, more than $90 \%$ of the patients and $80 \%$ of the family members liked that a graph was used and perceived the ability to take it home on paper as having added value. Both groups indicated that taking someone with you to the consultation facilitated information retention. Barriers in information retention were related to the emotions that accompanied receiving the diagnosis, cognitive impairment of the patient, and the setting of the consultation (e.g., when there were too many people present).

"Just put everything on paper. If you cannot recall it anymore you can check it again. If you then still do not recall it, you check it again. Paper is very patient." (center 3, family member without visual tool)

"The psychologist drew a figure of the cognitive profile of my mother. And then I thought it wasn't too bad ... A picture says more than a thousand words. Then you can see it visually." (center 2, family member without visual tool)

Adjustment after the consultation

During theinterviews, patientsandfamilymembersfrom both groupsmentioned that they discussed the results of the NPA within their social network. They also experienced that they were able to better cope with the cognitive complaints after the consultation (e.g., being more honest, more understanding toward the cognitive complaints). However, it remaineddifficultforsomefamilymemberstoadapttothechanged behaviorsofthepatient.

\section{Opinion of visual tool}

Patients and family members indicated that visual information was easier to understand and easier to remember compared to only receiving verbal information. One patient with dementia found the graph difficult to understand. Other aspects that added value included the ability to see their cognitive profile at one glance, the ability to receive implications of the NPA results for daily life, and an easier interpretation of their own performance by comparing it to a reference group. They also highly appreciated that they received something to take home (figure 5). Furthermore, they emphasized that the visual tool is only helpful when explained by psychologists during a face-to-face consultation. 


\section{CHAPTER 7}
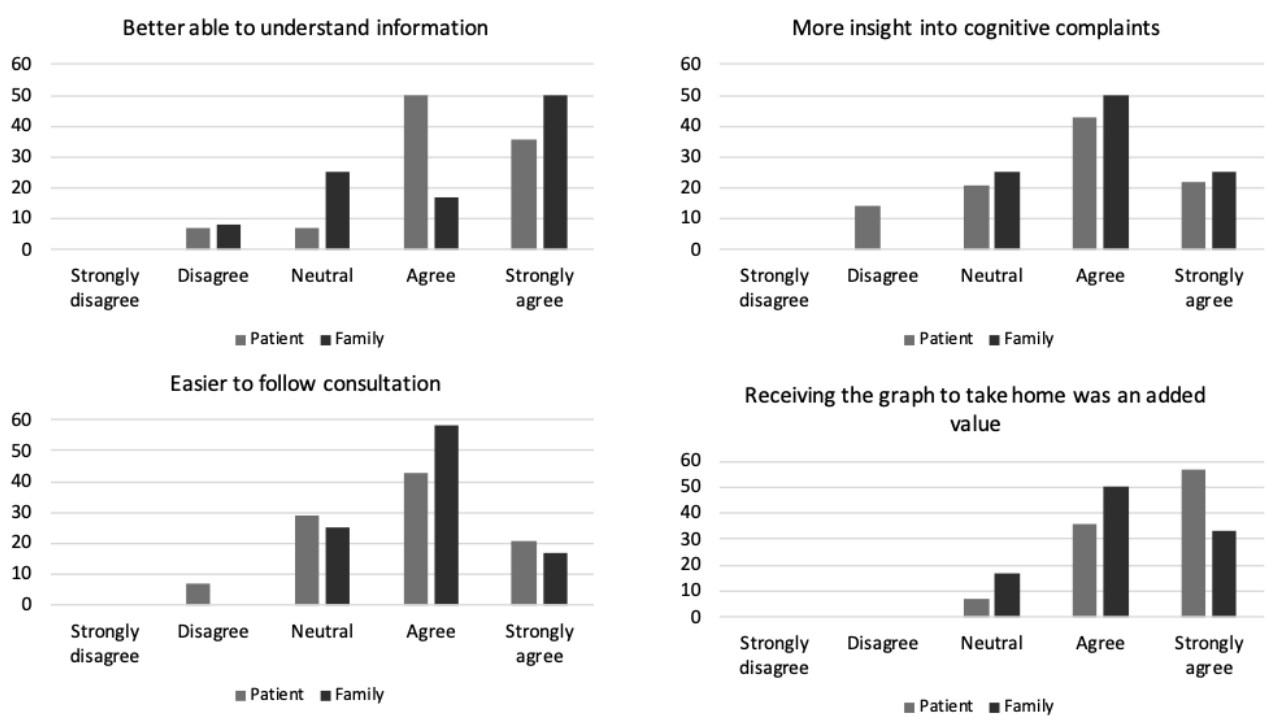

Figure 5. Level of agreement regarding the added value of the visual tool in patients $(n=15)$ and family members $(n=13)$.

\section{Results psychologists}

\section{Background characteristics}

Theworkexperienceofthepsychologistsinvolved $(n=8)$ wasonaverage $($ mean $\pm S D) 14.3 \pm$ 6.6years [range: 2.5 - 22]. Seven psychologistsfollowed basic or advanced post-master's professional clinical training, and one psychologist wasstill in training for a clinical license.

\section{Added value of visual tool}

In line with the patients and family members, psychologists reported seeing the cognitive strengths and weaknesses at one glance and giving something to take home as advantages of the visual tool. Having the reliable change index implemented in the tool was also considered a benefit. The psychologists argued that using multiple modalities (auditory, written and visual) might lead to a better understanding and retention of the information. The visual tool was evaluated as user-friendly and easy to use. Furthermore, some psychologists considered the visual tool as a way to standardize neuropsychological feedback sessions across psychologists.

"I think we say a lot to patients who sometimes only remember if they have dementia or not. By making it visual you can take them by the hand, and I think they will remember it much better ... It really helps because you when you explain this in words, that makes it easily gets more complicated. To keep the language simple, a visual aid is very supportive." (psychologist 8) 
"I think the added value is that you can see the profile of strengths and weakness in one image. With repeated measurements you can also see it at one glance, what went better and what takes more effort. You have to use less words to explain this, and the words you use are supported by the visual tool." (psychologist 2)

\section{Changes in the consultation}

Using the visual tool led to a different way of explaining NPA results. It was considered valuable for explaining NPA results because psychologists could use the tool to summarize their explanation, and it felt more professional as they did not have to search through papers or draw their own graphs on a board or piece of paper. According to the psychologists, the use of the visual tool did not necessarily lead to more interaction. However, they indicated that the structure of the interaction did change, as patients and family members were prompted by the tool to ask questions right away. All psychologists said they would use the tool in their clinical work, but using the tool was something they had to get used to. Furthermore, psychologists in two centers said they would only use it if barriers and concerns were solved. This was particularly related to the integration of more tests in the tool to fit better with routine practice.

"I had to get used to it, because I have a routine in how I say and explain things. ... I was searching for what I was actually seeing on my screen and how I could explain that in small steps to the person sitting in front of me." (psychologist 2)

"It makes it professional in a way. It appeals more to the imagination more than when I only have a folder full of loose sheets and papers" (psychologist 4)

\section{Barriers and concerns}

As mentioned above, a major concern was the limited number of tests available in the visual tool, which made it difficult to explain the full assessment. A few practical concerns were also raised, such as better integration with the software of the electronic patient files so that test results do not have to be entered twice, a lack of clarity with respect to the graphs due to grayscale printers at the clinics, and the low availability of computers in some consultation rooms.

"Just imagine that you administered other cognitive tests which are now missing in the tool. That can really change the visualization of the results. Sometimes it seemed as if the domain memory had a very low performance, but we administered other memory tests that went well. Then, I have to adapt that with a pen and that creates confusion." (psychologist 7)

Technology acceptance

All psychologists indicated that the visual tool was helpful for explaining NPA results and that the ability to select the implications of the results for daily life was an important 
feature of the system. They were satisfied with the system (mean \pm SD, range; $5.6 \pm 0.7$, $5-7)$ and indicated that it had a good design $(5.9 \pm 0.6,5-7)$, attractive layout $(6.0 \pm 0.5$, $5-7)$, and readable text $(5.8 \pm 0.7,5-7)$. Furthermore, high levels of agreement were present in the domains of perceived usefulness $(5.4 \pm 0.8,4.0$ - 6.2) and attitude toward using $(6.0 \pm 0.8,4.5-7.0)$. Average agreement was reported on perceived ease of use $(3.5 \pm 0.6,2.6-4.3)$.

\section{DISCUSSION}

The aim of this study was to develop a web-based visual tool to improve the explanation and understanding of neuropsychological test results, information retention and psychologist-patient communication. The second aim was to determine the usability, technology acceptance, and feasibility of the tool. An iterative process incorporating perspectives of different end-users (patients, family members, neuropsychology experts) was used to develop the tool. During the early development, already all users reported positive feedback about a visual tool to explain NPA results. The usability of the tool was evaluated as excellent by psychologists. The pilot study indicated that regardless of the visual tool, patients and family members were positive regarding the consultation with the psychologist. The visual tool led to an increase in understanding of NPA results. Patients, family members, and psychologists indicated that the overview of cognitive strengths and weaknesses, the implications of NPA results for daily life, and receiving something to take home had added value. However, the information retention in patients remained low. Psychologists indicated that the tool was useful and intuitive, and technology acceptance was high. Nevertheless, some barriers were mentioned that have to be addressed to increase feasibility in clinical practice.

\section{Experiences with neuropsychological feedback}

Patients and family members from both groups were positive regarding the consultation with the psychologist, which might be related to patients receiving useful feedback. ${ }^{8,11}$ Neuropsychological feedback is increasingly part of care as usual and used as a therapeutic intervention. ${ }^{8.45}$ However, in Dutch MCs, neuropsychological feedback is not part of standard practice. This is sometimes related to financial barriers but may also be due to the multidisciplinary nature of the $\mathrm{MC}^{46}$ in which the medical specialist often communicates the diagnosis. Based on the small body of literature on experiences with NPA in MC settings, a need for a follow-up consultation with the neuropsychologist has been reported. ${ }^{8,34,47,48}$ Furthermore, providing neuropsychological feedback has been related to positive outcomes in other disorders. ${ }^{7}$ For example, in patients with traumatic brain injury, feedback helped both patients and family cope with the consequences, ${ }^{49}$ and in patients with a mood disorder, reductions in psychiatric and cognitive symptoms were observed. ${ }^{50}$

\section{Information recall during neuropsychological feedback}

In our pilot study, the information retention of patients, with and without the visual tool, remained low. No other studies have investigated whether retention 
of neuropsychological feedback improved by offering visual aids, but other fields showed improved retention and understanding. ${ }^{20,51}$ Fewer worries were reported among patients and families in the center who had already received the diagnostic disclosure two weeks before receiving neuropsychological feedback. While low retention is likely to be at least partly due to memory problems, other factors may play a role as well. For example, the low level of information retention might be due to the emotional impact of receiving a diagnosis. Emotional information might be prioritized over other competing information, and neutral information has been found to decay over time more rapidly than emotionally loaded information.,5,52 Other explanations for low medical information retention could be clinician-related factors (e.g., using difficult terminology), patient-related factors (e.g., education, experienced stress), or a focus on diagnosis-related information. ${ }^{13,15}$ All participants indicated that receiving both oral, written, and visual information would facilitate information retention. To our knowledge, only two studies showed that written information increased free recall of neuropsychological recommendations, but no differences were found in the recall of diagnostic information. ${ }^{16,17}$ Offering tailored and high-quality information remains important because it can give patients the opportunity to take more responsibility for their health, respond better to health-related problems, ${ }^{53}$ feel more in control, ${ }^{54}$ and participate in a more active manner in shared decision making..$^{55}$ It is also important to provide neuropsychological feedback after patients have received the diagnostic disclosure and not at the same time. Furthermore, interventions that support information provision improved quality of life in patients with dementia. ${ }^{56}$

\section{Strengths and limitations}

A prominent strength of the current study is co-creation with different users of the tool, which might have resulted in the high rates of usability in our visual tool. The feedback of patients, family members, and neuropsychology experts on the content, design, and layout of the tool led to an adapted version that better fits the needs of the end-users. Co-creation involves different user perspectives because every individual brings their own knowledge, which can lead to collective creativity, ${ }^{57}$ a shared understanding of the product, ${ }^{58}$ innovative generation of ideas, critical thinking, reciprocal knowledge gain, and long-term involvement of the potential users. ${ }^{59}$. From a software development perspective, high usability (also referred to as "quality in use") prevents the occurrence of errors and results in higher user satisfaction, reduced training and documentation costs, and a better cost-benefit ratio. ${ }^{60}$ Another strength is the involvement of three different centers to take the variability between centers into account. The variability in the sample was further increased by using a purposive sampling approach to account for the heterogeneity present in memory clinic populations. Furthermore, multiple types of triangulation in our methodological approach have led to an enrichment of the data.

However, some limitations have to be considered as well. Due to the variability between the centers, it is difficult to generalize our findings to a broader memory clinic population. Methodological problems with questionnaire data should also be considered. For example, respondents often score equally high or low on domains of 


\section{CHAPTER 7}

outcome measures, which can lead to an underestimation. ${ }^{61}$ Another important note is that the visual tool might not be suitable for all participants. In our study, one patient with dementia found the visual tool too difficult to comprehend. However, the caregiver of this patient was very grateful for the information because it gave her more tools to cope with the diagnosis of her husband.

\section{CONCLUSION}

A standardized visual tool could be used as a communication aid during neuropsychological feedback sessions by giving the psychologist a frame of relevant feedback aspects, including the translation to daily life recommendations. The visual tool developed in this paper provides such a framework and can be used as a starting point. Future research should optimize the visual tool. More cognitive tests and normative data should be included. Additionally, integration with the hospital-based patient system would be ideal. Moreover, adaptation of the tool for other patient groups, such as patients with traumatic brain injury, stroke or psychiatric disorders, should be explored, as well as longer evaluation periods in larger samples.

\section{ACKNOWLEDGEMENTS}

We would like to express our gratitude to the software company that developed our tool and all participants (patients, family members, and neuropsychological experts) for their time, effort, and valuable feedback on the visual tool. We also would like to thank Angela Wenting and Susanne Valentijn for enabling us to organize focus groups and conduct the pilot study in the Catharina Hospital in Eindhoven. We would also like to thank the ANDI research group for sharing the normative scores of two cognitive tests. Our gratitude also goes to Martine van Zandvoort and Eva van Grinsven for sharing their reliable change index formula. This study was supported by an independent grant from the Noaber Foundation and Alzheimer Nederland. 


\section{CHAPTER 7}

\section{REFERENCES}

1. Lee SM, Roen K, Thornton A. The psychological impact of a diagnosis of

Alzheimer's disease. Dementia (London). 2014;13(3):289-305.

2. de Vugt ME, Verhey FR. The impact of early dementia diagnosis and intervention on informal caregivers. Prog Neurobiol. 2013;110:54-62.

3. Turner GM, McMullan C, Atkins L, Foy R, Mant J, Calvert M. TIA and minor stroke: a qualitative study of long-term impact and experiences of follow-up care. BMC Fam Pract. 2019;20(1):176.

4. Watt $\mathrm{S}$, Crowe SF. Examining the beneficial effect of neuropsychological assessment on adult patient outcomes: a systematic review. Clin Neuropsychol. 2018;32(3):368-390.

5. Postal KS, Armstrong K. Feedback that sticks: The art of effectively communicating neuropsychological assessment results. Oxford: Oxford University Press; 2013.

6. Gorske TT, Smith S. Collaborative Therapeutic Neuropsychological Assessment. New York: Springer Science and Business Media; 2009.

7. Rosado DL, Buehler S, Botbol-Berman E, et al. Neuropsychological feedback services improve quality of life and social adjustment. Clin Neuropsychol. 2018;32(3):422-435.

8. Bennett-Levy J, Klein-boonschate MA, Batchelor J, McCarter R, Walton N. Encounters with Anna Thompson: The consumer's experience of neuropsychological assessment. Clin Neuropsychol. 1994;8(2):219-238.

9. Westervelt HJ, Brown LB, Tremont G, Javorsky DJ, Stern RA. Patient and family perceptions of the neuropsychological evaluation: How are we doing? Clin Neuropsychol. 2007;21(2):263273.

10. Kirkwood MW, Peterson RL, Baker DA, Connery AK. Parent satisfaction with neuropsychological consultation after pediatric mild traumatic brain injury. Child Neuropsychol. 2017;23(3):273-283.

11. Farmer JE, Brazeal TJ. Parent perceptions about the process and outcomes of child neuropsychological assessment. Appl Neuropsychol. 1998;5(4):194-201.

12. Postal $K$, Chow $C$, Jung $S$, Erickson-Moreo $K$, Geier F, Lanca M. The stakeholders' project in neuropsychological report writing: a survey of neuropsychologists' and referral sources' views of neuropsychological reports. Clin Neuropsychol. 2018;32(3):326-344.

13. Kessels RPC. Patients' memory for medical information. J R Soc Med. 2003;96(5):219-222.

14. Langewitz W, Ackermann S, Heierle A, Hertwig R, Ghanim L, Bingisser R. Improving patient recall of information: Harnessing the power of structure. Patient Educ Couns. 2015;98(6):716721.

15. Ley P. Communicating with patients: Improving communication, satisfaction and compliance. New York: Croom Helm; 1988.

16. Fallows RR, Hilsabeck RC. Comparing two methods of delivering neuropsychological feedback. Arch Clin Neuropsychol. 2013;28(2):180-188.

17. Meth M, Calamia M, Tranel D. Does a simple intervention enhance memory and adherence for neuropsychological recommendations? Appl Neuropsychol Adult. 2016;23(1):21-28

18. Abley C, Manthorpe J, Bond J, et al. Patients' and carers' views on communication and information provision when undergoing assessments in memory services. J Health Serv Res Policy. 2013;18(3):167-173. 
1. Baum KT, von Thomsen C, Elam M, et al. Communication is key: the utility of a revised neuropsychological report format. Clin Neuropsychol. 2018;32(3):345-367.

2. Houts PS, Bachrach R, Witmer JT, Tringali CA, Bucher JA, Localio RA. Using pictographs to enhance recall of spoken medical instructions. Patient Educ Couns. 1998;35(2):83-88.

3. Houts PS, Witmer JT, Egeth HE, Loscalzo MJ, Zabora JR. Using pictographs to enhance recall of spoken medical instructions II. Patient Educ Couns. 2001;43(3):231-242.

4. Katz MG, Kripalani S, Weiss BD. Use of pictorial aids in medication instructions: A review of the literature. Am J Health Syst Pharm. 2006;63(23):2391-2397.

5. Van der Elst W, Van Boxtel MP, Van Breukelen GJ, Jolles J. The Concept Shifting Test: adult normative data. Psychol Assess. 2006; 18(4):424-432.

6. Vink $M$, Jolles J. A new version of the TrailMaking Test as an informant processing task. J Clin Neuropsychol. 1985;7:162.

7. Van der Elst W, Van Boxtel MP, Van Breukelen GJ, Jolles J. The Stroop Color-Word Test: influence of age, sex and education; and normative data for a large sample across the adult age range. Assessment. 2006;13:62-79.

8. Van der Elst W, van Boxtel MP, van Breukelen GJ, Jolles J. The Letter Digit Substitution Test: normative data for 1,858 healthy participants aged 24-81 from the Maastricht Aging Study (MAAS): influence of age, education, and sex. J Clin Exp Neuropsychol. 2006;28(6):998-1009.

9. Wechsler D. WAIS-IV-NI. Afname en scoringshandleiding. Amsterdam: Pearson; 2008.
10. Van der Elst W, Van Boxtel MP, Van Breukelen GJ, Jolles J. Normative data for the Animal, Profession and Letter M Naming verbal fluency tests for Dutch speaking participants and the effects of age, education and sex. J Int Neuropsychol Soc. 2006;12:80-89.

11. Van der Elst W, van Boxtel MPJ, van Breukelen GJ, Jolles J. Rey's verbal learning test: normative data from 1855 healthy participants aged 24-81 years and the influence of age, sex, education, and mode of presentation. J Int Neuropsychol Soc. 2005;11:290-302.

12. Lindeboom J, Schmand B. Visual Association Test. Handleiding. Leiden: PITS B.V; 2003.

13. Jaspers MWM. A comparison of usability methods for testing interactive health technologies: Methodological aspects and empirical evidence. Int J Med Inform. 2009;78(5):340-353.

14. Jacobson NS, Truax P. Clinical significance: a statistical approach to defining meaningful change in psychotherapy research. J Consult Clin Psychol. 1991;59(1):12-19.

15. Chelune Gl, Naugle RI, Lüders H, Sedlak J, Awad IA. Individual change after epilepsy surgery: Practice effects and base-rate information. Neuropsychology. 1993;7:41-52.

16. Gruters AAA, Christie HL, Ramakers IHGB, Verhey FRJ, Kessels RPC, de Vugt ME. Neuropsychological assessment and diagnostic disclosure at a memory clinic: A qualitative study of the experiences of patients and their family members. Clin Neuropsychol. 2020:1-17.

17. Bouma A, Mulder J, Lindeboom J, Schmand B (2012) Handboek neuropsychologische diagnostiek, Pearson, Amsterdam.

18. Ramakers I, Gruters A, Schmand B, et al. Monodisciplinaire richtlijn neuropsychologisch onderzoek bij lichte cognitieve stoornissen (MCl) en dementie. https://www.psynip. $\mathrm{nl} /$ secties/neuropsychologie/. Published September 2019. Accessed April 2020. 
1. Brooke J. SUS: A "quick and dirty" usability scale. In: Jordan P, Thomas B, Weerdmeester

$\mathrm{B}$, eds. Usability evaluation in industry. London, UK: Taylor \& Francis; 1996:189-194.

2. Lewis JR. The System Usability Scale: Past, present, and future. Int J Human Comput Int. 2018;34(7):577-590.

3. Bangor A, Kortum P, Miller J. Determining what individual SUS scores mean: adding an adjective rating scale. J Usability Studies. 2009;4(3):114-123.

4. Sustersic M, Gauchet A, Kernou A, et al. A scale assessing doctor-patient communication in a context of acute conditions based on a systematic review. Plos One. 2018;13(2):e0192306.

5. Zandbelt LC, Smets EMA, Oort FJ, Godfried $\mathrm{MH}$, de Haes HCJM. Satisfaction with the outpatient encounter: a comparison of patients' and physicians' views. J Gen Intern Med. 2004;19(11):1088-1095.

6. Van der Feltz-Cornelis CM, Van Oppen P, Van Marwijk HW, De Beurs E, Van Dyck R. A patient-doctor relationship questionnaire (PDRQ-9) in primary care: development and psychometric evaluation. Gen Hosp Psychiatry. 2004;26(2):115-120.

7. Davis FD. Perceived Usefulness, Perceived Ease of Use, and User Acceptance of Information Technology. MIS Quarterly. 1989;13(3):319-340.

8. Graneheim UH, Lundman B. Qualitative content analysis in nursing research: concepts, procedures and measures to achieve trustworthiness. Nurse Educ Today. 2004;24(2):105-112.

9. Curry KT, Hanson WE. National survey of psychologists' test feedback training, supervision, and practice: A mixed methods study. J Pers Assess. 2010;92(4):327-336.
10. Gruters AAA, Ramakers I, Kessels R, et al. Development of memory clinics in the Netherlands over the last twenty years. Int J Geriatr Psychiatry. 2019;34(8):1267-1274

11. Keady J, Gilliard J. The experience of neuropsychological assessment for people with suspected Alzheimer's Disease. In: Harris $\mathrm{BH}$, ed. The person with Alzheimer's Disease. Pathways to understanding the experience. Baltimore: The John Hopkins University Press; 2002.

12. Kunneman M, Pel-Littel R, Bouwman FH, et al. Patients' and caregivers' views on conversations and shared decision making in diagnostic testing for Alzheimer's disease: The ABIDE project. Alzheimers Dement (N Y). 2017;3(3):314-322.

13. Gass CS, Brown MC. Neuropsychological test feedback to patients with brain dysfunction. Psychol Assess. 1992;4(3):272-277.

14. Lanca M, Giuliano AJ, Sarapas C, et al. Clinical outcomes and satisfaction following neuropsychological assessment for adults: A community hospital prospective quasiexperimental study. Arch Clin Neuropsychol. 2019.

15. Garcia-Retamero R, Galesic M. Who proficts from visual aids: Overcoming challenges in people's understanding of risks. Soc Sci. 2010;70(7):1019-1025.

16. Kensinger EA. Remembering Emotional Experiences: The contribution of valence and arousal. Nat Rev Neurosci. 2004;15(4):241-252.

17. Heinemann AW, Magasi S, Hammel J, et al. Environmental factors item development for persons with stroke, traumatic brain injury, and spinal cord injury. Arch Physc Med Rehab. 2015;96(4):589-595. 


\section{CHAPTER 7}

1. Husson O, Mols F, van de Poll-Franse LV. The relation between information provision and health-related quality of life, anxiety and depression among cancer survivors: a systematic review. Ann Oncol. 2011;22(4):761772.

2. Martins JC. Patients' satisfaction with information on disease and morbidity. Rev Lat Am. 2009; 17(3):335-340.

3. Corbett A, Stevens J, Aarsland D, et al. Systematic review of services providing information and/or advice to people with dementia and/or their caregivers. Int J Geriatr Psychiatry. 2012;27(6):628-636.

4. Sanders EBN, Stappers PJ. Co-creation and the new landscapes of design. CoDesign. 2008;4(1):5-18

5. Kleinsmann M, Valkenburg R. Barriers and enablers for creating shared understanding in co-design projects. Des Stud. 2008;29(4):369386.

6. Rock J, McGuire M, Rogers A. Multidisciplinary perspectives on co-creation. Sci Commun. 2018;40(4):541-552.

7. Juristo N, Moreno AM, Sanchez-Segura M-I. Analysing the impact of usability on software design. J Syst Softw. 2007;80(9):1506-1516.

8. Song Y, Son YJ, Oh D. Methodological Issues in Questionnaire Design. J Korean Acad Nurs. 2015;45(3):323-328. 


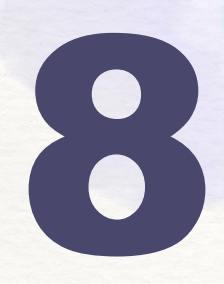

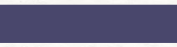

General discussion 


\section{CHAPTER 8}

\section{INTRODUCTION}

The relevance of neuropsychological assessment (NPA) and neuropsychological feedback in the diagnostic process of cognitive disorders, such as Mild Cognitive Impairment $(\mathrm{MCl})$ and dementia, has been increasingly recognized. ${ }^{1}$ The main aim of this thesis was to explore the role of NPA and neuropsychological feedback in Dutch memory clinics (MCs). Another aim was to explore if a visual aid could help in communicating neuropsychological test results to patients and family members. In the first part of this thesis, I explored the development of MCs in the past twenty years (Chapter 2), in particular their NPA procedures, and described the development of a monodisciplinary guideline for NPAs in $\mathrm{MCl}$ and dementia (Chapter 3). Furthermore, the experiences of patients and family members with NPA and diagnostic disclosure were evaluated (Chapter 4), and the cross-sectional and longitudinal association between subjective and objective cognitive decline, depressive symptoms, and progression to dementia in MC patients (Chapter 5). In the second part of this thesis, the literature on providing neuropsychological feedback to patients and family members was reviewed (Chapter 6), and the development of a visual tool for neuropsychological test results was described (Chapter 7).

This chapter starts with an overview of the main findings of this thesis. Next, methodological considerations, clinical implications, and future directions are discussed.

\section{MAIN FINDINGS AND IMPLICATIONS}

\section{Part one: $\quad$ Neuropsychological assessment at Dutch memory clinics}

\section{Early diagnosis of dementia and development of Dutch MCs}

In the past twenty years, MCs have become regular care facilities for making an early diagnosis of cognitive disorders. Their number and capacity have increased, and up to half of the incident cases of dementia are currently estimated to be diagnosed at an $\mathrm{MC}$ in the Netherlands (Chapter 2). Having more regular care facilities for diagnosing dementia is a positive development, as the prevalence of dementia is likely to increase further in the next decades, resulting in a larger health care demand. Furthermore, facilities for making an early diagnosis of dementia are being promoted worldwide, as stated in several national dementia strategies. ${ }^{2-4}$ Benefits of an early diagnosis include, among others, less uncertainty due to insight into the underlying disease, receiving timely support or access to information (e.g., via a case manager, psychosocial interventions, or other support), ${ }^{5-7}$ delaying institutionalization, and the opportunity to make decisions regarding the future with a relatively intact cognitive capacity. ${ }^{8}$ Another benefit is that in an MC setting, it is possible to reassure patients without cognitive impairment, who are often present at MCs (the 'worried well'). However, an early diagnosis of dementia may have negative consequences, such as stigmatization, feelings of hopelessness, or mood problems. ${ }^{9}$ Next, questions regarding the cost-benefit of an early diagnosis can be raised due to the absence of a curative treatment. ${ }^{10}$ The majority of patients, 
however, favor diagnostic disclosure over not knowing what is wrong with them, as disclosure may promote feelings of autonomy and enable patients to make plans about their future. Arguments against diagnostic disclosure included fear of getting upset or the absence of a treatment. ${ }^{11}$ In many studies both 'early' and 'timely' diagnosis have been used interchangeably. An 'early diagnosis' refers to receiving a diagnosis before any clinical symptoms have appeared (e.g., a diagnosis of Alzheimer's disease based on positive biomarkers in the prodromal phases). In contrast, a 'timely diagnosis' has a person-centered focus and is defined as receiving a diagnosis when it benefits the individual. ${ }^{12}$ Therefore, in the Dutch healthcare system, when a patient and family present to the general practitioner (GP) with worries about having dementia, the GP should gain insight into their reasons, needs, and wishes and ascertain that they know what they can expect from receiving a diagnosis. Ultimately, deciding whether to refer to an MC should be a shared-decision making process. ${ }^{13}$

\section{Diagnostic value of neuropsychological assessment}

An NPA is being used in nearly all MCs in the Netherlands, which shows its important role in the diagnostic process of cognitive disorders. The added diagnostic value of an NPA has been identified on several aspects. First, an NPA leads to improved diagnostic accuracy when integrated with findings of the initial clinical evaluation of the medical specialist or other diagnostic tools. ${ }^{1,14}$ Next, an NPA has a high sensitivity $(>80 \%)$ and specificity (>90\%) when differentiating between dementia and normal aging. ${ }^{15}$ Furthermore, a recent meta-analysis shows that MC patients who do not convert to dementia perform better on multiple cognitive subdomains compared to patients who do convert to dementia. ${ }^{16}$ Compared to cognitive screening tools, an NPA is more sensitive in diagnosing the early phases of cognitive decline due to neurodegenerative disease. ${ }^{17-19}$ NPA results can also be used therapeutically by giving feedback in a collaborative manner and the translation to daily life functioning. ${ }^{20}$ Patients' experiences with an NPA have not been studied extensively. Still, a few studies show positive findings in terms of experiences reported by patients visiting a neuropsychology outpatient clinic. ${ }^{21,22}$ Negative experiences (e.g., increased performance anxiety, feelings of discomfort due to realization of cognitive impairment) are reported by patients with dementia. ${ }^{23}$ Chapter 4 of this thesis shows that both patients and their family members have mixed (both positive and negative) emotions when undergoing an NPA.

\section{Harmonization and concerns about neuropsychological assessment}

When evaluating the characteristics of an NPA among psychologists working in Dutch MCs, we identify a large variability in cognitive tests, questionnaires, or rating scales. The majority of psychologists express a desire for harmonization, which led to the development of a monodisciplinary guideline (Chapter 3 ). The in-depth interviews in chapter 3 identify a few concerns related to neuropsychological testing. The first concern is the limited or lack of up-to-date normative data available, especially for specific populations (e.g., intellectually disabled or illiterate participants or individuals with non-Western cultural background) or the lack of specific tests for domains such 
as social cognition. This study was conducted before the full launch of the Advanced Neuropsychological Diagnostics Infrastructure (ANDI) project. In this research project, healthy control data from several research groups in the Netherlands and Flanders were combined into one normative database. This offers an infrastructure with updated, regression-based norms based on a large sample (including more individuals over 80). ANDI also enables multivariate comparisons, which are more sensitive to detect cognitive impairment. ${ }^{24}$ One final barrier mentioned by psychologists working in MCs in the survey was the inability to give neuropsychological feedback to patients and family members after an assessment was completed.

Association between self- and proxy-reported cognitive decline and neuropsychological tests

The results of chapter 5 show that proxy-reported cognitive decline is associated with objective cognitive functioning and conversion to dementia, while self-reported cognitive decline is associated with depressive symptoms. The number of patients visiting Dutch MCs with dementia decreased (Chapter 2: 85\% in 1998 to 53\% in 2016) and more patients are seen with $\mathrm{MCl}$ ( $10 \%$ in 1998 to $25 \%$ in 2016) or no cognitive impairment (5\% in 1998 to $22 \%$ in 2016). An explanation for this increase may be the fact that MCs have become a mainstream health-care facility for diagnosing cognitive disorders. Another explanation may be the increased awareness towards dementia in our society. In itself this is a positive change, but the downside of this development is that individuals might worry sooner about having dementia when they experience cognitive changes that are, for example, aging-related. The association between self-reported cognitive decline and depressive symptoms may be the result of a negative bias ${ }^{26}$ which alters the self-perception of cognitive functioning. ${ }^{27}$ Indeed, depressive patients seem to underestimate their cognitive functioning compared to healthy participants. ${ }^{28}$ This is in line with the recently introduced concept of functional cognitive disorders that relates a cognitive decline to affective symptomatology, negative self-evaluation, or negative illness perceptions. ${ }^{25}$ Patients with a subjective cognitive decline might be at-risk for misdiagnosis and therefore, future research is necessary to improve diagnosis and effective treatment of functional cognitive disorders.

\section{Part two: Insights into neuropsychological feedback and the development of a visual aid}

Importance of neuropsychological feedback

In most Dutch MCs, neuropsychological feedback is not routinely provided by the psychologists. Consequently, MC patients and family members cannot profit from the therapeutic benefits of neuropsychological feedback. Our scoping review on neuropsychological feedback (Chapter 6) indicate that patients are generally satisfied with neuropsychological procedures, especially when they receive useful feedback. The benefit of receiving neuropsychological feedback is demonstrated in various patient populations who experience cognitive problems, for example by an increase 
in quality of life, a reduction of psychiatric symptoms, or less subjective cognitive complaints. ${ }^{29-31}$ Furthermore, collaborative neuropsychological feedback sessions, using principles from motivational interviewing (MI), may have a therapeutic value by giving insight into cognitive strengths and weaknesses with a translation to daily life. ${ }^{32,33}$ However, recall of neuropsychological feedback is low. This is also in line with findings of our focus group study reported in Chapter 4, which show that both patients and family members remember little information after the diagnostic disclosure. Kessels ${ }^{34}$ describes that $40-80 \%$ of information told by healthcare professionals is forgotten immediately. The greater the amount of information, the less patients will recall. ${ }^{35} \mathrm{Another}$ issue is that only about half of the information that is being remembered is remembered correctly. ${ }^{36}$ Three types of variables can be identified that explain this phenomenon: 1) clinician-related factors (e.g., using difficult terminology), 2) patient-related factors (e.g., aging-related memory functioning, anxiety or distress, perceived importance of the information), and 3) mode of information (e.g., written, visual or verbal). ${ }^{34}$ The cognitive model of Ley ${ }^{37}$ emphasizes the importance of information recall and comprehension for patient satisfaction and treatment adherence. Figure 1 shows an adapted version of Ley's model to neuropsychological feedback sessions. 


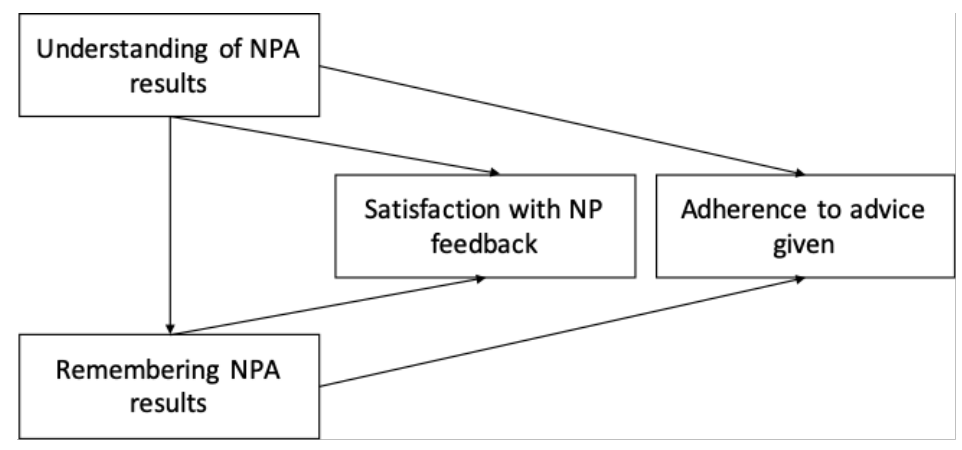

Figure 1. Adaptation of Ley's cognitive model of adherence to neuropsychological feedback settings. ${ }^{37}$ Abbreviations. NP: neuropsychological, A: assessment.

Preliminary findings show that neuropsychological feedback sessions using $\mathrm{Ml}$ techniques in patients with a substance use disorder $(n=30)$ increased attendance of these sessions ( $71 \%$ of participants present during feedback sessions versus $48 \%$ in the care as usual group). ${ }^{33}$ This offers another argument for giving neuropsychological feedback with MI techniques. Effectively communicating neuropsychological feedback is very important. However, this might be a challenge in patients with a cognitive impairment, which is characterizing of the majority of $\mathrm{MC}$ patients.

Content, usability, and feasibility of a visual tool of neuropsychological test results The low level of information recall in patients and their family members emphasizes the need for communication aids. Offering a written summary of neuropsychological feedback improves free recall of recommendations. However, the overall level of the information they remembered is still relatively low. 39.40 Therefore, the development of a visual tool for use in a MC setting may improve information recall and understanding, as well as satisfaction and treatment adherence (Figure 2), and eventually might even increase quality of life. ${ }^{41}$ 


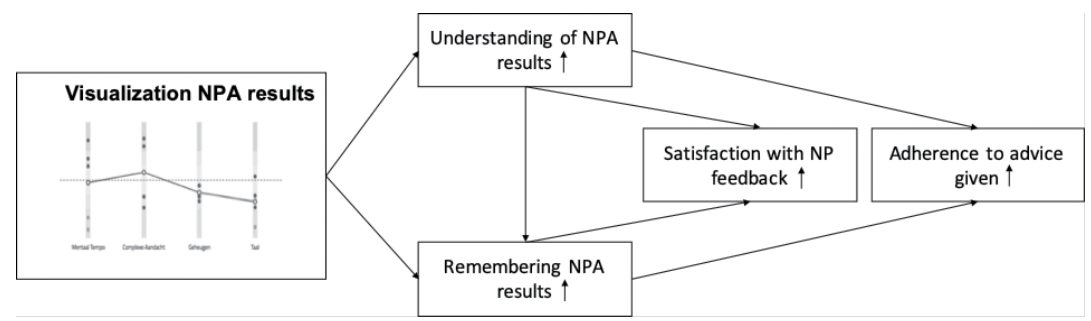

Figure 2. Understanding and recall of NPA results, based on the adaptation of Ley's cognitive model of adherence. ${ }^{37}$ Abbreviations. NP: neuropsychological, A: assessment.

Other authors have already reflected on the potential benefit of using visual aids to improve medical information recall. ${ }^{42,43}$ Pictures that are closely related to written or spoken text increases attention and recall of health information ${ }^{44}$. All patients may benefit from using visual aids, but patients with low literacy skills seem more likely to do so. ${ }^{44}$ Visual aids can transcend language and numeracy barriers which improves effective communication. ${ }^{45}$ Furthermore, tailored and high-quality information may help patients to take responsibility and better respond to health problems. ${ }^{46}$ It enables more active patient participation and shared-decision making. ${ }^{47}$ However, to our knowledge such a tool does not exist for giving neuropsychological feedback. To this end, we developed the visual tool during the 'Innovations in NeuroPsychological Assessment in the timely Diagnosis of Dementia' (INPAD) project (Chapter 7). The visual tool is overall evaluated positively by patients, family members, and psychologists. Identified benefits include having a visual overview of cognitive strengths and weaknesses, the translation of NPA results to daily life, and to receive something on paper to take home. Not only is the tool developed to improve understanding of information and remembering information, but also to improve the diagnostic workflow. Concerning the latter, some barriers are identified, such as the limited set of cognitive tests that could be processed. A consensus between all perspectives is that the tool should only be used during the in-person consultation with the patient and should only be used by psychologists. To implement the tool in $\mathrm{MC}$ practices, it first has to be expanded, making it possible to process more cognitive tests and use better normative data sets. Next, the tool should be evaluated in a multiple MCs for a longer time period to evaluate implementation facilitators and barriers. In addition, a long-term and self-sustaining business model should be developed to be able to adapt the tool in the future to changes and newly developed needs. The lack of such a business model is one of the key implementation barriers of eHealth interventions. ${ }^{48}$ 


\section{CHAPTER 8}

\section{METHODOLOGICAL CONSIDERATIONS}

\section{Strengths}

A main strength of this thesis is the use of an iterative process and involvement of patients, family members, and professionals during the development of the visual tool. Doing research with the public is referred to as patient and public involvement (PPI). ${ }^{49}$ Involving people living with dementia in research is also increasingly recognized, as it is incorporated in international research recommendations. ${ }^{50,51} \mathrm{PPI}$ improves the quality, relevance, and ethical conduct of research. ${ }^{52}$ Furthermore, it is highlighted as an essential component to carry out high-quality research. ${ }^{53}$ This iterative process is in line with the Medical Research Council (MRC) framework used for the development of complex interventions. ${ }^{54}$ Involving patients with a cognitive impairment in PPI leads to improved self-esteem, feeling connected to the community, and the experience that patient still contribute to society. ${ }^{55}$ Another strength of this thesis is the variation in research designs and methodology (survey, in-depth interviews, focus groups, longitudinal follow-up study, think-aloud sessions, pilot study). In the survey studies (Chapter 2 and 3), a high response rate is obtained implying a good representation of the Dutch MCs. Another strength is taking into account the heterogeneity of the MC population by using the purposive sampling method. By doing this, patients with no cognitive impairment, $\mathrm{MCl}$, and mild dementia are included.

\section{Limitations}

Some limitations also have to be considered when interpreting the data. First, the results in this thesis cannot be extended to other populations, MCs, or countries. Patients with moderate to severe dementia are not included in this study because those patients are often not seen in MCs in the Netherlands. Second, the sample sizes are small in some of the studies in this thesis, also related to the qualitative study design, which offers important insights into experiences and needs. Third, in chapters 4 and 7, patients and family members are interviewed together. While this facilitates support during the interview, they might have not felt comfortable sharing everything. Finally, in the longitudinal follow-up study (Chapter 5), there is an attrition bias which is not completely at random, as the group that dropped-out at follow-up moments was significantly older and performed worse on the NPA compared to the participants who did not drop-out. This might have caused an underestimation of the group differences because patients with a lower cognitive performance did not participate at follow-up. However, in the repeated-measures design, the maximum likelihood method was applied to account for missing data points.

\section{CLINICAL IMPLICATIONS}

The studies in this thesis provides insight into the NPA and neuropsychological feedback in MCs. There are several clinical implications that are discussed below.

First, findings in this thesis show that both NPA and neuropsychological feedback are of added value in the diagnostic process of cognitive disorders due 
to neurodegenerative disease and should ideally be part of the diagnostic routine. Although an NPA is part of the diagnostic set-up in most Dutch MCs, the proportion of patients in whom the assessment is used varied. For example, in some clinics carrying out an NPA was not possible due to practical reasons (e.g., waiting lists or time constraints) while in other clinics only a cognitive screening is used due to a different view on using an NPA in the early diagnosis of cognitive disorders. However, an NPA adds value to memory clinic procedures as it improves diagnostic accuracy in MC patients without cognitive impairment or those with $\mathrm{MCl}^{14}$ Furthermore, the diagnostic accuracy further increases when both an NPA and neuroimaging are combined. ${ }^{1}$ An NPA shows to be more sensitive to predict conversion to dementia and detect disease progression compared to neuroimaging and cerebrospinal fluid biomarkers, ${ }^{56,57}$ and can predict future cognitive deterioration in currently cognitively healthy people. ${ }^{58}$ In line with the Dutch multidisciplinary guideline of diagnosis and treatment of dementia, an NPA should always be used in case of doubt about the presence of cognitive impairment that might indicate a neurodegenerative disease. ${ }^{19}$ Next to having a diagnostic value, giving neuropsychological feedback offers the opportunity to give psychoeducation about cognitive strengths and weaknesses, as well as potential compensatory techniques in a therapeutic manner. ${ }^{20,59}$ Especially this last component is what separates an NPA from the other diagnostic tools in the MC. An NPA should be used to help patients and explain what they can do to deal with their cognitive complaints. Second, the low level of information recall is something clinicians should be aware of and take into account during their consultations, for example by using written or visual information. Several frameworks are described in chapter 6 which could guide psychologists in giving feedback.

Finally, another implication for clinical practice is that the study described in chapter 5 shows that especially proxy-reported cognitive decline is related to an increased risk of dementia. Although involving an informant has always been part of diagnostic guidelines, informant history taking in dementia diagnostic processes has received little scientific attention. This is worrisome because the perspective of family members is important to, for example, adequately differentiate between cognitive impairment due to a neurodegenerative disease and other causes by evaluating interference in daily live. The default position in clinical practice should be that a clinician always asks a patient which family member they would want to involve. When informant history is taken together with the patient present, it might give insight into differences between family members and patients. The reactions of patients to what family members say during this intake consultation might be very informative in itself.

\section{FUTURE DIRECTIONS}

Findings from this thesis show that an NPA with neuropsychological feedback is of added value for MC practices. It remains important to further follow-up on the development of Dutch MCs and characteristics of the NPA. Interesting research questions are whether there are still concerns regarding neuropsychological assessment, and whether the monodisciplinary guideline led to more harmonization between clinics. Repeated 


\section{CHAPTER 8}

monitoring of this development offers insight into the experiences and needs of clinicians in the early diagnosis of cognitive disorders.

Furthermore, the importance of neuropsychological feedback and experiences with neuropsychological procedures is described in the current thesis. However, this thesis shows that methodological rigor in previous studies was lacking. More highquality studies are needed to formulate stronger statements about the long-term effects of giving neuropsychological feedback and experiences with these procedures (e.g., less stress or caregiver burden). This might be a challenge due to the unblinded character of giving feedback. Nevertheless, other research designs might also be appropriate such as mixed-methods studies. Future studies should include specific populations such as immigrants and patients with low literacy. Adhering to the criteria from the CONSORT for Social and Psychological Interventions (CONSORT-PSI) might be helpful in setting up such studies. ${ }^{67}$

\section{CONCLUDING REMARKS}

In conclusion, the research presented in this thesis provides a valuable contribution to the knowledge on neuropsychological procedures within Dutch MCs, specifically on giving neuropsychological feedback. Findings show that an NPA has a clear diagnostic value in an MC population, and that giving neuropsychological feedback is related to positive patient outcomes and can be used therapeutically. These results can be used to inform both clinicians and researchers of the benefits of neuropsychological feedback and the positive contribution of using a visual aid in delivering this feedback. 


\section{CHAPTER 8}

\section{REFERENCES}

1. Watt S, Crowe SF. Examining the beneficial effect of neuropsychological assessment on adult patient outcomes: a systematic review. Clin Neuropsychol. 2018;32(3):368-390.

2. Department of Health. The Irish National Dementia Strategy. Department of Health: 2014.

3. Department of Health. Living Well with Dementia: A National Dementia Strategy. London: Department of Health; 2009.

4. Alzheimer's Association. Factsheet: Healthy People 2020. https://www.alz.org/media/ Documents/healthy-people-fact-sheet-2015. pdf. Published April 2017. Accessed June 2020.

5. Waldemar G, Phung KT, Burns A, et al. Access to diagnostic evaluation and treatment for dementia in Europe. Int $J$ Geriatr Psychiatry. 2007:22(1):47-54.

6. Nliffe S, Manthorpe J, Eden A. Sooner or later? Issues in the early diagnosis of dementia in general practice: a qualitative study. Fam Pract. 2003;20(4):376-381.

7. de Vugt ME, Verhey FR. The impact of early dementia diagnosis and intervention on informal caregivers. Prog Neurobiol. 2013;110:54-62.

8. Borson S, Frank L, Bayley PJ, et al. Improving dementia care: the role of screening and detection of cognitive impairment. Alzheimers Dement. 2013;9(2):151-159.

9. Mattson N, Brax D, Zetterberg H. To know or not to know: Ethical issues related to early diagnosis of Alzheimer's disease. Int J Alzheimers Dis. 2010;2010:1-4.

10. Melis RJF, Meeuwsen EJ, Parker SG, Olde Rikkert MGM. Are memory clinics effective? The odds are in favour of their benefit, but conclusive evidence is not yet available. $J R$ Soc Med. 2009;102(11):456-457.

11. van den Dungen $P$, van Kuijk $L$, van Marwijk $\mathrm{H}$, et al. Preferences regarding disclosure of a diagnosis of dementia: a systematic review. Int Psychogeriatr. 2014;26(10):1603-1618.

12. Brooker D, La Fontaine J, Evans S, Bray J, Saad K. Public health guidance to facilitate timely diagnosis of dementia: Alzheimer's cooperative valuation in Europe recommendations. Int J Geriatr Psychiatry. 2014;29(7):682-693.

13. Verhey FR, de Vugt ME, Schols JM. Should all elderly persons undergo a cognitive function evaluation? Where is the patient's perspective? J Am Med Dir Assoc. 2016;17(5):453-455.

14. ansen WJ, Handels RL, Visser PJ, et al. The diagnostic and prognostic value of neuropsychological assessment in memory clinic atients. J Alzheimers Dis. 2016;55(2):679689.

15. Jacova C, Kertesz A, Blair M, Fisk JD, Feldman $\mathrm{HH}$. Neuropsychological testing and assessment for dementia. Alzheimers Dement. 2007;3(4):299-317.

16. Prado CE, Watt S, Treeby MS, Crowe SF. Performance on neuropsychological assessment and progression to dementia: A meta-analysis. Psychol Aging. 2019;34(7):954977.

17. Mitchell AJ. A meta-analysis of the accuracy of the mini-mental state examination in the detection of dementia and mild cognitive impairment. J Psychiatr Res. 2009;43(4):411431.

18. Tierney MC, Szalai JP, Dunn E, Geslani D, McDowell I. Prediction of probable Alzheimer disease in patients with symptoms suggestive of memory impairment. Value of the MiniMental State Examination. Arch Fam Med. 2000;9(6):527-532. 
1. Nederlandse Vereniging voor Klinische Geriatrie, Nederlandse Vereniging voor Neurologie, Nederlandse Vereniging voor Psychiatrie. Richtlijn Diagnostiek en Behandeling van dementie. https://www. nvvp.net/stream/richtlijn-diagnostiek-enbehandeling-van-dementie-2014. Published 2014. Accessed June 2020.

2. Poston JM, Hanson WE. Meta-analysis of psychological assessment as a therapeutic intervention. Psychol Assess. 2010;22(2):203212.

3. Bennett-Levy J, Klein-boonschate MA, Batchelor J, McCarter R, Walton N. Encounters with Anna Thompson: The consumer's experience of neuropsychological assessment. Clin Neuropsychol. $1994 ; 8(2): 219-238$

4. Westervelt HJ, Brown LB, Tremont G, Javorsky DJ, Stern RA. Patient and family perceptions of the neuropsychological evaluation: How are we doing? Clin Neuropsychol. 2007;21(2):263273.

5. Keady J, Gilliard J. The experience of neuropsychological assessment for people with suspected Alzheimer's Disease. In: Harris $\mathrm{BH}$, ed. The person with Alzheimer's Disease. Pathways to understanding the experience. Baltimore: The John Hopkins University Press; 2002.

6. Huizenga HM, Smeding H, Grasman $\mathrm{RP}$, Schmand B. Multivariate normative comparisons. Neuropsychologia. 2007; 45(11):2534-2542.

7. McWhirter L, Ritchie C, Stone J, Carson A. Functional cognitive disorders: A systematic review. Lancet Psychiat. 2020;7(2):191-207.

8. Beck A, Rush J, Shaw B, Emery G. Cognitive therapy of depression. New York: Guilford; 1979.
9. Crane MK, Bogner HR, Brown GK, Gallo JJ. The link between depressive symptoms, negative cognitive bias and memory complaints in older adults. Aging Ment Health. 2007;11(6):708715.

10. Schwert C, Stohrer M, Aschenbrenner S, Weisbrod M, Schroder A. Biased neurocognitive self-perception in depressive and in healthy persons. J Affect Disord. 2018;232:96-102.

11. Rosado DL, Buehler S, Botbol-Berman E, et al. Neuropsychological feedback services improve quality of life and social adjustment. Clin Neuropsychol. 2018;32(3):422-435.

12. Kirkwood MW, Peterson RL, Connery AK, Baker DA, Forster J. A pilot study investigating neuropsychological consultation as an intervention for persistent postconcussive symptoms in a pediatric sample. Pediatrics. 2016;169:244-249.e241.

13. Lanca M, Giuliano AJ, Sarapas C, et al. Clinical outcomes and satisfaction following neuropsychological assessment for adults: A community hospital prospective quasiexperimental study. Arch Clin Neuropsychol. 2019.

14. Postal KS, Armstrong K. Feedback that sticks: The art of effectively communicating neuropsychological assessment results. Oxford: Oxford University Press; 2013.

15. Gorske TT, Smith S. Collaborative Therapeutic Neuropsychological Assessment. New York: Springer Science and Business Media; 2009.

16. Kessels RPC. Patients' memory for medical information. J R Soc Med. 2003;96(5):219-222.

17. McGuire LC. Remembering what the doctor said: organization and adults' memory for medical information. Exp Aging Res. 1996;22(4):403-428. 
1. Anderson JL, Dodman S, Kopelman M, Fleming A. Patient information recall in a rheumatology clinic. J Rheumatol. 1979;18(1):18-22.

2. Ley P. Communicating with Patients: Improving Communication, Satisfaction and Compliance. New York: Croom Helm; 1988.

3. DiMatteo MR, Haskard-Zolnierek KB, Martin LR. Improving patient adherence: a three-factor model to guide practice. Health Psychol Rev. 2012;6(1):74-91.

4. Fallows RR, Hilsabeck RC. Comparing two methods of delivering neuropsychological feedback. Arch Clin Neuropsychol. 2013;28(2):180-188.

5. Meth M, Calamia M, Tranel D. Does a simple intervention enhance memory and adherence for neuropsychological recommendations? Appl Neuropsychol Adult. 2016;23(1):21-28

6. Corbett A, Stevens J, Aarsland D, et al. Systematic review of services providing information and/or advice to people with dementia and/or their caregivers. Int J Geriatr Psychiatry. 2012;27(6):628-636.

7. Garcia-Retamero R, Galesic M. Who proficts from visual aids: Overcoming challenges in people's understanding of risks. Soc Sci. 2010;70(7):1019-1025.

8. Watson PW, McKinstry B. A systematic review of interventions to improve recall of medical advice in healthcare consultations. J R Soc Med. 2009;102(6):235-243.

9. Houts PS, Doak CC, Doak LG, Loscalzo MJ. The role of pictures in improving health communication: A review of research on attention, comprehension, recall, and adherence. Patient Educ Couns. 2006;61(2):173-190.

10. Pratt M, Searles GE. Using Visual Aids to Enhance Physician-Patient Discussions and Increase Health Literacy. J Cutan Med Surg. 2017;21(6):497-501.
11. Heinemann AW, Magasi S, Hammel J, et al. Environmental factors item development for persons with stroke, traumatic brain injury, and spinal cord injury. Arch Phys Med Rehab. 2015;96(4):589-595.

12. Martins JC. Patients' satisfaction with information on disease and morbidity. Reev Lat Am Enfermagem. 2009;17(3):335-340.

13. Christie HL, Martin JL, Connor J, et al. eHealth interventions to support caregivers of people with dementia may be proven effective, but are they implementation-ready? Internet Inter. 2019;18:100260.

14. INVOLVE. Briefing notes for researchers: public involvement in NHS, public health and social care research. http://www.invo.org.uk/wpcontent/uploads/2012/04/INVOLVEBriefing NotesApr2012.pdf. Published 2012. Accessed June 2020.

15. Alzheimer Europe. Involving people with dementia. https://www.alzheimer-europe. org/Ethics/Ethical-issues-in-practice/2011Ethics-of-dementia-research/Involving-peoplewith-dementia?\#fragment1.Published 2011. Accessed June 2020.

16. Gove D, Diaz-Ponce A, Georges J, et al. Alzheimer Europe's position on involving people with dementia in research through PP (patient and public involvement). Aging Ment Health. 2018;22(6):723-729.

17. 52.Edelman N, Barron D. Evaluation of public involvement in research: time for a major re-think? J Health Serv Res Policy. 2015;21(3):209-211.

18. Daveson BA, de Wolf-Linder S, Witt J, et al. Results of a transparent expert consultation on patient and public involvement in palliative care research. Palliat Med. 2015;29(10):939949. 


\section{CHAPTER 8}

1. Craig P, Dieppe P, Macintyre S, Michie S, Nazareth I, Petticrew M. Developing and evaluating complex interventions: the new Medical Research Council guidance. BMJ. 2008;337.

2. Rodgers PA. Co-designing with people living with dementia. CoDesign. 2018;14(3):188-202.

3. Cui Y, Liu B, Luo S, et al. Identification of conversion from mild cognitive impairment to Alzheimer's disease using multivariate predictors. PloS One. 2011;6(7):e21896.

4. Schmand B, Rienstra A, Tamminga $\mathrm{H}$, et al. Responsiveness of magnetic resonance imaging and neuropsychological assessment in memory clinic patients. J Alzheimers Dis. 2014;40(2):409-418.

5. Burrell JR, Piguet O. Lifting the veil: How to use clinical neuropsychology to assess dementia. J Neurol Neurosurg Psychiatry. 2015;86(11):1216-1224.

6. Harvey PD. Clinical applications of neuropsychological assessment. Dialogues Clin Neurosci. 2012;14(1):91-99.

7. Curry KT, Hanson WE. National survey of psychologists' test feedback training, supervision, and practice: A mixed methods study. J Pers Assess. 2010;92(4):327-336.

8. 61.Debruyne $H$, Van Buggenhout M, Le Bastard N, et al. Is the geriatric depression scale a reliable screening tool for depressive symptoms in elderly patients with cognitive impairment? Int J Geriatr Psychiatry. 2009;24(6):556-562.

9. Ismail Z, Smith EE, Geda Y, et al. Neuropsychiatric symptoms as early manifestations of emergent dementia: Provisional diagnostic criteria for mild behavioral impairment. Alzheimers Dement. 2016;12(2):195-202.
10. Jorm AF, Butterworth $P, A$ Anstey KJ, et al. Memory complaints in a community sample aged 60-64 years: associations with cognitive functioning, psychiatric symptoms, medical conditions, APOE genotype, hippocampus and amygdala volumes, and white-matter hyperintensities. Psychol Med. 2004;34(8):1495-1506.

11. Vraamark ET, Stokholm J, Høgh P, Waldemar G. Diagnostic profile of young and middleaged memory clinic patients. Neurology. 2002;59(8):1259-1262.

12. Briggs $R, O^{\prime}$ Neill $D$. The informant history: a neglected aspect of clinical education and practice. QJM. 2016;109(5):301-302.

13. Royal College of Psychiatrists. National Audit of Dementia Care in General Hospitals 2012 13. Second Round Audit Report and Update. London: Rocal College of Psychiatrists; 2013.

14. Montgomery P, Grant S, Mayo-Wilson E, et al. Reporting randomised trials of social and psychological interventions: the CONSORTSPI 2018 Extension. Trials. 2018;19(1):407. 


\title{
ADDENDUM
}

\author{
Summary \\ Nederlandse samenvatting (Dutch summary) \\ Knowledge Valorization \\ Dankwoord (acknowledgments)
}

Thesis defenses from Alzheimer Center Limburg and MHeNS 2019-2020

List of publications

Curriculum Vitae 


\section{SUMMARY}

Dementia is a disorder which is characterized by a deterioration in cognitive functioning and the inability to function independently in daily life, and is mainly caused by a neurodegenerative disease. A dementia diagnosis has a huge impact on both the patient and family, which emphasizes the need for high-quality diagnostic assessment and disclosure. One of the most frequently used diagnostic tools in the diagnosis of cognitive decline due to a neurodegenerative disease is a neuropsychological assessment (NPA). An NPA and neuropsychological feedback have a clear diagnostic and therapeutic value, such as improved diagnostic accuracy and positive impact of feedback on patient outcomes. However, the recall of feedback is low, which might lead to lower satisfaction and treatment adherence. Furthermore, neuropsychological feedback is not a regular practice in Dutch memory clinics (MCs). Therefore, the main aim of the first part of this thesis is to gain more insight into the development of MCs in the Netherlands and characteristics of the NPA within these clinics. The aim of the second part is to investigate the literature on neuropsychological feedback and to develop a web-based visual tool to improve the communication about neuropsychological test results in feedback sessions.

Chapter 1 provides a general introduction to the topics and aim of this thesis. Information on cognitive complaints, cognitive disorders resulting from neurodegenerative diseases, and the importance of neuropsychological assessment and feedback is provided. Furthermore, an outline with research questions is presented.

In Chapter 2, results of a survey on the development of Dutch MCs in 1998, 2004, 2009, and 2016 are presented. During this period, MCs have become a mainstream facility for the timely diagnosis of cognitive disorders. The number and capacity of these clinics increased tremendously. In addition, more patients with milder cognitive problems seek for help at a MC and MCs are better embedded in regional care chains. Finally, there appeared to be a lot of variation in the diagnostic tools used.

Chapter 3 describes a survey study and additional in-depth interviews among psychologists working in a MC setting. The aim was to gain insight into the characteristics and working methods of the NPA. The results from the survey and interviews showed that both the procedure and content of the NPA varied widely between MCs. This mainly concerned the cognitive tests, questionnaires, and rating scales used. The psychologists also indicated a need for harmonization and a need for a monodisciplinary guideline. Based on these findings, we elaborate in Chapter 3 on the development of the monodisciplinary guideline 'Neuropsychological assessment in mild cognitive impairment (MCI) and dementia'. This guideline proposes a harmonized neuropsychological core battery to use in MCs.

In Chapter 4, four focus groups in three different MCs were carried out with fourteen patients and thirteen family members. Three overall themes were identified: uncertainty, early diagnostic paradox, and knowledge utilization. The results showed that both patients and family members felt uncertain before, during, and after their visit 
at the MC. The early diagnostic paradox refers to the presence of negative (discomfort due to the awareness of cognitive complaints) and positive experiences and emotions (relief or confirmation due to outcome of the NPA and diagnosis). Finally, it appears that only a small proportion of the information given can be remembered.

Chapter 5 describes on a large five-year follow-up cohort study: The Bio-Bank Alzheimer Center Limburg (BBACL) study. In this study, 405 patients from the Maastricht MC were included. Results from this study showed that subjective cognitive decline was associated with lower performance on an NPA and with more depressive symptoms. However, proxy-reported decline was more strongly associated with a widespread pattern of lower cognitive performance and with the development of dementia within five years. There was no relation between self-reported cognitive decline and NPA performance or conversion to dementia.

In Chapter 6, a scoping review on feedback about neuropsychological findings, and recommendations for clinical practice was described. In this review, 41 papers were included, of which 26 were research papers. Most studies showed that the satisfaction with an NPA was high. Furthermore, offering neuropsychological feedback was related to positive patient outcomes (e.g., increase of quality of life, increased understanding of the disease, and decrease of psychiatric/cognitive symptoms). However, in line with findings of Chapter 4 , information of neuropsychological feedback was low. Previous studies showed that communication aids, such as providing written information, improved remembering neuropsychological outcomes.

Chapter 7 describes the development of a web-based tool aimed at visualizing neuropsychological performances. In addition, usability, technology acceptance, and feasibility were investigated. The tool consists of a data-entry tool that psychologists can use to fill in raw data from an NPA. The tool automatically calculates and presents the normative standardized scores. Furthermore, the tool offers an automatized translation of the results to visual graphs (also for repeated measurements) in two modules: one for the psychologist and one for the patient and family members. In the patient module, a translation of the test results to daily life recommendations is included. The development was characterized by co-creation with patients, family members, and professionals. They were repeatedly involved to continuously adapt the initial concept versions, and in later stages the prototype, to better fit the needs of these end users. High usability was reported by psychologists during early development. A pilot study was carried out in patients and family members receiving neuropsychological feedback without $(n=30)$ and with the tool $(n=28)$. Regardless of the visual tool, both patients and family members were positive about the consultation with the psychologist. However, information recall in patients remained low in both groups. Nevertheless, patients, family members, and psychologists were positive about the visual tool. Psychologists described the tool as intuitive to use and technology acceptance was high. Furthermore, patients, family members, and psychologists appreciated the benefit that there was an overview of cognitive strengths and weaknesses, a translation to daily life recommendations, and to receive information on paper to take (or give) home. Finally, some important barriers were identified by psychologists (e.g., missing other commonly used cognitive tests) 
ADDENDUM

that should be addressed for future implementation.

In Chapter 8, the main results are summarized and integrated. In addition, a critical reflection is given on methodological aspects and implications for clinical practice and future research. 


\section{NEDERLANDSE SAMENVATTING}

Dementie wordt gekenmerkt door een achteruitgang van het cognitief functioneren evenals het onvermogen om onafhankelijk te functioneren in het dagelijks leven, en is doorgaans het gevolg van een neurodegeneratieve aandoening. Een dementie diagnose heeft een grote impact op zowel de patiënt als zijn of haar naasten, hetgeen het belang van een gedegen diagnostisch onderzoek en een uitslaggesprek benadrukt. In de diagnostiek heeft het neuropsychologisch onderzoek (NPO) een belangrijke plaats. Het NPO heeft zowel een diagnostische als therapeutische waarde, waar het weergavegesprek een belangrijke plek bij inneemt. Patiënten en hun naasten onthouden echter maar weinig informatie, waardoor ze soms ook minder tevreden zijn over dit gesprek en de therapietrouw niet optimaal is. Daarnaast blijkt ook dat het weergavegesprek waarin de neuropsychologische testresultaten besproken worden niet altijd onderdeel is van de klinische praktijk binnen de Nederlandse geheugenpoli's (GPS). Daarom is het doel van het eerste deel van dit proefschrift inzicht te krijgen in de werkwijze van GPs en de plaats van het NPO hierin. Het doel van het tweede deel is het in kaart brengen van de literatuur over neuropsychologische weergavegesprekken en het ontwikkelen van een geautomatiseerd visueel hulpmiddel als communicatiehulp bij het terugkoppelen van NPO-resultaten.

Hoofdstuk 1 geeft een algemene inleiding op het thema en de doelstellingen van dit proefschrift. In dit hoofdstuk komen cognitieve klachten, cognitieve stoornissen als gevolg van neurodegeneratieve aandoeningen, het belang van het NPO en de terugrapportage hiervan aan bod. Tevens komen de onderzoeksvragen en de opzet naar voren.

In Hoofdstuk 2 wordt een vragenlijstonderzoek beschreven over de ontwikkeling van Nederlandse GPs in 1998, 2004, 2009, en 2016. GPs zijn in deze periode reguliere faciliteiten geworden gericht op de tijdige diagnostiek van cognitieve stoornissen. Zowel het aantal als de capaciteit van deze poli's is enorm toegenomen. Daarnaast worden er meer patiënten gezien met lichtere cognitieve problemen en is er sprake van een betere inbedding in de regionale ketenzorg. Tenslotte blijkt er veel variatie te zijn in de gebruikte diagnostische instrumenten.

Hoofdstuk 3 beschrijft een follow-upvragenlijstonderzoek (ingevuld door psychologen werkzaam op de GP) met als doel inzicht te krijgen in de kenmerken van en werkwijze rondom het NPO. Aanvullende diepte-interviews werden uitgevoerd met elf psychologen. De resultaten van de vragenlijsten en interviews laten zien dat zowel de procedure als de inhoud van het NPO sterk varieert tussen de GPS. Dit betreft dan vooral de gebruikte cognitieve tests, vragenlijsten en beoordelingsschalen. De ondervraagden geven tevens de behoefte totharmonisatie aan enzien de noodzaakvan een monodisciplinaire richtlijn. Op basis van deze bevindingen is de monodisciplinaire richtlijn: "Neuropsychologisch onderzoek bij lichte cognitieve stoornissen (MCl) en dementie" ontwikkeld, die ook beschreven wordt in hoofdstuk 3. De richtlijn bevat een geharmoniseerde neuropsychologische kernbatterij voor GPs.

In Hoofdstuk 4 werden vier focusgroepen georganiseerd in drie verschillende GPs met veertien patiënten en dertien naasten. Drie thema's werden geïdentificeerd: 
onzekerheid, vroege diagnostische paradox en kennisverwerving. De vroege diagnostische paradox verwijst naar zowel de negatieve (als gevolg van confrontatie met cognitieve klachten) als positieve ervaringen en emoties (opluchting of bevestiging door uitkomsten NPO en diagnose) in het diagnostische traject. Zowel patiënten als naasten gaven aan zich onzeker te voelen voor, tijdens en na het bezoek aan de GP. Tenslotte blijkt dat er weinig van de gegeven informatie beklijft.

Hoofdstuk 5 beschrijft een grote vijfjarige follow-upcohortstudie: de Bio-Bank Alzheimer Center Limburg (BBACL)-studie. In dit hoofdstuk werden 405 patiënten van de Maastrichtse GP geïncludeerd. Uit dit onderzoek bleek dat de subjectief ervaren cognitieve achteruitgang samen hing met lagere testprestaties op het NPO en met meer depressieve klachten. De door de naaste gerapporteerde cognitieve achteruitgang van de patiënt hing sterk samen met de cognitieve achteruitgang op verschillende domeinen, en met conversie naar dementie. Er bleek geen samenhang te zijn tussen zelf-gerapporteerde cognitieve achteruitgang en de prestatie op NPO-taken of conversie naar dementie.

In Hoofstuk 6 wordt een verkennende literatuurstudie beschreven naar de effecten van het weergavegesprek gericht op het bespreken van neuropsychologische resultaten, met aanbevelingen voor de klinische praktijk. Er werden 41 artikelen geïncludeerd, waarvan 26 onderzoeksartikelen. De studies weergeven dat de tevredenheid met het NPO hoog is. Het bespreken van neuropsychologische uitslagen bleek samen te hangen met een betere kwaliteit van leven en een beter begrip van de aandoening. Ook hier blijkt weer dat maar weinig informatie onthouden wordt. Enkele onderzoeken laten echter wel zien dat communicatiehulpmiddelen, zoals bijvoorbeeld het aanbieden van geschreven informatie, het onthouden van de besproken resultaten verbeterde.

Hoofstuk 7 beschrijft de ontwikkeling van een visueel hulpmiddel gericht op het weergeven van neuropsychologische testresultaten. Hier werd ook de gebruiksvriendelijkheid, acceptatie van de technologie en de haalbaarheid in de klinische praktijk onderzocht. Het hulpmiddel biedt de psycholoog of psychologisch medewerker de mogelijkheid om ruwe neuropsychologische testuitslagen in te voeren van de geharmoniseerde geheugenpolibatterij, die vervolgens automatisch worden omgerekend naar gestandaardiseerde normscores. Daarnaast biedt het hulpmiddel verschillende visuele weergavemogelijkheden (bijvoorbeeld ook voor herhaalonderzoek) in twee modules: een voor de psycholoog en een voor de patiënt en naaste. In de patiëntmodule wordt tevens een vertaling van de resultaten naar het dagelijks leven gepresenteerd. De ontwikkeling vond plaats in samenwerking met patiënten, naasten en professionals. Zij werden nauw betrokken bij de ontwikkeling van de conceptversies in de beginfase en bij het uiteindelijke prototype. Tijdens de eerste fases beoordeelden psychologen de gebruiksvriendelijkheid als hoog. Een pilotstudie werd uitgevoerd bij patiënten en naasten binnen drie GPs, waarbij neuropsychologische uitslagen zonder $(n=30)$ en met het visuele hulpmiddel besproken werden $(n=28)$. Zowel patiënten als naasten waren positief over het gesprek met de psycholoog. Ze bleken echter nog steeds weinig te onthouden van de aangeboden informatie. Dit bleek het geval voor de groep die uitleg zonder het hulpmiddel had gekregen alsmede 
voor de groep met het hulpmiddel. Desalniettemin gaven patiënten, naasten en psychologen aan positief te zijn over het visuele hulpmiddel. Psychologen vonden het gebruik intuïtief en de technologieacceptatie was hoog. Zowel patiënten, naasten als psychologen vonden het een voordeel dat cognitieve sterktes en zwaktes in een oogopslag zichtbaar waren, dat er een vertaling naar het dagelijks leven gemaakt werd, dat men iets op papier kon meegeven of ontvangen. Er werden tevens een aantal belangrijke belemmeringen geïdentificeerd (bijvoorbeeld het ontbreken van andere veelgebruikte cognitieve tests), die relevant zijn voor toekomstige implementatie.

In Hoofdstuk 8 worden de belangrijkste resultaten samengevat en geïntegreerd. Daarnaast wordt een kritische reflectie gegeven op methodologische aspecten en ingegaan op de implicaties voor de klinische praktijk en op mogelijkheden voor toekomstig onderzoek. 


\section{KNOULEDGE VALORIZATION}

Knowledge resulting from the studies described in this thesis have, next to scientific value, both clinical and societal value. This paragraph addresses how the acquired knowledge can be made valuable in the social and clinical contexts.

\section{Societal relevance}

Worldwide, around 50 million people live with dementia. The next 25 years, these numbers will double as a result of the aging population. Dementia is the main cause of disability and dependency in the elderly population. The impact of dementia is present on several domains (e.g., physical, psychological, social, economic) in both patients and their family members, and can lower their quality of life. Furthermore, dementia has a significant social and economic impact due to the high medical and social care costs. In 2018, the global cost of dementia was one trillion US dollars, and this number is expected to further increase as more people live with dementia. This was argument for both the World Health Organization and the European Union to declare dementia a global public health priority.

Currently, no curative pharmacotherapy is available. However, psychosocial interventions and support during the prodromal and early phases of dementia have been shown to be effective (e.g., by lowering caregiver burden). Due to the huge impact of a dementia diagnosis it is important to carry out high-quality diagnostic assessment. Findings in this thesis showed that memory clinics have become a mainstream facility for the diagnosis of dementia and that almost all clinics used a neuropsychological assessment. Our results also showed that both patients and family members experienced high levels of uncertainty during their visit at the memory clinic. They appreciated a follow-up consultation with the neuropsychologist focused on providing neuropsychological feedback. It is important to offer support after receiving the diagnosis and offer insight into what their cognitive performance means for their daily life functioning. However, the studies in this thesis confirmed that the recall of medical information is low. Therefore, a web-based visual tool was developed to explain neuropsychological results to improve the understanding and retention of results.

\section{Target audience}

The findings in this thesis could be relevant to a broad audience. Our findings are relevant for people with cognitive complaints that visit a memory clinic. They can benefit from this research as the visual tool developed in this thesis was reported to improve understanding of neuropsychological assessment results. Furthermore, the insight resulting from the other studies might lead to improvements in clinical practice which is beneficial to patients (e.g., more awareness for feelings of uncertainty and low information retention).

The findings are also relevant for clinicians, especially for neuropsychologists working in memory clinics. The clinical implications reported in several chapters might be specifically informative. For example, they might pay extra attention to which cognitive tests they use and might adhere to the harmonized cognitive core 
battery described in the monodisciplinary guideline for Dutch psychologists. They might also pay attention to the way they provide neuropsychological feedback, use communication aids or involve a family member to ascertain that the information is better remembered. Furthermore, psychologists can use the visual tool to more easily explain neuropsychological results to patients and family members. During the feasibility study the visual tool was introduced in three memory clinics during which they used the tool in their daily practice. Results showed that patients, family members, and psychologists were positive regarding the tool. It was easier to understand results, they received (or gave) an overview of their cognitive performance at one glance, and implications of the results for their daily life.

Our results are also relevant for scientists as more scientific evidence was gathered regarding the benefit of using a neuropsychological assessment in a memory clinic. The visual tool also contains a database which can be of interest to collect data while also being part of routine clinical practice. Furthermore, the guideline developed in this thesis might lead to more harmonization between memory clinics and therefore making it easier to conduct research across clinics and compare findings.

Due to the increasing number of patients visiting a memory clinic and patients with dementia our findings might also be of interest to policy makers. Our studies showed that carrying out a neuropsychological assessment with a separate neuropsychological feedback session after receiving the diagnosis was of added value. For policy makers, it might be interesting to learn that neuropsychological feedback is recommended to be included as part of clinical routine.

\section{Activities, innovation, and products}

Based on the user input from patients, family members, and professionals the webbased visual tool was developed to explain neuropsychological assessment results. The visual tool comprises of multiple modules (psychologist modules, patients/family members modules) which can be tailored to the findings of the individual patient. The visual tool is also tailored to the experiences and needs of all users, while stressing the translation of the neuropsychological findings to daily life. The visual tool was piloted in the Maastricht UMC+, Radboudumc Nijmegen, and Catharina Hospital Eindhoven. We also developed a monodisciplinary guideline neuropsychological assessment in mild cognitive impairment $(\mathrm{MCl})$ and dementia to harmonize neuropsychological procedures in the Netherlands. Another product resulting from this thesis is an overview of the development of memory clinics in the past twenty year which was distributed among all participating Dutch memory clinics. We also visited meetings of the national psychologist association and the Dutch memory clinic network to present preliminary findings of our studies. We also gave presentations at Alzheimer Cafés, client panel meetings of the Alzheimer Center Limburg, Dialogues around Dementia, and several international conferences (Alzheimer-Europe, FESN). 
Schedule and implementation

Overall, the visual tool was evaluated positively. Therefore, the next step is to implement the tool for a longer period in the Maastricht memory clinic to evaluate the experiences and needs during a longer period of use. Feedback gathered after this period can be used to optimize the tool. To be implemented in other memory clinics more cognitive tests and corresponding normative data have to be added. Also, a long-term and selfsustaining business model has to be developed to make sure the visual tool can be adapted in the future or when other needs arise. The first step is now to implement the tool in the Maastricht memory clinic as all tests used there are available in the tool. Future steps will be adapting the tool with more commonly used tests in other in other Dutch memory clinics. Financial means might also have to be obtained to translate the tool to other target groups (e.g., other tests or daily life recommendations). 


\section{DANKWOORD (ACKNOULEDGMENTS)}

Na vier jaar is het eindelijk zo ver ... mijn proefschrift is klaar! Aan het begin van mijn promotie leek dit moment nog mijlenver te zijn, maar wat is dit (cliché) voorbijgevlogen. Terugblikkend heb ik vooral veel geleerd en ook een hele fijne tijd gehad, mede dankzij de prettige collega's en mensen om me heen. Ik wil dan ook graag iedereen bedanken die direct of indirect betrokken is geweest bij mijn proefschrift. Een aantal mensen wil ik extra in het zonnetje zetten.

Om te beginnen met mijn promotieteam: dr. Inez Ramakers, prof. dr. Marjolein de Vugt, prof. dr. Frans Verhey en prof. dr. Roy Kessels.

Inez, met jou heb ik het meest te maken gehad van ons team. Van onze treinreizen door Nederland voor INPAD of voor de richtlijn tot verscheidene congressen of symposia. Wat heb ik verschrikkelijk veel geleerd van jou, zowel op vlak van onderzoek als op klinisch vlak. Jij bent een enorm fijne dagelijkse begeleider. Je hebt altijd een luisterend oor en je bent benieuwd naar alle ontwikkelingen, zowel over onze studies als privé. Ondanks dat je zelf zo'n drukke agenda hebt kon je altijd tijd vrijmaken voor de vele uren overleg die we hebben gehad. Bedankt voor alles!

Marjolein, wat ben ik nog steeds van jou onder de indruk. Hoe jij in zowel je klinische werk als in onderzoeksland zover bent gekomen. Alweer meer dan twee jaar geleden ben jij benoemd tot hoogleraar. Ik wil je graag bedanken voor je kritische blik, met altijd een toeziend oog op het ontwikkelen van mijn eigen mening, maar ook op hoe met mij ging. Ook dank voor je vertrouwen toen ik de laatste maanden het afronden van mijn proefschrift combineerde met een nieuwe baan in Eindhoven.

Frans, jou wil ik graag bedanken voor de kans die je me hebt geboden en jouw persoonlijke betrokkenheid en kennis. Ik weet nog goed dat ik je voor de vacature opbelde om je wat vragen te stellen in de hoop dat ik een blijvende indruk zou achter laten. Hopelijk is dat gelukt! Ook wil ik je danken voor alle promotie-overleggen, mede dankzij jou was er altijd een gemoedelijke sfeer.

Roy, een paar maanden na mijn start werd jij betrokken als mijn externe promotor vanuit Nijmegen. Ook jou wil ik bedanken voor wat ik geleerd heb van je enorm grote kennis over de neuropsychologie. Je bent een inspiratiebron en een grote motivatie waardoor ik graag het pad zou willen bewandelen om ooit klinisch neuropsycholoog te worden. Dank voor alle momenten dat je extra tijd vrijmaakte en de uitgebreide feedback met ook oog op talige zaken.

De leden van de beoordelingscommissie zou ik graag hartelijk willen bedanken voor het lezen en beoordelen van mijn proefschrift. 
Daarnaast wil ik graag stil staan bij alle deelnemers van de verschillende onderzoeken in mijn proefschrift. De patiënten, naasten en professionals. Zonder jullie was er geen onderzoek geweest om over te schrijven. Vooral bij de ontwikkeling van de visuele tool (INPAD) zijn er veel mensen betrokken geweest en zonder hen was er nu geen mooie eerste versie van het product geweest. Bedankt voor jullie inspirerende verhalen. Dit geldt ook voor de leden van het Alzheimer Centrum Limburg cliëntpanel. Jullie verhalen hebben mij des te meer gemotiveerd om de lessen uit mijn proefschrift voort te zetten in de klinische praktijk bij andere patiënten en naasten. Speciaal dank aan Frans Vergeldt. Hij was degene die jaren geleden het idee naar voren bracht dat het zo belangrijk was gebruik te maken van een visuele ondersteuning.

Ook wil ik graag de medewerkers van llionx bedanken voor de prettige samenwerking tijdens de ontwikkeling van de visuele tool. Ook dank aan Joost en Ron voor hun ondersteuning vanuit de technische hoek. Nico Rozendaal zou ik graag extra in het zonnetje willen zetten. Nico, dankzij jou voelde ik me op dag 1 onderdeel van het Alzheimer Centrum Limburg. Dankzij het vele werk wat jij al had gestopt in het PDBsysteem is daar nu de visuele tool uit voort gekomen. De afdeling is toch niet meer helemaal hetzelfde zonder jou, maar dank voor alle gezellige klets momenten bij het koffiezetapparaat!

Hartelijk dank aan de co-auteurs met wie ik heb mogen samen werken tijdens mijn proefschrift. Jullie input iszeer leerzaam geweest. De leden van de richtlijn commissie en de externe beoordelaars van de richtlijn zou ik ook hartelijk willen danken. Wat heb ik veel geleerd van de discussies tijdens de bijeenkomsten. Het was vooral een plezier om met jullie samen te mogen werken.

Mijn lieve paranimfen, Jeske en Sara, met jullie achter mij komt het helemaal goed.

Jeske, ik ben heel blij dat jij weer zo'n bijzondere dag wilt delen. Nog niet zo lang geleden was ik jouw paranimf en was jij getuige op mijn bruiloft. Ondanks dat we niet meer in dezelfde straat wonen weten we altijd wat we aan elkaar hebben. Wat ben ik blij dat je na een jaar Aruba weer terug bent in Nederland! Ook fijn dat jij af en toe door dingen heen kan prikken.

Sara, you were the best office buddy someone could wish for. I really enjoyed all our long conversations. Especially how we could brainstorm about research-related stuff or about wedding dresses. You are an inspiring person and an amazing researcher. I would like to thank you for all the times you listened to me and helped me by giving awesome advice. You made going to the office so much more fun!

Dank aan alle lieve collega's en oud-collega's van de afdeling Psychiatrie en Neuropsychologie en het Alzheimer Centrum Limburg. Ook dank aan alle stagiaires voor jullie ondersteuning bij het uitvoeren van de BBACL studies. Een paar collega's zou ik nog graag extra in het zonnetje willen zetten: 
Mignon, ook jij bent een van mijn beste office buddies geworden in de afgelopen jaren. We hebben veel met elkaar gemeen. Ik hoop dat we de gezellige momenten nog maar heel vaak mogen voortzetten, en dat we ook nog pretparken mogen bezoeken waar ik je achtbanenangst mag kalmeren (iets met exposure?). Dank dat je zo'n lieve en zorgzame vriendin bent!

In de afgelopen jaren heb ik binnen het ACL binnen verschillende werkgroepen het vooral erg gezellig gehad. Het groepje wat hierbij eruit springt is natuurlijk de profileringsgroep, van het maken van een nieuwe brochure tot het organiseren van een symposium. We waren er maar druk mee. Willemijn, dank voor de gezelligheid en wat fijn dat we weer Brabantse buren zijn geworden. Ik ben enorm onder de indruk van wat voor goede onderzoeker je bent, dat komt wel goed met jou! Niels: 'Koot? Koot!' en 'Prolifering' zijn toch wel de eerste twee woorden (oké en uiteraard ook 'bordspellen') die bij me te binnen schieten. Dank voor je altijd luisterende oor en dat je ook altijd open stond om te sparren en te filosoferen over onderzoek/ingewikkelde statistiek. Fijn dat we ook even roomies zijn geweest! Fania, ook jij hebt altijd een luisterend oor en bent enorm betrokken bij het ACL. Het was heerlijk om met jou te kletsen en veel foto's van baby Lily te mogen bewonderen. Daphne, jij bent ons meest recente lid. Wat leuk dat je nu een collega bent geworden na mijn stagiaire te zijn geweest. Ik kijk er naar uit je nog even te begeleiden bij het begin van je promotie.

Toen ik net begon in Maastricht was het enorm fijn om te merken dat ik niet de enige was die een treinreis naar het 'noorden' moest afleggen. Elles, Isabelle en Whitney. Dank aan jullie allen, ook voor de inspiratie die jullie gaven voor mij als beginnende PhD. Jullie maakten de reistijd enorm gezellig. Stevie, jij kwam er pas wat later bij als mede treinreiziger, maar wat was het fijn om weer een trein buddy te hebben. Ook waren er meerdere collega's die altijd in waren voor een gezellig praatje. Jeroen, als mede gamer hadden wij altijd wel iets om over te sparren (of bijna een vliegtuig missen...). Linda, ook jij dank voor de gezellige momenten! Lieke en Leonie, jullie dank voor de fijne samenwerking met de BBACL supervisie. Jullie zijn fijne collega's en wat was het ook gezellig met zijn drietjes in Florence.

Danielle en Els, jullie ook heel veel dank voor jullie fijne ondersteuning bij het plannen van talloze afspraken en de soms uitdagende puzzel van de combinatie van de agenda van Frans en Marjolein. Astrid, de dank aan jou is ook zeer groot. Je deur stond altijd open om even binnen te wandelen.

Ook de collega's die werken op de geheugenpoli wil ik graag bedanken. Een gedeelte van mijn onderzoek vond toch ook daar plaats, mede dankzij jullie kon ik ervaring blijven opdoen in de kliniek. Carla en Tanja, wat heb ik veel geleerd van jullie op de GP+ en DOC-PG dagen. Dymphie, Annelien en Claire. Voor jullie geldt hetzelfde. Ik heb van jullie als psychologen enorm veel geleerd. Claire, jij extra dank voor dat ik altijd bij je binnen kon lopen en dat jij me de kans hebt gegeven om behandelervaring op te doen. 
Ook dank aan mijn nieuwe collega's van de afdeling Medische Psychologie en het Obesitascentrum in Eindhoven. Jullie lieten me gelijk welkom voelen! Wat enorm leuk ook dat jullie allen zo geïnteresseerd zijn geweest in de afronding van mijn proefschrift. Ik kijk er naar uit om me verder te ontwikkelen als clinicus met zulke fijne collega's om me heen. Angela en Susanne, jullie ben ik ook heel dankbaar voor jullie meedenken en actieve bijdrage aan de onderzoeken die ik in Eindhoven heb kunnen uitvoeren. Angela, ik kijk er ook naar uit om elkaars supervisor te blijven. Ik kan zo enorm veel van jou leren op klinisch vlak en fijn dat ik jou op vlak van onderzoek kan helpen. Eveline, jij bent een van de personen door wie ik me gelijk welkom voelde op de afdeling. Het is zo fijn dat de deur altijd open bij jou staat om even te kletsen. Angélique S, mede dankzij jouw inzet vorig jaar werk ik nu bij jullie en ga ik straks de GZ-opleiding in. Jij inspireerde mij om de stap te zetten, maar ik ben je vooral ook erg dankbaar voor het vertrouwen.

Lieve familie en vrienden, dank voor jullie vragen en interesse in mijn onderzoek. Ik ben nu dan toch echt 'afgestudeerd'.

Lieve Merel, als beste vriendinnetje steun jij mij door dik en dun. Onze wekelijkse telefoongesprekken heb ik altijd enorm gewaardeerd en ik weet zeker dat mede door jou sta ik waar ik sta. Op naar de komende tien jaar. Blijf zoals je bent! Lieve Bas, ook jij als beste vriend speelt een belangrijke rol in mijn leven. Natuurlijk wil ik je nog eens extra bedanken voor de tijd die je wilde vrijmaken voor de lay-out en cover van mijn proefschrift. Natuurtalentje! Op naar nog vele gezellige sleepovers met leuke series/ films/games, gesprekken en lekker eten.

Lieve Cindy, wat is het toch bijzonder dat wij zo'n fijne band hebben. Zowel nichten als vriendinnen, en nu wonen we zelfs op loopafstand van elkaar. Ik geniet van onze gezellige avonden gevuld met series, gesprekken en bordspellen. Lieve Rick, jij zorgt er mede voor dat deze avonden altijd gevuld zijn met humor en aandacht voor het spel.

Lieve Nancy en Arjan, bedankt voor jullie interesse in mijn onderzoek en de gezellige avonden.

Ook dank aan mijn lieve D\&D groep. Midas en David, al sinds de middelbare school bevriend en het is dan ook een genoegen dat we nu veel meer contact hebben. Lars en Norène, ondanks dat we elkaar nog maar korter kennen zijn jullie enorm goede vrienden geworden als mede Disney/Fantasy/Bordspel liefhebbers. Op naar nog vele D\&D avonturen met elkaar met vele natural 20's!

Lieve mam en pap, jullie zijn er uiteraard altijd voor mij geweest en wat heb ik er een respect voor gekregen hoe jullie mij altijd onvoorwaardelijk hebben gesteund. Dank dat jullie altijd achter mij staan en dat jullie mij hebben gevormd tot de persoon die ik nu ben. Zonder jullie was dit proefschrift er niet geweest. 
Lieve Mariska, naast mijn kleine zusje ben je een heel belangrijk en waardevol persoon in mijn leven. Dank voor de gezelligheid en de interesse die je altijd in een ander hebt. Lieve Gerben, ook jij dank voor de leuke aanvulling die je brengt in onze familie. Op naar nog heel veel bordspelavonden en pretparkbezoeken met $z^{\prime} n$ viertjes.

Ook mijn schoonfamilie wil ik bedanken voor hun onvoorwaardelijke steun. Bedankt voor jullie oprechte interesse en vragen naar mijn onderzoek in de afgelopen jaren. Lieve Anita en Rob, jullie hebben me omarmd als schoondochter en ik voel me thuis bij jullie. Lieve Evelien en Stef, ik ben enorm trots op hoe jullie je als ouders en gezin ontwikkelen. Wat ben ik blij dat we onderdeel mogen zijn van de vele oppasmomenten en leuke momenten met jullie (zoals proberen Stef te verslaan met bordspellen). Lieve Marleen en Jeroen, ook jullie dank voor de gezellige avonden en het heerlijke eten van Marleen! Ik kijk uit naar nog heel veel leuke en gezellige avonden met jullie allemaal.

Lieve Jaap, last but not least! Jij bent onmisbaar, mijn rots. Ook jij bent een van de belangrijkste redenen dat mijn proefschrift er nu dan echt is. Jij zorgt ervoor dat ik met twee voeten op de grond blijf en dat ik mezelf niet kwijtraak. Jij brengt elke dag humor met je mee. Wat ben ik enorm gelukkig met jou, mijn beste vriend en lieve echtgenoot! Op naar onze toekomst waar we samen alles zeker aankunnen.

Nu op naar de volgende uitdaging!

Angélique Anna Adriana Gruters, Veldhoven, 29-09-2020

\section{生き甲斐}




\section{THESIS DEFENSES FROM ALZHEIMER CENTER LIMBURG AND MHENS 2020}

Johan Haumann, Prevalence and pharmacological treatment of pain in patients with cancer; The role of opioids with and without NMDA receptor affinity. Supervisor: prof dr. E.A. Joosten; co-supervisors: Prof.dr. M.H.J. van den Beuken-van Everdingen; dr. S.M.J. Van Kuijk.

Joost Riphagen, Vascular matters in aging and dementia. Supervisor: prof.dr. F.R.J. Verhey; cosupervisor: Dr. H.I.L. Jacobs.

Nikos Priovoulos, Structural and functional imaging of the locus coeruleus at $7 \mathrm{~T}$ : from methodological to clinical application. Supervisor: prof.dr. F.R.J. Verhey; co-supervisors: Dr. H.I.L. Jacobs; dr. B.A. Poser.

Simone Verhagen, The power of individual landscapes; A clinical exploration of personal experience sampling and new horizons. Supervisors: prof.dr. P.A.E.G. Delespaul; prof.dr. J.J. van Os, UM/UU; co-supervisor: dr. C.J.P. Simons.

Nagy Youssef, Epigenetics, resilience and brain stimulation: advances in the mechanistic and therapeutic utility in patients with affective (PTSD and mood) disorders. Supervisor: Prof.dr. B.P.F. Rutten; co-supervisor: Prof. dr. P. Sienaert, KU Leuven.

Abhishek Appaji, Retinal vascular features as a biomarker for psychiatric disorders. Supervisor: Prof. Dr. C.A.B. Webers; co-supervisor: Dr. T.T.J.M. Berendschot, Dr. Naren P. Rao.
Koos Hovinga, Angiogenesis Inhibition in Glioblastoma. Supervisor: prof. dr. Y. Temel; cosupervisor: Prof. V. Tabar, New York, USA.

Gerhard Drenthen, Myelin and networks, Magnetic Resonance Imaging in Epilepsy. Supervisors: prof.dr.ir. W.H. Backes; Prof.dr. A.P. Aldenkamp; co-supervisor: dr. J.F.A. Jansen.

Anna Gorlova, Understanding the Molecular Mechanisms of Aggression in BALB/C and TPH2-Deficient Mice. Supervisor: prof.dr. K. Lesch, Universitätsklinikum Würzburg, co-supervisors: dr. T. Strekalova; prof.dr. L. Bettendorff, University of Liège.

Ekaterina Veniaminova, The impact of the 'Western Diet' on Emotional, Social and Cognitive Behaviours as revealed by a study on conventional and serotonin TransporterDeficient Mice. Supervisor: prof.dr. K. Lesch, Universitätsklinikum Würzburg, co-supervisors: dr. T. Strekalova; prof. D.C. Anthony, Oxford.

Dmitrii Pavlov, The contribution of CNS inflammation and Glycogen Synthase Kinase-3 (GSK-3)-cascades on adverse memory learning on mouse models of emotional stress. Supervisor: prof.dr. K. Lesch, Universitätsklinikum Würzburg, cosupervisors: dr. T. Strekalova; prof.dr. L. Bettendorff, University of Liège.

Eric Fonseca Wald, Absence Epilepsy and Panayiotopoulos Synrome: Neurocognition and Brain Development. Supervisor: prof.dr. R.J. Vermeulen; co-supervisors: Dr. S. Klinkenberg; dr. M.J.A. Debeij-van Hall; Dr. J.G.M. Hendriksen, Epilepsiecentrum Kempenhaeghe. 
Kimberley S. Noij, Cervical vestibular evoked myogenic potentials; Toward optimizing clinical use. Supervisors: prof.dr. H. Kingma; prof. S.D. Rauch, MD, Massachusetts Eye and Ear, Harvard; co-supervisor: Dr. R. van de Berg.

Mark J. van Tilburg, Advancement in cVEMP's. Supervisors: prof.dr. H. Kingma; prof.dr. S. Rauch, Harvard; co-supervisors: dr. R. van de Berg; dr. B. Herrmann, Boston.

Nalini Atcharayam, Duchenne Muscular Dystrophy: The NIMHANS Experience. Supervisors: prof.dr. T. Delhaas; prof.dr. B.W. Kramer.

Murat L Atagün, Cognitive neurophsysiology and neurochemistry in bipolar disorder. Supervisor: Prof. Dr. Therese van Amelsvoort; co-supervisors: Dr. Sinan Guloksuz; Dr. Marian Drukker.

Majed Aldehri, Deep brain stimulation, memory functions and mechanisms. Supervisor: Prof. dr. Y. Temel; co-supervisors: dr. S. Hescham; dr. A. Jahanshahianvar.

Printha Kentheeswaran-Wijesinghe, Agerelated cytoskeletal pathologies: A study on elderly brains to investigate the extent of neuropathological and cerebrovascular changes at death ad their risk factors. Supervisor: Prof. dr. H. Steinbusch, Prof. dr. R. De Silva - (University of Sri Jayewardenepura), Prof. dr. D. Shankar - (NIMHANS Bangalore).

Mahmoud Elbatrik, Network pharmacology for mechanistically redefined comorbidities. Supervisor: Prof. dr. H.H.H.W. Schmidt; COsupervisors: Dr. A.I. Casas Guijarro. Alexander Grønning, Big Data Analytics in Bioinformatics. Supervisors: Prof. dr. J. Baumbach - (University of Southern, Denmark), Prof. dr. H.H.H.W. Schmidt; cosupervisor: Dr. R. Röttger.
Britta Nijsse, Cognition after stroke; various perspectives. Supervisors: Prof. dr. C.M. van Heugten, Prof. dr. J.M.A. Visser/Meily, Prof. dr. J.M. Spikman; co-supervisor: Dr. P.L.M. de Kort.

Eva Koetsier. Dorsal Root Ganglion Stimulation for Pain Relief in Painful Polyneuropathy: Efficacy and Mechanism of Action. Supervisors: Prof. dr. E.A.J Joosten Prof. dr. J.A.M. van Zundert; co-supervisor: Dr. S.M.J. van Kuijk.

Youssef Yakkioui, Molecular biomarkers in skull base chordoma. Supervisors: Prof. dr. Y. Temel, Prof. dr. M. van Engeland.

Sascha Meyer, Visual Associative Learning in Alzheimer's Disease and Performance Validity. Supervisor: Prof. dr. R.W.H.M. Ponds; co-supervisor: Dr. J.F.M. de Jonghe.

Daniël Verberne, Psychosocial outcome after stroke and traumatic brain injury - Longitudinal perspectives and recommendations for aftercare. Supervisors: Prof

dr. C.M. van Heugten, Prof. dr. R.W.H.M. Ponds; cosupervisor: Dr. M.E.A.L. Kroese.

Britt van Hagen, Improving Pattern Separation and Cognition: Effects of Pharmacological Interventions on Rodent Behavior and Neuroplasticity. Supervisors: Prof. dr. J. Prickaerts, Prof. dr. H. Schmidt.

Sara Bartels, Monitoring Everyday Life in Aging \& Dementia - Perspectives from Experience Sampling and Technology Use. Supervisors: Prof. dr. F.R.J. Verhey, Prof. dr. M.E. de Vugt; cosupervisors: Dr. R.J.M. van Knippenberg, Dr. C. Malinowsky - (Karolinska Institutet, Sweden).

Roel van Reij, Genetic Risk Factors in prediction and tratment of Chronic Post-Surgical Pain. Supervisor: Prof. dr. E.A.J. Joosten; co-supervisor: Dr. N.J. van den Hoogen. 


\section{ADDENDUM}

Hannah Christie, The Implementation of EHealth in Dementia Care: Lessons Learned. Supervisors: Prof. dr. M.E. de Vugt, Prof. dr. F.R.J. Verhey; cosupervisor: Dr. H.J. Tange.

\section{Further dissertations can be found online:}

https://mhens.mumc.maastrichtuniversity.nl/mhens-school-mental-health-andneuroscience-1 


\section{LIST OF PUBLICATIONS}

Gruters, A., Ramakers, I., de Vugt, M., Kessels, P., Blom, M., Bouwman, F., ... Verhey, F. (2018). GeheugenpoliMonitor 2016. Alzheimer Centrum Limburg, Maastricht. Retrieved from: https://centraal.mumc.nl/sites/central/files/rapportage_gpmonitor_2016.pdf

Gruters, A., Ramakers, I., Verhey, F., Köhler, S., Kessels, R., Vugt, M. (2019). Association between proxy- or self-reported cognitive decline and cognitive performance in memory clinic visitors. Journal of Alzheimer's Disease, 70: 1225-1239.

Gruters, A., Ramakers, I., Kessels, R., Bouwman, F., Olde Rikkert, M., Blom, M.,... Verhey, F. (2019). Development of memory clinics in the Netherlands over the last 20 years. International Journal of Geriatric Psychiatry, 34: 1267 - 1274.

Ramakers, I., Gruters, A., Schmand, B., Kessels, R., de Vugt, M., Appels, B., ... Knipping, A. (2019). Monodisciplinaire richtlijn Neuropsychologisch onderzoek bij lichte cognitieve stoornissen (MCl) en dementie. Retrieved from: https://www.psynip.nl/wp-content/ uploads/2019/10/richtlijn-MCl-dementie.pdf

Gruters, A., Christie, H., Ramakers, I., Verhey, F., Kessels, R., de Vugt, M. (2020). Neuropsychological assessment and diagnostic disclosure at a memory clinic: A qualitative study of the experiences of patients and their family members. The Clinical Neuropsychologist, 1-17.

Ramakers, l., Gruters, A., Schmand, B., Kessels, R., de Vugt, M.,Appels, B., ... Knipping, A. (2020). Neuropsychologisch onderzoek bij de diagnostiek van lichte cognitieve stoornissen (MCI) en dementie: De weg naar een monodisciplinaire richtlijn. Tijdschrift voor Neuropsychologie, 15(2): 91-105.

Wenting, A., Gruters, A., van Os, Y., Verstraeten, S., Valentijn, S., Ponds, R., de Vugt, M. (2020). Medisch Psychologische nazorg van COVID-19. Post Intensive Care Syndroom (PICS) en andere (neuro)psychologische gevolgen. De Psycholoog: 40-50.

Wenting, A., Gruters, A., van Os, Y., Verstraeten, S., Valentijn, S., Ponds, R., de Vugt, M. (2020).COVID-19 neurological manifestations and underlying Mechanisms: A scoping review. Frontiers of Psychiatry, 11: 1-6.

Gruters, A., Christie, H., Ramakers, I., Verhey, F., Kessels, R., de Vugt, M. (2020). Ervaringen van patiënten en naasten met het neuropsychologisch onderzoek en het uitslaggesprek op de geheugenpoli. Tijdschrift voor Neuropsychologie, 15(3). 


\section{CURRICULUM VITAE}

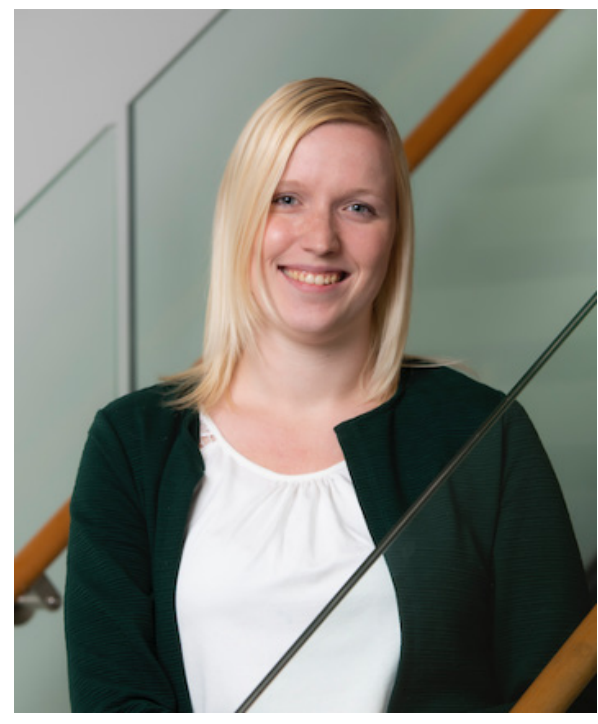

Angélique Anna Adriana Gruters werd geboren op 25 mei 1992 in Nieuwegein. In 2012 behaalde zij haar vwo-diploma aan het St. Bonifatiuscollege in Utrecht. Hierna verhuisde zij naar Enschede om daar te beginnen aan de bachelor Psychologie. Tijdens deze studie kwam zij erachter dat de kruising tussen de psychologie en geneeskunde haar het meest aansprak, waarbij haar oog specifiek viel op de richting neuropsychologie. Ze solliciteerde voor de master medische psychologie in Tilburg en werd aangenomen. De klinische- en onderzoeksstage deed zij in het Universitaire Ziekenhuis in Leuven en op de psychiatrische afdelingen in Kortenberg. Zij kwam er tijdens haar stage achter veel interesse te hebben in patiënten met dementie en hun naasten. Daarnaast kwam zij er tijdens het schrijven van haar master thesis achter dat zij een vervolg ambieerde in het doen van onderzoek. In 2015 studeerde zij af waarna ze een jaar lang als scientist practitioner werkt bij de Academische Werkplaats 'Leven met een verstandelijke beperking' van Tranzo in Tilburg. Zij voerde tientallen diepte-interviews uit bij mensen met een verstandelijke beperking in heel Nederland. In 2016 begon zij aan haar promotieonderzoek aan de universiteit van Maastricht onder supervisie van prof. dr. Marjolein de Vugt, prof. dr. Frans Verhey, prof. dr. Roy Kessels en dr. Inez Ramakers. Aldaar onderzocht zij het neuropsychologisch onderzoek op de Nederlandse geheugenpoli's. Het grootste projectwasgerichtop deontwikkeling vaneenvisueleweergavevoorhetterugkoppelen van neuropsychologische testprestaties aan patiënten en naasten. Momenteel werkt Angélique nog een dag in de week als postdoctoraal onderzoeker aan de afdeling Psychiatrie en Neuropsychologie bij de Universiteit Maastricht. De andere vier dagen werkt zij als masterpsycholoog bij de afdeling Medische Psychologie in het Catharina Ziekenhuis te Eindhoven. Vanaf januari zal zij aldaar de GZ-opleiding beginnen. 